\title{
MAPEAMENTO GEOESTATÍSTICO DE PROPRIEDADES GEOLÓGICO-GEOTÉCNICAS OBTIDAS DE SONDAGENS DE SIMPLES RECONHECIMENTO
}

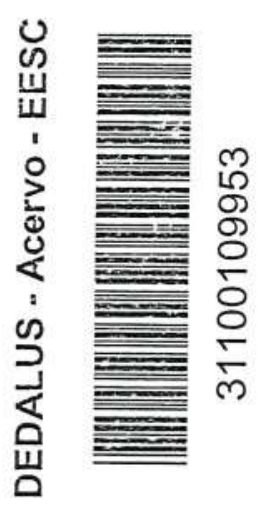

\section{JOSÉ RICARDO STURARO}

Tese apresentada à Escola de Engenharia de São Carlos, da Universidade de São Paulo, como parte dos requisitos para obtenção do Título de Doutor em Engenharia - Área Geotecnia.

ORIENTADOR: Prof. Dr. Paulo Milton Barbosa Landim

\section{São Carlos}


FOLHA DE APROVAÇÃO

TESE DEFENDIDA EM 11/10/94

E APROVADA PELA COMISSÃO JULGADORA:

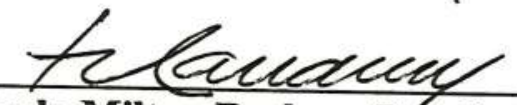

Prof.Dr. Paulo Milton Barbosa Landim - (Orientador) - UNESP / Rio Claro
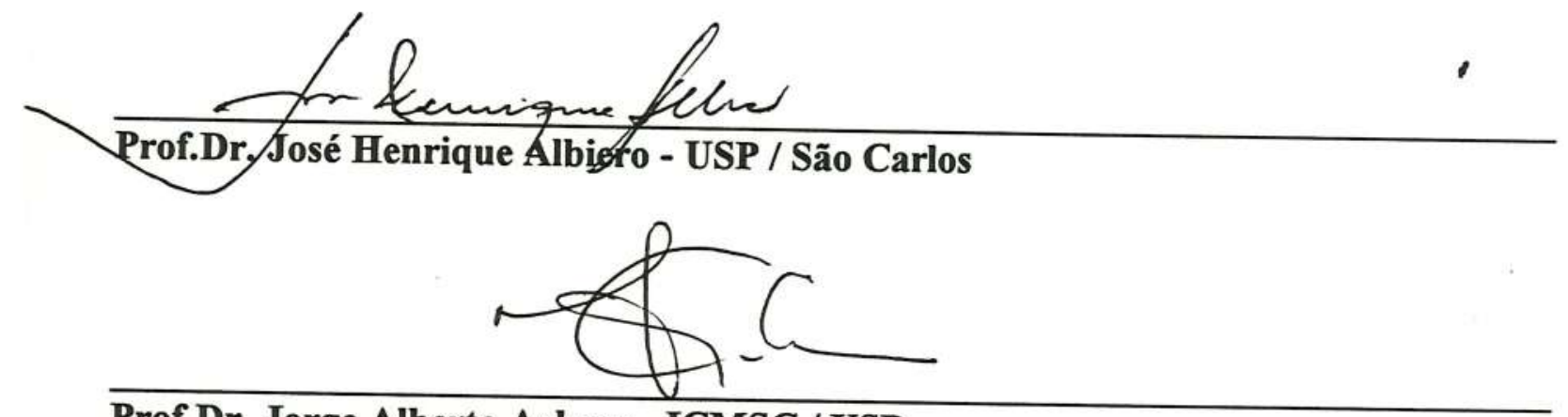

Prof.Dr. Jorge Alberto Achcar - ICMSC / USP
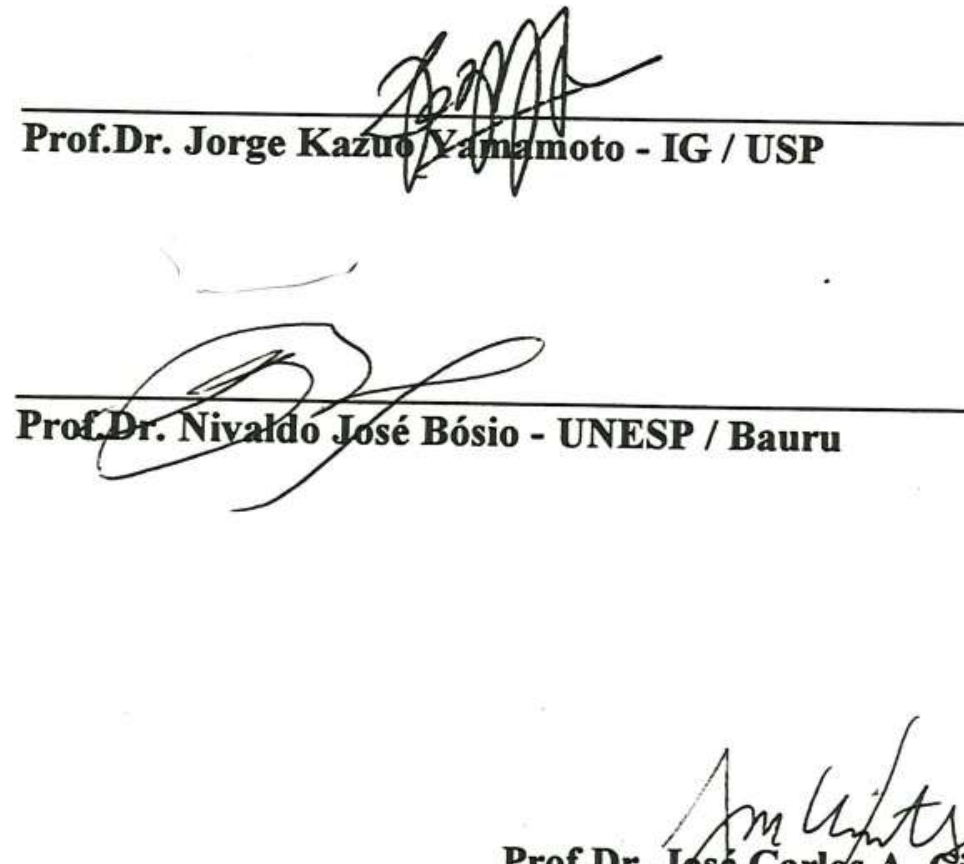

Prof.Dr. José Carlos A. Cintra

Coordenador da Área de Geotecnia 
Ao meu pai, Arlindo Sturaro, in memoriam. 


\section{AGRADECIMENTOS}

Ao Professor Paulo Milton Barbosa Landim, pela orientação, confiança e apoio para elaboração deste trabalho.

Aos professores Nariaqui Cavaguti e Nivaldo José Bósio, pelo irrestrito apoio no levantamento dos dados.

Ao Professor Walter Malagutti Filho, que viabilizou e muito auxiliou nos trabalhos geofísicos.

Ao Professor Armando Zaupa Remacre, pelas discussões técnicas e auxílio na obtenção de programas geoestatísticos.

Ao Pesquisador Fernando Ximenes Salomão, pelo auxílio na interpretação pedológica da área de estudo.

Aos colegas Ari Araldo Xavier de Camargo e Gustavo Tadeu Zaniboni, pelo apoio no processamento dos dados.

Aos funcionários Francisco Manuel Garcia Barrera, Alan de Oliveira, Claudio Ribeiro da Silva e Antônio Fernandes Pereira pelos trabalhos de campo.

Às secretárias Márcia Regina Tavolari do Amaral, Elaine Brigatto e Laura Silmara Pedroso Pereira Narcizo, pela prestimosa colaboração na digitação dos textos.

À bibliotecária Terezinha Regina Lorenzon Rodrigues, que revisou as referências bibliográficas.

A desenhista Sandra Belinelli, pela dedicação na confecção dos desenhos.

Ao Professor Job Jesus Batista e sua esposa Regina Ferreira Batista, pelas sugestões e revisão gramatical.

Aos professores e colegas dos departamentos de Geologia Aplicada - UNESP - Rio Claro e de Engenharia Cívil - UNESP - Bauru, pela troca de idéias e sugestões apresentadas.

À FAPESP, pelo auxílio à pesquisa concedido.

À Paulina Setti Riedel, esposa e companheira, sempre presente em todas etapas deste trabalho. 


\section{SUMÁRIO}

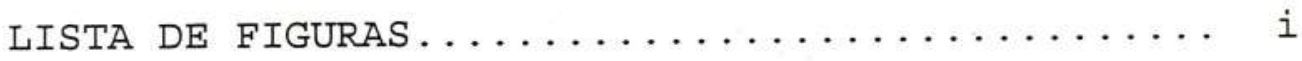

LISTA DE TABELAS.................. ii

LISTA DE SÍMBOLOS ..................

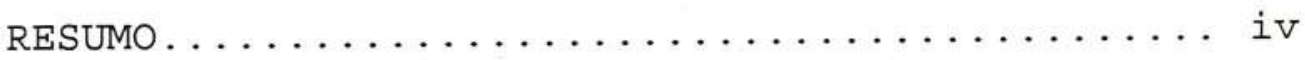

ABSTRACT .................. $v$

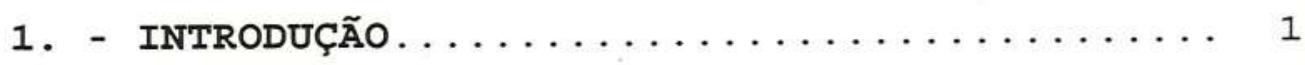

1.1 - Considerações iniciais............. 1

1.2 - Modelos matemáticos em geociências....... 2

1.3 - Aplicação da geoestatística em Geotecnia.. 3

2. - TÉCNICAS dE OBTENÇÃo dos dAdOS.......... 5

2.1 - Sondagens de simples reconhecimento..... 5

2.1 .1 - Definição e origem................ 5

2.1 .2 - Processo de perfuração............ 6

2.1 .3 - Amostragem e identificação do solo..... 7

2.1 .4 - Determinação do nível de água........ 8

2.1 .5 - Ensaio de penetração padronizada - SPT. 9

2.1 .6 - Fatores que influenciam o índice de resistência penetração........... 10

2.1 .7 - Vantagens do uso do ensaio de penetração padronizada................. 12

2.1 .8 - Interpretação do ensaio de penetração padronizada.................. 13

2.1.8.1 - Correlações do SPT com parâmetros geotécnicos................... 13

2.1.8.2 - Aplicações do SPT na Engenharia Geotécnica .................... 18

2.2 - Estudos Geofísicos - Sísmica de refração.. 24 
2.2.1 - Teoria básica da técnica de Refração

sísmica..................... 24

2.2 .2 - Descrição dos equipamentos e ensaios de campo................... 30

3. - METOdologiA dE ANÁLISE dOS DADOS........ 33

3.1 - Elaboração do banco de dados 33

3.2 - Análise estatística básica.......... 38

3.2 .1 - Definição de variáveis aleatórias...... 39

3.2 .2 - Modelos de distribuição de probabilidades 39

3.2 .3 - Estatística descritiva........... 42

3.2 .4 - Correlação e regressão linear........4 46

3.3 - Análise geoestatística............ 48

3.3 .1 - Definição e interpretação de

Geoestatística.............. 48

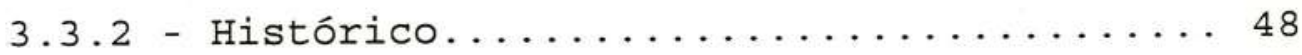

3.3 .3 - Modelos determinísticos e probabilísticos 49

3.3 .4 - Variáveis regionalizadas.......... 50

3.3 .5 - Análise de variabilidade espacial..... 51

3.3 .5 .1 - Função variograma............. 52

3.3 .5 .2 - Modelos variográficos........... 56

3.3 .6 - Estimativas geoestatísticas......... 59

3.3.6.1 - Variância dos erros estimados....... 62

3.3 .6 .2 - Krigagem ordinária...........6 64

3.3 .6 .3 - Cokrigagem............... 66

3.3.6.4 - Estimativa de distribuição e krigagem indicativa................ 68

4. - LOCALIZAÇÃO E ASPECTOS FISIOGRÁFICOS DA ÁREA DE

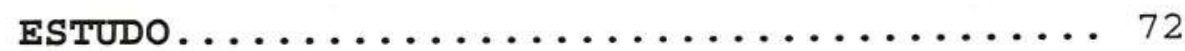

4.1 - Localização................... 72

4.2 - Clima e pluviometria............... 72

4.3 - Relevo...................... 74

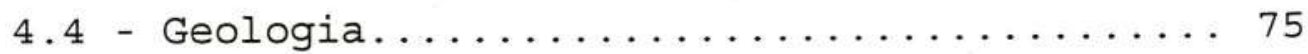

4.4 .1 - Tectônica e estruturas............ 80

4.5 - Pedologia................... 81 
5. - REVISÃO DOS ESTUDOS GEOTÉCNICOS REALIZADOS NA

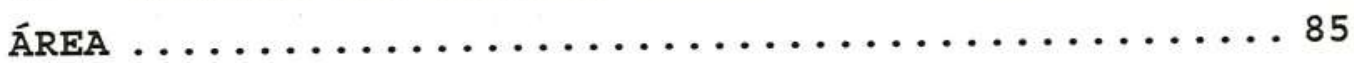

5.1 - Mapeamento geotécnico . . . . . . . . . 85

5.1 .1 - Mapa de zoneamento geotécnico de Bauru ... 86

5.2 - Colapsividade dos solos de Bauru .......... 93

5.2.1 - Aspectos teóricos do mecanismo de colapso. 93

5.2 .2 - Avaliação da colapsividade do solo de Bauru .................... 94

5.3 - Capacidade de carga e recalques ..........95

6. - APRESENTAÇÃO E DISCUSSÃO DOS RESULTADOS .... 98

6.1 - Estudos Geofísicos - Sísmica de Refração ... 98

6.2 - Estatísticas básicas .............. 108

6.3 - Análise dos dados pela Geoestatística . . . . 114

6.3.1 - Estimativas através da krigagem ordinária 114

6.3 .1 .1 - Análise variográfica ............. 115

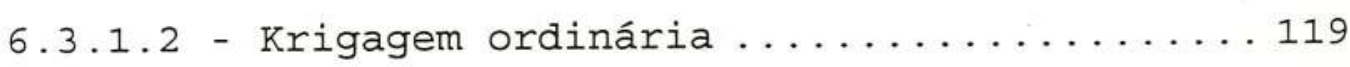

6.3 .2 - Estimativas pela cokrigagem .......... 127

6.3.2.1 - Análise variográfica ............ 128

6.3 .2 .2 - Estimativas pela cokrigagem ......... 133

6.3.2.3 - Estimativas das profundidades do lençol freático e do topo do impenetrável. ....134

6.3 .3 - Estimativas pela krigagem indicativa . . . 139

6.3.3.1 - Análise variográfica indicativa e

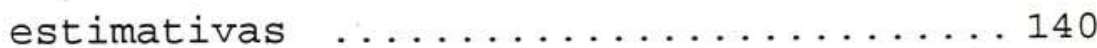

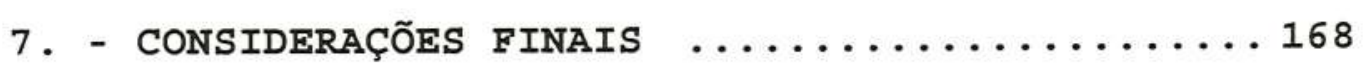

8. - REFERÊNCIAS BIBLIOGRÁFICAS ............ 173

APÊNDICE I

APÊNDICE II

APÊNDICE III 


\section{LISTA DE FIGURAS}

Figura 2.1 - Perfuração a trado manual nas sondagens de simples reconhecimento ........ 7

Figura 2.2 - Detalhes da execução da perfuração, com avanço por lavagem ........... 8

Figura 2.3 - Amostrador padrão pronto para descer no furo ................... 10

Figura 2.4 - Marcação nas hastes dos intervalos de penetração do amostrador padrão . . . . 11

Figura 2.5 - Relação entre N, pressão geostática efetiva e densidade relativa para solos não coesivos ............... 15

Figura 2.6 - Relação do ângulo de atrito $(\phi)$ com valores de SPT ............. 17

Figura 2.7 - Correlação entre a capacidade de carga admissível para se obter $25 \mathrm{~mm}$ de recalque e o valor de SPT ........ 18

Figura 2.8 - Previsão da capacidade de cargas para solos arenosos ...............21

Figura 2.9 - Representação esquemática da técnica de refração sísmica ............. 25

Figura 2.10 -Configuração para o caso de duas camadas ................ 26

Figura 2.11 -Configuração para o caso de três camadas ................. 28

Figura 2.12 -Preparação de uma carga de explosivo31

Figura 2.13 -Esquema de campo, empregado no ensaio de sísmica de refração ............ 32

Figura 3.1 - Planilha base para elaboração do banco de dados, das sondagens à percussão 34

Figura 3.2 - Fluxograma do banco de dados ..... 36

Figura 3.3 - Relação empírica entre a média, mediana, moda em distribuições assimétricas . 46

Figura 3.4 - Diagrama de dispersão de uma variável 
$\mathrm{V}(\mathrm{x})$ para uma determinada distância h. 52

Figura 3.5 - Esquema básico de uma função variograma ................ 54

Figura 3.6 - Tipos de anisotropia variográfica:

a) geométrica b) zonal .........56

Figura 3.7 - Modelos variográficos com patamar. . . 57

Figura 3.8 - Modelo aleatório ............. 58

Figura 3.9 - Modelos lineares generalizados ......559

Figura 4.1 - Localização da área de estudo. . . . . 73

Figura 4.2 - Mapa geológico da área de estudo. ...76

Figura 4.3 - Mapa pedológico da área de estudo. . . 83

Figura 5.1 - Mapa geotécnico da área de estudo . . 87

Figura 5.2 - Boçoroca causada por fenômenos de "piping". ............... 90

Figura 6.1 - Mapa de localização dos perfis médios das sondagens e das seções sísmicas. 99

Figura 6.2 - Seção sísmica da base 1.......... 101

Figura 6.3 - Seção sísmica da base 2......... 102

Figura 6.4 - Seção sísmica da base 3. ......... 104

Figura 6.5 - Seção sísmica da base 4.......... 105

Figura 6.6 - Seção sísmica da base 5. . . . . . . 107

Figura 6.7 - Distribuição de freqüência relativa para todos os dados $($ SPT $<60)$. . . 109

Figura 6.8 - Gráfico de correlação SPT x profundidade ............... 109

Figura 6.9 - Distribuição de freqüência relativa do estrato superficial (espessura 5m). . 110

Figura 6.10 - Histogramas dos SPT's dos níveis: a) 1

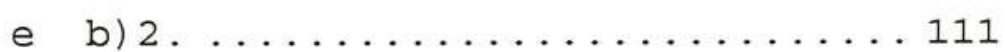

Figura 6.11 - Histogramas dos SPT's dos níveis: a) 3;

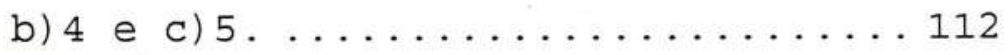

Figura 6.12 - Variogramas para os níveis (profundidade): a) $1 \mathrm{~m}$; b) $2 \mathrm{~m}$; c) $3 \mathrm{~m} .116$

Figura 6.13 - Variogramas para os níveis: a) 4m; b) $5 \mathrm{~m}$ e c) camada superficial. . . . . 117

Figura 6.14 - Mapas do nível 1, estimados pela krigagem ordinária: a) SPT estimado ; b) desvios-padrão das estimativas. . 121 
Figura 6.15 - Mapas do nível 2, estimados pela krigagem ordinária: a) SPT estimado ;

b) desvios-padrão das estimativas. . 122

Figura 6.16 - Mapas do nível 3, estimados pela krigagem ordinária: a) SPT estimado ;

b) desvios- padrão das estimativas.123

Figura 6.17 - Mapas do nível 4, estimados pela krigagem ordinária: a) SPT estimado ;

b) desvios-padrão das estimativas. . 124

Figura 6.18 - Mapas do nível 5, estimados pela krigagem ordinária: a) SPT estimado ;

b) desvios- padrão das estimativas. 125

Figura 6.19 - Mapas da camada superficial, estimados pela krigagem ordinária: a) SPT estimado;b) desvios-padrão das

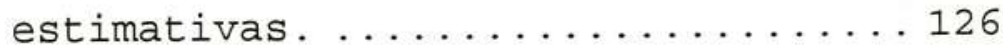

Figura 6.20 - Diagramas de dispersão: a) topo do lençol freático x cota topográfica;

b) topo do impenetrável $x$ cota topográfica . . . . . . . . . 127

Figura 6.21 - Mapa das malhas primária e secundária . . . . . . . . . 129

Figura 6.22 - Variogramas: a) cota topográfica; b) topo do lençol freático; c) topo do impenetrável . . . . . . . . . 130

Figura 6.23 - Variogramas cruzados das cotas topográficas com: a) topo do lençol freático; b) topo do impenetrável. . 132

Figura 6.24 - Mapas estimados pela krigagem ordinária do relevo: a) cotas topográficas, b) desvios- padrão das estimativas. 135

Figura 6.25 - Mapas estimados pela cokrigagem para :

a) topo do lençol freático

b) desvios - padrão das estimativas 136

Figura 6.26 - Mapas estimados pela cokrigagem para :

a) topo do impenetrável

b) desvios-padrão das estimativas . . 137 
Figura 6.27 - Mapas estimados (deduzidos) das profundidades: a) lençol freático;

b) topo do impenetrável ......... 138

Figura 6.28 - Variogramas indicativos para o nível 01, com níveis de corte: a) 1.75 ;

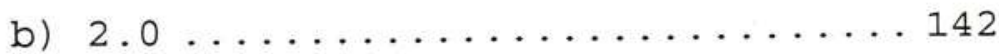

Figura 6.29 - Variogramas indicativos para o nível 01, com níveis de corte: a) 2.63 ; b) 3.0 ; c) $3.63 \ldots \ldots \ldots \ldots \ldots \ldots \ldots \ldots$

Figura 6.30 - Mapa probabilístico do nível 01: probabilidade do $\mathrm{SPT}>2.65 . \ldots \ldots 144$

Figura 6.31 - Variogramas indicativos do nível 02, com níveis de corte: a) 1.86 , b) 2.32146

Figura 6.32 - Variogramas indicativos do nível 02 , com níveis de corte: a) 3.0 ; b) 3.7 ;

c) $4.3 \ldots \ldots \ldots \ldots \ldots \ldots \ldots \ldots \ldots \ldots \ldots$

Figura 6.33 - Mapa probabilístico do nível 02 ;

Probabilidade do $\mathrm{SPT}>3.2 \ldots \ldots .148$

Figura 6.34 - Variogramas indicativos do nível 03 , com níveis de corte a) 2.0 ; b) $2.8 \ldots 150$

Figura 6.35 - Variogramas indicativos do nível 03 , com níveis de corte: a) 3.6 ; b) 4.4 ;

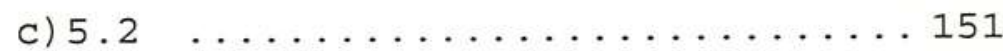

Figura 6.36 - Mapa probabilístico do nível 03.

Probabilidade do $\mathrm{SPT}>4.0 \ldots \ldots . .152$

Figura 6.37 - Variogramas indicativos do nível 04 , com níveis de corte: a) 2.7 ; b) 3.7 .154

Figura 6.38 - Variogramas indicativos do nível 04, com níveis de corte: a) 4.7 ;b) 5.5 ;

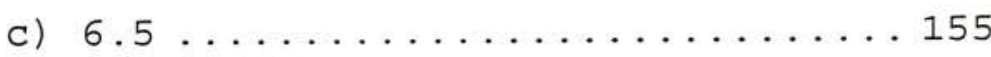

Figura 6.39 - Mapa probabilístico do nível 04: probabilidade do $\mathrm{SPT}>5.0 \ldots \ldots .156$

Figura 6.40 - Variogramas indicativos do nível 05, com níveis de corte: a) 3.4 ; b) $4.6 \ldots 158$

Figura 6.41 - Variogramas indicativos do nível 05, com níveis de corte: a) 5.5 ; b) 6.5 ;

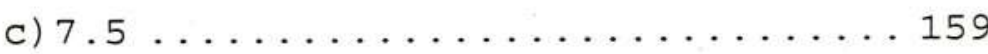


Figura 6.42 - Mapa probabilístico do nível 05: probabilidade do $\mathrm{SPT}>6.0 \ldots 160$

Figura 6.43 - Variogramas indicativos da camada superficial com níveis de corte: a) 2.0 ;
b) 2.8 ;
c) 3.6
. 163

Figura 6.44- Variogramas indicativos da camada superficial com níveis de corte: a)4.2; b) 5.0 ; c) $6.0 \ldots \ldots \ldots \ldots \ldots \ldots$

Figura 6.45 - Mapa probabilístico da camada superficial.Probabilidade do SPT estar no intervalo de 0.0 e $4.0 \ldots \ldots . .165$

Figura 6.46 - Mapa probabilístico da camada superficial. Probabilidade do SPT estar no intervalo de 4.0 e $10.0 \ldots . .166$

Figura 6.47 - Mapa probabilístico da camada superficial. Probabilidade do SPT estar situado no intervalo de $10.0 \mathrm{a}$

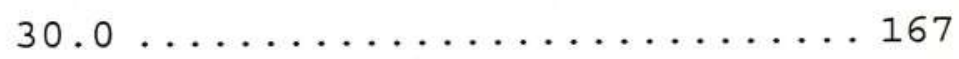




\section{LISTA DE TABELAS}

TABELA 2.1 - Classificação do SPT de acordo com a compacidade do solo . . . . . . . . . 14

TABELA 2.2 - Relação da compacidade com a densidade relativa ................. 15

TABELA 2.3 - Relação do SPT (N), consistência das argilas e resistência à compressão simples ................. 15

TABELA 2.4 - Valores de compacidade associados a solos granulares ............ 17

TABELA 2.5 - Relação entre a consistência de argilas e tensões admissíveis para fundações diretas ..................... 19

TABELA 2.6 - Relação entre a compacidade de areia e e tensões admissíveis para fundações diretas .................... 19

TABELA 2.7 - Valores de $\mathrm{K}_{\mathrm{DQ}}$ ( $\mathrm{KPa} / \mathrm{golpe}$ ) empregados no método de Decourt-Quaresma .....2 21

TABELA 5.1 - Pressões de ruptura e admissíveis

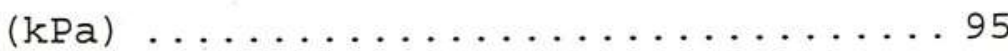

TABELA 5.2 - Carga última prevista por DecourtQuaresma, e coeficientes de correção. 96

TABELA 5.3 - Recalques (mm) para uma pressão de 100

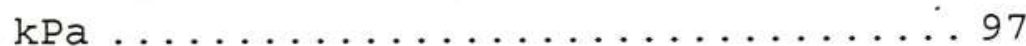

TABELA 6.1 - Estatísticas básicas do SPT dos diversos níveis e da camada superficial ................ 113

ABELA 6.2 - Estatísticas básicas alternativas do SPT para distribuições assimétricas ..... 113 
TABELA 6.3 - Parâmetros dos modelos esféricos ajustados . . . . . . . . . . . 118

TABELA 6.4 - Avaliação da componente aleatória . . 119

TABELA 6.5 - Parâmetros dos modelos variográficos indicativos- nível $01 \ldots \ldots . \ldots 141$

TABELA 6.6 - Parâmetros dos modelos variográficos indicativos- nível $02 \ldots \ldots \ldots \ldots$

TABELA 6.7 - Parâmetros dos modelos variográficos indicativos- nível $03 \ldots \ldots \ldots . \ldots 149$

TABELA 6.8 - Parâmetros dos modelos variográficos indicativos- nível $04 \ldots \ldots \ldots 153$

TABELA 6.9 - Parâmetros dos modelos variográficos indicativos- nível $05 \ldots \ldots \ldots 157$

TABELA 6.10- Parâmetros dos modelos variográficos

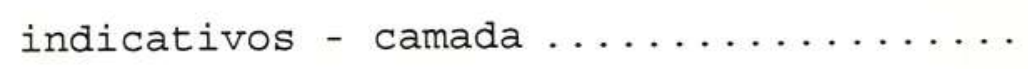




\section{LISTA DE SÍMBOLOS}

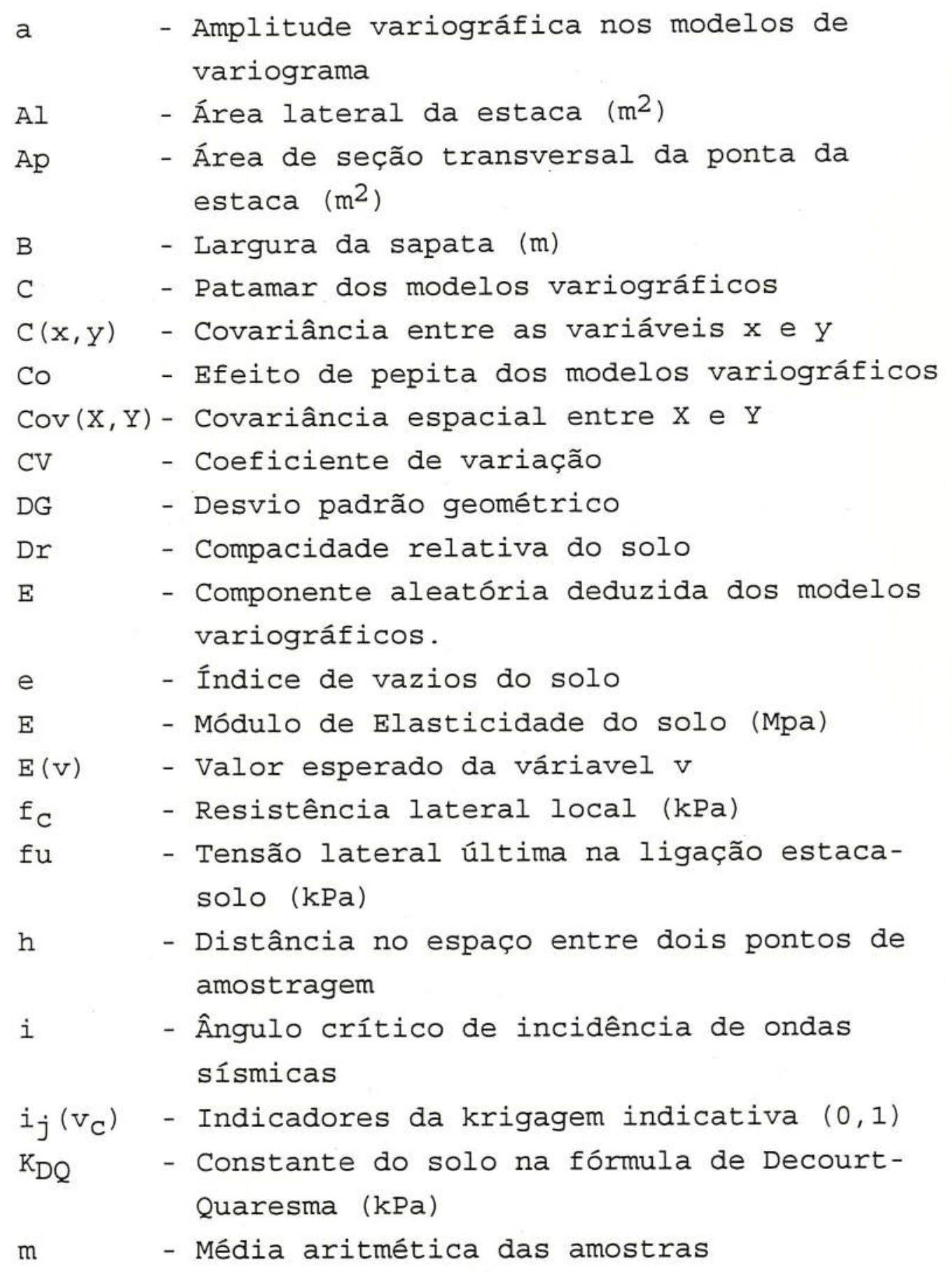




\begin{tabular}{|c|c|}
\hline MG & - Média geométrica \\
\hline N & - Índice de Resistência à Penetração (SPT) \\
\hline $\mathrm{n}$ & - Número de dados nas análises estatísticas \\
\hline $\mathrm{p}$ & $\begin{array}{l}\text { - Probabilidade de sucesso na distribuição } \\
\text { binomial }\end{array}$ \\
\hline $\mathrm{p}(\mathrm{x})$ & - Probabilidade de ocorrência do evento x \\
\hline$P_{\text {adm }}$ & - Pressão admissível (kPa) \\
\hline Plu & - Carga lateral última (kN) \\
\hline Ppu & - Carga de ponta última (kN) \\
\hline q & - Pressão aplicada pela fundação $\left(\mathrm{kN} / \mathrm{m}^{2}\right)$ \\
\hline q & $\begin{array}{l}\text { - Probabilidade de insucesso na distribuição } \\
\text { binomial }\end{array}$ \\
\hline$q_{C}$ & - Resistência à penetração do cone (kPa) \\
\hline$r$ & - Coeficiente de correlação linear \\
\hline RC & - Resistência a compressão simples (kPa) \\
\hline $\mathrm{V}(\mathrm{x})$ & - Váriavel regionalizada na posição x \\
\hline$v_{i}$ & - Valor observado da amostra v \\
\hline $\mathrm{V}_{\mathrm{n}}$ & - Velocidade de onda no $\mathrm{n}$ estrato $(\mathrm{km} / \mathrm{s})$ \\
\hline$w_{i}$ & - Ponderadores da estimativa de uma váriavel \\
\hline $\mathrm{x}(\mathrm{n}-1) \mathrm{n}$ & $\begin{array}{l}\text { - Distância crítica de chegada de ondas } \\
\text { sísmicas, refratadas nos estratos n-1 e n }\end{array}$ \\
\hline$\hat{\mu}_{0}$ & - Valor médio estimado na cokrigagem \\
\hline$\hat{V}$ & - Estimativa da váriavel regionalizada V \\
\hline$\sigma_{v}$ & - Pressão geoestática (kPa) \\
\hline$\sigma_{r}^{2}$ & - Variância dos erros da krigagem \\
\hline$\theta$ & - Expoente dos modelos variográficos lineares \\
\hline$\phi$ & - Ângulo de atrito (graus) \\
\hline$\sigma$ & - Desvio padrão populacional \\
\hline$\mu$ & $\begin{array}{l}\text { - Média aritmética populacional no modelo de } \\
\text { distribuição normal }\end{array}$ \\
\hline$\delta$ & - Recalque do solo (mm) \\
\hline$\Phi\left(\mathrm{A}, \mathrm{v}_{\mathrm{C}}\right)$ & $\begin{array}{l}\text { - Distribuição espacial de probabilidades } \\
\text { local }\end{array}$ \\
\hline$\gamma(\mathrm{h})$ & - Função variograma \\
\hline$\sigma^{2}$ & - Variância populacional \\
\hline$\mu_{i}$ & $\begin{array}{l}\text { - Parâmetros de Lagrange utilizados nos } \\
\text { sistemas de krigagem }\end{array}$ \\
\hline
\end{tabular}




\section{RESUMO}

STURARO, J.R. Mapeamento geoestatístico de propriedades geológico-geotécnicas obtidas em sondagens de simples reconhecimento. São Carlos, 1994. 180p. Tese (Doutorado em Geotecnia). Escola de Engenharia de São Carlos, Universidade de São Paulo.

Como a variabilidade espacial de propriedades geológico-geotécnicas não é devidamente avaliada nos mapeamentos geotécnicos, unidades geotécnicas consideradas homogêneas segundo determinadas propriedades, podem apresentar elevadas variações no espaço, que inviabilizam $\circ$ uso destas unidades na prática. Tendo isso em mente, são apresentadas, neste trabalho, técnicas para avaliar esta variabilidade espacial, bem como formas de empregá-las adequadamente em mapeamentos geotécnicos dirigidos. A caracterização do meio físico da área estudada, ou seja o sitio urbano de Bauru(SP), foi feita através de estudos geofísicos integrados com sondagens de simples reconhecimento préexistentes e, também, em conjunto com o levantamento bibliográfico de trabalhos específicos da área. Estabelecido o arcabouço geológico-geotécnico, foi analisada a variabilidade espacial segundo várias técnicas de variografia que, após modelamentos, foram empregadas para mapeamentos geoestatísticos. Como produto final obteve-se, mapas quantificados das propriedades geológico-geotécnicas estudadas, as quais foram interpoladas, extrapoladas e classificadas espacialmente, demonstrando a aplicabilidade da metodologia geoestatística em Geotecnia.

Palavras chaves: mapeamento geotécnico, variabilidade, geoestatística 


\section{ABSTRACT}

STURARO, J.R. Geoestatistical mapping of geologicalgeotechnical properties obtained by borehole. São Carlos, 1994. 180p. Tese (Doutorado em Geotecnia). Escola de Engenharia de São Carlos, Universidade de são Paulo.

The spatial variability of geological-geotechnical properties is not properly evaluated in geotechnical mapping and for so geotechnical units considered homogeneous, according to some properties, present spacial variability, which difficultate pratical application in civil engineering building planning. Geostatistical techniques for evaluate this variability are presented, as well as procedures to applicate them to especific geotechnical mapping. The physical environment characterization of the choosen area, in the urban city of Bauru, has been done through geophysical studies integrated to existing borehole and bibliographical review. Stablished the geological-geotechnical properties, the spatial variability had been analised according to several variographical techniques applied in geoestatistical mapping. Quantificated maps of the studied geologicalgeotechnical properties has been obtained, through interpolation, extrapolation and spatial classification.

Key-words: geotechnical mapping, variability, geoestatistics. 


\section{1. - INTRODUÇÃO}

\section{1 - CONSIDERAÇÕES INICIAIS}

Solos e rochas, dos quais resultam as propriedades geotécnicas, constituem-se em materiais de elevada heterogeneidade e conforme a escala de mapeamento a ser adotada, a hipótese de classificação homogênea pode se revelar totalmente inadequada.

Este importante aspecto torna-se mais relevante quando se deseja quantificar as propriedades dos solos ou rochas, sem considerar a variabilidade natural destas propriedades. Nestes casos, é usual a atribuição de valores numéricos para zonas consideradas homogêneas, os quais não apresentam qualquer significado prático. A variabilidade é considerada por somente um único valor, cuja determinação seguramente envolve julgamentos pessoais ou, ainda, é ignorada, quando a média aritmética ou outro valor médio, obtidos do conjunto de amostras, são empregados como parâmetros no modelamento dos projetos (LEE et al., 1983).

Por outro lado, a aplicação da estatística clássica está, por razões formais, limitada nas avaliações da variabilidade, pela dispersão dos valores em torno de um valor médio ou de tendência central. Entretanto, a variabilidade de natureza espacial das propriedades físicas, que é resultante de uma formação complexa como solos e rochas, requer um novo conjunto de ferramentas de análise, encontrado atualmente na estatistica espacial ou geoestatística.

A importância da variabilidade espacial pode ser ressaltada, por exemplo, quando se classificam solos segundo algumas propriedades geotécnicas. Desse modo, 
dois solos distintos podem possuir a mesma distribuição de frequiência, com médias e variâncias estatisticamente iguais, porém a variação espacial das propriedades geotécnicas, dentro de cada tipo de solo, pode ser completamente diferente.

$\mathrm{Na}$ análise geoestatística, a variabilidade espacial é profundamente avaliada e modelada, para em seguida se empregar técnicas apropriadas de estimativas, cujos resultados serão imagens representativas da distribuição no espaço, das propriedades que estão sendo analisadas.

\section{2 - MODELOS MATEMÁTICOS EM GEOCIÊNCIAS}

Para se efetuarem estimativas em locais onde não foram feitas amostras, é necessário ter-se um modelo do comportamento do fenômeno natural que deu origem às variáveis em estudo. Entretanto, o conhecimento em detalhes dos fenômenos naturais é muito difícil. Basta para isso, imaginar a formação de solos ou rochas que normalmente são o suporte das propriedades geológicogeotécnicas.

Caso houvesse um perfeito conhecimento dos processos físicos elou químicos que geraram os valores das variáveis, poder-se-iam, então, usar modelos determinísticos com um número pequeno de amostras, para se fazerem estimativas. Porém este não é o caso, em Geociências, onde as variáveis comumente pesquisadas são - resultado de um vasto número de processos com interações complexas, que praticamente impossibilitam a sua descrição quantitativamente. Desse modo, para a análise da maioria das variáveis, oriundas de fenômenos naturais, é necessário se admitir alguma incerteza no comportamento destes fenômenos entre duas posições espaciais da amostragem (ISAAKS \& SRIVASTAVA, 1989).

Esta complexidade dos processos que originam os dados, faz parecer que os mesmos possuem um comportamento aleatório, quando, de fato, eles refletem 0 
desconhecimento que se tem de todos os processos e das suas interações no fenômeno natural.

Dentro deste contexto, os modelos probabilisticos surgem como uma consistente alternativa para modelar este comportamento, através do uso de funções aleatórias.

\section{3 - APLICAÇÃO DA GEOESTATÍSTICA EM GEOTECNIA}

As propriedades geotécnicas, dado às suas características, enquadram-se no universo de variáveis, cujos valores são respostas a processos naturais, como os geológicos, pedológicos e outros. Desta forma, técnicas como a geoestatística, fundamentada nos modelos probabilísticos, constituem-se em uma abordagem apropriada para quantificar a aparente aleatoriedade das variáveis geotécnicas, efetuando-se estimativas e avaliando-se incertezas.

o principal objetivo deste trabalho é, portanto, introduzir a metodologia da geoestatística em Geotecnia, principalmente no ramo de mapeamento geotécnico. Como resultado, espera-se reproduzir criteriosamente a variabilidade espacial de algumas propriedades geológicogeotécnicas, através de mapas geoestatisticos e que sejam, por extensão, utilizados nos modelos determinísticos de larga tradição em engenharia.

Para a aplicação da metodologia, foi escolhida a cidade de Bauru-SP, por representar um grande centro urbano e situar-se sobre materiais aparentemente homogêneos, que são os solos residuais das formações arenosas Marília e Adamantina.

A principal fonte de dados foram as propriedades geológico-geotécnicas obtidas nas sondagens de simples reconhecimento, assessoradas por levantamento dos solos da região e ensaios geofísicos.

Foram utilizadas várias técnicas de estimativas geoestatísticas para se atenderem as principais necessidades de qualquer mapeamento, que são: 
interpolação, extrapolação e classificação espacial das propriedades em análise.

Estas técnicas foram aplicadas para uma camada superficial, individualizada do perfil de alteração da área de estudo, resultando numa detalhada caracterização no espaço do Índice de Resistência à Penetração (SPT) . Por outro lado, foram extrapoladas para a região periférica do centro urbano da cidade de Bauru, onde a malha de dados é rarefeita, os topos do lençol freático e do impenetrável ao amostrador padrão, obtidos das sondagens de simples reconhecimento.

Estes trabalhos integrados permitiram uma definição consistente do arcabouço geológico-geotécnico do sítio urbano de Bauru-SP, segundo algumas propriedades geotécnicas, que podem, portanto, ser empregados para determinados fins, dentro do contexto de planejamento urbano. 


\section{2. - TÉCNICAS DE OBTENÇÃO DOS DADOS}

\section{1 - SONDAGENS DE SIMPLES RECONHECIMENTO}

A principal fonte de informações desta pesquisa foram as sondagens de simples reconhecimento ou a sondagem de percussão, efetuadas no sítio urbano da cidade de Bauru - SP, voltadas para obras de engenharia.

Foram analisadas 720 sondagens, feitas por diferentes empresas de perfuração, que estão distribuídas em 174 obras da cidade. Assim, pela importância deste tipo de sondagem para a origem dos dados deste trabalho, será feita, a seguir, uma descrição detalhada desta técnica de prospecção do subsolo.

\section{1 .1 - Definição e origem}

A sondagem de simples reconhecimento é definida no Brasil, como um tipo de prospecção do subsolo, que visa às determinações do perfil estratigráfico, nível d'água e às características de resistência dos solos, através de ensaios de simples execução (BORTOLUCCI, 1983).

A origem destas sondagens, está estritamente associada aos ensaios de resistência à penetração. De acordo com FLECTCHER (1965), a sondagem de simples reconhecimento teve origem no início do século, quando, em 1902, Charles R. Gow introduziu a amostragem a seco, em substituição aos furos com lavagem. Esta amostragem era obtida pela cravação direta de um tubo de $25,4 \mathrm{~mm}$ de diâmetro e com 36 a $45 \mathrm{~cm}$ de comprimento com ponta aberta e biselada. A cravação do tubo amostrador era feita, 
então, com auxílio de um soquete com cerca de $50 \mathrm{~kg}$ de massa.

A partir de 1926, Linton Hart e Gordon F. A. Fletcher, trabalhando juntos na Raymond Concrete Pille Co., padronizaram as sondagens à percussão 0 que resultou no mundialmente conhecido teste denominado de "SPT", referente às iniciais de "Standard Penetration Test". No ano seguinte, foi projetado o amostrador padrão de duas polegadas de diâmetro externo do tipo Raymond.

Em 1930, baseada nos trabalhos de campo de Fletcher e nas pesquisas de Henry A. Mohr, foi estabelecida a padronização do ensaio, que consistia na queda de um martelo de 65 quilos de massa, situado a uma altura de $76 \mathrm{~cm}$ para cravar o amostrador padrão. Contava-se, então, - número de golpes necessários para cravar $30 \mathrm{~cm}$ do amostrador no solo.

Desde esta época, até os dias de hoje, embora tenham sido feita algumas alterações no equipamento e na forma do ensaio, a estrutura básica do equipamento e os procedimentos principais foram mantidos.

\subsection{2 - Processo de Perfuração}

Com o passar do tempo, após sucessivas adaptações, as sondagens de simples reconhecimento tiveram sua execução normalizada no Brasil, conforme a NBR 6484 de 1980 da ASSOCIAÇÃO BRASILEIRA DE NORMAS TÉCNICAS - ABNT, que estabeleceu $\circ$ amostrador com diâmetro externo de $50.8 \mathrm{~mm}$ e interno de $34.8 \mathrm{~mm}$.

A perfuração deve ser iniciada com $\circ$ trado cavadeira ou concha manual até a profundidade de um (1) metro (Figura 2.1), quando será instalado o primeiro tubo de revestimento. A perfuração prossegue com o trado espiral, intercalada com a cravação do barrilete amostrador, até que esta forma de perfuração torne-se inoperante, ou, seja encontrado o nível d'água. Caso ocorra uma destas situações, o processo de perfuração 
passa a ser efetuado com circulação de água, fazendo-se - uso do trépano de lavagem para continuar a escavação, cujos detalhes do equipamento podem ser observados na Figura 2.2.

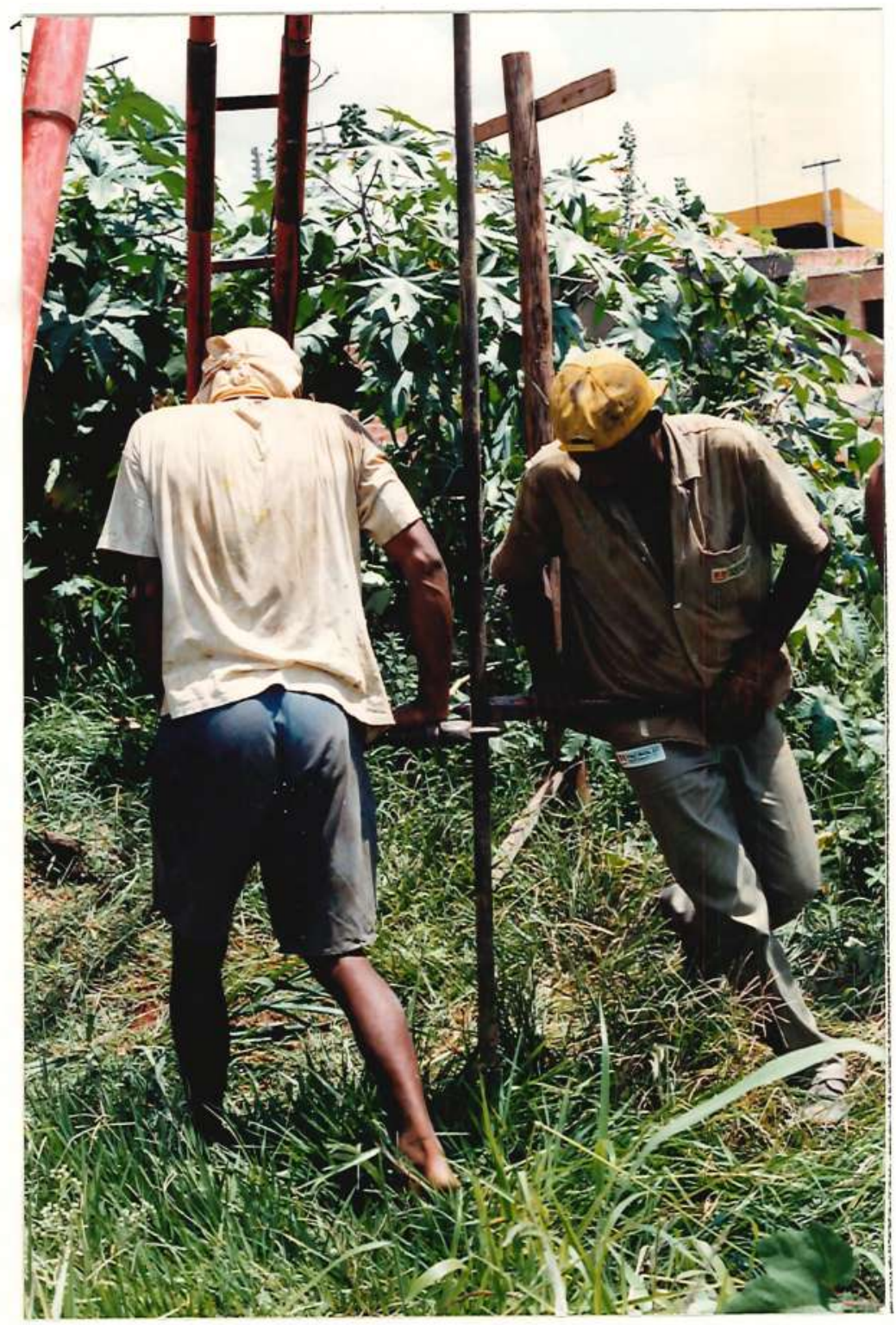

Figura 2.1 - Perfuração a trado manual nas sondagens de simples reconhecimento.

\subsection{3 - Amostragem e Identificação do Solo}

Durante o processo de perfuração, é de fundamental importância a determinação dos contatos entre camadas ou lentes do material perfurado. o solo deve ser analisado 
de forma expedita, através de uma análise táctil e visual.

Quando o avanço é feito a trado, a identificação é feita pelo material trazido pelo próprio trado e durante a perfuração com circulação de água, a análise é feita no material colhido em baldinhos com a água que sai do furo. As amostras do barrilete amostrador deverão, sempre que possível, ser acondicionadas, mantendo-se intactos os cilindros dos solos obtidos (ABGE, 1977).

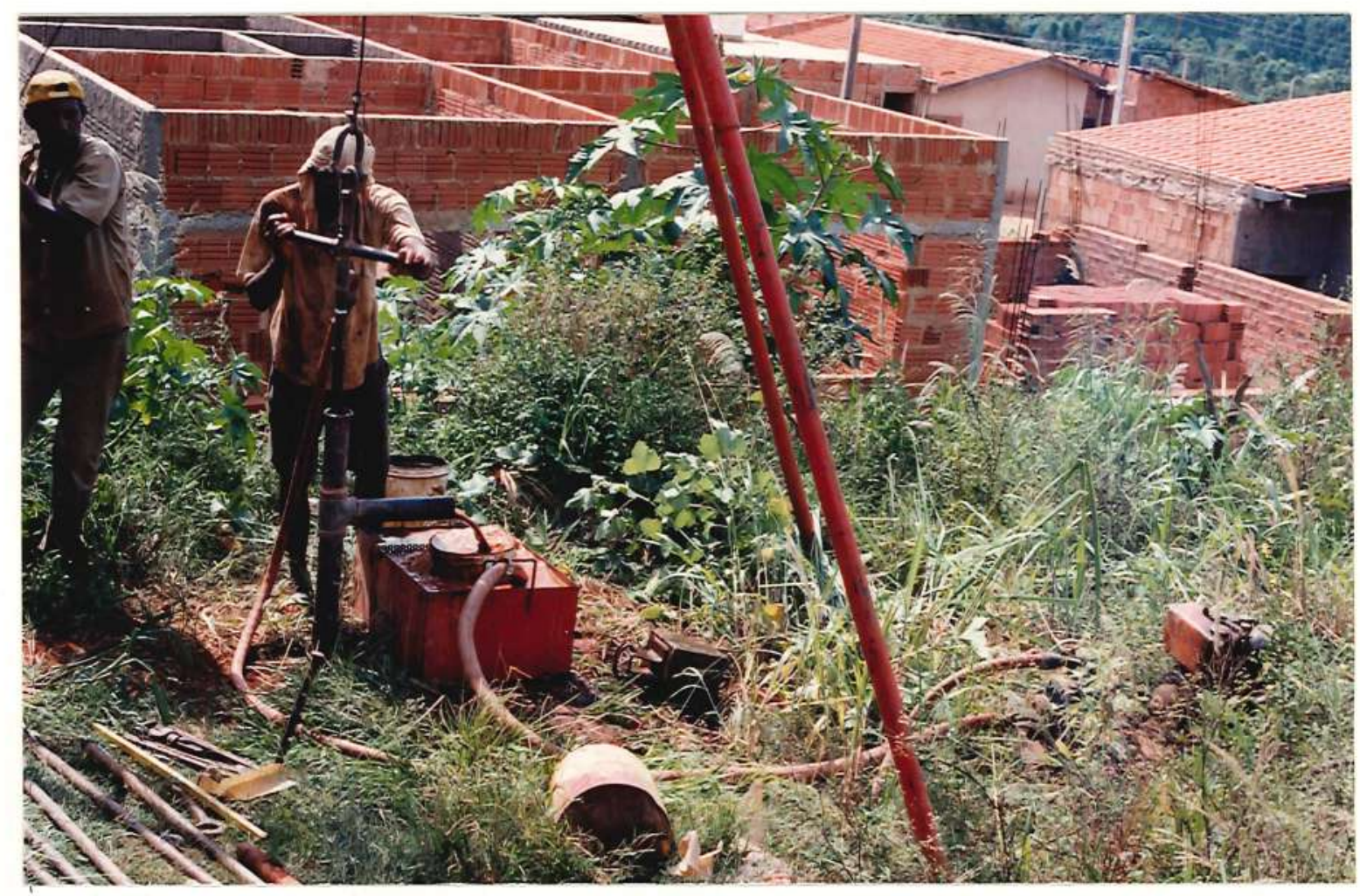

Figura 2.2 - Detalhes da execução da perfuração, com avanço por lavagem.

\subsection{4 - Determinação do Nível de Água}

Nas situações onde o nível d'água é encontrado durante a sondagem, a sua profundidade deve ser anotada. No caso de ocorrer artesianismo, a altura máxima de elevação da água, no interior do revestimento, deve ser medida. Além disso, o nível d'água ou as características do artesianismo deverão ser anotados, todos os dias, 
antes do início dos trabalhos e na manhã do dia seguinte, após a conclusão das sondagens.

\subsection{5 - Ensaio de Penetração Padronizada - SPT}

De acordo com ABGE (1990), o ensaio de penetração padronizada (SPT) é um ensaio executado a cada metro, durante a sondagem à percussão, com o propósito de se obterem índices de resistência à penetração do solo.

Basicamente, o ensaio consiste na cravação do amostrador padrão (Figura 2.3), através da queda de um martelo de $65 \mathrm{~kg}$ que cai livremente de uma altura de $75 \mathrm{~cm}$. Cada queda do martelo corresponde a um golpe e serão aplicados tantos golpes quantos forem necessários à cravação de $45 \mathrm{~cm}$ do amostrador. É anotado o número de golpes para a cravação de cada segmento de $15 \mathrm{~cm}$ do amostrador, referenciado através de marcas de giz feitas na haste de perfuração (Figura 2.4). o valor da resistência à penetração(SPT), consistirá do número de golpes necessários à cravação dos $30 \mathrm{~cm}$ finais do amostrador.

TEIXEIRA (1993), apresenta uma análise de penetração do amostrador parcializada, onde cada intervalo de $15 \mathrm{~cm}$ de penetração $\left(\mathrm{N}_{\mathrm{i}}\right)$ é correlacionado com o número total de golpes $\left(N_{t}\right)$, para penetrar todo 0 amostrador $(45 \mathrm{~cm})$. As correlações estatisticas, baseadas em mais de 4000 ensaios penetrométricos feitos sob rígido controle, são as seguintes:

$$
\begin{aligned}
& \mathrm{N}_{1}=0.22 \mathrm{~N}_{\mathrm{t}} \\
& \mathrm{N}_{2}=0.33 \mathrm{~N}_{\mathrm{t}} \\
& \mathrm{N}_{3}=0.45 \mathrm{~N}_{\mathrm{t}}
\end{aligned}
$$

Por definição do SPT, tem-se:

$$
\mathrm{SPT}=\mathrm{N}=\mathrm{N}_{2}+\mathrm{N}_{3}=0.33 \mathrm{~N}_{\mathrm{t}}+0.45 \mathrm{~N}_{\mathrm{t}}=0.78 \mathrm{~N}_{\mathrm{t}}
$$

Estas correlações podem ser utilizadas para avaliar, de forma expedita, a qualidade da sondagem. 


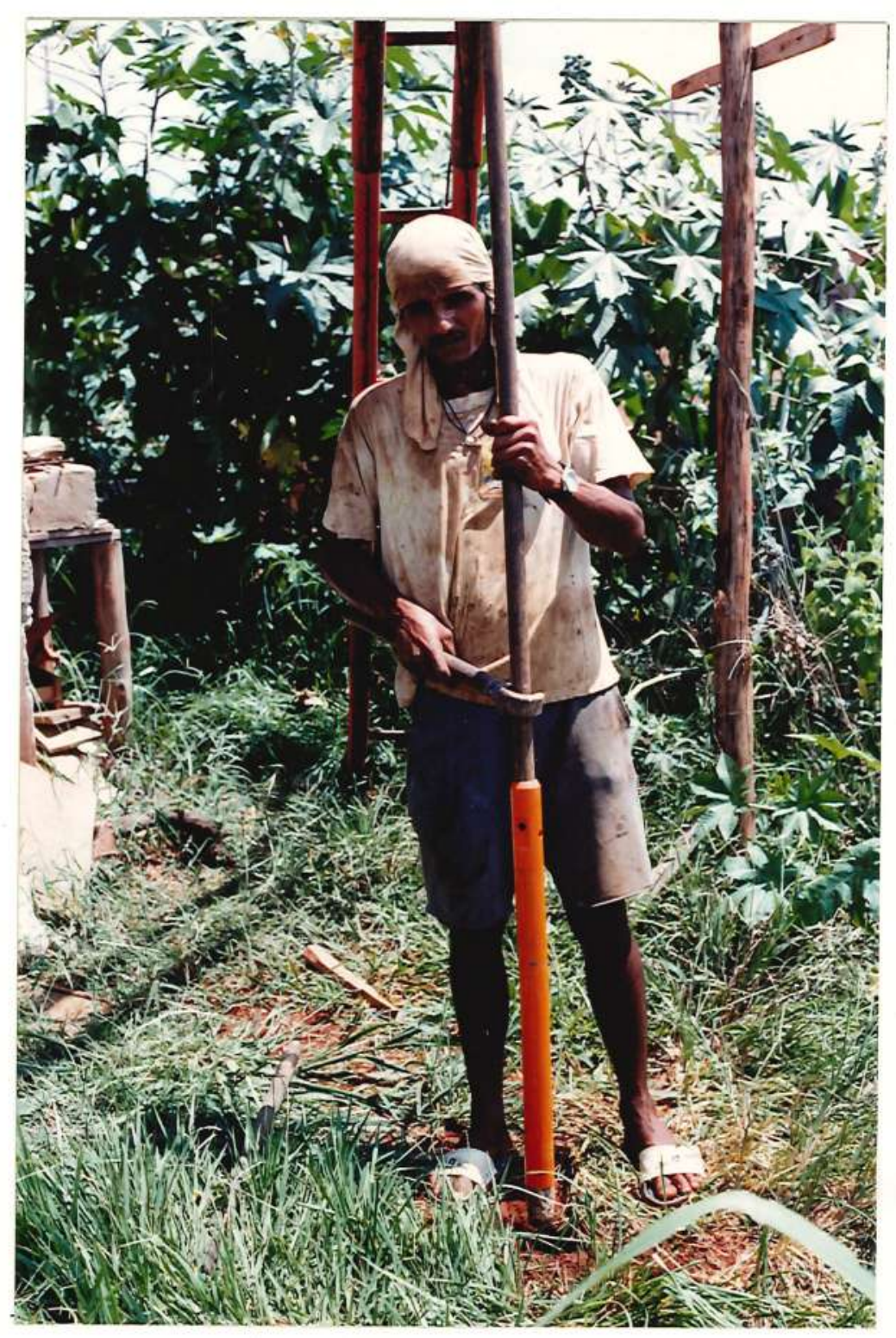

Figura 2.3 - Amostrador padrão pronto para descer no furo.

2.5.1. Fatores que influenciam o índice de resistência à penetração

Existem vários fatores que podem afetar os valores dos índices de resistência à penetração (SPT), relatados em FLECTCHER (1965), MELLO (1971), LIMA (1979), BUENO \& VILLAR (1981) e TEIXEIRA (1993). Esses fatores constituem-se numa significativa fonte de erros e representam uma parcela da variabilidade dos SPT's, detectada nos estudos estatísticos e geoestatísticos. 


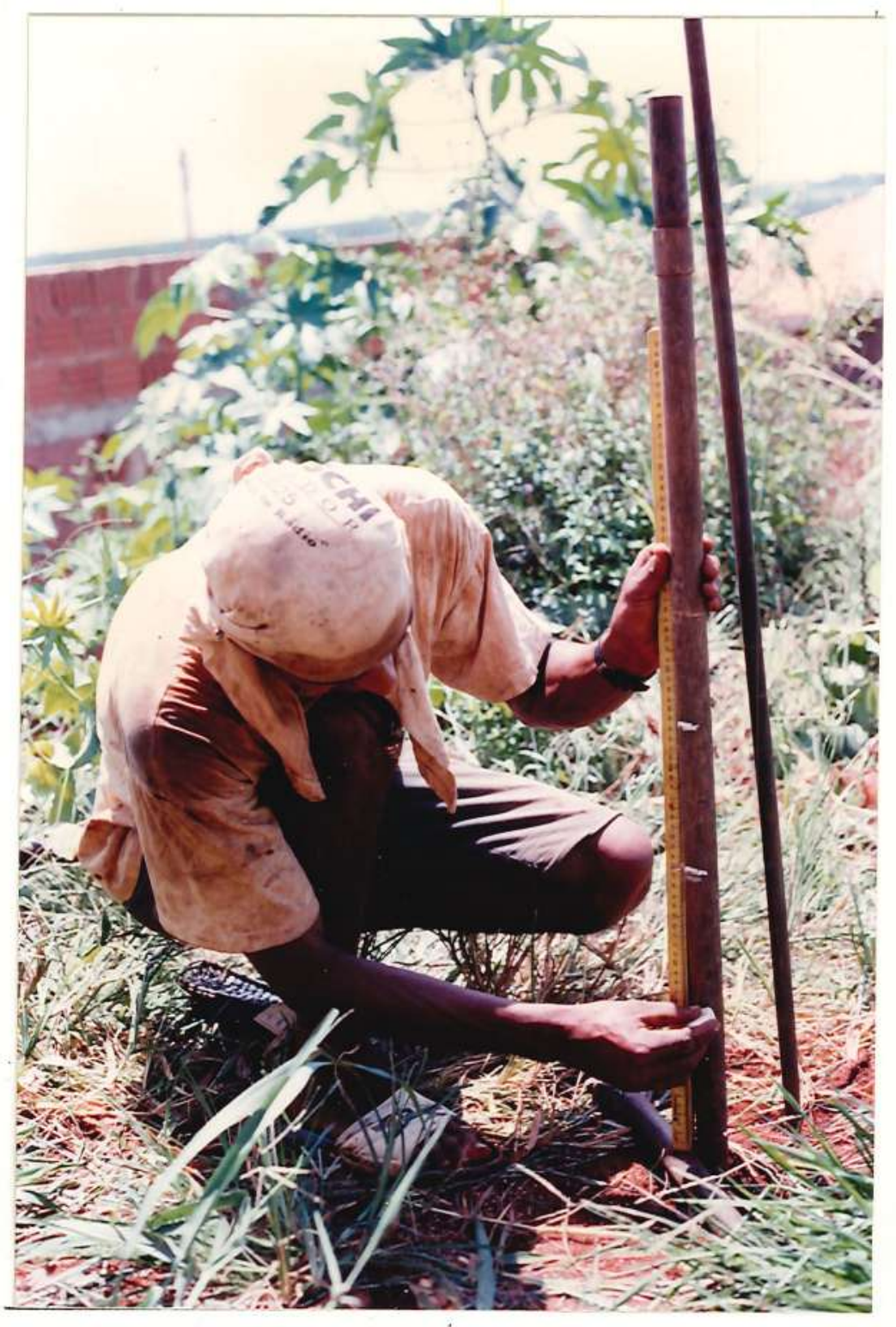

Figura 2.4 - Marcação nas hastes dos intervalos de penetração do amostrador padrão.

Basicamente, estes fatores estão associados à forma de execução das sondagens, bem como às características e estado de conservação do equipamento, que afetam a transferência da energia potencial teórica do martelo(478J), para as hastes e o amostrador.

Com relação à execução das sondagens, destacam-se:

- Variação na altura de queda do martelo e atrito no cabo de sustentação do mesmo, que resultam num número maior de golpes para um determinado intervalo ensaiado; 
- Emprego da técnica de avanço por circulação de água acima do nível d'água;

- Características do furo, como a de não estar alargado o suficiente para a passagem do amostrador ou então, a má limpeza do furo com a formação de pedregulhos;

- Excesso de lavagem para cravação do revestimento;

- Erro na contagem ou anotação errada do número de golpes.

Com relação aos equipamentos, destacam-se os seguintes fatores:

- Estado de conservação do amostrador padrão;

- Estado de conservação das hastes ou ainda o caso de hastes de diferentes pesos;

- Martelo ou hastes não calibrados e natureza da superfície de impacto (ferro sobre ferro ou adoção de uma superfície amortecedora).

Notam-se, portanto, várias fontes de erros que incidem sobre 0 índice de resistência à penetração, o que requereria uma padronização e uma automação maior dos equipamentos, para minimizar os erros.

\subsection{2 - Vantagens do Uso do Ensaio de Penetração Padronizada}

Apesar dos vários fatores desfavoráveis ao uso do SPT, o emprego desta técnica é muito comum, dado aos seguintes aspectos:

- o equipamento é robusto e relativamente simples.

- A execução do ensaio é simples, o que permite uma alta frequiência do mesmo ao longo da sondagem.

- A coleta de amostra é feita facilmente.

- Pode ser empregado praticamente em todo tipo de solo e mesmo em rochas brandas.

- É executado sem problemas, tanto acima como abaixo do lençol freático.

- Possibilita a elaboração de perfís do subsolo com adequada precisão para os fins desejados. 
Em função das caracteristicas acima, este ensaio é amplamente utilizado no Brasil e tem fornecido, há décadas, importantes subsídios para os projetos em Engenharia Geotécnica.

\subsubsection{Interpretação do ensaio de penetração padronizada}

2.5.3.1. Correlações do SPT com parâmetros geotécnicos

Os valores de SPT podem ser correlacionados a diversos parâmetros geotécnicos, segundo várias formulações empíricas. Essas correlações remontam à década de 40 e importantes trabalhos que envolvem revisões sobre este assunto, são encontrados em MELLO (1971) e VERRUIJT et al. (1982).

Compacidade e densidade relativa: compacidade constitui uma característica de densidade (maior ou menor) dos solos não coesivos. Para estes tipos de solo pode-se expressar a compacidade, no sentido de ser mais compacto (denso) ou mais fofo (solto), relacionada ao seu maior peso por unidade de volume (VARGAS, 1977).

A compacidade de uma areia que tenha seu índice de vazios naturais $e$, é definida, então, pelo seu grau de compacidade, ou densidade relativa de acordo com a expressão:

$$
D_{r} \%=\frac{e_{\max }-e}{e_{\max }-e_{\min }} * 100
$$

onde: $e_{\max }$ representa $\circ$ índice de vazios do solo nas condições de compacidade máxima;

$e_{\min }$ representa $\circ$ índice de vazios do solo nas condições de compacidade mínima.

As correlações entre $\circ \operatorname{SPT}(\mathrm{N})$ e a Densidade Relativa (Dr), representa uma das relações mais importantes na Engenharia Geotécnica, principalmente 
quando se relaciona a Dr com o comportamento ou capacidade de carga das fundações (MELLO, 1971).

TERZAGHI \& PECK (1967) apresentam a compacidade em função do SPT(N), como demonstra a Tabela 2.1.

TABELA 2.1 - CLASSIFICAÇÃO DO SPT DE ACORDO COM A COMPACIDADE DO SOLO

\begin{tabular}{||c|c||}
\hline $\mathrm{N}$ & COMPACIDADE \\
\hline $0-4$ & Muito fofa \\
\hline $4-10$ & Fofa \\
\hline $10-30$ & Medianamente compacta \\
\hline $30-50$ & Muito compacta \\
\hline$>50$ & \\
\hline
\end{tabular}

GIBBS \& HOLTZ (1957) apud GIULIANI \& NICOLL (1982) estabeleceram a seguinte relação entre $\operatorname{Dr}$ e SPT(N):

$$
\frac{D_{r}}{100}=1.5\left(\frac{N}{F}\right)^{0.222}-0.6
$$

onde: $\quad F=0.0065 \bar{\sigma}^{2}+1.68 \bar{\sigma}+14$

$\bar{\sigma}$ é a pressão vertical (geoestática) dada em $t / \mathrm{m}^{2}$.

BAZARAA (1967) apud FERREIRA (1991), relacionou as seguintes expressões de acordo com $\sigma_{v}$ (pressão vertical).

$$
\begin{aligned}
& N=20 D_{r}^{2}\left(1+0.4 \sigma_{v}\right) \quad \text { para } \sigma_{v}<73 \mathrm{kPa} \\
& N=20 D_{r}^{2}\left(3.25+0.1 \sigma_{v}\right) \text { para } \sigma_{v}>73 \mathrm{kPa}
\end{aligned}
$$

MEYERHOF (1956) estabeleceu os seguintes valores de densidade relativa em função da compacidade, demonstrados na Tabela 2.2.

RODIN et al. (1974) apud ALBIERO (1990) demonstram a influência da tensão efetiva vertical (profundidade)e da compacidade, no valor da resistência à penetração N, conforme o gráfico da Figura 2.5. 
TABELA 2.2 - RELAÇÃO DA COMPACIDADE COM A DENSIDADE RELATIVA

\begin{tabular}{|c|c||}
\hline COMPACIDADE & DENSIDADE RELATIVA ( $\%)$ \\
\hline Muito fofa & $20-40$ \\
\hline Fofa & $40-60$ \\
\hline Medianamente compacta & $60-80$ \\
\hline Compacta & $>80$ \\
\hline Muito compacta & \\
\hline
\end{tabular}

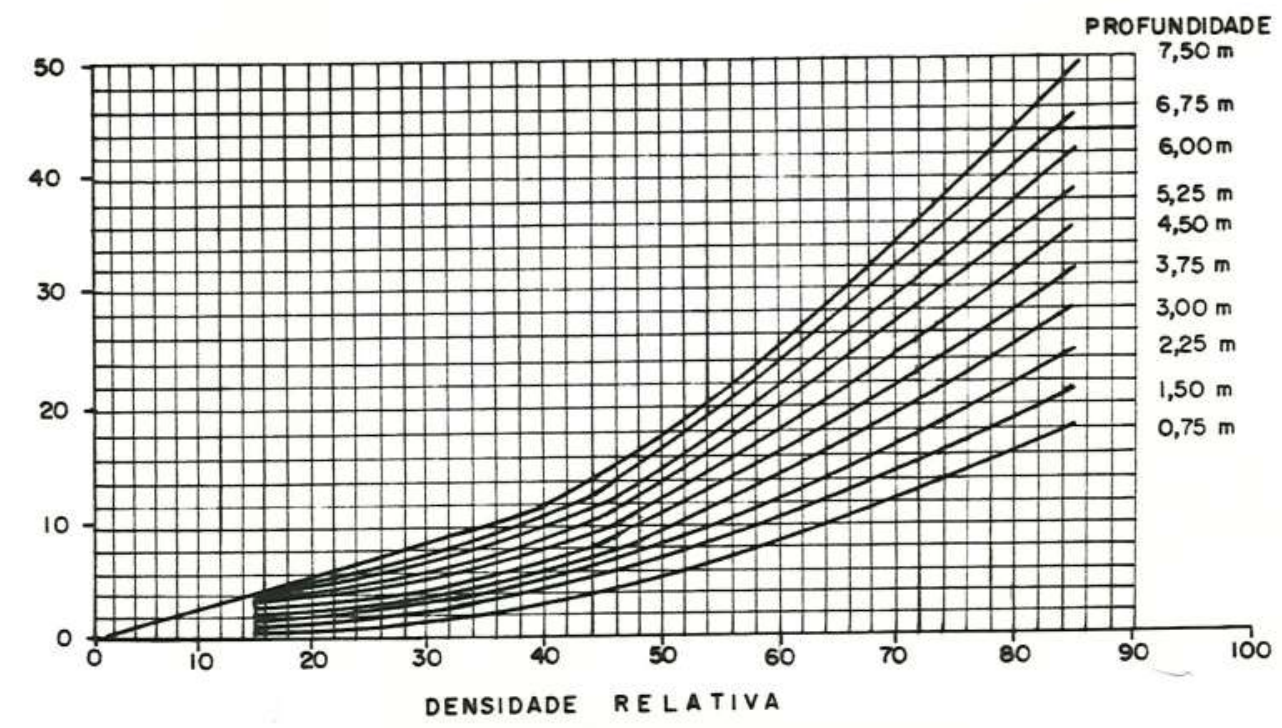

\begin{tabular}{|l|l|l|l|l|}
\hline WUITO FOFA & FOFA & $\begin{array}{c}\text { MEDIANAMENTE } \\
\text { COMPACTA }\end{array}$ & COMPACTA & $\begin{array}{c}\text { MUITO } \\
\text { COMPACTA }\end{array}$ \\
\hline
\end{tabular}

Figura 2.5 - Relação entre N, pressão geostática efetiva e densidade relativa para solos não coesivos

Consistência de Argilas e Resistência à Compressão Simples: A consistência refere-se aos solos coesivos e é definida como o grau de dureza em que uma argila é encontrada na natureza.

Através do ensaio de compressão simples, comprimese um corpo de prova até a ruptura. A carga da ruptura dividida pela área média do cilindro de prova é chamada de resistência à compressão simples (Rc), e pode ser usada como medida de consistência dos solos (VARGAS, 1977). 
O SPT, a Consistência e a Resistência à Compressão Simples foram relacionados, conforme mostra a Tabela 2.3 por TERZAGHI \& PECK (1967).

TABELA 2.3 - RELAÇÃO DO SPT (N), CONSISTÊNCIA DAS ARGILAS E RESISTENNCIA À COMPRESSÃO SIMPLES

\begin{tabular}{||c|c|c||}
\hline N & CONSISTÊNCIA & $R C(\mathrm{KPa})$ \\
\hline$<2$ & Muito mole & $<25$ \\
\hline $2-4$ & Mole & 25 a 50 \\
\hline $4-8$ & Média & 50 a 100 \\
\hline $8-15$ & Rija & 100 a 200 \\
\hline $15-30$ & Muito rija & 200 a 400 \\
\hline$>30$ & Dura & $>400$ \\
\hline \multicolumn{2}{|c|}{} \\
\hline
\end{tabular}

Ângulo de Atrito (ф): A resistência dos solos é proporcionada por forças de atrito resultantes de enlaces moleculares nas superfícies de contato. Segundo a lei de Coulomb, a resistência por atrito é função da força normal no plano de deslizamento relativo. Assim, o ângulo de atrito $(\phi)$ representa o ângulo máximo que a força resultante forma com a normal, quando sujeita a uma força $\tau$ perpendicular a esta força normal, que dá início ao deslocamento relativo dos corpos no plano de deslizamento (VILAR \& BUENO, 1985).

Segundo PECK et al. (1953) e MEYERHOF (1956), O ângulo de atrito interno para solos granulares $(c=0)$ é relacionado com os valores de SPT, de acordo com o gráfico da Figura 2.6

Estudos realizados por MELLO(1967, 1971) em areias secas, estabeleceu a seguinte equação de regressão para 0 SPT (N), em função do ângulo de atrito $(\phi)$ e da pressão vertical $(\sigma)$ :

$$
S P T=4.0+0.015 \times \frac{2.4}{\operatorname{tg} \phi}\left[\operatorname{tg}^{2}\left(\frac{\pi}{4}+\frac{\phi}{2}\right) e^{\pi g \phi}-1\right]+\sigma g^{2}\left(\frac{\pi}{4}+\frac{\phi}{2}\right) e^{\pi g \phi} \pm 8.7
$$




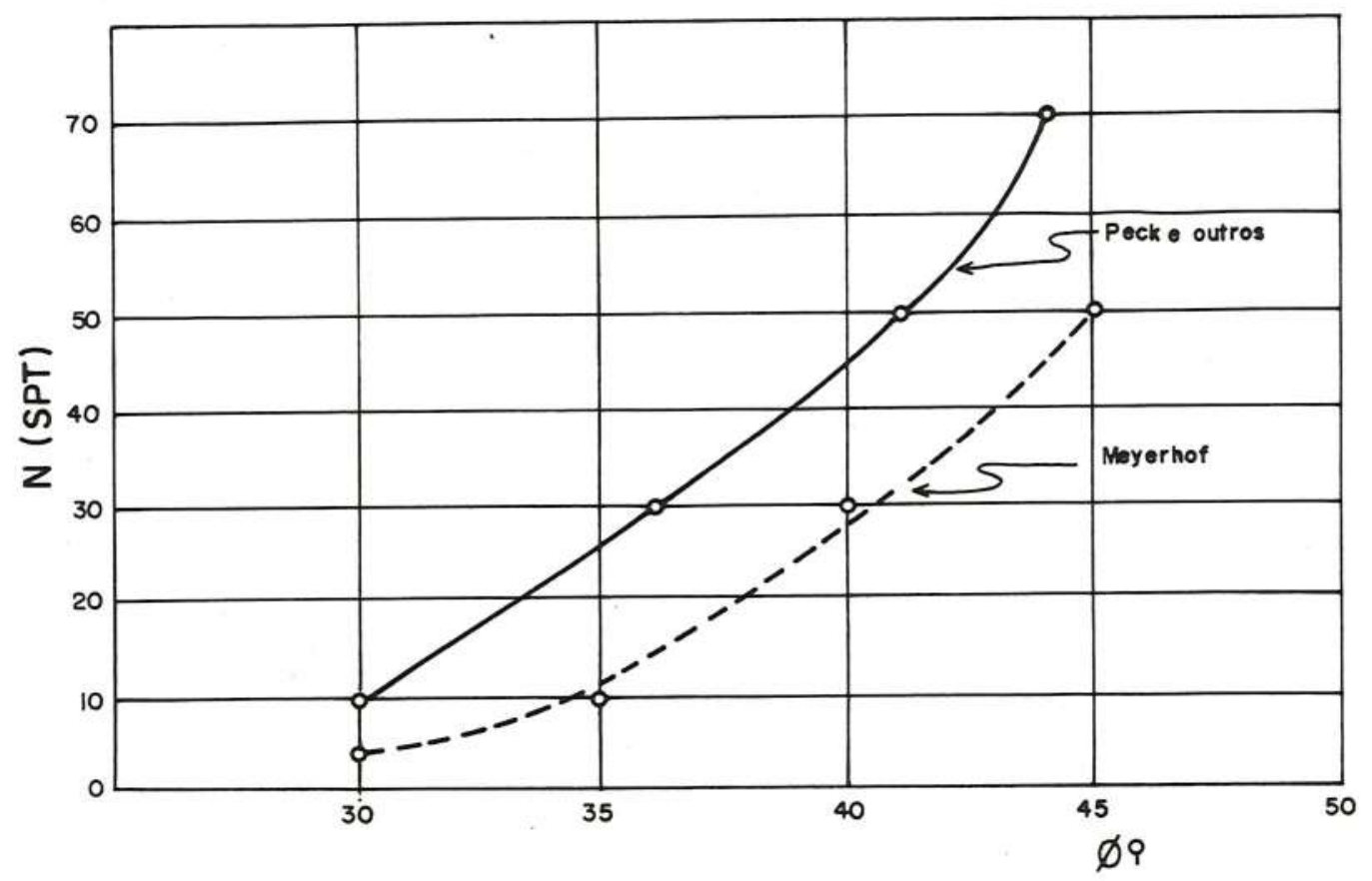

Figura 2.6 - Relação do ângulo de atrito $(\phi)$ com valores de SPT.

DAS (1985) apud FERREIRA (1991), apresenta valores mais comuns para $\circ$ ângulo de atrito interno ( $\phi$ ) para solos granulares em função da sua compacidade, como mostra a Tabela 2.4.

TABELA 2.4 - VALORES DE COMPACIDADE ASSOCIADOS A SOLOS GRANULARES

\begin{tabular}{||c|c|c||}
\hline Tipo de Solo & Compacidade & ângulo de atrito \\
\hline Areias com & Fofa & 280 a 300 \\
grãos & Média & 300 a $35^{\circ}$ \\
arredondados & Compacta & 350 a $38^{\circ}$ \\
\hline Areias com & Fofa & 300 a 350 \\
grãos & Média & 350 a 400 \\
angulares & Compacta & 400 a 450 \\
\hline Pedregulhos & & 340 a 480 \\
arenosos & & \\
\hline
\end{tabular}


2.5.3.2 - Aplicações do SPT na Engenharia Geotécnica

Recalque em Solos Granulares: Define-se como "recalque", a deformação vertical positiva de uma superfície qualquer delimitada no terreno.

Existem vários métodos de previsão de recalques, baseados no SPT. Serão aqui citados alguns métodos, em função do pioneirismo e da simplicidade dos mesmos.

THERZAGHI \& PECK (1948) propuseram várias correlações entre o valor do SPT(N) e a pressão admissível para se obter um recalque de $25 \mathrm{~mm}$, para uma determinada sapata de largura B, que estão expressas na Figura 2.7.

Neste caso, se o lençol freático estiver ao nível da fundação, a pressão admissível deve ser considerada como a metade da estimada.

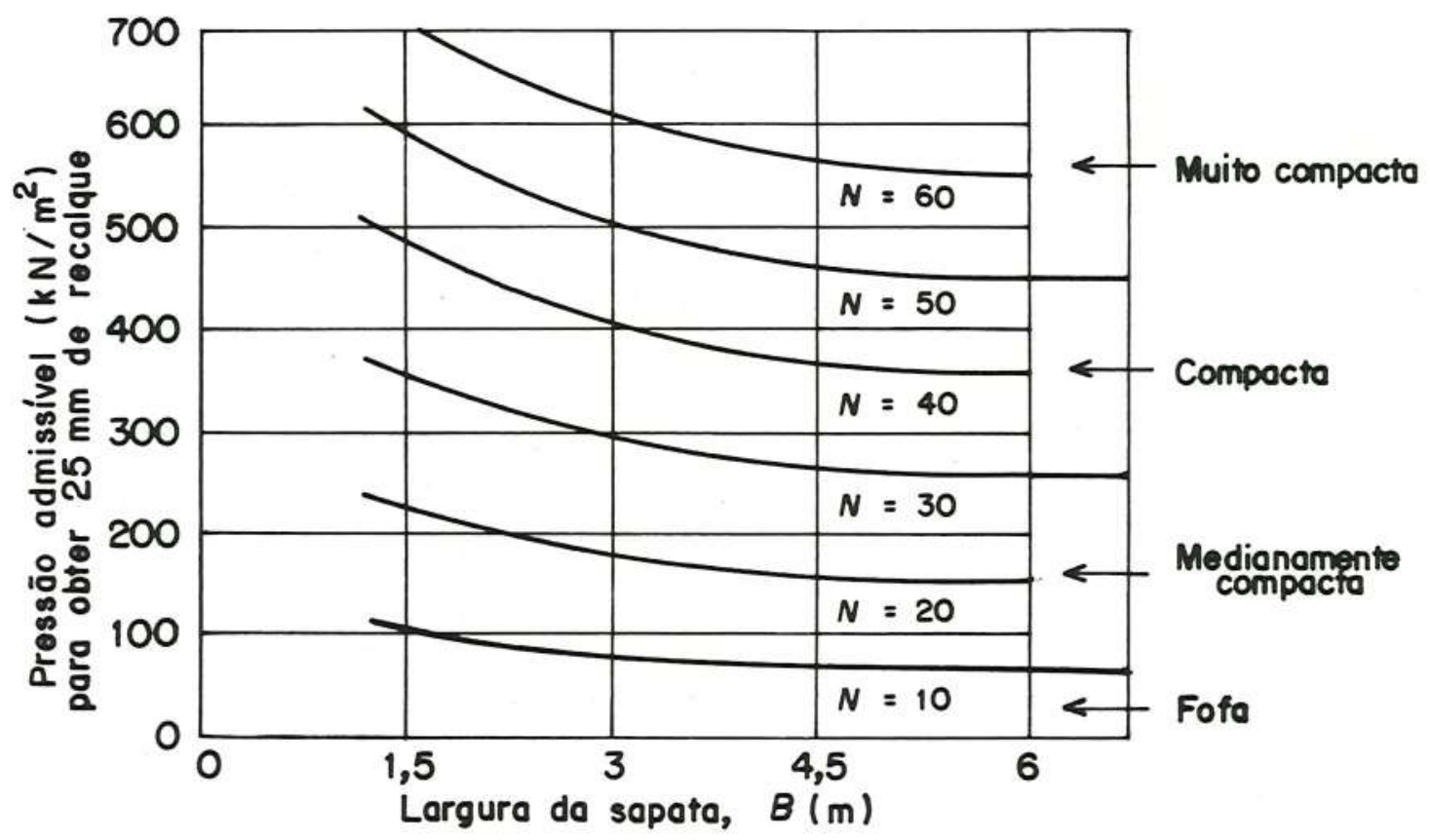

Figura 2.7 - Correlação entre a capacidade de carga admissível para se obter $25 \mathrm{~mm}$ de recalque e o valor de SPT. 
MEYERHOF (1965) propôs os cálculos dos recalques - $\delta$ (mm) de estruturas assentadas em solos arenosos, de acordo com as seguintes expressões:

$$
\begin{array}{ll}
\delta=\frac{1.99}{N} & \text { para } B<1.25 m \\
\delta=\frac{2.84 q}{N}\left(\frac{B}{B+0.33}\right)^{2} & \text { para } B>1.25 m \\
\delta=\frac{2.84 q}{N} & \text { para } B \rightarrow \infty(\text { radiers })
\end{array}
$$

onde:

$\mathrm{N}$ = média feita para um intervalo de profundidade igual largura da sapata

$B=$ Largura da sapata

$q=$ pressão aplicada pela fundação

Outros métodos que envolvem correlações de recalques com valores de SPT são encontrados em ALPAN (1964), PARRY (1977), SCHULTZE \& SHERIF (1973), BURLAND et al.(1977), SIMONS \& MENZIES (1977) entre outros.

Capacidade de Carga: Define-se "capacidade de carga" de uma fundação, àquela que resista no limite da ruptura, ou, ainda, em condições adequadas de deformação, que não afete a estrutura nela apoiada.

Para contornar as dificuldades de se obter amostras indeformadas de solos não coesivos, MEYERHOF (1956) sugere o calculo da capacidade de carga destes solos através de ensaios de penetração dinâmico e estático no local da obra.

De acordo com LIMA (1979), a carga admissível a ser transmitida por uma fundação direta ao solo, pode ser correlacionada com a consistência ou compacidade deduzida dos ensaios de penetração (SPT). Deve-se ressaltar que, estas correlações devem ser empregadas juntamente com a experiência do engenheiro na região, assim como a importância da obra. 
As tabelas 2.5 e 2.6 expressam as relações entre o $\mathrm{SPT}$ com as tensões admissiveis para solos argilosos e arenosos.

TABELA 2.5 - RELAÇÃO ENTRE A CONSISTÊNCIA DE ARGILAS E TENSÕES ADMISSÍVEIS EM FUNDAÇÕES DIRETAS

\begin{tabular}{||l|c|c|c||}
\hline \multicolumn{1}{||}{ ARGILA } & SPT (N) & \multicolumn{2}{|c||}{$\begin{array}{l}\text { TENSÕES ADMISSÍVEIS } \\
\left(\mathrm{kg} / \mathrm{cm}^{2}\right)\end{array}$} \\
\hline & & $\begin{array}{l}\text { Sapata } \\
\text { quadrada }\end{array}$ & Sapata contínua \\
\hline Muito mole & $<2$ & $<0.30$ & $<0.22$ \\
\hline Mole & $3-4$ & $0.33-0.60$ & $0.22-0.45$ \\
\hline Média & $5-8$ & $0.60-1.20$ & $0.45-0.90$ \\
\hline Rija & $9-15$ & $1.20-2.40$ & $0.90-1.80$ \\
\hline Muito rija & $16-30$ & $2.40-4.80$ & $1.80-3.60$ \\
\hline Dura & $>30$ & $>4.80$ & $>3.60$ \\
\hline
\end{tabular}

TABELA 2.6 - RELAÇÃO ENTRE A COMPACIDADE DE AREIA E TENSÕES ADMISSÍVEIS PARA FUNDAÇOES DIRETAS

\begin{tabular}{||l|c|c||}
\hline \multicolumn{1}{|c|}{ AREIA } & SPT (N) & $\begin{array}{c}\text { TENSÃO ADMISSÍVEL } \\
\left(\mathrm{Kg} / \mathrm{cm}^{2}\right)\end{array}$ \\
\hline \multicolumn{1}{|c|}{ Fofa } & 54 & $1.0-2.0$ \\
\hline Pouco Compacta & $11-30$ & $2.0-4.0$ \\
\hline $\begin{array}{l}\text { Medianamente } \\
\text { compacta }\end{array}$ & $31-50$ & $4.0-6.0$ \\
\hline $\begin{array}{l}\text { Compacta } \\
\begin{array}{l}\text { Muito } \\
\text { Compacta }\end{array}\end{array}$ & $>50$ & $>6.0$ \\
\hline
\end{tabular}

HOUGHT (1957) elaborou de forma empírica um gráfico que fornece uma previsão da capacidade de carga em função do SPT, textura do solo e densidade relativa. As curvas do gráfico apresentado na Figura 2.8, são representativas para fundações diretas convencionais. 


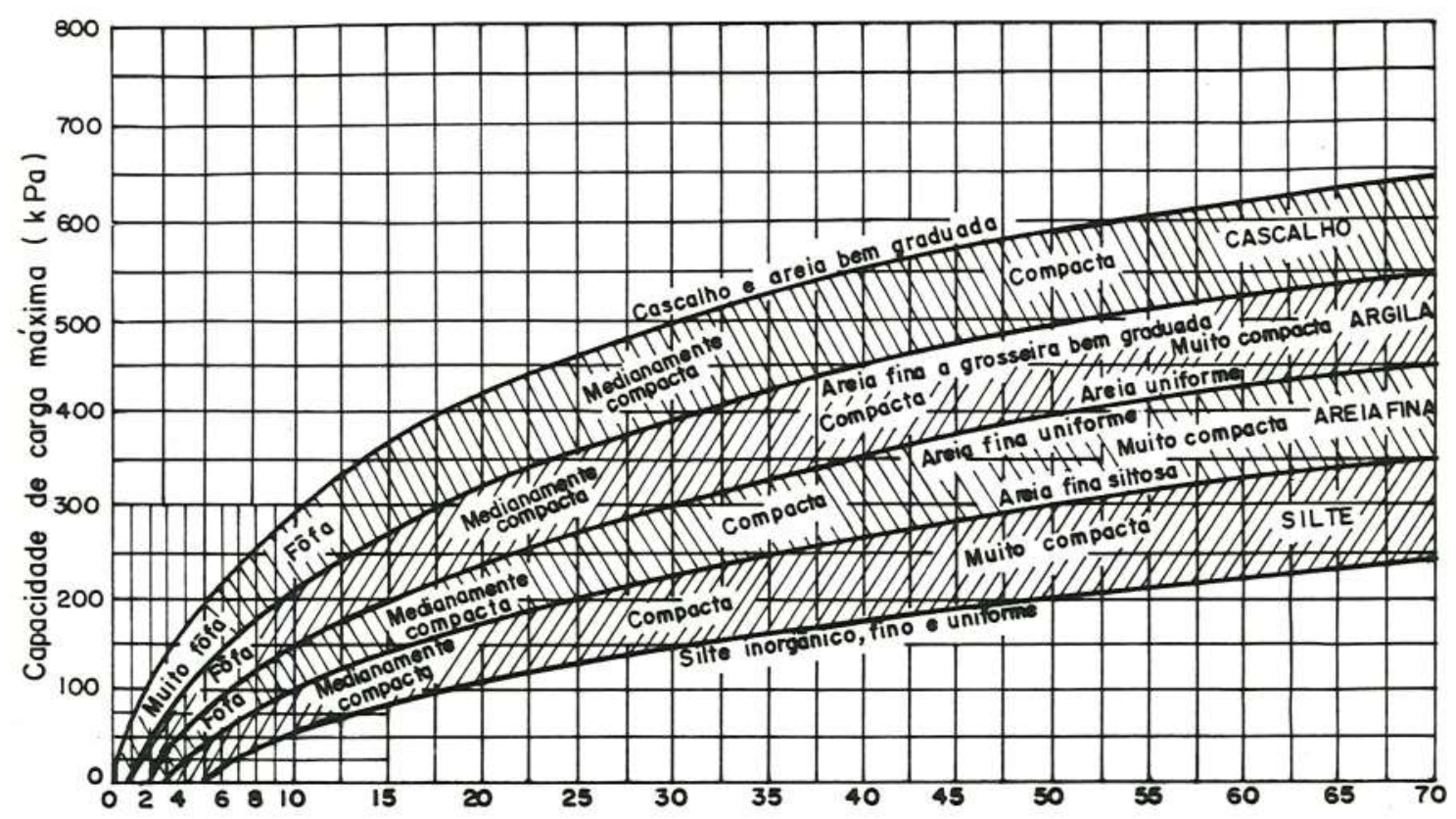

Figura 2.8 - Previsão da capacidade de cargas para solos arenosos (HOUGHT, 1957).

Quando o elemento de fundação é estaca, as correlações que fazem uso do SPT se ampliam, fornecendo valores de capaciade de carga satisfatórios para uso geral.

Dentre os vários métodos, será descrito o método desenvolvido por DECOURT \& QUARESMA (1978) e DECOURT (1982), conforme descrição em LOBO (1991).

A carga última da estaca é dado pela soma da carga lateral última(Plu) e da carga de ponta última(Ppu).

A carga lateral última é dada por:

$P l u=f u \times A l$

onde $f u$ é a aderência estaca-solo e $A l$ a área lateral da estaca.

A aderência estaca-solo (fu) pode ser estimada a partir dos valores de resistência à penetração (N), obtidos nas sondagens de simples reconhecimento de acordo com as expressões: 


$$
\begin{aligned}
& f u=3.33(\mathrm{kPa} / \text { golpe }) \times \dddot{N}_{1}+10(\mathrm{kPa}) \quad \text { para estacas de deslocamento } \\
& f u=2.33(\mathrm{kPa} / \text { golpe }) \times \dddot{N}_{1}+7(\mathrm{kPa}) \quad \text { para estacas escavadas }
\end{aligned}
$$

A estimativa da carga de ponta última da estaca é dada pelo produto da área de ponta da estaca (Ap) pela resistência última do solo na ponta da estaca (qu), isto é:

$$
P p u=q u \times A p
$$

A resistência última da ponta é estimada em função do valor médio do SPT na área da ponta da estaca ( $\dddot{N} p$ ), obtido nas sondagens de simples reconhecimento, ou seja:

$$
\begin{aligned}
& q u=K_{D Q} \times \dddot{N}_{p} \\
& \text { onde: } N_{p}=\frac{N_{p-1}+N_{p}+N_{p+1}}{3}
\end{aligned}
$$

$K_{D Q}$ é uma constante para cada tipo de solo, fornecida pela Tabela 2.7.

TABELA 2.7 - VALORES DE KDQ (KPa/golpe) EMPREGADOS NO MÉTODO DE DECOURT-QUARESMA

\begin{tabular}{|c|c|c||}
\hline \multirow{2}{*}{ SOLO } & \multicolumn{2}{|c|}{ TIPO DE ESTACA } \\
\cline { 2 - 3 } & Deslocamento & Escavada \\
\hline Argila & 120 & 100 \\
\hline Silte Argiloso (Residual) & 200 & 120 \\
\hline Silte Arenoso (Residual) & 250 & 140 \\
\hline Areia & 400 & 200 \\
\hline
\end{tabular}

A carga admissível pela estaca é estimada a partir da carga última, adotando-se coeficientes de segurança diferenciados para a carga lateral e de ponta, de acordo com o fator de segurança global igual a dois, determinado pela NBR 6122. A expressão é assim definida: 


$$
P a d m=\frac{P l u}{1.3}+\frac{P p u}{4.0}
$$

Outros métodos para a estimativa de carga última para estacas, que utilizam valores de SPT, estão demonstrados em LOBO (1991).

Às vezes o SPT pode ser usado indiretamente nos projetos de fundação, através de estimativas de outros parâmetros geotécnicos, como "ângulo de atrito" ( $\phi)$, "coesão" ou, ainda, em associação com outros tipos de ensaios como o Ensaio Estático do Cone de Penetração, cujos exemplos, podem ser vistos em KRUIZINGH(1982) e ALBIERO (1990).

DENVER(1982) apresenta uma relação linear entre o $\mathrm{N}(\mathrm{SPT})$ e o Módulo de Young (E), segundo a equação:

$$
\mathrm{E}=\mathrm{s}_{1} \mathrm{~N}+\mathrm{s}_{2}(\mathrm{MPa})
$$

onde $s_{1}$ e $s_{2}$ são constantes, especificada para diferentes tipos de solo. Uma outra relação, do tipo parabólica, também foi apresentada:

$$
\mathrm{E}=\mathrm{B} \sqrt{\mathrm{N}}(\mathrm{MPa})
$$

onde $\mathrm{B}$ é igual a $7 \mathrm{MPa}$.

- Ensaio de Penetração Padronizada tem sido utilizado, principalmente nos Estados Unidos e Japão, para prever o potencial de liquefação do solo causado por vários tipos de vibração, originados por terremotos, tráfego ferroviário, explosões e outros. Estes estudos são mais frequientes nos projetos para implantação de usinas nucleares, como medida de segurança.

Outras aplicações do SPT são encontradas nas áreas de controle de compactação (SAITO, 1977) e classificação de rochas brandas (STAMATOPOULOS \& KOTZIAS, 1980).

Como visto, existe uma série de relações entre o SPT com propriedades ou parâmetros geotécnicos, que pode ser de grande utilidade nos projetos de engenharia. 


\section{2 - ESTUDOS GEOFÍSICOS - SÍSMICA DE REFRAÇÃO}

Com o intuito de caracterizar melhor o perfil de alteração da área em estudo, empregou-se também a técnica da sísmica de refração. Através desta técnica, associada aos trabalhos pedológicos realizados e as descrições das sondagens, pode-se estabelecer a estratificação e as dimensões dos principais estratos da cobertura pedológica.

\subsection{1 - Teoria Básica da Técnica de Refração Sísmica}

Conforme MALAGUTTI FILHO(1991), a técnica da refração sísmica consiste, basicamente, na medida do tempo de percurso de ondas elásticas, geradas na superficie as quais, ao sofrerem refração total em uma ou mais interfaces, em profundidade, retornam à superfície. Ao chegarem à superfície, essas ondas serão captadas em detectores, denominados geofones, que são previamente espaçados e alinhados de acordo com a profundidade a ser pesquisada.

A Figura 2.9 demonstra o princípio da técnica de refração sísmica, para o caso de duas camadas.Assim, as ondas são geradas na ponto $F$ e os tempos de percussão são registrados nos receptores $R$, que captam o tempo de chegada da onda longitudinal, em função da respectiva distância até a fonte. Estes valores são representados em gráficos "tempo X distância", denominados "dromocrônicas".

Nota-se que o referido gráfico possui duas retas com inclinações diferentes. A primeira reta que passa pela origem, corresponde aos geofones mais próximos das ondas. Estes captam as ondas que caminham na superfície do terreno, denominadas ondas diretas. A inclinação desta reta é igual ao inverso da velocidade $\left(1 / \mathrm{V}_{1}\right)$ da onda direta, o que possibilita caracterizar o estrato superior. 

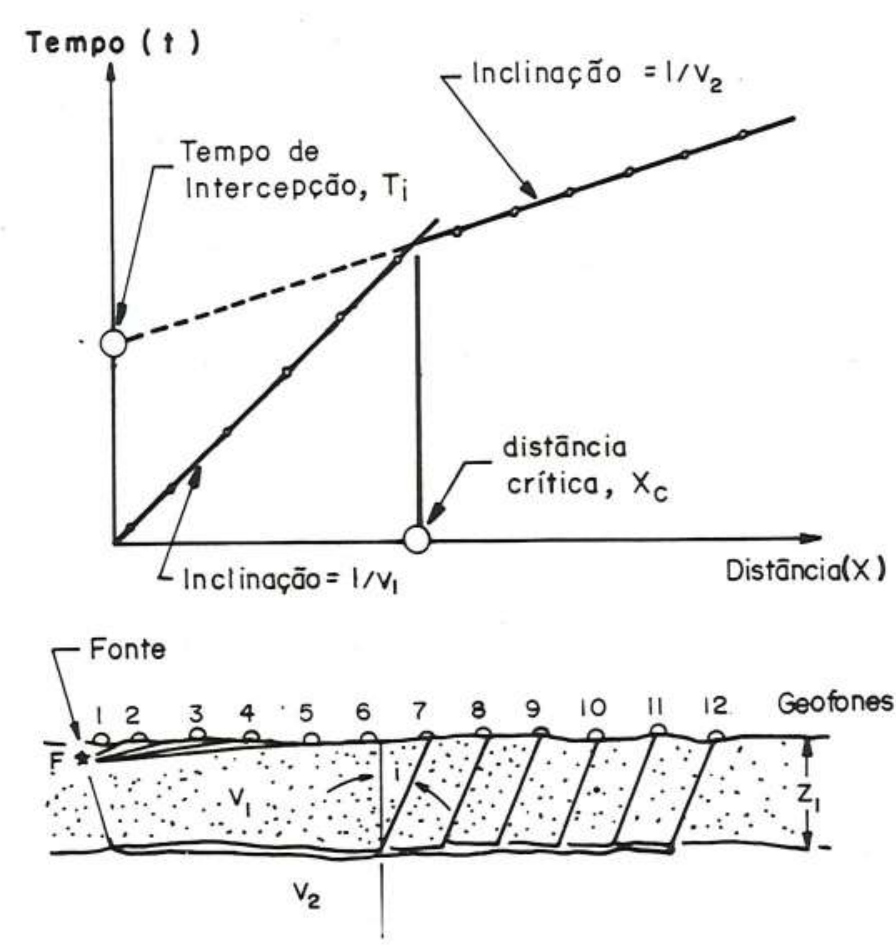

Figura 2.9 - Representação esquemática da técnica de refração sísmica.

Um ponto importante deste gráfico corresponde à distância critica $\left(\mathrm{x}_{\mathrm{C}}\right)$, que representa a chegada das ondas que se propagam com velocidade $V_{2}$ até a interface entre os dois estratos sísmicos e se refratam totalmente no estrato inferior com velocidade $V_{2}$, retornando à superfície com a velocidade $V_{1}$ do estrato superior. Estas ondas definem um ramo da dromocrônica, cuja inclinação $\left(1 / \mathrm{V}_{2}\right)$ possibilita caracterizar $\circ$ estrato inferior. o prolongamento deste ramo intercepta o eixo dos tempos num valor denominado de tempo de interceptação(Ti) (MALAGUTTI FILHO, 1991).

- cálculo da profundidade do refrator, abaixo do ponto de tiro, pode ser efetuado com base no tempo de interceptação ou pela distância crítica. A seguir será exposta a formulação matemática para o caso de duas e três camadas ou ainda, para o caso genérico de n camadas segundo SJOGREEN (1984). 


\section{a) Caso de duas camadas}

A notação empregada corresponde à Figura 2.10, que mostra um caso simples com velocidade constante e interfaces plano paralela.

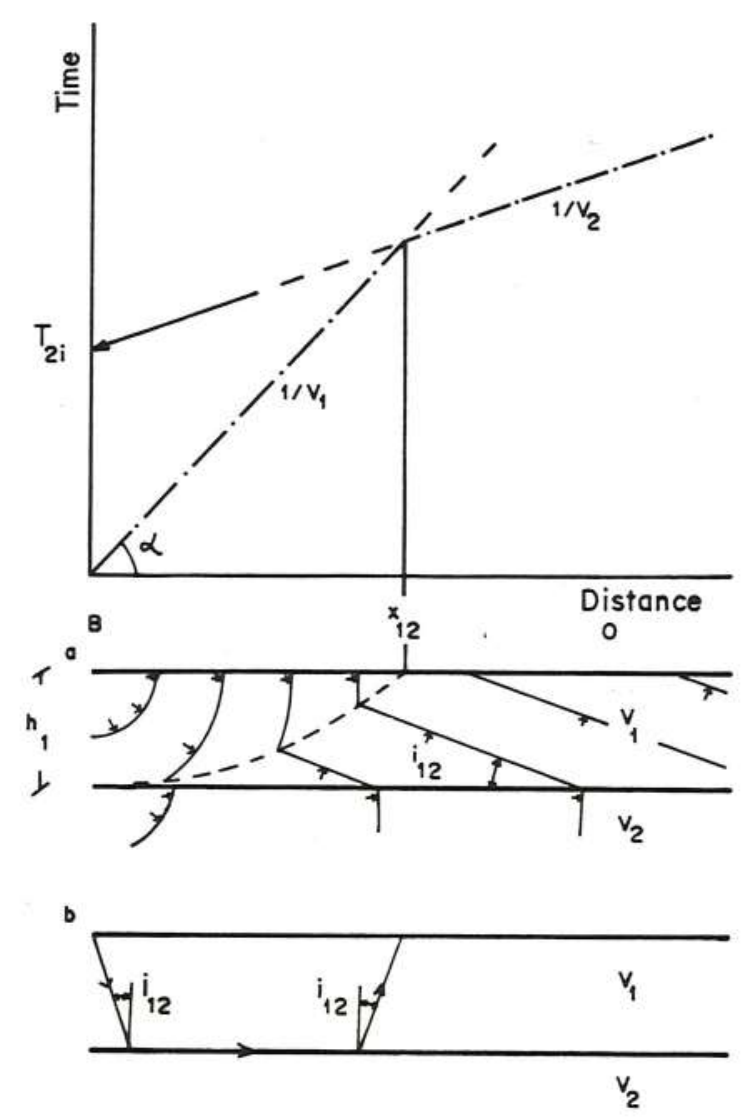

Figura 2.10 - Configuração para o caso de duas camadas.

o ângulo crítico(i) é dado pela relação $\operatorname{sen} i_{12}=V_{1} / V_{2}$ e a profundidade do segundo estrato é $h_{1}$.

Cálculo de $h$ com base no tempo de interceptação:

A equação para $\circ$ tempo de chegada $t_{1}$ das ondas diretas é:

$$
t_{1}=\frac{x}{V_{1}}
$$


que corresponde à equação de uma reta que passa na origem ou no ponto de tiro do ensaio, cuja inclinação é igual a $1 / V_{1}$.

Para $\circ$ tempo $t_{2}$, relacionado à chegada das ondas refratadas, a equação é:

$$
T_{2}=\frac{x}{V_{2}}+\frac{2 h_{1} \cos i_{12}}{V_{1}}
$$

que corresponde à equação de uma reta com inclinação $1 / \mathrm{V}_{2}$.

$\mathrm{Na}$ interceptação do eixo do tempo, onde a distância $\mathrm{X}$ é igual a zero, tem-se:

$$
T_{2 i}=\frac{2 \mathrm{~h}_{1} \cos i_{12}}{\mathrm{~V}_{1}}
$$

Assim, a espessura do primeiro estrato $\left(h_{1}\right)$ é obtida:

$$
h_{1}=\frac{T_{2 i} V_{1}}{2 \cos i_{12}}
$$

\section{Cálculo de $h_{1}$, com base na distância crítica:}

A intersecção dos dois ramos do gráfico da Figura 2.10, corresponde à distância crítica $x_{12}$, onde $\mathrm{T}_{1}=\mathrm{T}_{2}$. Desta forma, a profundidade $h_{1}$ é dada pela seguinte expressão:

$$
h_{1}=\frac{x_{12}\left(1-\operatorname{sen} i_{12}\right)}{2 \cos i_{12}}
$$

b) Para o caso de três camadas: 
A Figura 2.11, mostra o caso para dois estratos com velocidades $V_{1}$ e $V_{2}$, sobrepostos a um refrator de base com velocidade $V_{3}$. Apresenta também os ângulos críticos de incidência, $i_{12}$ e $i_{23}$.
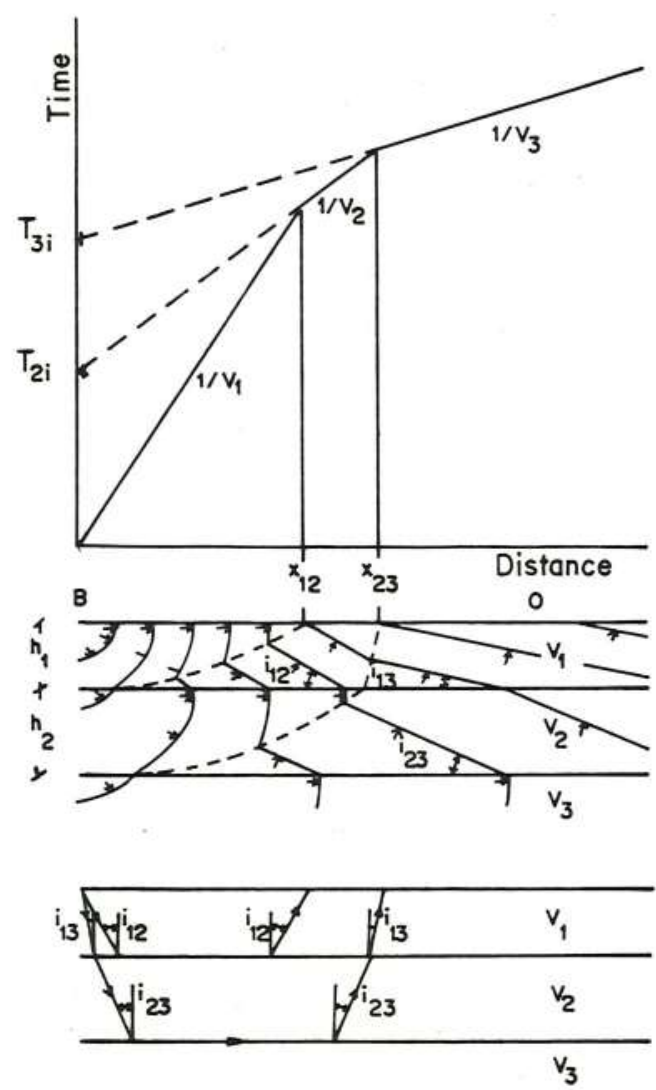

Figura 2.11 - Configuração para o caso de três camadas.

Cálculo da espessura $h_{2}$ com base no tempo de interceptação:

A equação para $\circ$ tempo de chegada $T_{3}$ da onda que passa pelo terceiro estrato é:

$$
T_{3}=\frac{2 h_{1} \cos i_{13}}{V_{1}}+\frac{2 h_{2} \cos i_{23}}{V_{2}}+\frac{x}{V_{3}}
$$

que corresponde à equação de uma reta com inclinação $1 / \mathrm{V}_{3}$. 
$\mathrm{Na}$ interceptação do eixo dos tempos, onde a distância X é igual a zero, tem-se:

$$
T_{3 i}=\frac{2 h_{1} \cos i_{13}}{V_{1}}+\frac{2 h_{2} \cos i_{23}}{V_{2}}
$$

Desta forma a espessura do segundo estrato $\left(h_{2}\right)$ é obtida:

$$
h_{2}=\frac{T_{3 i} V_{2}}{2 \cos i_{23}}-\frac{V_{2} h_{1} \cos i_{13}}{V_{1} \cos i_{23}}
$$

Cálculo da espessura $h_{2}$, com base na distância crítica:

$$
h_{2}=\frac{x_{23}\left(1-\operatorname{sen} i_{23}\right)}{2 \cos i_{23}}-\frac{h_{1}\left(\cos _{13}-\cos i_{12}\right)}{\cos _{23} \operatorname{sen} i_{12}}
$$

C) Para o caso de $n$ camadas

As fórmulas empregadas para os casos anteriores podem ser estendidas para qualquer número de estratos, desde que a velocidade nos estratos superiores seja maior que nos estratos inferiores (SJOGREEN, 1984).

Com base nos tempos de interceptação:

$$
h_{(h-1)}=\frac{T_{n i} \cdot V_{(n-1)}}{2 \cos i_{(n-1) n}}-\frac{V_{(n-1)}}{\cos i_{(n-1) n}} \sum_{v=1}^{n-2} \frac{h_{v} \cos i_{v n}}{V_{v}}
$$

Com base na distância crítica:

$$
h_{(h-1)}=x_{(n-1) n} \frac{1-\operatorname{sen} i_{(n-1) n}}{2 \cos i_{(n-1) n}}-\sum_{v=1}^{n-2} h_{v} \frac{\cos _{v n}-\cos i_{v(n-1)}}{\cos i_{(n-1) n} \cdot \operatorname{sen} i v(n-1)} \text { (2.24) }
$$


onde: $T_{n i}=$ tempo de interceptação feito pelo $\mathrm{n}$ segmento de reta.

$i_{(n-1) n}=$ representa $\circ$ ângulo de incidência entre $\mathrm{n}-1$

e o n estrato.

$V_{n}=$ corresponde à velocidade do enésimo estrato.

$x_{(n-1) n}=E ́$ a intersecção (distância crítica) das retas de velocidades $n-1$ e $n$.

\subsection{2 - Descrição dos Equipamentos e Ensaio de Campo}

\section{a) - Equipamentos}

Foi empregado neste trabalho o sismógrafo digital "Geopro 8024" da Bison Instruments Inc.

De acordo com MALAGUTTI FILHO(1991), os sismógrafos digitais apresentam microprocessadores internos, cujas funções podem ser acessadas via teclado próprio, além de memória digital, que possibilita tratar a qualidade dos registros como: ajuste de ganhos, ajuste do tempo de varredura do sinal, ganhos automáticos, soma de sinais, filtragem etc. Os registros podem ser visualizados num monitor de raios catódicos, que possibilita avaliar durante o ensaio a qualidade do sismograma.

Para os ensaios, foi utilizado um conjunto de 24 geofones do tipo dinâmico, que apresentam em sua constituição uma bobina móvel, suspensa por molas dentro de um campo magnético de um imã permanente. 0 movimento oscilatório, causado pela passagem da onda, faz com que a bobina corte as linhas de fluxo magnético do imã, gerando assim, nos terminais da bobina, uma força eletromotriz proporcional à velocidade do movimento oscilatório. Este sinal elétrico é transmitido ao sismógrafo por cabos multicondutores, onde são processados e armazenados. 
b) - Ensaios de Campo

Os ensaios de sísmica de refração objetivaram estabelecer seções que representassem, da melhor forma possível, as espessuras das diferentes camadas do subsolo e suas respectivas velocidades. Desta forma, utilizou-se como técnica de campo do ensaio sísmico, a configuração de um perfil contínuo, espaçando-se os pontos de tiro e os geofones ao longo de uma mesma linha. A separação entre os geofones foi de 5 metros, com objetivo de se atingirem profundidades que variassem de 25 a 35 metros. Estas profundidades foram avaliadas pela média dos topos do impenetrável aos amostradores das sondagens à percussão. Por outro lado, procurou-se manter o nível de resolução almejado dentro da escala de trabalho.

A Figura 2.12 mostra a preparação de uma carga de explosivo, utilizada na base 1 deste trabalho.

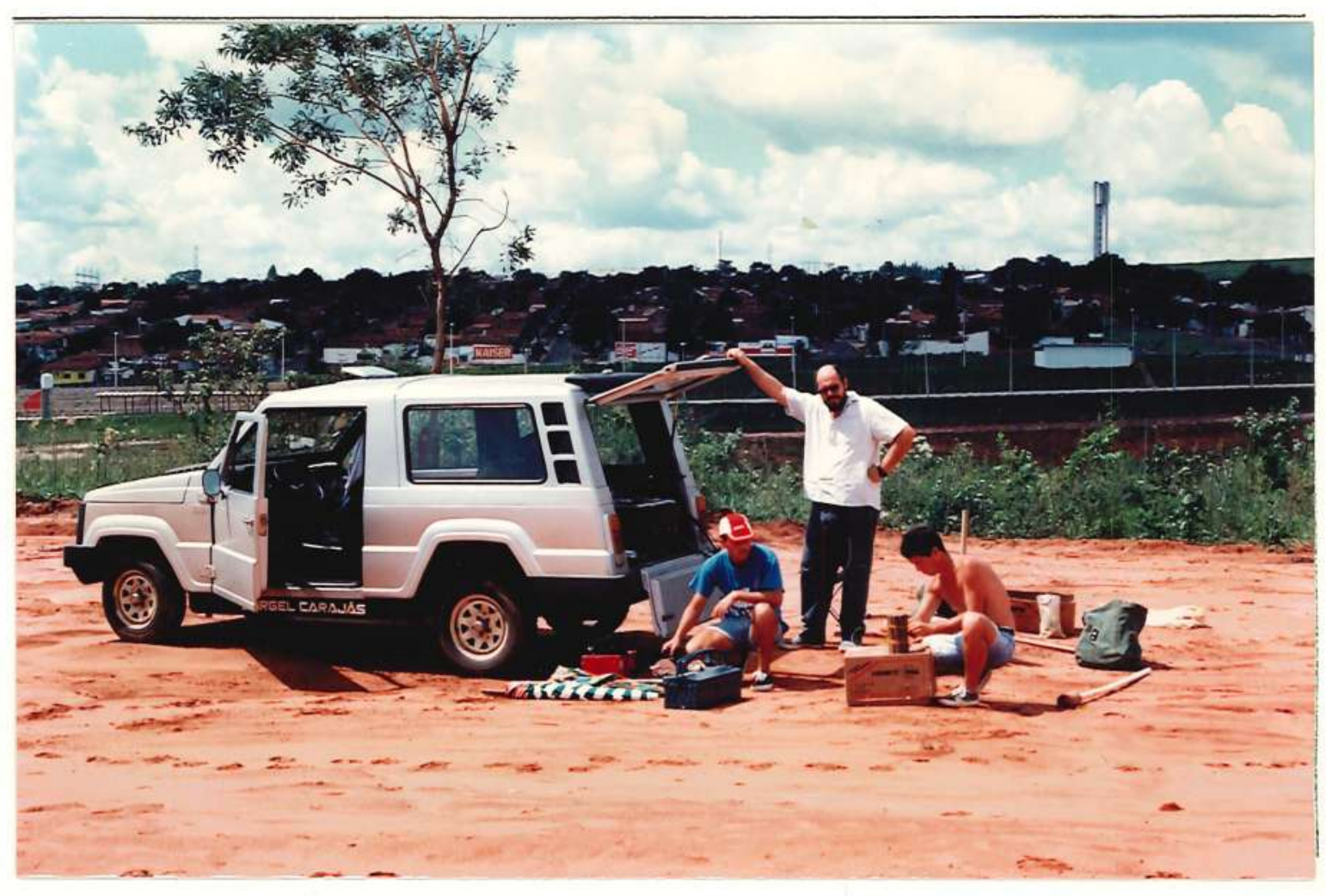

Figura 2.12 - Preparação de uma carga de explosivo na base sísmica 1 . 
Nos pontos de tiro, com a finalidade de minimizar os efeitos da absorção da energia gerada pela explosão, as cargas explosivas foram colocadas dentro de furos feitos a trados, com profundidades de 2 metros.

Para cada furo foi feita uma análise táctil visual do solo, observações quanto à presença do nível d'água e também a coleta de, pelo menos, uma amostra à profundidade de 2 metros, para análise granulométrica, o que muito auxiliou na caracterização do estrato sísmico superficial.

Os tiros externos ( 1 e 5) empregaram 15 bananas de dinamite cada um, enquanto os tiros internos(2 e 4), empregaram 12 bananas de explosivo. O tiro 3, localizado no centro do ensaio, utilizou em média, 7 bananas de dinamite para todas as bases sísmicas.

A Figura 2.13 mostra o esquema do ensaio, com a localização dos pontos de tiro.

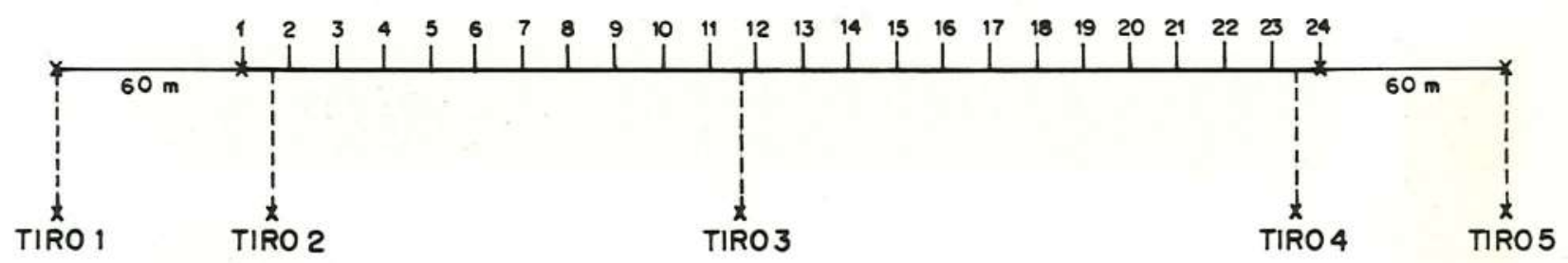

Figura 2.13 - Esquema de campo, empregado no ensaio de sísmica de refração.

As bases foram distribuidas de tal forma que representassem toda a área de estudo, localizando-se em áreas onde houvesse, nas proximidades, sondagens de simples reconhecimento ou, então, a presença de vossorocas, que permitissem possíveis correlações do perfil de alteração com as interpretações dos estratos sísmicos. 


\section{3. - METODOLOGIA DE ANÁLISE DOS DADOS}

\section{1 - ELABORAÇÃO DO BANCO DE DADOS}

Nesta fase dos trabalhos, foi feito um levantamento do maior número possível das sondagens de simples reconhecimento efetuadas na área.

Este levantamento consistiu-se em visitas às principais empresas de sondagens que atuaram na prospecção do subsolo para obras de engenharia civil, na cidade de Bauru. Desta forma, foram coletados os relatórios das sondagens que apresentaram uma descrição da perfuração, dos ensaios de penetração realizados a cada metro, da profundidade do nível d'água, da profundidade do impenetrável e uma descrição resumida do solo perfurado. Um exemplo deste relatório encontra-se no Apêndice I.

Todos os relatórios de sondagem foram codificados em uma planilha, como mostra a Figura 3.1. Esta planilha possui dados extraídos diretamente dos relatórios das sondagens bem como, dados avaliados das folhas topográficas do IGC(1983) na escala 1:10.000, como as coordenadas X e Y e a cota da boca da sondagem.

Deve-se enfatizar que não foram coletadas todas as sondagens de uma determinada obra. O critério de escolha sempre foi a distribuição espacial uniforme dos dados dentro desta obra. Por exemplo, em um viaduto que tenha 20 sondagens, eventualmente pode ter sido coletada cerca da metade das sondagens distribuidas da forma mais eqüidistante possível, baseando-se na planta da situação constante dos relatórios das empresas. 
Outro aspecto a ser considerado é com relação à cota dos furos de sondagem. A rigor, esta cota foi utilizada nos procedimentos de análise que envolveram correlações com a cota do nível d'água e com a cota do impenetrável. Por outro lado, a posição espacial de cada ensaio de penetração está baseada nas coordenadas X e Y do mapa e na coordenada $z$ correspondente à profundidade do ensaio e não à sua cota. Este aspecto é de fundamental importância para os estudos geoestatísticos, tendo em vista que a continuidade espacial da variável SPT, deve ser avaliada coerentemente com o "estrato" de compactação em que ela está inserida.

\begin{tabular}{|l|l|l|l|l|l|l|l|l|l||}
\hline $\begin{array}{l}\text { N.० } \\
\text { da } \\
\text { obra }\end{array}$ & Empre- & Sa & Y & $\begin{array}{l}\text { N.० } \\
\text { do } \\
\text { furo }\end{array}$ & $\begin{array}{l}\text { Cota } \\
\text { do } \\
\text { nível } \\
\text { d'água }\end{array}$ & $\begin{array}{l}\text { Cota } \\
\text { do } \\
\text { Impene } \\
\text { trável }\end{array}$ & $\begin{array}{l}\text { Cota } \\
\text { da } \\
\text { boca } \\
\text { do } \\
\text { furo }\end{array}$ & $\begin{array}{l}\text { S } \\
\text { P } \\
\text { T }\end{array}$ & $\begin{array}{l}\text { S } \\
\text { I } \\
0\end{array}$ \\
\hline 001 & código & & 1 & & & & & \\
\hline. & alfa & & &. & & & & & \\
\hline. & & & &. & & & & & \\
\hline. & & & &. & & & & & \\
\hline 999 & & & & $\mathrm{n}$ & & & & & \\
\hline
\end{tabular}

Figura 3.1 - Planilha base para elaboração do banco de dados, das sondagens à percussão.

Após a elaboração das planilhas, que atingiram um total de 720 dados, estes foram armazenados em disquetes de computadores para serem posteriormente processados. Nesta etapa foi elaborado um programa que trabalha com estruturação de banco de dados para desempenhar este passo inicial, que foi $\circ$ de gravar as planilhas e de emitir relatórios ou subprodutos do arquivo geral, denominado neste projeto de "main-dat".

Este arquivo geral, elaborado para todas as obras, apresenta as seguintes informações:

- Código da obra: número inteiro (001-999) 
- Cota impenetrável: cota em relação ao nível do mar para o impenetrável da sondagem a percussão.

- Cota do nível d'água: cota em relação ao nível do mar para o nível d'água quando encontrado, caso não, foi adotado o valor 999999.99.

- Cota do nível do ensaio: todos os ensaios de penetração estão referenciados a uma cota topográfica com base o nível do mar.

- Ensaio de penetração: índice de resistência à penetração.

- Tipo de solo: foram estabelecidos códigos para identificar as principais litologias, que são:

$$
\begin{array}{ll}
\text { AF } & =\text { Areia fina } \\
\text { AFS } & \text { Areia fina siltosa } \\
\text { AFSA } & \text { Areia fina siltosa (t arenosa) } \\
\text { AFSAG } & \text { Areia fina silto-argilosa } \\
\text { AFGA } & \text { Areia fina argilosa } \\
\text { AM } & =\text { Areia média } \\
\text { AS } & \text { Areia siltosa } \\
\text { AGA } & \text { Argila arenosa } \\
\text { AGS } & \text { Argila siltosa } \\
\text { SA } & \text { Silte arenoso } \\
\text { SAG } & \text { Silte argiloso }
\end{array}
$$

Todas as obras foram localizadas em folhas topográficas na escala 1:10.000 e suas coordenadas foram extraídas via programas gráficos como $\circ$ AUTOCAD-R.11 da AUTODESK, INC (1990). As cotas topográficas também foram extraídas da mesma forma, salvo os casos em que 0 relatório da empresa de sondagem já apresentava as cotas reais, em relação ao nível do mar ou do local da obra.

A etapa seguinte consistiu na elaboração de programas na linguagem de programação própria de banco de dados, para manipulação do arquivo geral (main.dat). A principal função destes programas foi gerar subprodutos para atenderem aos programas estatisticos e geoestatísticos que efetivamente executariam a análise interpretativa, dos dados das sondagens. 
O fluxograma da Figura 3.2 esquematiza a relação entre os programas do banco de dados, bem como os produtos gerados, que foram utilizados nesta fase dos trabalhos.

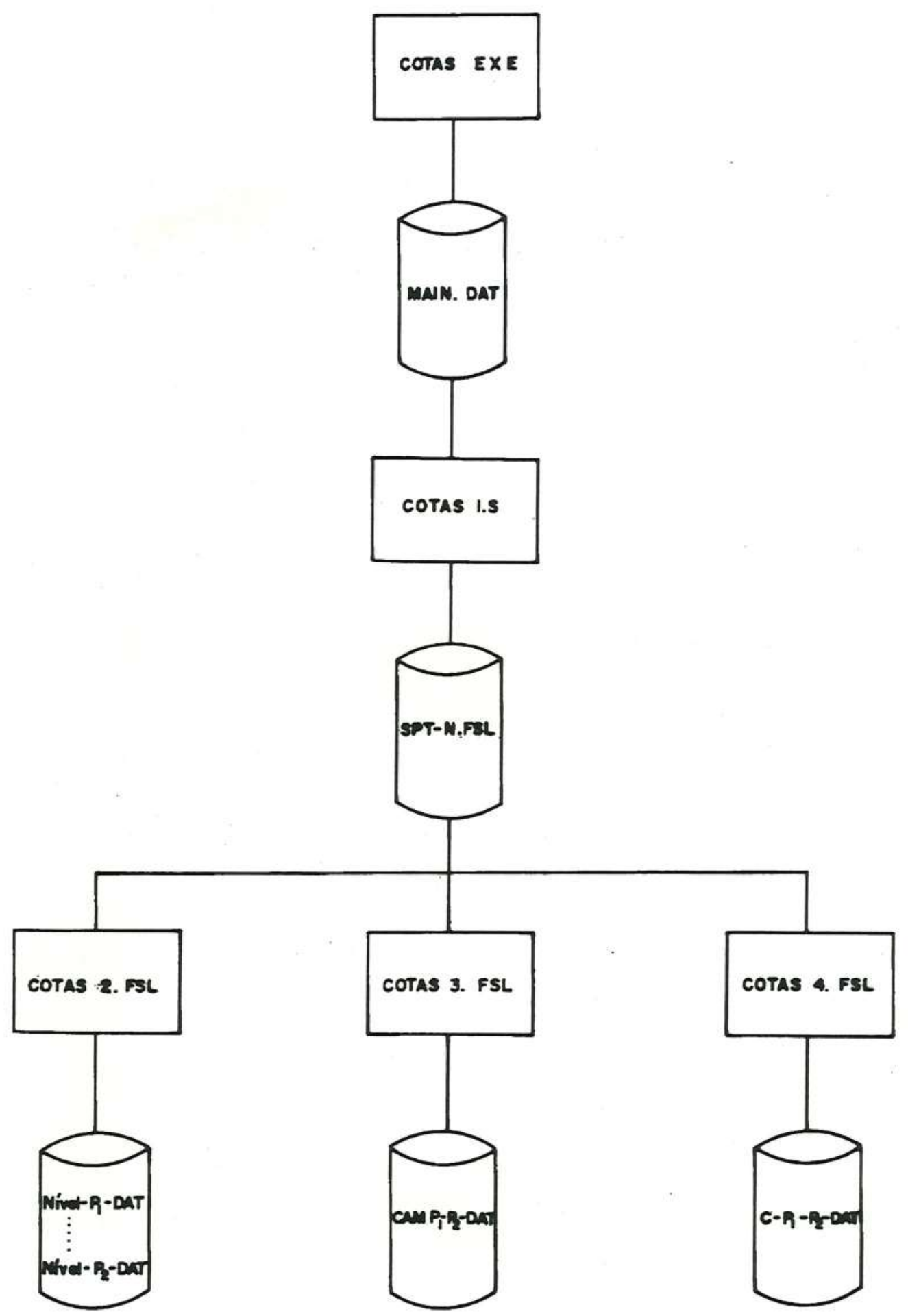

Figura 3.2 - Fluxograma do banco de dados 
Os programas do banco de dados e seus produtos são descritos a seguir.

Programa: COTAS.EXE Produto: MAIN.DAT

Programa principal que cadastra todas as sondagens, bem como todos os ensaios de penetração metro a metro. Gera como produto vários tipos de relatórios, sendo que neste trabalho, propiciou a montagem do arquivo geral main. dat.

Programa: COTAS $1 . \mathrm{S}$ Produto: SPT-N.FSI

Nesta passagem, $\circ$ programa reduz os dados do arquivo geral (MAIN.DAT), para o arquivo SPT-N.FSL. Este arquivo constitui-se nas médias aritméticas das variáveis obtidas das sondagens para cada obra. Desta forma foi elaborado um perfil médio para cada obra. O valor de $\mathrm{N}$, que aparece no nome do arquivo, representa $\circ$ índice de resistência à penetração que passou por uma filtragem, ou seja, acima deste valor, os índices de resistência foram ignorados ou ainda, não participaram das efetivações das médias.

Supor por exemplo, que uma obra tenha 10 furos de sondagem. Para estabelecer-lhe o perfil médio, são mantidas as variáveis que são próprias da obra, como 0 código da obra e a profundidade de cada ensaio de penetração. A seguir, são feitas as médias aritméticas das variáveis, a cota da boca da sondagem, a cota do nível d'água e a cota do impenetrável.

o próximo passo é efetuar as médias aritméticas de todos os ensaios realizados em uma determinada profundidade, ou seja:

$$
s p t=\sum_{i=1}^{n}\left(s p t_{i}\right) / n
$$

onde: spt $_{i}$ corresponde ao iésimo ensaio da penetração padronizada para a profundidade $\mathrm{p}, \mathrm{e} n$ é igual ao número de valores de SPT, abaixo de um determinado máximo. 
Programa: COTAS 2.FSL Produto: NIVEL P. DAT

Este programa é responsável pela geração de arquivos para cada metro perfurado das sondagens. 0 produto NIVEL P.DAT tem como constituição as coordenadas $\mathrm{X}$ e $\mathrm{Y}$ da obra e o índice de resistência à penetração para a profundidade $\mathrm{P}$ ensaiada.

Programa: COTAS 3.FSL Produto: CAMP1.P2.DAT

Este programa gera um arquivo que constitui a média aritmética do índice de resistência à penetração na vertical da profundidade P1 até a profundidade P2. Este recurso é importante quando se trabalha em uma camada homogênea, pois os SPT's são estatisticamente provenientes da mesma população.

Programa: COTAS4.FSL Produto: C-P1-P2.DAT

Este programa constitui-se em uma variação do programa anterior. A diferença é que este não faz as médias na vertical, mas simplesmente arranja o conjunto tridimensional $X, Y, Z$ e $O$ valor do ensaio na profundidade $z$. Como se percebe pelo nome do arquivoproduto, pode-se definir qualquer intervalo de NP1 até NP2, que corresponde respectivamente à profundidade inicial (NP1) e a final (NP2).

\section{2 - ANÁLISE ESTATÍSTICA BÁSICA}

A análise básica dos dados através dos métodos estatísticos clássicos, constitui-se em uma etapa praticamente obrigatória, quando se trabalha com amostragens e processamento de uma quantidade significativa de dados e de variáveis. Estes métodos, além de classificarem e depurarem os dados, possibilitam também, análises interpretativas quanto aos modelos de distribuição de probabilidades, correlações e ajustes de funções de regressão. 


\subsection{1 - Definição de variáveis aleatórias}

Variáveis aleatórias são caracterizadas como as variáveis provenientes de algum mecanismo probabilístico. Elas podem ser classificadas em variáveis aleatórias discretas e contínuas.

- Variáveis aleatórias discretas: São variáveis que apresentam um conjunto de valores possiveis finito ou infinito numerável, isto é, os valores da variável podem ser colocados na forma de lista como $\mathrm{x}_{1}, \mathrm{x}_{2}, \ldots, \mathrm{x}_{\mathrm{n}}$ (MEYER, 1981)

- Variáveis aleatórias contínuas: Representam a maioria das variáveis em Geociências. São as variáveis que podem assumir um conjunto contínuo de valores, isto é, uma variável $\mathrm{x}$ é considerada contínua se $\mathrm{x}$ puder assumir todos os valores em um intervalo $\mathrm{a}<\mathrm{x}<\mathrm{b}$, onde $\mathrm{a}$ e b podem ser $-\infty$ e $+\infty$ respectivamente.

\subsection{2 - Modelos de distribuição de probabilidades}

Os modelos representam a probabilidade que um possivel resultado ou intervalo da variável, possa ter dentro de um processo probabilisticamente interpretado.

os modelos de distribuição empregados para variáveis discretas são:

- Modelo de distribuição binomial: Se uma variável discreta é regida por este modelo, a probabilidade $p(k)$ de um evento acontecer exatamente $\mathrm{k}$ vezes em $\mathrm{n}$ tentativas é dado pela função:

$$
p_{(k)}=\frac{n !}{k !(n-k) !} p^{k} q^{n-k}
$$

onde $\mathrm{p}$ é a probabilidade de sucesso e q é a probabilidade de insucesso.

Os parâmetros básicos de uma distribuição binominal são: 
Valor esperado: $E(v)=m=\sum_{i=1}^{n} p_{i} V_{(i)}$

$$
\text { Variância }=\operatorname{var}(V)=\sum_{i=1}^{n} p_{i} V_{(i)}^{2}-\left(\sum_{i=1}^{n} p_{i} V_{(i)}\right)^{2}
$$

Modelo de distribuição de Poisson: Este modelo pode ser considerado como um caso limite do binomial, ou seja, quando n, o número de tentativas, torna-se muito grande, e p, a probabilidade de sucesso em qualquer uma das tentativas, torna-se muito pequeno. A função para 0 modelo de Poisson, é a seguinte:

$$
p(X)=\frac{e^{-\lambda} \lambda^{x}}{X !}
$$

onde $\lambda$ é igual a n.p, que representa o valor esperado da distribuição.

Para as variáveis aleatórias contínuas destacam-se dois modelos:

- Modelo de distribuição normal: Constitui-se em uma das distribuições mais importantes da estatística e representa a maioria dos fenômenos naturais. A função de densidade de probabilidade deste modelo é assim expressa:

$$
f(v)=\frac{1}{\sigma \sqrt{2 \pi}} e^{-0.5}\left(\frac{v-\mu}{\sigma}\right)^{2}
$$

onde $\mu$ é a média aritmética da variável $v$ e $\sigma$ o desvio padrão.

-Modelo de distribuição lognormal: Quando os logaritmos de variável aleatória contínua seguem o modelo de distribuição normal. Neste caso a função matemática é dada pela expressão:

$$
f(v)=\frac{1}{\sigma \sqrt{2 \pi}} e^{-0.5}\left(\frac{\log v-\mu}{\sigma}\right)^{2}
$$


onde $\mu$ é a média aritmética dos logaritmos da variável $v$ e $\sigma$ o desvio padrão dos logaritmos da variável v.

Nos trabalhos práticos, onde os valores das variáveis são provenientes de um trabalho de amostragem, as variáveis aleatórias são organizadas em forma de tabelas de frequências simples ou acumulada.

A densidade de freqüência, para um intervalo de classe de uma tabela de freqüência, é calculada pela razão da freqüência da classe com seu respectivo intervalo de classe. Quando o número de dados aumenta indefinidamente e o intervalo de classe tende a zero, a distribuição de freqüência passa para uma distribuição de densidade de probabilidades.

Outra forma de definir as variáveis aleatórias, é através das distribuições de freqüência acumulada, onde a freqüência dos intervalos é somada sucessivamente. Como acontece na distribuição de freqüência simples, quando o número de dados aumenta indefinidamente e 0 intervalo tende a zero; a curva acumulativa deste gráfico de freqüências, resulta na função de densidade de probabilidade acumulada (fda). Esta função é muito útil, pois possibilita calcular a probabilidade acumulada de todos os possíveis resultados abaixo de um determinado valor, ou seja:

$$
F(V)=P\{V \leq v\}
$$

onde $V$ é a variável aleatória e $v$ são os possíveis resultados desta variável.

$A$ função $F(V)$ permite também calcular a probabilidade de uma variável aleatória que esteja situada dentro de qualquer intervalo, por exemplo:

$$
\begin{aligned}
P\{a \leq V \leq b\} & =P\{V \leq b\}-P\{V \leq a\} \\
& =F(b)-F(a)
\end{aligned}
$$


Ressalte-se ainda, que a derivada primeira de $F(V)$, resultará na função de densidade de probabilidade (fdp), responsável pela probabilidade relativa para resultados particulares.

$$
\frac{d F(V)}{d u}=f(u) e \int_{-\infty}^{+\infty} f(u) d u=1
$$

\subsection{3 - Estatística descritiva}

Os dados obtidos através de amostragem podem ser descritos e analisados através de estatísticas que são úteis para a caracterização das distribuições de frequiência e inferências sobre a população.

Este tratamento estatístico deve ser aplicado de forma sistemática, para os casos de desenvolvimento de bases de dados específicos, como mostra STURARO et al. (1993), onde foi elaborado um banco de dados seguido por uma análise estatística básica de dados geotécnicos.

A seguir, serão descritas as principais medidas estatísticas baseadas em KOCK \& LINK (1971), DAVIS (1978)e LANDIM ( 1993 ).

As estatísticas que descrevem as distribuições de freqüência podem ser classificadas em 3 grupos:

- Medidas de localização na distribuição: média, mediana, modo e quartis;

- Medidas de dispersão: Variância, Desvio Padrão

- Medidas de forma: Coeficientes de assimetria, curtose e de variação.

Medidas de localização da distribuição:

- Média Aritmética: constitui-se na média simples dos dados:

$$
m=\frac{1}{n} \sum_{i=1}^{n} x_{i}
$$


- Moda: Corresponde à classe de maior freqüência da distribuição. A moda pode não existir ou ainda, quando existir, pode não ser única.

- Quartis: Da mesma forma que a mediana, que divide - conjunto de dados em duas partes iguais, os quartis dividem $\circ$ conjunto em 4 partes iguais. Estes valores, representados por Q1, Q2 e Q3 são chamadas de primeiro, segundo e terceiro quartis, sendo Q2 igual à mediana.

Outras medidas similares aos quartis são os decis e os percentis, que dividem o conjunto de dados em 10 e 100 partes respectivamente.

\section{Medidas de dispersão:}

- Variância: Corresponde à média das diferenças quadráticas dos valores observados em relação à sua média.

$$
\sigma^{2}=\frac{1}{n} \sum_{i=1}^{n}\left(X_{i}-m\right)^{2}
$$

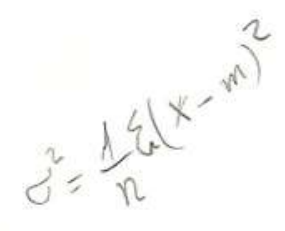

- Desvio Padrão: Constitui-se na raiz quadrada da variância. Assim o desvio padrão apresenta as mesmas unidades que a variável em análise.

- Amplitude dos dados: Corresponde ao intervalo total de variação dos dados

$$
A=X \max -X \min
$$

\section{Medidas de forma da distribuição:}

- Coeficiente de assimetria: Avalia a assimetria da distribuição de freqüência:

$$
\text { Assimetria }=\frac{1}{n} \sum_{i=1}^{n}\left(X_{i}-m\right)^{3} / \sigma^{3}
$$


- Coeficiente de curtose: Avalia o grau de achateamento da distribuição de freqüência:

$$
\text { Curtose }=\frac{1}{n} \sum_{i=1}^{n}\left(X_{i}-m\right)^{4} / \sigma^{4}
$$

- Coeficiente de Variação: Constitui-se em uma medida de dispersão relativa e também numa alternativa, para avaliar a simetria das distribuições.

$$
C V=\frac{\sigma}{m}
$$

Valores de coeficientes de variação maiores que 1 , significam a presença de valores altos e/ou erráticos no conjunto de dados, que representarão problemas para a maioria dos métodos de estimativas (KIM, 1988).

Os coeficientes que avaliam a forma da distribuição, são usualmente empregados para verificar se a distribuição apresenta uma configuração da distribuição normal.

PRESTON (1970), estabeleceu um teste de normalidade dos dados, com base nas curvas e tabelas de PEARSON e HARTLEY (1966). De acordo com este teste, os dados seguem uma distribuição normal, se as seguintes medidas estiverem dentro dos intervalos associados, dado um $\mathrm{N}$ igual a 175, que representa o caso deste trabalho:

$$
\begin{aligned}
0.0 & <\text { assimetria } & <0.32 \\
2.4 & <\text { curtose } & <3.64 \\
4.5 & <\mathrm{A} / \sigma & <6.40
\end{aligned}
$$

(para um nível de significancia igual a 95\%)

Se os dados apresentarem uma distribuição lognormal (assimétrica), as principais estatísticas básicas devem ser calculadas considerando a assimetria da distribuição dos dados. 
Nestes casos, são mais apropriadas para as medidas de tendência central (valor médio), estatísticas como, a média geométrica e a mediana.

A média geométrica constitui-se no antilogaritmo da média aritmética dos logaritmos dos dados, demonstrada a seguir:

Inicialmente, transformam-se os dados originais $\left(x_{i}\right)$, através da função logarítmica;

$$
y_{i}=\ln x_{i}
$$

Calcula-se a seguir a média aritmética dos dados transformados;

$$
m y=\sum_{i=1}^{n} y_{i} / n
$$

A média geométrica (MG) é dada pela conversão logaritmica;

$$
M G=e^{m y_{i}}
$$

A dispersão da distribuição lognormal pode ser avaliada pelo desvio geométrico (DG), obtido pelo antilogaritmo do desvio padrão dos dados transformados $\left(\sigma y_{i}\right):$

$$
D G=e^{o y_{i}}
$$

Outra medida representativa de tendência central de distribuições assimétricas é a mediana, constituída pelo valor médio ou a média aritmética de dois valores centrais de um conjunto de dados ordenados pela ordem de grandeza.

A Figura 3.3 demonstra empiricamente a relação entre a média aritmética, a mediana e a moda, para distribuições de freqüência unimodal assimétricas, segundo SPIEGEL (1975). 

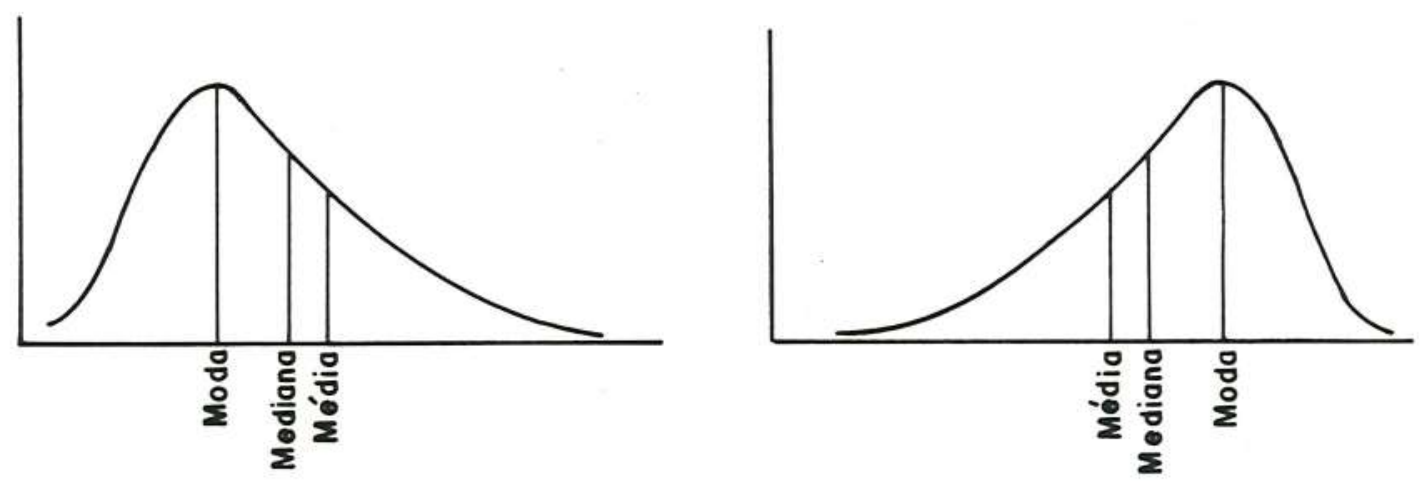

Figura 3.3- Relação empírica entre a média, mediana e a moda em distribuições assimétricas.

\subsection{4 - Correlação e Regressão Linear}

A comparação entre duas variáveis pode ser feita de forma semi-quantitativa, através de gráficos de dispersão, onde a coordenada x representa o valor de uma variável e a coordenada y a outra variável.

De outra forma, podem ser calculadas algumas estatísticas que expressam a relação entre duas variáveis, relacionadas a seguir:

A covariância constitui-se no produto das dispersões das variáveis, isto é:

$$
C(x, y)=\frac{1}{n} \sum_{i=1}^{n}\left(X_{i}-M_{x}\right)\left(Y_{i}-M_{y}\right)
$$

onde: $\mathrm{M}_{\mathrm{X}}$ e $\mathrm{M}_{\mathrm{Y}}$ são as médias das variáveis $\mathrm{X}$ e $\mathrm{Y}$ $\mathrm{n}$ é o número de pares de dados.

Entretanto, a covariância é influenciada pela magnitude das variáveis, o que dificulta as comparações. Assim, dividindo-se a covariância pelos desvios-padrão das duas variáveis, o valor resultante adimensional, estará situado no intervalo de 1 a +1 . Este valor é 
conhecido como coeficiente de correlação de Pearson, cuja expressão é a seguinte:

$$
r=\frac{C(x, y)}{\sigma_{x} \times \sigma_{y}}
$$

Os valores próximos a +1 , representam uma correlação linear máxima positiva, enquanto no outro extremo, correspondente a -1 , a correlação linear é máxima, mas inversa. Entre estes dois extremos, situam-se todos os possiveis valores de correlação entre duas variáveis e, quando igual a zero, ocorre à inexistência de correlação linear.

CHAPMAN (1975) e HOWARTH (1983) relacionam uma série de aspectos que influenciam o coeficiente de correlação de Pearson, como a comparação de dados provenientes de populações diferentes, valores erráticos, escala de variação dos dados das variáveis e o número de amostras comparadas. Constatada uma significativa correlação linear entre duas variáveis, pode-se estabelecer uma função que expresse esta correlação, ou seja, uma variável pode ser estimada pela outra. A técnica mais simples para estabelecer esta função, é a regressão linear, cuja equação é assim expressa:

$$
Y=a x+b
$$

onde $a$ é a inclinação da reta $e$ b é 0 intercepto constante da ordenada.

Estes parâmetros podem ser obtidos pelas relações:

$$
\begin{aligned}
& a=r \frac{\sigma_{y}}{\sigma_{x}} \\
& b=m_{y}-a \cdot m_{x}
\end{aligned}
$$

onde $r$ é o coeficiente de correlação linear, oy e ox são os respectivos desvios-padrão das variáveis $Y$ e X, MY $e$ $\mathrm{Mx}$ são as médias das variáveis $\mathrm{Y} e \mathrm{X}$. 


\section{3 - ANÁLISE GEOESTATÍSTICA}

\subsection{1 - Definição e Interpretação de Geoestatística}

A Geoestatistica consiste na aplicação da teoria das variáveis regionalizadas para se efetuar estimativas dentro de um contexto, regido por um fenômeno natural. Este, por sua vez, é caracterizado pela distribuição no espaço de uma ou mais variáveis, que são denominadas de "variáveis regionalizadas".

A diferença básica entre a Estatística Clássica e a Geoestatística, consiste em que, a primeira requer valores das amostras independentes espacialmente, enquanto que a segunda requer valores das amostras correlacionadas (dependentes) no espaço. Por esta característica, a Geoestatística tem tido grandes aplicações em Geologia, principalmente para efetuar estimativas e/ou simulações de variáveis em locais não avaliados.

A metodologia da geoestatística proporciona extrair de uma aparente aleatoriedade dos dados coletados, as maiores características estruturais do fenômeno natural assim como uma medida de correlação entre os valores, situados numa determinada vizinhança no espaço (HUI JBREGTS, 1975).

\subsection{2 - Histórico}

A Geoestatistica, originou-se pela necessidade de se efetuarem estimativas de reservas minerais. Por volta de 1950, na África do Sul, D.G. Krige concluiu que não poderia estimar de forma adequada o conteúdo de ouro em blocos mineralizados se não considerasse a configuração geométrica das amostras (localização e volume). Estas avaliações, a princípio empíricas e de aplicações localizadas, foram importantes para o engenheiro francês Georges Matheron desenvolver a teoria que estuda 0 comportamento de variáveis distribuídas espacialmente e 
que representam um fenômeno natural. Assim, Matheron, durante a década de 60, generalizou os métodos de estimativas usados por Krige e desenvolveu os fundamentos teóricos da variabilidade de amostragem associada com o tamanho das amostras bem como, formulou uma teoria completa dos erros de estimativas. Este desenvolvimento teórico encontra-se divulgado em MATHERON (1962, 1971).

Desde os anos 60 até os dias de hoje, a Geoestatística tem contribuído para diversas áreas das Geociências, especialmente na Pesquisa e Avaliação Mineral, Hidrogeologia, Cartografia Automática e, recentemente, nas Ciências Ambientais.

\subsection{3 - Modelos Determinísticos e Probabilísticos}

Normalmente nos trabalhos que requerem um entendimento do fenômeno natural, como, por exemplo, a estimativa em locais não amostrados, necessitam de modelos matemáticos. Entretanto, a caracterização quantitativa de um processo geológico ou similares, constitui-se numa tarefa relativamente complexa.

os modelos determinísticos são os que determinam 0 resultado de um processo de acordo com uma lei bem definida e, assim, só podem ser empregados nos processos onde todos os componentes estão bem caracterizados e a influência dos mesmos no processo é bem conhecida.

Infelizmente, poucas são as aplicações em Ciências da Terra, onde todos os fatores de um fenômeno natural são conhecidos suficientemente, permitindo um enfoque determinístico. A determinação de uma variável em local desconhecido, por exemplo, é acompanhada de muita incerteza. Neste contexto, os métodos geoestatísticos, baseados em modelos probabilísticos, propiciam uma avaliação da variável juntamente com a inevitável incerteza (ISAAKS \& SRIVASTAVA, 1989). 
Os modelos probabilísticos tratam os dados como resultados de um processo aleatório que não corresponde exatamente à realidade, visto que $\circ$ fenômeno que gerou uma determinada condição geológica, como jazidas minerais, áreas poluídas e outros, são extremamente complicados e o entendimento a respeito deles é tão pobre que sua complexidade parece ter um comportamento aleatório. Isto entretanto, não significa que os fenômenos são efetivamente aleatórios mas sim, que se ignora muito a respeito destes processos.

Desta forma, os modelos probabilísticos surgem como um processo alternativo eficaz para compreender os resultados originados de um fenômeno natural. Este tipo de modelamento foi o empregado neste trabalho, através das técnicas geoestatísticas, que serão apresentadas nos próximos tópicos.

\subsection{4 - Variáveis Regionalizadas}

Uma variável pode ser considerada regionalizada, se a mesma apresentar uma distribuição no espaço, juntamente com um determinado grau de correlação espacial. A maioria das variáveis utilizadas em Geociências, pode ser considerada como regionalizadas, por exemplo: topo de uma formação geológica, espessura de uma camada, teores geoquímicos, profundidade do lençol freático e muitas outras.

A teoria das variáveis regionalizadas está fundamentada nos modelos probabilísticos, onde as variáveis são consideradas como a realização única de uma determinada função aleatória (MATHERON, 1962). Os principais objetivos desta teoria, consistem em avaliar as características estruturais das variáveis regionalizadas e em efetuar estimativas que atenderão aos projetos de engenharia.

Desta forma, é necessário conhecer as características do processo aleatório em que a variável está compreendida. Estas características podem ser 
obtidas a partir dos trabalhos de amostragem, bem como de algumas suposições de estacionaridade do processo aleatório.

A hipótese de estacionaridade assume que seja constante o valor médio esperado, para diversos locais. Assim, cada par de dados $V i$ e $V j$, separados por uma distância h qualquer, é considerado como uma realização diferente das variáveis regionalizadas Vi e Vj.

Assume-se também, para os fenômenos naturais de elevadas dispersão, a hipótese intrínseca. Esta hipótese considera que os dois primeiros momentos da diferença das variáveis $\mathrm{Vi}$ e $\mathrm{Vj}$, são independentes das suas localizações, sendo função somente, do vetor que as separam (OLEA, 1984).

\subsection{5 - Análise de Variabilidade Espacial}

Uma das principais características das variáveis regionalizadas, constitui-se na sua continuidade ou variabilidade espacial, cujo entendimento e modelamento representa a base de toda a análise geoestatistica.

A forma de avaliação desta continuidade está fundamentada nos princípios de regressão linear, empregados na estatística clássica, para analisar a dependência entre duas variáveis (JOURNEL, 1989). Em geoestatística esta análise é feita para avaliar a dependência de uma variável com ela mesma, mas separadas por um vetor $h$.

Através deste procedimento, o grau de dependência entre uma variável $\mathrm{V}(\mathrm{x})$ para com ela mesma, separada por um vetor $h$, pode ser captado pelo coeficiente de correlação, covariância e ainda pelo momento de inércia, que pode ser representado por uma função denominada variograma.

Tendo em vista a tradição do emprego da função variograma em geoestatística, serão desenvolvidos os aspectos teóricos desta função; entretanto as demais medidas de correlação espacial, são importantes tanto 
quanto o variograma, principalmente a covariância. Uma avaliação consistente, mais detalhada das funções variograma e covariância pode ser encontrada em SRIVASTAVA (1987).

\subsubsection{1 - Função Variograma}

A função variograma é derivada do momento de inércia, calculado para uma variável $\mathrm{V}(\mathrm{x})$ em diversos intervalos de distância de um vetor $h$. O gráfico da Figura 3.4, demonstra a interpretação do variograma a partir do momento de inércia.

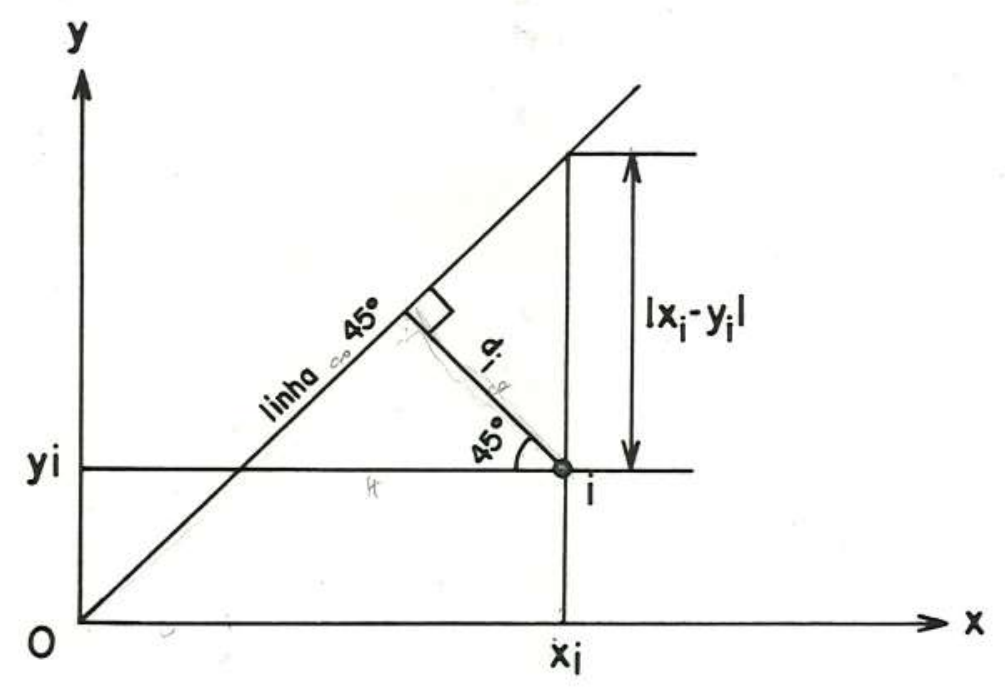

Figura 3.4 - Diagrama de dispersão de uma váriavel V(x) para uma distância h (JOURNEL, 1989).

O momento de inércia, definido neste contexto como variograma, constitui-se na metade da média das diferenças quadráticas entre as coordenadas de cada par de pontos do diagrama de dispersão espacial de $\mathrm{V}(\mathrm{x})$, ou seja:

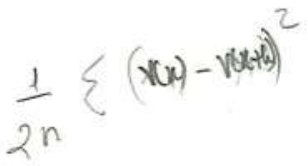




$$
\text { Variograma }=\frac{1}{2 n} \sum_{i=1}^{n}\left(V_{(x)}-V_{(x+h)}\right)^{2}
$$

- fator $1 / 2$ da equação, representa a distância $\left(\cos 45^{\circ}\right)$ perpendicular dos pontos em relação à linha de 45 graus do diagrama de dispersão. Este aspecto, conduz muitos geoestatísticos a denominar de semi-variograma para o momento de inércia, contudo por uma questão de simplicidade será denominado, neste trabalho, de variograma $(\gamma(\mathrm{h}))$.

Desta forma, quando se calcula o momento de inércia para vários intervalos de distância, elabora-se a seguir um gráfico para uma determinada direção, denominado de variograma experimental da variável $\mathrm{V}(\mathrm{x})$. Estes variogramas são normalmente feitos para várias direções, notadamente aquelas que possuem maior e menor continuidade da variável, constatado em trabalhos preliminares.

- mesmo conceito de variograma para uma variável pode ser estendido para descrever a continuidade espacial de duas variáveis conjugadas, isto é, no lugar de se trabalhar com pares da mesma variável em locais diferentes, trabalha-se com variáveis diferentes em localizações diferentes. Em geoestatística esta definição corresponde aos variogramas cruzados, cuja expressão analítica é assim equacionada:

$$
\gamma_{v v}(h)=\frac{1}{2 N(h)} \sum_{i, j}^{n}\left(V_{(i)}-V_{(j)}\right) \cdot\left(U_{(i)}-U_{(j)}\right)
$$

Após a elaboração dos variogramas experimentais (simples ou cruzados) para várias direções, a etapa seguinte consiste em estabelecer um modelo matemático, que represente da melhor forma possível a variabilidade em estudo. 
Antes de se analisar os modelos, propriamente dito, serão definidos os parâmetros e características da função variograma, com base no esquema da Figura 3.5.

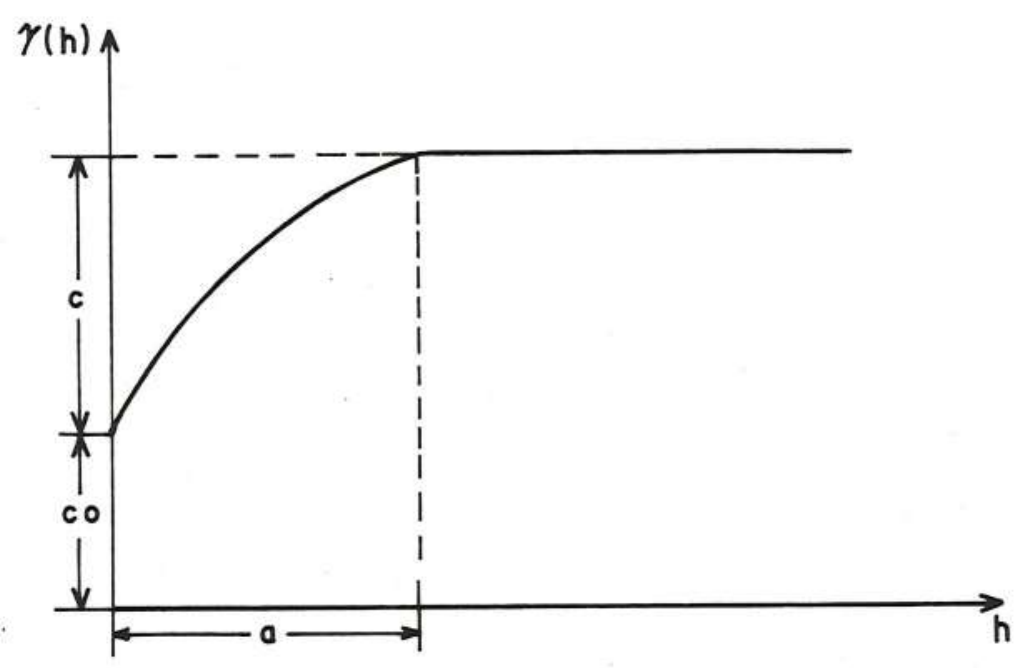

Figura 3.5 - Esquema básico de uma função variograma.

- Amplitude Variográfica (a): A medida que a distância entre os pares aumenta, a variabilidade tenderá a aumentar até atingir um determinado nível. A distância onde o variograma atinge este nível é considerada a amplitude variográfica, também denominada de "range".

- Patamar (C): Representa o nível de variabilidade onde - variograma se estabiliza. Este patamar deve ser teoricamente igual à variância estimada a priori, ou seja a variância populacional. Este parâmetro é também denominado de "sill".

- Efeito Pepita(Co): Para distância igual a zero ( $h=0)$, - variograma deveria apresentar variabilidade nula. Entretanto vários fatores como, erros de amostragens, erros de medidas ou ainda microregionalizações da variável em análise, causam uma descontinuidade na origem do variograma, denominada de efeito de pepita. 
De acordo com GARCIA (1988), a relação entre os parâmetros Co e C, indicada por $E$, é denominada de efeito de pepita relativo e expressa 0 grau de aleatoriedade do fenômeno regionalizado. A classificação desta componente aleatória é assim definida:

$$
\begin{aligned}
\mathrm{E}<0,15: \text { componente aleatória pequena } \\
0,15<\mathrm{E}<0,30 \text { : componente aleatória significativa } \\
\mathrm{E}<0,30 \text { : componente aleatória muito }
\end{aligned}
$$
significativa

Os variogramas experimentais podem ser elaborados para várias direções, com 0 intuito de detectar anisotropias. As feições anisotrópicas são caracterizadas em geoestatística nos seguintes tipos, conforme mostra a Figura 3.6 .

- Anisotropia Geométrica: Resulta quando a variabilidade é diferente de uma direção para a outra, mas mantém o mesmo patamar. Nestes casos, a anisotropia pode ser corrigida por uma transformação linear das coordenadas dos eixos anisotrópicos.
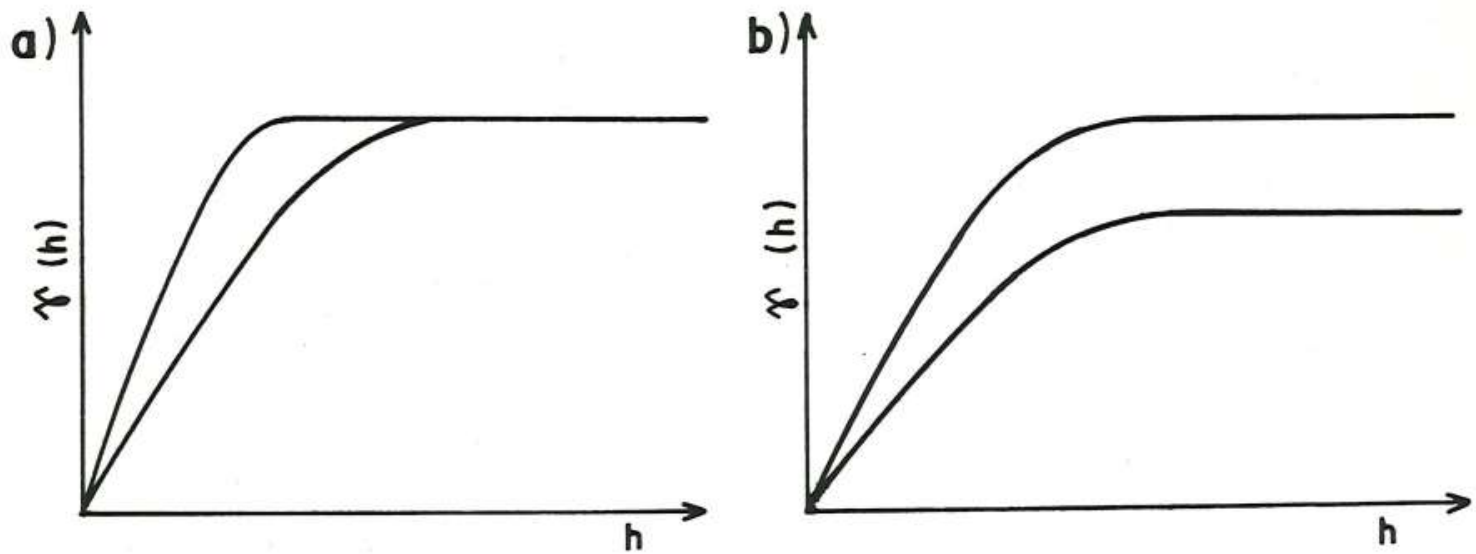

Figura 3.6 - Tipos de anisotropia variográfica;
a) geométrica
b) zonal

- Anisotropia Zonal: Neste tipo de anisotropia, tanto a amplitude como o patamar, variam conforme uma determinada direção e este comportamento está associado 
ao zoneamento espacial da variável ou ainda à uma possível associação de populações distintas.

Normalmente, os variogramas experimentais são elaborados sobre malhas com distribuição irregular das amostras. Desta forma, os programas computacionais que calculam os valores variográficos, pesquisam os dados em área de acordo com determinadas tolerâncias para a distância e a direção dos cálculos. Basicamente este procedimento estabelece uma regularização da malha. Deve-se verificar, contudo, que os dados obtidos no campo, através de técnicas diversas de amostragem, antes de serem submetidos à variografia, possuam o mesmo suporte ou volume. Caso não tenham tais características, estes dados devem ser regularizados, conforme descrição pormenorizada em RENDU (1978) e CLARK (1979).

Confeccionados os variogramas experimentais, ou ainda, os variogramas cruzados, a próxima etapa com vista às estimativas, consiste em ajustar um modelo matemático que represente, da melhor forma possível, a configuração das curvas dos variogramas.

\subsubsection{2 - Modelos Variográficos}

As funções teóricas, usadas para modelar variogramas, deverão atender à condição de serem "positiva definida", ou seja, o sistema estruturado a partir destas funções, para efetuar estimativas, deve possuir uma solução única e estável para o sistema de equações. Dada esta condição, o conjunto de funções básicas para modelar variogramas é limitado; entretanto a combinação dessas funções produzirá um conjunto de modelos, que atenderá de forma suficiente, às necessidades requeridas para se avaliarem os fenômenos regionalizados.

Os modelos variográficos podem ser subdivididos em 2 grupos, que são: os modelos com patamar e os modelos sem patamar. 
Nestes modelos a função variograma aumenta a medida que incrementa a distância, até atingir um patamar ("sill"), onde a função se estabiliza. Este patamar, teoricamente deve ser igual à variância da população.

os principais modelos estabelecidos dentro deste grupo estão representados na Figura 3.7, cujas expressões matemáticas são as seguintes:

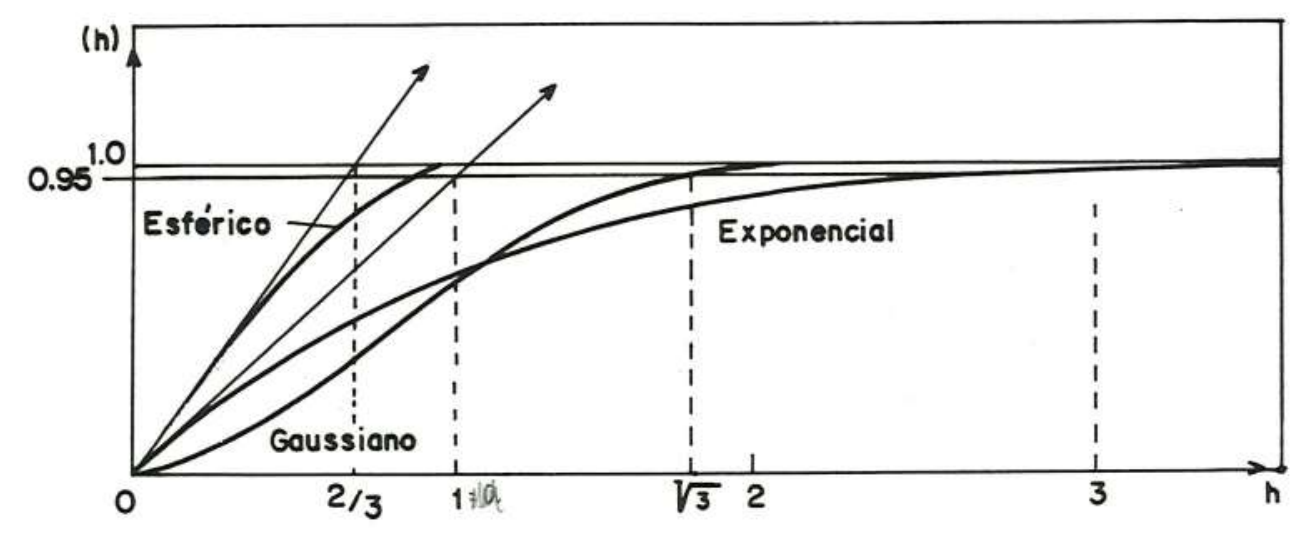

Figura 3.7 - Modelos variográficos com patamar.

\section{Modelo esférico:}

$$
\gamma(h)=\left\{\begin{array}{lr}
C \times 1.5 h / a-0.5(h / a)^{3} & \text { para } \mathrm{h} \leq \mathrm{a} \\
C & \text { para } \mathrm{h}>\mathrm{a}
\end{array}\right.
$$

onde C é o patamar e a representa a amplitude variográfica. Quando dos ajustes deste modelo, aplica-se usualmente a regra de que a tangente na origem, atinge o patamar a uma distância de $2 / 3$ da amplitude (a).

Modelo exponencial:

$$
\gamma(h)=C\left(1-e^{-\frac{h}{a}}\right)
$$


- patamar (C) é a assíntota desta função enquanto a amplitude (a), corresponde a 5 vezes à distância, onde a tangente na origem, atinge o patamar.

Modelo gaussiano:

$$
\gamma(h)=C\left(1-e^{-\frac{h^{2}}{a^{2}}}\right)
$$

Este modelo, cuja função tem comportamento parabólico na origem, apresenta larga amplitude variográfica (a) e patamar (C) semelhante aos modelos exponenciais.

Estes modelos são representativos de fenômenos naturais com elevada continuidade espacial.

Destaca-se ainda neste grupo o modelo aleatório (Figura 3.8), que se caracteriza pelo efeito de pepita puro. Este modelo, ao contrário de gaussiano, é representativo de fenômenos naturais de elevada aleatoriedade e sua expressão matemática é assim definida:

$$
\gamma(h)= \begin{cases}0 & \text { para } \mathrm{h}=0 \\ C & \text { para } \mathrm{h}>0\end{cases}
$$

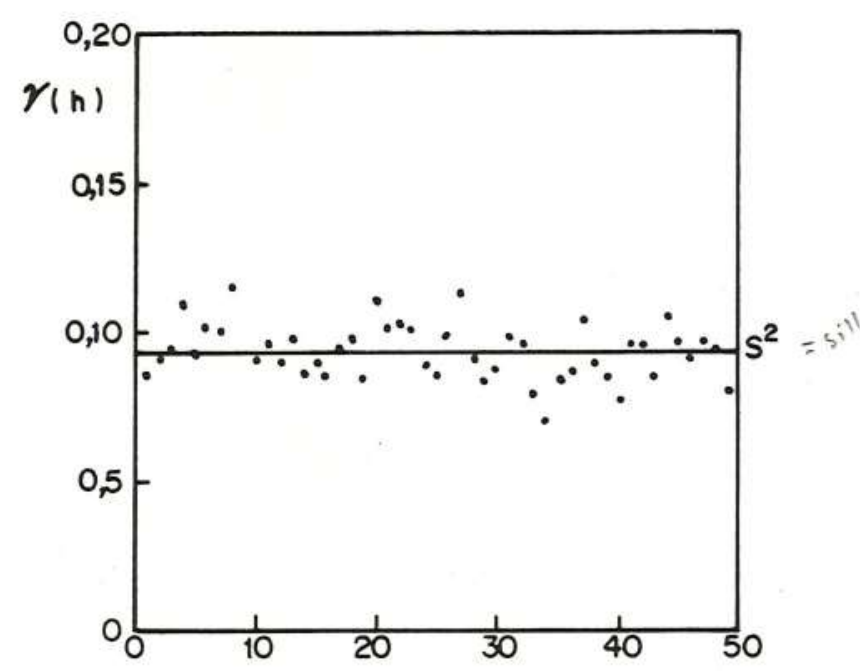

Figura 3.8 - Modelo aleatório 
Via de regra o efeito de pepita é somado aos demais modelos variográficos como uma constante Co.

- Modelos sem patamar:

Constituem-se nos modelos que apresentam um aumento constante da variabilidade à medida em que a distância é incrementada. Estes modelos são generalizados como modelos lineares e estão representados na Figura 3.9. Sua expressão matemática é:

$$
\gamma(h)=\alpha h^{\theta}
$$

onde $\theta$ varia de 0 a 2 e $\alpha$ representa a inclinação da reta.

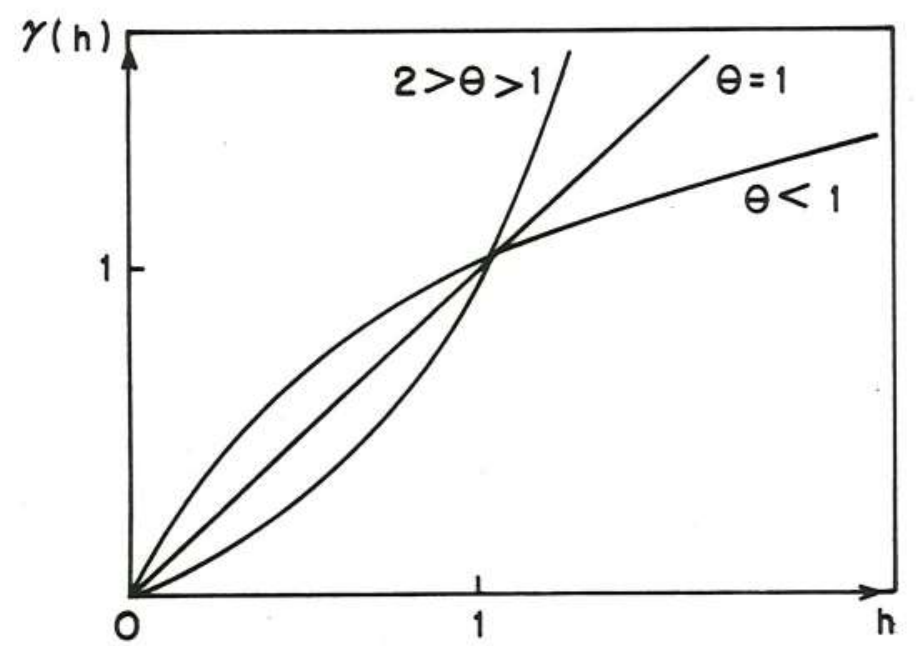

Figura 3.9 - Modelos lineares generalizados

\subsection{6 - Estimativas Geoestatisticas}

Uma necessidade constante na área de Geociências, principalmente em cartografia, é a estimativa de valores em locais onde não foram feitas amostragens.

Esta fase constitui-se num passo importante, visto que a malha de pontos estimada será responsável pela qualidade dos mapas a serem gerados. Os pontos desta malha devem ser estimados por métodos robustos e consistentes, para gerarem mapas confiáveis, podendo, 
assim, auxiliarem nos projetos que requerem estimativas com determinada precisão.

Dentre os métodos de estimativas, comumente empregados, o método geoestatístico da krigagem ordinária pode ser considerado como o melhor estimador linear sem viés, dado às seguintes características:

linear: as estimativas são feitas através de uma combinação linear dos dados;

sem viés: o método objetiva que o erro residual médio seja igual a zero;

melhor estimador: o método objetiva minimizar a variância dos erros.

Nota-se que as duas últimas proposições, do ponto de vista prático, são difíceis de serem concebidas, visto que não se conhecem os valores reais dos pontos estimados para se avaliar o erro e a variância verdadeiros.

Para superar estes aspectos, a krigagem ordinária baseia-se em um modelo probabilistico, cujo erro residual médio, bem como a variância dos erros podem ser estimados. Desta forma, podem-se atribuir pesos às amostras usadas nas estimativas, de tal modo que o erro médio seja zero e a variância dos erros seja mínima.

o desenvolvimento teórico a ser apresentado, foi baseado nos textos básicos de geoestatística como ISAAKS \& SRIVASTAVA (1989), KIM (1990), JOURNEL \& HUIJBREGTS (1978) e JOURNEL (1988).

Supondo-se a estimativa de um ponto não amostrado, através de uma combinação linear dos pesos de amostras, situados em uma vizinhança definida ao redor deste ponto:

$$
\hat{V}=\sum_{j=1}^{n} w_{j} v_{j}
$$

o erro cometido nesta estimativa constituirá na diferença do valor estimado com o valor real no ponto: 
erro no ponto estimado $=r_{i}=\hat{V}_{i}-V_{i}$

e o erro médio após uma série de estimativas $k$, é dado por:

$$
\hat{j}^{j^{2}}\left(m_{r}\right)=\frac{1}{k} \sum_{t=1}^{n} r_{i}=\frac{1}{k} \sum_{i=1}^{k} \hat{V}_{i}-V_{i}
$$

Como já expresso anteriormente, os valores reais não são conhecidos. Este problema é solucionado em geoestatística, através de um modelo probabilístico em que, os valores estimados são resultados de um processo aleatório estacionário.

Neste modelo, assume-se que o valor médio esperado é constante para as diversas localizações, ou ainda, que todos os valores avaliados constituem em variáveis aleatórias de uma mesma população. Desta forma, cada par destas variáveis possuem uma distribuição conjunta que depende somente da separação entre dois pontos e não das suas localizações.

Todos os valores neste modelo são vistos como $\circ$ resultado de uma variável aleatória, tanto as amostras como o valor desconhecido a ser estimado. O valor a ser estimado por sua vez, também é uma variável aleatória, visto que ele será uma combinação linear das variáveis aleatórias, que são as amostras, ou seja:

$$
\hat{V}\left(x_{0}\right)=\sum_{i=1}^{n} w_{i} V\left(x_{i}\right)
$$

Da mesma forma, o erro da estimativa, definido como a diferença entre o valor estimado pelo modelo aleatório e o valor verdadeiro, é também considerado uma variável aleatória, isto é:

$$
R\left(x_{0}\right)=\hat{V}\left(x_{0}\right)-V\left(x_{0}\right)
$$


Por substituição, o erro da estimativa, pode ser assim definido:

$$
R\left(x_{0}\right)=\sum_{i=1}^{n} w_{i} V\left(x_{i}\right)-V\left(x_{0}\right)
$$

A condição de não viés, que estabelece o erro residual médio igual a zero, pode então ser desdobrada analiticamente da seguinte forma:

$$
\begin{aligned}
E\left\{R\left(x_{0}\right)\right\} & =E\left\{\sum_{i=l}^{n} w_{i} V\left(x_{i}\right)-V\left(x_{0}\right)\right\} \\
& =\sum_{i=l}^{n} w_{i} E\left\{V\left(x_{i}\right)\right\}-E\left\{V\left(x_{0}\right)\right\}
\end{aligned}
$$

Pela hipótese da estacionaridade:

$$
\begin{aligned}
& E\left\{R\left(x_{0}\right)\right\}=\sum_{i=1}^{n} w_{i} E\{V\}-E\{V\} \\
& E\left\{R\left(x_{0}\right)\right\}=0=E\{V\} \sum_{i=1}^{n} w_{i}-E\{V\} \\
& E\{V\} \sum_{i=1}^{n} w_{i}=E\{V\} \\
& \text { e } \quad \sum_{i=1}^{n} w_{i}=1
\end{aligned}
$$

3.3.6.1 - Variância dos Erros Estimados

A principal característica da krigagem, constituise em avaliar a variância do erro de estimativa e tentar minimizá-la.

o erro de estimativa, como já foi dito é assim definido :

$$
R\left(x_{0}\right)=\sum_{i=1}^{n} w_{i} V\left(x_{i}\right)-V\left(x_{0}\right)
$$

Tendo em vista que a variância de uma combinação linear ponderada, pode ser equacionada em termos de covariância, segundo a expressão: 


$$
\operatorname{Var}\left\{\sum_{i=1}^{n} w_{i} V_{i}\right\}=\sum_{i=1}^{n} \sum_{j=1}^{n} w_{i} w_{j} \cdot \operatorname{cov}\left\{V_{i} V_{j}\right\}
$$

- variância do erro da estimativa pode então ser desdobrada:

$$
\begin{aligned}
& \operatorname{Var}\left\{R\left(x_{0}\right)\right\}=\operatorname{Cov}\left\{\hat{V}\left(x_{0}\right) \hat{V}\left(x_{0}\right)\right\}-\operatorname{Cov}\left\{\hat{V}\left(x_{0}\right) V\left(x_{0}\right)\right\}-\operatorname{Cov}\left\{V\left(x_{0}\right) \hat{V}\left(x_{0}\right)\right\}+\operatorname{Cov}\left\{V\left(x_{0}\right) V\left(x_{0}\right)\right\} \\
& \operatorname{Var}\left\{R\left(x_{0}\right)\right\}=\operatorname{Cov}\left\{\hat{V}\left(x_{0}\right) \hat{V}\left(x_{0}\right)\right\}-2 \operatorname{Cov}\left\{\hat{V}\left(x_{0}\right) V\left(x_{0}\right)\right\}-\operatorname{Cov}\left\{V\left(x_{0}\right) V\left(x_{0}\right)\right\}
\end{aligned}
$$

- sendo que, o primeiro termo é a covariância de $\hat{V}_{(x 0)}$ com ela mesma, que é igual à variância de uma combinação linear de variáveis aleatórias:

$$
\operatorname{Var}\left\{\hat{V}\left(x_{0}\right) \hat{V}\left(x_{0}\right)\right\}=\operatorname{Var}\left\{\sum_{i=1}^{n} w_{i} V_{i}\right\}=\sum_{i=1}^{n} \sum_{j=1}^{n} w_{i} w_{j} C_{i j}
$$

O segundo termo, pode ser desdobrado da seguinte forma :

$$
\begin{aligned}
2 \operatorname{Cov}\left\{\hat{V}\left(x_{0}\right) \hat{V}\left(x_{0}\right)\right\} & =2 \operatorname{Cov}\left\{\left(\sum_{i=1}^{n} w_{i} V_{i}\right) V_{0}\right\} \\
& =2 E\left\{\sum_{i=1}^{n} w_{i} V_{i} V_{0}\right\}-2 E\left\{\sum_{i=1}^{n} w_{i} V_{i}\right\} E\left\{V_{0}\right\} \\
& =2 \sum w_{i} E\left\{V_{i} V_{0}\right\}-2 \sum w_{i} E\left\{V_{i}\right\} E\left\{V_{0}\right\} \\
& =2 \sum_{i=1}^{n} w_{i} \operatorname{Cov}\left\{V_{i} V_{0}\right\} \\
& =2 \sum_{i=1}^{n} w_{i} C_{i 0}
\end{aligned}
$$

- terceiro termo é a covariância da variável aleatória $V\left(x_{i}\right)$ com ela mesma, que é igual à variância de $V\left(x_{0}\right)$. Pela condição de estacionaridade, todas as variáveis aleatórias têm a mesma variância $\sigma^{2}$, assim:

$$
\operatorname{Cov}\left\{V\left(x_{0}\right) V\left(x_{1}\right)\right\}=\sigma^{2}
$$


Finalmente, após estas deduções, a variância dos erros de estimativas pode ser expressa pela sua equação básica:

$$
\sigma_{k}^{2}=\sigma^{2}+\sum_{i=1}^{n} \sum_{j=1}^{n} w_{i} w_{j} C_{i j}-2 \sum w_{i} C_{i, 0}
$$

\subsubsection{2 - Krigagem Ordinária}

A próxima etapa, conforme as propostas dos métodos geoestatísticos, é minimizar numericamente a equação da variância e igualar as $n$ derivadas parciais de primeira ordem a zero.

Isto resultará no clássico sistema de equações lineares simultâneas. Entretanto, existe a condição de não viés, que implica na somatória dos ponderadores do sistema ser igual a 1 (um). Para contornar esta restrição, é empregada a técnica lagrangiana, que introduz um novo parâmetro na equação sem afetar sua igualdade. Assim, o sistema pode ser solucionado, resultando num conjunto de ponderadores cuja somatória é $1\left(\sum w_{i}=1\right)$.

Desta forma, o conjunto de ponderadores que minimiza a variância dos erros de estimativas, sob a condição de somarem 1 , é obtido pela seguinte seqüência matemática:

$$
\frac{\partial \sigma_{R}^{2}}{\partial w_{i}}=0 \quad \text { para } \mathrm{i}=1,2,3, \ldots, \mathrm{n}
$$

Desta derivada, resulta as seguintes equações:

$$
\begin{aligned}
& \sum_{j=1}^{n} w_{j} C_{i j}-\mu=C_{i 0} \quad \forall_{\mathrm{i}}=1, \ldots, n \\
& \sum_{j=1}^{n} w_{j}=1
\end{aligned}
$$


que podem ser representadas matricialmente:

$$
\begin{array}{r}
{\left[\begin{array}{cccccc}
C_{11} & \cdot & \cdot & \cdot & C_{1 n} & 1 \\
\cdot & \cdot & \cdot & \cdot & \cdot & \cdot \\
\cdot & \cdot & \cdot & \cdot & \cdot & \cdot \\
\cdot & \cdot & \cdot & \cdot & \cdot & \cdot \\
C_{n 1} & \cdot & \cdot & \cdot & C_{n n} & 1 \\
1 & \cdot & \cdot & \cdot & 1 & 0
\end{array}\right] \times\left[\begin{array}{c}
w_{1} \\
w_{2} \\
\cdot \\
\cdot \\
w_{n} \\
-\mu
\end{array}\right]=\left[\begin{array}{c}
C_{10} \\
\cdot \\
\cdot \\
\cdot \\
C_{n 0} \\
1
\end{array}\right]} \\
{[\mathrm{C}]} \\
{[\mathrm{W}] \quad[\mathrm{D}]}
\end{array}
$$

Cuja solução é :

$$
[W]=[C]^{-1} \times[D]
$$

A variância dos erros, minimizada pela krigagem ordinária, é obtida através da solução da expressão:

$$
\sigma_{R}^{2}=\sigma^{2}-[W][D]
$$

Nota-se nas matrizes C e D, a função de covariância para inúmeros pares de pontos. Esta função é originada do modelo variográfico efetuado para compreender a continuidade espacial da variável de interesse.

Em função do uso comum do variograma, tem-se para os modelos de funções aleatórias estacionárias, a seguinte relação entre variograma e a covariância:

$$
C_{i j}=\sigma^{2}-\gamma_{i j} \quad C(h)=c(0)-\gamma(h)
$$

Esta relação possibilita trabalhar-se com a função variograma na fase de modelamento da variabilidade espacial e com a função covariância, nos processos de estimativas. 
3.3 .6 .3 - Cokrigagem

Como visto, a krigagem ordinária trabalha com uma variável para cada processo de estimativa. Entretanto, é muito comum nos diversos trabalhos de prospecção geológica, trabalhar-se com um conjunto de variáveis em uma determinada área, podendo ocorrer, por questões operacionais, que algumas variáveis sejam mais avaliadas que outras. Nestas situações, pode-se analisar a correlação espacial cruzada entre as variáveis e fazer uso do método geoestatístico da cokrigagem, para se efetuar estimativas da variável sub-mostrada, através do uso de outra variável melhor conhecida.

A cokrigagem, procura minimizar a variância dos erros de estimativas, explorando a correlação cruzada entre diversas variáveis, ou seja, as estimativas são feitas com base nos variogramas cruzados efetuados entre as variáveis de interesse.

Por exemplo, em cartografia geotécnica, uma variável que se encontra normalmente à disposição são as cotas topográficas, obtidas de mapas topográficos de detalhe, com escalas maiores que $1: 10.000$ que, via de regra, podem ser correlacionáveis com as cotas do lençol freático, bem como com as cotas do nível impenetrável ao amostrador padrão.

A dedução matemática apresentada a seguir foi feita com base em duas variáveis; entretanto, a técnica pode ser expandida para múltiplas variáveis.

A cokrigagem é uma combinação linear de variáveis primárias e secundárias, expressa da seguinte forma:

$$
\hat{\mu}_{0}=\sum_{i=1}^{n} a_{i} \mu_{i}+\sum_{j=1}^{m} b_{j} v_{j}
$$

onde:

$\hat{\mu}_{0}=$ a estimativa de $\mu$ na posição 0

$\mu 11, \ldots, \mu_{n}=$ dados primários vizinhos à posição 0

$\mathrm{v}_{11}, \ldots, \mathrm{v}_{\mathrm{n}}=$ dados secundários vizinhos à posição 0 
$a 1, \ldots$, an $e b 1, \ldots, b n=$ pesos das amostras que comporão - sistema a ser solucionado

Como na krigagem, o desenvolvimento do sistema da cokrigagem inicia-se pelo erro da estimativa:

$$
\begin{aligned}
& R=\hat{U}_{0}-U_{0} \\
& R=\left(\sum_{i=1}^{n} a_{i} U_{i}+\sum_{j=1}^{m} b_{j} V_{j}\right)-U_{0}
\end{aligned}
$$

onde:

$u_{i}, \ldots, u_{n}$ : são variáveis do fenômeno u para $n$ amostras $v_{1}, \ldots, v_{m}$ : são variáveis do fenômeno $v$ para $m$ amostras

A equação () é uma combinação linear de $\mathrm{n}+\mathrm{m}-1$ funções aleatórias de $U_{1} \ldots U_{n}, V_{1} \ldots V_{n}$ e $U_{0}$.

Em termos matriciais, tem-se:

$R=w^{t} \times Z$

onde:

${ }^{t}{ }^{t}=\left(a_{1}, \ldots a_{n}, b_{1}, \ldots b_{m-1}\right)$

$z^{t}=\left(u_{1}, \ldots, u_{n}, v_{1}, \ldots, v_{n}, u_{0}\right)$

A variância dos erros de estimativas, após o desdobramento e simplificação da sua expressão, pode ser expressa matricialmente;

$$
\operatorname{Var}\{R\}=w^{t} C_{z} w
$$

onde $C_{z}$ é a matriz de covariância de $z$.

o sistema da cokrigagem deve ser desenvolvido de tal forma que satisfaça à condição básica de não viés, ou seja:

$$
\begin{aligned}
& \sum_{i=l}^{n} a_{i}=1 \\
& \sum_{j=1}^{m} b_{j}=0
\end{aligned}
$$

Da mesma forma que a krigagem ordinária, o sistema da cokrigagem para atender às restrições dada a condição 
de não viés, é equacionado, introduzindo-se os multiplicadores de Lagrange $\mu_{1}$ e $\mu_{2}$ :

$$
\operatorname{Var}\{R\}=w^{t} C_{z} w+2 \mu_{1}\left(\sum_{i=l}^{n} a_{i}-1\right)+2 \mu_{2}\left(\sum_{j=1}^{m} b_{j}\right)
$$

Esta equação é minimizada, calculando-se as derivadas parciais de $\operatorname{Var}\{R\}$ com relação a $n+m+1$ pesos $e$ os dois multiplicadores de Lagrange, o que resulta no sistema da cokrigagem:

$$
\begin{array}{ll}
\sum_{i=1}^{n} a_{i} \operatorname{Cov}\left\{U_{i} U_{j}\right\}+\sum_{i=1}^{m} b_{j} \operatorname{Cov}\left\{V_{i} U_{j}\right\}+\mu_{1}=\operatorname{Cov}\left\{U_{0} U_{j}\right\} & \text { para } \mathrm{j}=1, \mathrm{n} \\
\sum_{i=1}^{n} a_{i} \operatorname{Cov}\left\{U_{i} V_{j}\right\}+\sum_{i=1}^{m} b_{j} \operatorname{Cov}\left\{V_{i} V_{j}\right\}+\mu_{2}=\operatorname{Cov}\left\{U_{0} V_{j}\right\} & \text { para } \mathrm{j}=1, \mathrm{~m} \\
\text { e } \sum_{\mathrm{i}=1}^{\mathrm{n}} \mathrm{a}_{\mathrm{i}}=1, \sum_{\mathrm{i}=1}^{\mathrm{m}} \mathrm{b}_{\mathrm{i}}=0 &
\end{array}
$$

Finalmente, a variância dos erros de estimativas pode ser calculado da seguinte forma:

$$
\operatorname{Var}\{R\}=\operatorname{Cov}\left\{U_{0} U_{0}\right\}+\mu_{1}-\sum_{i=1}^{n} a_{i} \operatorname{Cov}\left\{U_{i} U_{0}\right\}-\sum_{j=1}^{m} b_{j} \operatorname{Cov}\left\{V_{j} U_{0}\right\}
$$

A variabilidade espacial é modelada através dos variogramas que são convertidos para covariâncias a serem usados no sistema da cokrigagem através da relação:

$$
C_{u v}(h)=\gamma_{u v}(\infty)-\gamma_{U V}(h)
$$

\subsubsection{4 - Estimativa de Distribuição de Probabilidades através da Krigagem Indicativa}

Como se pode observar no processo de estimativa da krigagem ordinária, a estimativa é feita para um valor médio em um determinado local. De outra forma, podem-se 
fazer estimativas de proporções que se situam abaixo (ou acima) de um determinado nível de corte.

Este procedimento, estabelecido para vários níveis, como por exemplo, os quartis de uma distribuição, conduzirá a uma estimativa da função da distribuição acumulada em um determinado local.

Para se atingir estes objetivos, o primeiro passo é transformar os dados originais em indicadores, isto é, transformar os valores que estão acima de um determinado nível de corte em zero (0) e os que estão abaixo em um (1) .

$$
i_{j}\left(v_{c}\right)=\left\{\begin{array}{lll}
1 & \text { se } & v_{\mathrm{j}} \leq v_{c} \\
0 & \text { se } & v_{\mathrm{j}}>v_{c}
\end{array}\right.
$$

onde $v_{c}$ é o nível de corte e $v_{j}$ é o valor observado.

Assim, a freqüência acumulada de valores observados abaixo do nível de corte, pode ser expressa:

$$
F\left(v_{c}\right)=\frac{1}{n} \sum_{j=1}^{n} i_{j}\left(v_{c}\right)
$$

Da mesma forma, a proporção de valores abaixo do nível de corte, também pode ser considerada como a média ponderada dos indicadores (1), situados na vizinhança do local avaliado, de acordo com a expressão:

$$
\hat{F}\left(v_{c}\right)=\sum_{j=1}^{n} w_{j} i_{j}\left(v_{c}\right)
$$

onde $w_{j}$ são os pesos, $i_{j}$ os indicadores e Vc o nível de corte.

Os pesos, pela condição de não viés, devem somar 1 , ou seja:

$$
\sum w_{j}=1
$$


Matematicamente, de acordo com JOURNEL(1983), a distribuição espacial de uma variável aleatória, para um local (ponto) dentro de uma região A, é assim definida:

$$
\phi\left(A, v_{c}\right)=\frac{1}{A} \int_{x \in A} i\left(x, v_{c}\right) d x
$$

onde: $\phi\left(A, v_{c}\right)$ constitui-se na distribuição espacial dos valores no local dentro da região $\mathrm{A}$ e $v_{c}$ representa 0 valor de corte.

A distribuição espacial $\phi\left(A, v_{c}\right)$ pode ser considerada como uma realização de uma variável aleatória $\Phi\left(A, v_{c}\right)$. Assim, o valor esperado desta variável pode ser determinado da seguinte forma:

$$
\begin{aligned}
E\left[\Phi\left(A, v_{c}\right)\right] & =\frac{1}{A} E\left[\int_{X \in A} I\left(x, v_{c}\right) d x\right]=\frac{1}{A} \int_{x \in A} E\left[I\left(x, v_{c}\right)\right] d x \\
E\left[\Phi\left(A, v_{c}\right)\right] & =\frac{1}{A} \int_{x \in A}\left\{(1) \operatorname{Pr}\left[v(x) \leq v_{c}\right]+(0) \operatorname{Pr}\left[v(x)>v_{c}\right]\right\} d x \\
& =\frac{1}{A}\left[v(x) \leq v_{c}\right] \text { para estacionaridade de } v(x) \\
& =F\left(v_{c}\right)
\end{aligned}
$$

onde:

$\operatorname{Pr}\left[v(x) \leq v_{c}\right]=$ Probabilidade $\operatorname{de} \mathrm{v}(\mathrm{x}) \leq \mathrm{v}_{\mathrm{c}}$

$F\left(v_{c}\right)=$ Função de distribuição acumulada univariada

A krigagem indicativa consiste em solucionar a expressão linear 3.61, através da krigagem ordinária, com base nos modelos variográficos elaborados para a variável transformada.

Desta forma são calculados os variogramas experimentais indicativos para determinados níveis de corte, que podem ser os quartis e estabelecem-se os modelos variográficos para os mesmos. Os variogramas indicativos podem ser estimados pela função:

$$
\gamma_{i}\left(h, v_{c}\right)=\frac{1}{2 N_{h}} \sum_{i=1}^{N_{h}}\left[i\left(x+h, v_{c}\right)-i\left(x, v_{c}\right)\right]^{2}
$$


Por fim, emprega-se a krigagem ordinária para calcular as proporções, situadas abaixo dos níveis de corte, préviamente estabelecidos. De posse dessas proporções, pode-se elaborar a função de distribuição acumulada em um determinado local da área, para a variável em análise. 


\section{4. - LOCALIZAÇÃO E ASPECTOS FISIOGRÁFICOS DA ÁREA DE ESTUDO}

\section{1 - LOCALIZAÇÃO}

A área de estudo é constituída basicamente pelo município de Bauru que se situa no planalto ocidental do Estado de São Paulo e está compreendida pelos paralelos

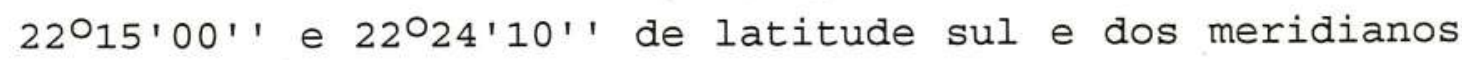
de 48056'51'' e 49010'38'' de longitude oeste (Figura 4.1). A cidade de Bauru é a sede da $7 \underline{a}$ região administrativa do Estado de São Paulo e possui atualmente uma população de cerca de 300.000 habitantes. A área urbanizada estende-se por um raio de $5 \mathrm{~km}$, atravessada por diversos cursos de água formadores das cabeceiras do rio Bauru, com destaque para o Córrego Águas das Flores, Ribeirão da Grama, Córrego do Sobrado, Água da Forquilha e Água da Ressaca.

\section{2 - CLIMA E PLUVIOMETRIA}

De acordo com a localização geográfica da região, situada entre as latitudes $22^{\circ}$ e 230 sul, o clima tropical predomina na região, cuja característica mais marcante é determinada por uma estação muito chuvosa e outra seca.

A temperatura média anual é de cerca de $20^{\circ} \mathrm{C}$, que representa a predominância de temperaturas mais elevadas, principalmente nas estações primavera e verão, quando a temperatura média situa-se na ordem de $24^{\circ} \mathrm{C}$.

Segundo NIMER(1977), o clima da região é tropical sub-quente, onde os meses mais frios (junho e julho) 
podem apresentar temperatura média mínima diária, da ordem de $8^{\circ} \mathrm{C}$.
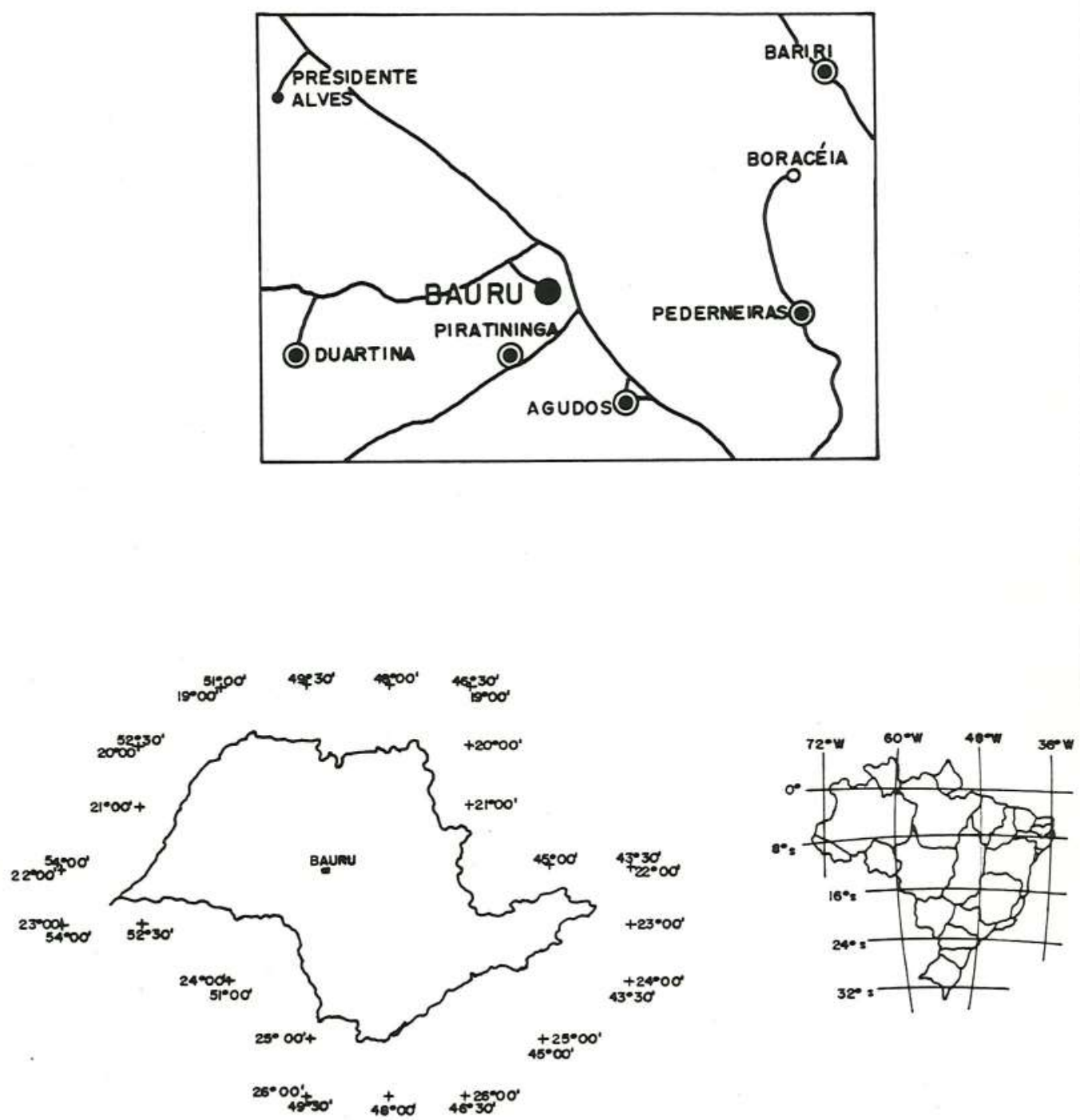

Figura 4.1 - Localização da área de estudo.

o trimestre mais chuvoso corresponde aos meses de dezembro, janeiro e fevereiro e a média anual de precipitação está em torno de $1250 \mathrm{~mm}$. O regime de chuvas apresenta o máximo de precipitação na época em que os dias são mais longos que as noites e o mínimo quando as noites são mais longas que os dias, tratando-se, 
portanto, de um regime estacional típico das regiões de clima tropical (SILVA \& COUTO, 1980)

\section{3 - RELEVO}

A região de Bauru está inserida dentro da província geomorfológica do Planalto Ocidental do Estado de São Paulo.

Esta província, constituída quase que inteiramente pelo Grupo Bauru, apresenta-se em um relevo uniforme e monótono, com extensos espigões de perfis convexos e cimos ondulados, com terminações laterais lobadas que configuram colinas baixas e amplas. Estas colinas avançam em direção aos vales dos principais rios que buscam $\circ$ rio Paraná, separando seus afluentes. A maior parte desse relevo encontra-se a menos de $600 \mathrm{~m}$ de altitude, e seus desniveis locais raramente se aproximam de uma centena de metros. A convexidade geral das formas topográficas é de notável suavidade com reduzidos ângulos dos perfis das vertentes (ALMEIDA, 1964).

Deve-se considerar também uma forte imposição estrutural no relevo do planalto Ocidental, sob o controle de camadas sub-horizontais, com leve caimento para oeste, formando uma extensa plataforma estrutural extremamente suavizada, nivelada em cotas próximas a 500 metros, atingindo a foz do rio Paranapanema a 247 metros de altitude. A drenagem é organizada na maior parte por rios conseqüentes, formados dentro dos limites da província, ou ainda por cursos d'água tributários dos três principais rios paulistas, o Paranapanema, o Tietê e - Grande. Essa rede de drenagem mostra um acentuado paralelismo de eixos alinhados para NW e apresenta evidências de capturas em vários locais no interior do Planalto (PONÇANO et al., 1981).

A nível local o relevo de colinas amplas, caracteriza-se por apresentar interflúvios com área superior a $1,0 \mathrm{Km}^{2}$, topos extensos e aplainados, vertentes com perfis retilíneos e ligeiramente convexos, 
cuja convexidade se acentua na parte inferior da vertente e apresentam grande extensão, com comprimento não inferior a $700 \mathrm{~m}$. As declividades das vertentes são relativamente baixas, com valores da ordem de $3 \%$ nos topos e no máximo de $15 \%$ no restante da vertente. As drenagens se apresentam com baixa densidade de ocorrência, de padrão geral subparalelo, vales abertos, predominando formas em U ou em berço (IPT, 1991).

A área de estudo apresenta também um relevo dominado por colinas médias, com interflúvios relativamente estreito, com área inferior a $500 \mathrm{~m}^{2}$ e topos aplainados ou angulosos quando próximo de morrotes alongados. As vertentes são curtas, convexas e irregulares, com rupturas de declive próximo à base da vertente. A declividade predominante é elevada, sendo que os valores mais baixos, da ordem de $6 \%$, ocorrem nos topos enquanto o restante da vertente apresenta declives de $12 \%$ ou superiores. As drenagens são mais densas do que no relevo de colinas amplas, com padrão subdendrítico, valores entalhados e fechados, cujas formas em U são predominantes (IPT,1991).

\section{4 - GEOLOGIA}

A área faz parte da Bacia sedimentar do Paraná, onde as rochas superficiais predominantes são do Grupo Bauru (Cretáceo Superior) conforme mostra a Figura 4.2.

Embora a geologia de superfície seja relativamente simples, a geologia de subsuperfície apresenta aspectos mais complexos visto que, a região da cidade de Bauru, situa-se no flanco de um "horst" pertencente a uma estrutura maior, conhecida como a Estrutura de Piratininga.

Dentro desta conjuntura, constatou-se que rochas do Grupo Bauru estão sobrepostas diretamente às formações Pirambóia, Botucatu (Triássico-Jurássico) e Grupo Passa Dois ( Permiano). 


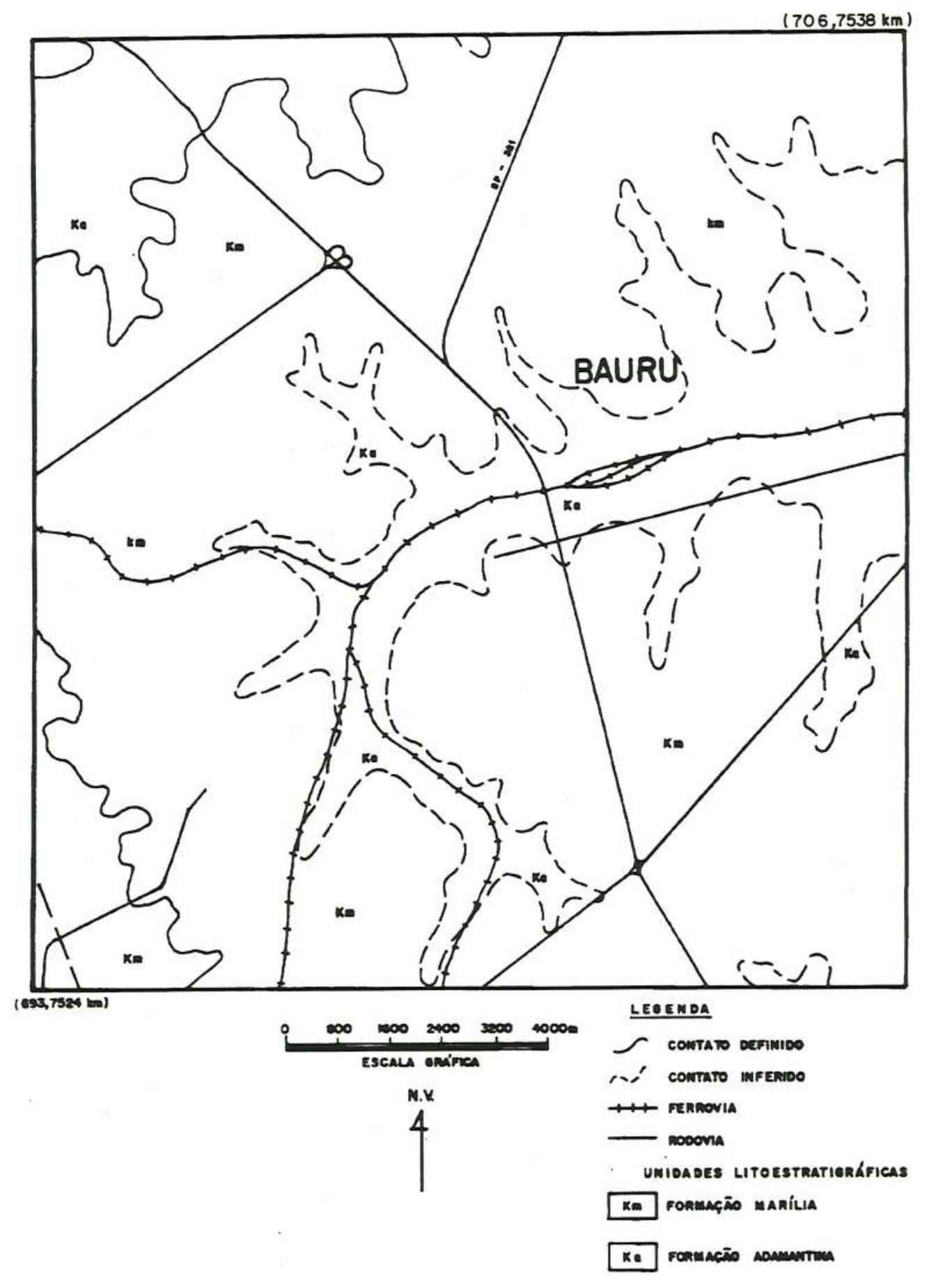

Figura 4.2 - Mapa geológico da área de estudo. (adaptado de IPT, 1991) 
Este fato pode ser observado através de sondagens efetuadas para a prospecção de água subterrânea e de petróleo, bem como em superfície, na Fazenda São José e adjacências, a cerca de 7 quilômetros a SSE da cidade de Piratininga. Esta situação, provocada por falhamentos normais, afeta toda a coluna vulcano-sedimentar que veio posteriormente a constituir o embasamento para a sedimentação Neocretácea (SILVA \& COUTO,1980).

De acordo com estudos efetuados por SILVA (1988) e SILVA \& CAVAGUTI (1992), com base em diversos poços de exploração de água subterrânea na região, a estratigrafia local das formações mesozóicas, apresenta-se da seguinte forma:

- Formação Pirambóia: caracteriza-se por uma sequiência predominantemente arenosa com intercalações delgadas de lamitos avermelhados e teor de argila crescente para a base. Em subsuperfície, esta Formação ocorre em toda extensão da cidade de Bauru, com espessuras que variam de 60 a 200 metros, assentados discordantemente sobre a Formação Teresina (Permiano).

SILVA \& CAVAGUTI (1992) estabeleceram uma sequiência de litofácies onde a Formação Pirambóia foi totalmente preservada da erosão pré-Bauru, do topo para a base. Foram definidas as fácies de arenitos finos a grossos de cor avermelhada com espessura média de 75 metros, arenitos grosseiros a conglomeráticos com espessura de 25 metros e a fácies de arenitos argilosos, avermelhados com espessura média de 40 metros.

Esta unidade apresenta, na região, contato superior com a Formação Botucatu, de modo transicional, e, com a Formação Bauru, de modo discordante.

- Formação Botucatu: foram constatadas espessuras da ordem de 114 metros na porção nordeste da área, adelgaçando para sudoeste até se ausentar completamente.

Esta Formação constitui-se praticamente de arenitos finos a muito finos, uniformes, com boa seleção de grãos foscos com alta esfericidade; são avermelhados e exibem estratificação cruzada tangencial de médio a grande 
porte, o que caracteriza sua origem eólica. Apresenta na região contatos transicionais com a Formação Pirambóia subjacente e contatos superiores com a Formação Serra Geral de modo abrupto ou interdigitado ou ainda com o Grupo Bauru de modo discordante.

- Formação Serra Geral: compreende um conjunto de rochas eruptivas dispostas em uma sequiência de derrames basálticos com os quais intercalam-se arenitos com as características dos pertencentes à Formação Botucatu.

Os basaltos acham-se ausentes, em subsuperficie, na maior parte da área em estudo, ocorrendo somente no extremo norte e nordeste. A maior espessura desta unidade constatada, foi de 172 metros, com tendência de espessamento para nordeste.

Regionalmente, a Formação Serra Geral se espessa para oeste em direção ao eixo da Bacia, onde pode ser constatada espessura superior a 1750 metros, como no poço perfurado em Cuiabá Paulista, 2-CB-1-SP (VIOT et al., 1981).

Um dos grandes problemas para a prospecção de água subterrânea e para definições estratigráficas das rochas basálticas é a identificação dos corpos formados por intrusão. Desta forma, as implicações estratigráficas de basaltos e diabásios são de difícil esclarecimento (SOARES, 1973).

A Formação Serra Geral faz contato inferior com a Formação Botucatu e superior de modo discordante, com o Grupo Bauru.

- Grupo Bauru: A estratigrafia atual do Grupo Bauru foi definida a partir de uma série de trabalhos efetuados no sudoeste do Estado de São Paulo, com destaque para LANDIM \& SOARES (1976), SOARES et al. (1979) e SOARES et al. (1980).

- Grupo Bauru é constituído pelas formações Caiuá, Santo Anastácio, Adamantina e Marília.

$\mathrm{Na}$ área em estudo, contudo, o Grupo Bauru está representado pelas formações Adamantina e Marília. 
Formação Adamantina: é caracterizada de forma geral por um conjunto de fácies, constituída por banco de arenitos de granulação fina a muito fina, cor rósea a castanho, com estratificação cruzada e espessuras que variam entre 2 a 20 metros, alternada com bancos de lamitos, siltitos e arenitos lamíticos, cor castanhoavermelhado a cinza-castanho, maciços ou com acamamento plano paralelo grosseiro, sendo freqüente a presença de marcas de onda e microestratificação cruzada.

$\mathrm{Na}$ área de estudo, a Formação Adamantina apresentase no vale do rio Batalha e seus principais afluentes, bem como nos vales do rio Bauru e Ribeirão Grande a leste da cidade de Bauru.

Conforme relatório do IPT (1991), foram identificadas dentro desta unidade, duas litofácies: uma mais basal, com arenitos grossos e amarelados, estratificação cruzada de pequeno a médio porte, clastos de argila na base, gradando para arenito argiloso e lamitos, representando ciclos de sedimentação fluvial meandrante, cuja espessura reconhecida foi da ordem de 1 a 2 metros; a outra litofácies, correspondente ao topo da Formação Adamantina, é constituída basicamente de arenitos argilosos avermelhados com manchas esbranquiçadas, granulação fina a média, com alguns níveis de seixos esparsos, dispostos em bancos homogêneos com espessura de até 2 metros, maciços ou intercalados, com lamitos e arenitos com nódulos carbonáticos esparsos. Foram descritos ainda nesta litofácies, arenitos friáveis amarelados com níveis conglomeráticos na base, caracterizando fácies de canal.

A Formação Adamantina pode jazer sobre a Formação Pirambóia, Botucatu ou serra Geral, através de discordância erosiva e possivelmente angular.

Formação Marília: esta Formação é definida como uma unidade composta por arenitos grosseiros a conglomeráticos, com grãos angulosos, teor de matriz variável, seleção pobre, ricos em feldspatos, minerais pesados e minerais instáveis. Ocorre em bancos com 
espessura média entre 1 a 2 metros, maciços ou com acamamento incipiente subparalelo e descontínuo; raramente apresenta estratificação cruzada de médio porte, com seixos concentrados nos estratos cruzados. Esta Formação pode apresentar ainda, camadas descontínuas de lamitos vermelhos e calcário.

$\mathrm{Na}$ área de estudo, a Formação Marília ocorre de forma generalizada pelas partes altas e nas cornizas do "planalto Bauru". Litologicamente é representada por arenitos pardacentos, creme ou róseos, de granulação fina a grossa, às vezes conglomeráticos, mal selecionados, grãos subangulosos, dispostos em bancos de 1 a 3 metros de espessura, cuja característica mais marcante é a presença de nódulos carbonáticos irregulares ora esparsos nos arenitos, ora concentrados em níveis por retrabalhamento. A unidade como um todo é essencialmente arenosa, com raros lamitos marrom-avermelhados, lentiformes de até 0,5 metro de espessura, onde, ainda, arenitos argilosos, são descritos. Podem ocorrer, de forma inexpressiva, seixos esparsos ou em níveis conglomeráticos, de 1 a $2 \mathrm{~cm}$ de diâmetro, constituídos por ágata, calcedônia e basalto, cuja origem provável seria a Formação Serra Geral.

A espessura da Formação Marília, atinge o máximo na cidade homônima a oeste de Bauru, com 160 metros, recoberta por sedimentos cenozóicos; faz contato com a Formação Adamantina, de modo discordante, através de sucessivas superfícies erosivas, ora com mudança brusca de litologia e conglomerado basal, ora com recorrência das litologias de uma unidade na outra, indicando interdigitamento (SOARES et al., 1980).

\subsection{1 - Tectônica e Estruturas}

De acordo com SOARES et al. (1979), após o evento magmático juro-cretácico, surgiram as ações tectônicas pós-basálticas, que iriam fornecer o embasamento para a deposição dos sedimentos do Grupo Bauru, no Cretáceo 
Superior. A sedimentação do Grupo Bauru se processou num estágio de compartimentação da bacia sedimentar do Paraná. O início da compartimentação é antecedido por uma série de reativações nos antigos elementos geotectônicos da bacia, como os altos internos, arcos centrais e marginais, que estabeleceram um padrão de evolução do relevo pré-Bauru. Durante a sedimentação do evento tectosedimentar Bauru, não existiu adição de novos elementos tectônicos, mas sim variação de intensidade dos maiores elementos apontados que, com as variações climáticas associadas à evolução da sedimentação, governaram praticamente todo o evento sedimentar Bauru, desde as suas formações inferiores, até 0 final da sua sedimentação, representado pelos sedimentos da Formação Marília.

Segundo SILVA \& CAVAGUTI (1992), os falhamentos pré-cambrianos estão reativados, preferencialmente nas direções nordeste e noroeste, formando mosaicos estruturados em "grabens" e "horsts". Na cidade de Bauru, estes efeitos se fizeram presentes como a ocorrência do levantamento do Alto de Piratininga, do qual a área estudada faz parte no seu flanco nordeste.

No fim do Cretáceo ou início do Terciário, iniciase novo ciclo erosivo na Bacia, culminando com 0 aplainamento Sul-Americano e posterior recorrência de novos ciclos erosivos cenozóicos (SOARES et al. 1980).

\section{5 - PEDOLOGIA}

Segundo o CNEPA.CS (1960), os arenitos do Grupo Bauru, aprentam dois tipos principais de agregação, que são as rochas com cimento calcário e as rochas sem o cimento calcário, normalmente argiloso.

Quando $\circ$ arenito apresenta cimento calcário, os solos são mais férteis com saturação de bases alta e são neutros a ligeiramente ácidos. Por outro lado, quando o cimento não é calcário, os solos são mais ácidos e saturação de bases baixa. 
Nas áreas onde ocorrem ou predominam os basaltos, o solo é constituído pela variedade terra roxa.

A nível local, de acordo com estudos realizados por IPT (1991) e SALOMÃO(1994), representados no mapa da Figura 2.3, a cobertura pedológica que envolve a área do rio Bauru e seus afluentes da região estudada é constituída, desde o topo da vertente até sua porção mais inferior, próximo ao fundo dos vales, por solos com características latossólicas. Uma análise detalhada destes solos, através de furos a trados feitos em toposeqüências, revelou um horizonte arenoso bifásico, com espessura máxima de $20 \mathrm{~cm}$, passando gradualmente para um solo-areno-pouco argiloso, vermelho e estrutura microagregada. Com o aumento da profundidade, torna-se um pouco mais argiloso, mantendo a coloração e a estrutura, até atingir profundidades de 10 a 15 metros, onde se diferencia gradualmente em material menos argiloso com indícios da rocha subjacente. Esta cobertura latossólica se mantém até aproximadamente $200 \mathrm{~m}$ a montante do fundo do vale, quando se observa uma passagem gradual para uma cobertura com características podzólicas.

Estes solos definidos como Podzólico Vermelho Amarelo, apresentam horizonte superior arenoso com espessura da ordem de 0,5 metro, de cor bruno com leitos centimétricos mais argilosos de coloração vermelha. Abaixo desta camada superficial arenosa, encontra-se um horizonte areno-argiloso a argilo-arenoso de coloração vermelho-amarelo com espessura máxima de 1,5 metro. Sotoposto a este horizonte, passa-se gradualmente para um horizonte areno pouco argiloso de coloração vermelhoescuro, com concreções ferruginosas arredondadas e milimétricas, com espessura aproximada à do horizonte superior.

o solo Podzólico Vermelho-Amarelo ocupa uma faixa contínua na base da vertente com pouco mais de 100 metros de largura e passa bruscamente a juzante, para solos hidromórficos, que se estendem em forma de várzeas junto às margens dos cursos d'água (IPT, 1991) 


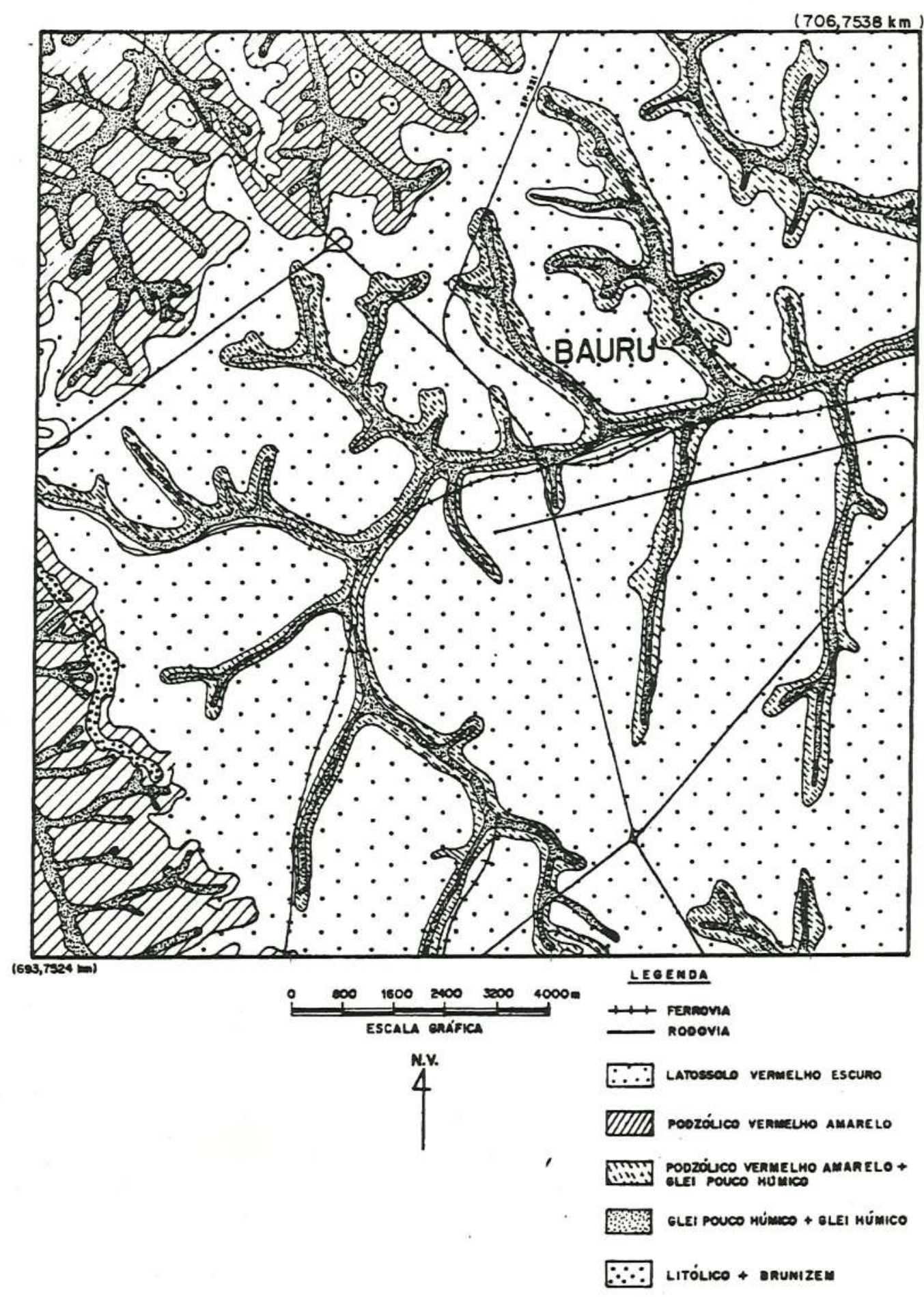

Figura 4.3 - Mapa pedológico da área de estudo. ( adaptado de IPT, 1991) 
Nas porções noroeste e sudoeste, fora da área urbana, ocorrem coberturas, ora com seqüências latossolopodzólico-hidromórfico, ora com seqüências podzólicohidromórfico.

No primeiro caso, o topo da colina é ligeiramente aplainado e no segundo o topo é muito estreito e com forma angulosa.

Nestes locais, a cobertura latossólica, quando presente, ocupa o topo ligeiramente aplainado da colina, e é constituída por um horizonte superior arenoso com espessura média de $20 \mathrm{~cm}$, com muita areia lavada e coloração bruna dominante. Logo abaixo, com passagem gradual, observa-se material areno-argiloso de cor vermelha. Esse material mostra-se pouco diferenciado em profundidade, contudo, nota-se a presença de horizontes com agregados poliédricos, pouco nítidos, em contato gradual com horizonte areno-argiloso com estrutura maciça.

Em direção ao vale, nota-se a presença dominante da cobertura podzólica, caracterizada por um horizonte superficial arenoso, com espessura média de 1,0 metro, coloração bruno escuro com presença de bandas onduladas mais argilosas e de cor vermelha. Logo abaixo deste horizonte, situa-se em contato abrupto, um horizonte argilo-arenoso a argiloso, cor vermelho amarelado, gleizado, estrutura poliédrica bem desenvolvida e com espessura da ordem de 1,5 a 3,0 metros. Subjacente a este horizonte, encontra-se outro nível mais arenoso de coloração vermelho-escuro, estrutura maciça, cujos teores de areia e constituintes residuais de rocha aumentam com a aproximação do substrato rochoso. Próximo à base da vertente, observa-se a passagem da cobertura podzólica para um solo hidromórfico, constituído por um horizonte superior arenoso, sobreposto a um horizonte argiloso gleizado, proveniente da alteração do substrato arenítico. 


\section{5. - REVISÃO DOS ESTUDOS GEOTÉCNICOS REALIZADOS NA ÁREA}

Vários trabalhos de natureza geológico-geotécnica foram realizados no sítio urbano do município de Bauru, com destaque para CAVAGUTI (1981), IPT (1991), FARAH et al. (1993), que analisaram áreas amplas envolvendo toda a cidade de Bauru e os trabalhos mais localizados de AlBIERO (1990), FERREIRA (1991), LOBO (1991) e AGNELLI (1992) voltados para fundações.

\section{1 - MAPEAMENTO GEOTÉCNICO}

De acordo com THOMAS, 1970 apud ZUQUETTE, 1987, O mapeamento geotécnico representa um processo que tem por finalidade básica levantar, avaliar e analisar os fatores que compõem $\circ$ meio físico, sejam geológicos, hidrogeológicos, hidrológicos e outros, que poderão ser associados e gerar interpretações para vários fins em áreas como: engenharia, planejamento, agronomia, saneamento e outros. As informações devem ser manipuladas através de processos de seleção, generalização, adição e transformação, para que possam ser selecionadas, correlacionadas, interpretadas e representadas em mapas, cartas e anexo descritivo.

As informações levantadas nos trabalhos geotécnicos, qualitativas ou quantitativas, poderão ser apresentadas das seguintes maneiras, conforme ZUQUETTE (op.cit.):

- Mapas das Condições Geotécnicas

- Mapas de Zoneamento Geotécnico Geral

- Mapas de Zoneamento Geotécnico Específico ou Carta de Aptidão. 
De acordo com a escala dos mapas, bem como os objetivos específicos a serem atingidos, os trabalhos de cartografia das propriedades geotécnicas constantes deste trabalho, devem ser enquadrados no tipo zoneamento Geotécnico Específico a nível de semi-detalhe (escala $1: 25.000$ a $1: 10.000)$.

\subsection{1 - Mapa de zoneamento geotécnico de Bauru}

Tendo por objetivo principal, o desenvolvimento de metodologias, que possibilitassem a interpretação dos processos erosivos em áreas urbanas e rurais e de assoreamento de cursos d'água, condicionados pela ocupação do solo, o Instituto de Pesquisas Tecnológicas do Estado de São Paulo - IPT, elaborou o relatório $n^{\circ}$ 29.789, com vista a ações preventivas e corretivas da erosão urbana de Bauru, publicados em IPT (1991), FARAH et al. (1993) e SALOMÃO (1994).

Com base em informações obtidas do reconhecimento das características do terreno, dos aspectos geológicogeotécnicos e dos problemas relacionados à ocupação do solo, foi elaborada a Carta de Aptidão Física do Solo para o Uso Urbano, tendo como fator restritivo principal a susceptibilidade do solo à erosão (Figura 5.1).

Para o desenvolvimento desta carta, foram efetuados diagnósticos das erosões por ravinas e boçorocas, levantamento e tratamento de dados básicos relativos ao meio físico, e por fim, o aspecto de maior importância para a elaboração da Carta de Aptidão, que se constitui na interpretação da susceptibilidade à erosão.

De acordo com os autores, 0 procedimento metodológico utilizado baseou-se na análise integrada da paisagem, ponderando-se o comportamento das águas com relação ao substrato geológico, relevo e cobertura pedológica. A influência do substrato geológico está relacionada ao desenvolvimento pedogenético e ao comportamento das águas subsuperficiais, no tocante ao gradiente hidráulico e no poder de arrasto de partículas. 


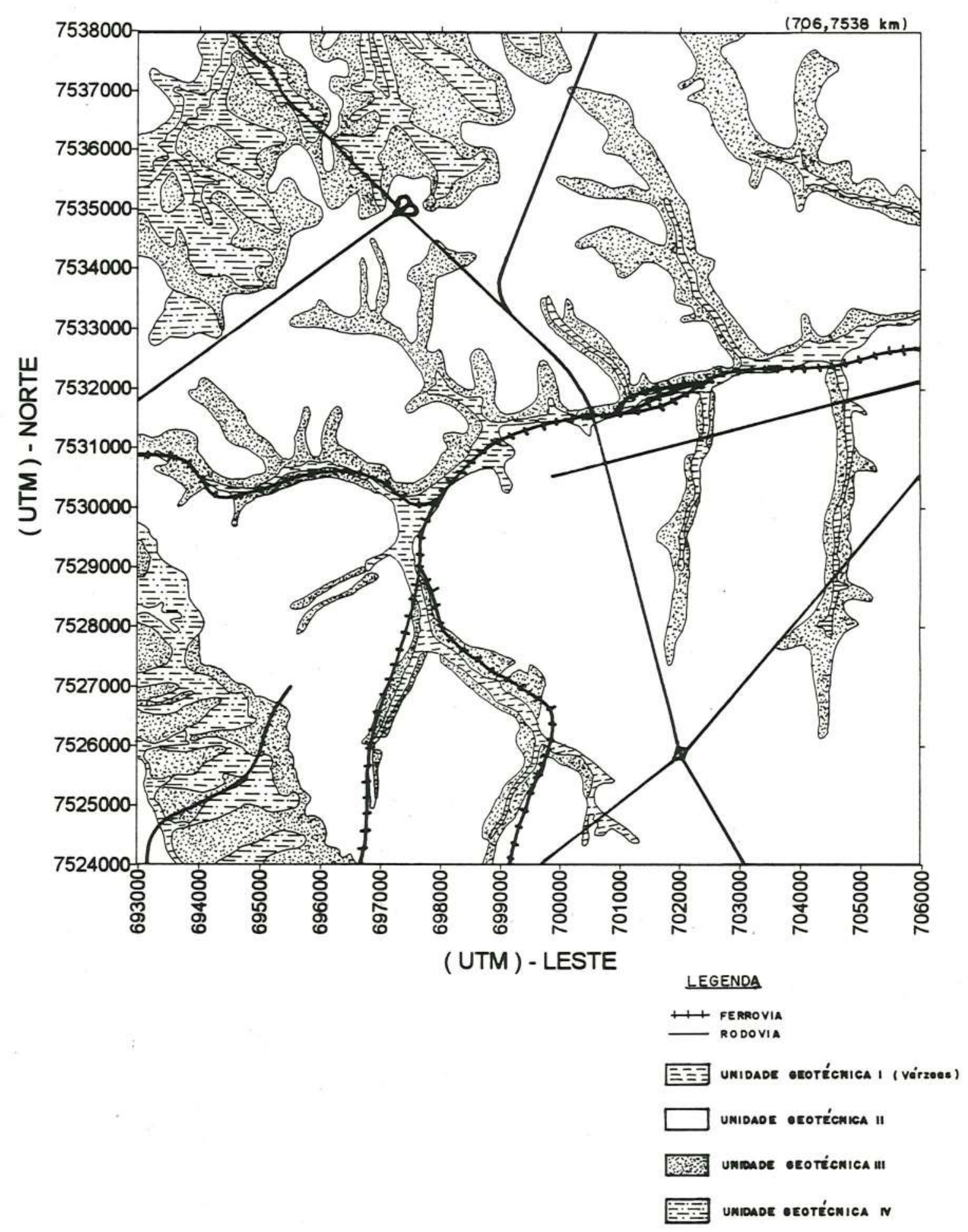

Figura 5.1 - Mapa geotécnico da área de estudo (adaptado de IPT, 1991) 
Com relação ao relevo, foram consideradas as características da forma, comprimento e declividade das vertentes e também das características dos interflúvios. Quanto às características pedológicas, destacam-se a influência da textura dos solos, espessura, estrutura e gradiência textural entre os horizontes.

A área estudada foi compartimentada em 5 unidades geotécnicas homogêneas, cuja disposição espacial servirá como base para uma análise conjunta com os estudos geoestatísticos de dados de sondagens, realizados neste trabalho.

Unidade geotécnica I: corresponde às áreas de várzea que ocorrem junto aos fundos de vale dos principais cursos d'água. São áreas constituídas em geral por rochas areníticas pertencentes à Formação Adamantina e parcialmente por arenitos da Formação Marília, sobrepostas por solos hidromórficos, que, em muitos casos, encontram-se descaracterizados por "depósitos tecnogênicos arenosos", em geral com alguns metros de espessura provenientes de processos de erosão e assoreamento (OLIVEIRA et al., 1990, apud IPT, 1991).

Os solos hidromórficos apresentam uma camada superficial (horizonte A) areno-argilosa ou argiloarenosa, com muita matéria orgânica, total ou parcialmente decomposta, com espessuras variadas, desde algumas dezenas de centímetros até alguns metros e camadas subsuperficiais (horizonte $C$ ), normalmente compostos por uma argila siltosa com diferentes proporções de areia.

são áreas em permanente estado de saturação, com ocorrência de terrenos alagadiços onde o nível d'água encontra-se próximo à superfície ou aflorante.

Dado às características descritas, é provável a presença de solos de consistência mole, com baixa capacidade de carga e de suporte, sendo previsíveis recalques em edificações e em obras de infra-estrutura como arruamentos, canalizações, tubulações e outras. São áreas sujeitas a enchentes $e$, por conseguinte, à 
contaminação de esgotos domésticos e poluentes industriais.

Unidade geotécnica II: esta unidade representa mais da metade da área estudada e corresponde aos topos e a grande parte das vertentes de colinas amplas a colinas médias, com declives normalmente inferiores a $12 \%$. Apresenta substrato rochoso constituído tanto por rochas da Formação Marília, como da Formação Adamantina, onde desenvolveram os solos do tipo Latossolo Vermelho Escuro de textura média. Estes solos são bem desenvolvidos, apresentando horizontes A e B (solo superficial) da ordem de 10 metros, que passa gradualmente para horizonte $C$ (solo de alteração), cuja espessura pode atingir 10 metros. Ensaios geofísicos de sísmica de refração realizados nesta unidade, detectaram uma espessura do manto de alteração da ordem de 16 a 24 metros de espessura.

Os horizontes A e B são constituídos basicamente por areia de fina a média, com teores variando de 75 a 85\% com argila tipo caulinita; e os teores de silte situam-se na faixa de $3 \%$. O horizonte $C$ apresenta variação textural e mineralógica muito gradual em profundidade, passando de um material com características muito semelhantes ao horizonte $B$, para um material com características residuais do substrato rochoso; sendo essencialmente arenoso, com níveis centimétricos argilosiltosos, enquanto, próximo ao contato com a rocha, observa-se passagem para um material argilo-siltoso com freqüentes níveis centimétricos de concreções milimétricas e placas ferruginosas. Ensaios granulométricos efetuados na área, nas bases sísmicas 2, 3, 4 e 5, a uma profundidade de 2 metros, e todos pertencentes a esta unidade geotécnica, caracterizaram uma areia fina silto-argilosa.

FERREIRA (1991) e LOBO (1991) encontraram curvas granulométricas similares, cujos teores das frações se mantiveram com razoável uniformidade com a profundidade. 
A Figura 5.2 mostra parte do perfil do solo desta unidade geotécnica, em uma boçoroca causada por fenômenos de "piping", resultantes da interceptação do lençol freático por águas superficiais concentradas pelo arruamento de loteamentos periféricos.

Este solo apresenta-se muito permeável, com exceção dos níveis centimétricos argilo-siltosos que ocorrem no horizonte $\mathrm{C}$, que apresentam permeabilidades muito inferiores com possibilidades de formação do lençol suspenso e da camada argilo-siltosa inferior do horizonte C, em contato com a rocha.

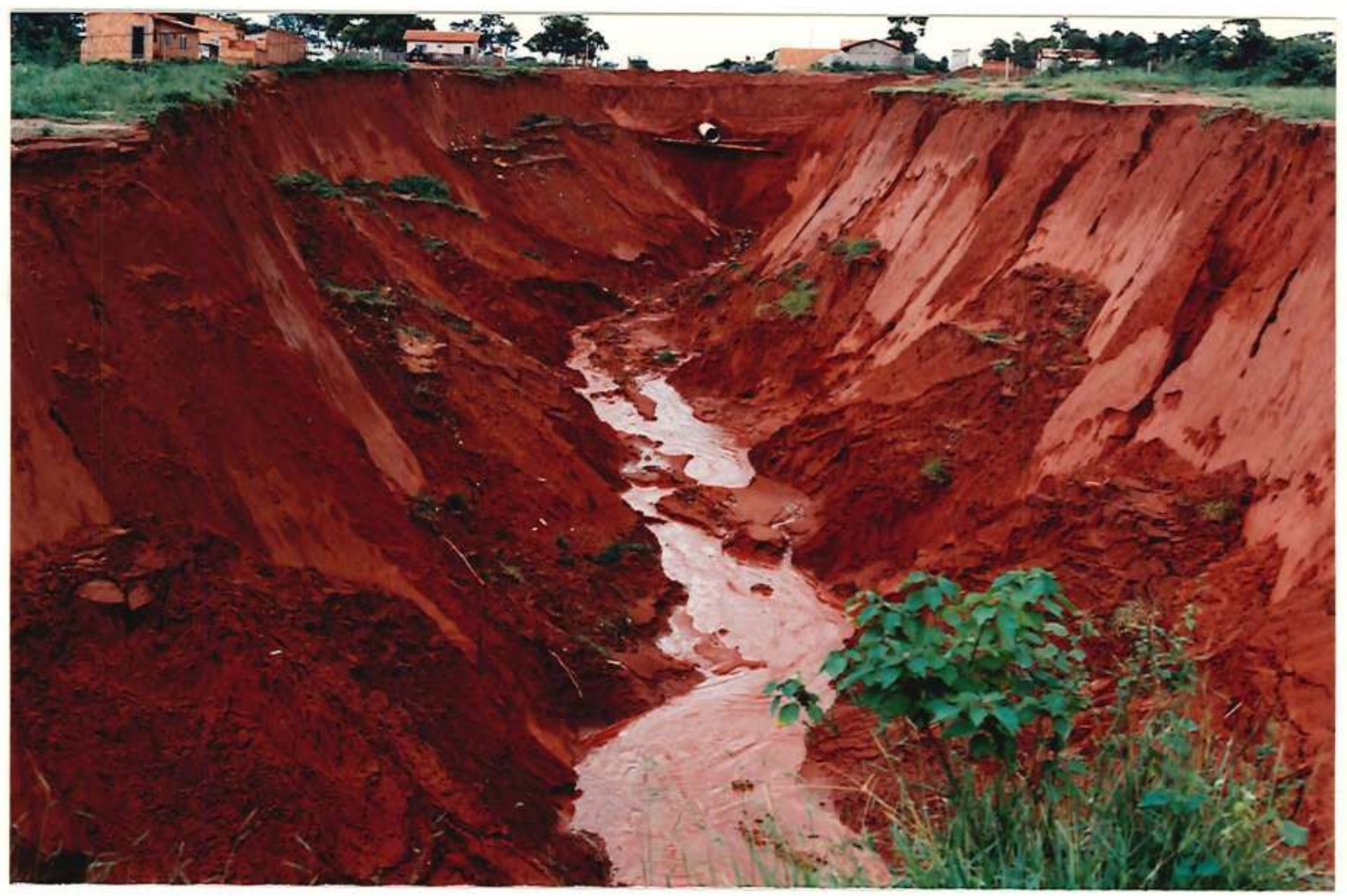

Figura 5.2 - Boçoroca causada por fenômenos de "piping".

De acordo com FERREIRA (1991), com base em ensaios de permeabilidade efetuados em laboratório de solos correspondentes a esta unidade geotécnica, o coeficiente de permeabilidade decresce com a profundidade, situandose na faixa de $0,1 \times 10^{-5}$ a $7,5 \times 10^{-5} \mathrm{~cm} / \mathrm{s}$, com valor médio de $1,2 \times 10^{-5} \mathrm{~cm} / \mathrm{s}$. 
Com relação à compacidade, IPT (1991) concluiu que a cobertura pedológica formadora desta unidade geotécnica é baixa, enquanto a coesão apresenta pequenas variações com a profundidade. Os materiais constituintes dos horizontes A e B apresentam baixa coesão, mas com forte agregação entre as partículas de argila e areia, o que fornece uma certa resistência a estes materiais, quando expostos nos taludes de cortes e em paredes de escavação.

Os materiais do horizonte $\mathrm{C}$, apresentam estrutura maciça, consistência muito baixa e coesão praticamente nula. Com essas características geotécnicas, pode-se prever fácil escavação dos materiais, boa resistência ao desmoronamento e à erosão de taludes dos materiais relativos aos horizontes $\mathrm{A}$ e $\mathrm{B}$, e baixa resistência dos materiais do horizonte $C$. Pode-se prever ainda, uma capacidade de suporte muito boa dos materiais, com exceção da parte inferior do horizonte $C$, próximo ao contato com o substrato rochoso, que apresenta baixa capacidade de suporte, com possibilidades de recalque quando submetida a esforços por pressão.

A avaliação quanto à capacidade de suportes, principalmente da camada superficial desta unidade, será melhor analisada nos capítulos posteriores, quando serão elaborados os mapas dos índices de resistência à penetração através da geoestatística.

Unidade geotécnica III: esta unidade está associada principalmente às vertentes de colinas médias e de morretes alongados com declividades predominantes de 6 a $20 \%$ e junto aos fundos dos vales de colinas amplas. 0 substrato rochoso é constituído por arenitos carbonáticos da Formação Marília e de zonas de transição para a Formação Adamantina.

Os solos são do tipo podzólico vermelho-amarelo, de textura arenosa média e com espessura média de 10 metros. O horizonte A é essencialmente arenoso com presença de níveis centimétricos de material argilo-arenoso com espessuras que podem atingir pouco mais de 1,0 metro. Logo abaixo deste horizonte, passa-se de forma abrupta 
para um horizonte B textural de composição argilosa ou argilo-arenosa, com espessuras variáveis de poucos centímetros até alguns metros. Em seguida, passa-se gradualmente em profundidade para um horizonte $B$ latossólico de composição areno-argilosa, com espessura que pode atingir até alguns metros. Abaixo, em contato gradual, encontra-se 0 horizonte $C$, de composição arenosa, textura média com níveis argilo-siltoso.

Em termos de distribuição granulométrica, o horizonte $\mathrm{A}$ apresenta teores médios de areia superiores a $80 \%$, enquanto que 0 horizonte $B$ textural apresenta em média 70\% de areia, 20\% de argila tipo caulinítica e 10\% de silto.

A permeabilidade destes solos é extremamente variável devido à textura dos diferentes horizontes. No horizonte $A$ os materiais são muito permeáveis, com exceção dos níveis argilosos, intercalados na camada de areia. A permeabilidade muda bruscamente com a passagem para o horizonte B textural que émenos permeável, o que favorece a concentração de águas de infiltração. Com relação aos horizontes B latossólico e C, pode-se dizer que apresentam comportamento de permeabilidade moderada.

A compacidade dos materiais que compõem os horizontes A, B latossólico e C, pode ser admitida como relativamente baixa, enquanto no horizonte $B$ textural, em estado natural, é de moderada a alta.

A coesão e a consistência dos horizontes A e C são admitidas como muito baixas e relativamente mais elevadas para o horizonte $B$ textural, enquanto 0 horizonte $B$ latossólico apresenta baixa coesão, possuindo entretanto relativa resistência à desagregação quando em estado natural, dado à sua estruturação em microagregados. A capacidade de suporte dos materiais é inferida como muito boa, com exceção em parte do horizonte C, próximo ao contato com a rocha sã, onde se encontram camadas de material argilo-siltoso com baixa capacidade de suporte.

Unidade geotécnica IV: constitui os contornos de cabeceiras das drenagens e de fundo de vales, formada por 
solos podzólicos vermelho amarelo de textura arenosa média com solos gleisados.

As áreas pertencentes a esta unidade apresentam constantes afloramentos do lençol freático com surgências e nascentes de drenagem, bem como concentrações de fluxos d'água subterrânea com elevados gradientes hidráulicos. Desta forma, a possibilidade de desenvolvimento de fenômenos de "piping" associados à formação de boçorocas.

\section{2 - COLAPSIVIDADE DOS SOLOS DE BAURU}

\subsection{1 - Aspectos teóricos do mecanismo de colapso}

Vários parâmetros da mecânica dos solos são avaliados em corpos de prova ou de ensaios a um nível macroscópico entretanto, a fração argilosa age no solo de forma similar a colóides. Isto significa que muitas propriedades dos solos se processam a um nivel microscópico ou coloidal. Os colóides consistem em materiais que são dominados pelas forças de superfície de atração e repulsão, ao invés de forças que agem em um volume como um todo. De forma análoga, as partículas de argila possuem uma rede superficial de cargas negativas que variam de acordo com o tipo de argilo-mineral. As superfícies das partículas de argila atraem dipolos de água e cátions que formam uma camada dupla difusa que é primariamente controlada pela concentração e tipo do cátion (ANDERSON, 1968).

As relações das partículas de argila no espaço são controladas por forças eletrostáticas de atração e repulsão. Quando as forças de repulsão dominam, as partículas de argila tendem a procurar orientações que maximizam a separação das partículas. Por outro lado, quando as forças de atração dominam, as partículas de argila tendem a constituir flóculos, formando um estado floculado.

Outro fator importante de união dos grãos de solos no estado insaturado são as forças de capilaridade. 
Devido à curvatura da interfaces água-ar existentes entre os grãos dos solos insaturados, são geradas tensões nos poros, que tendem a segurar juntos os grãos.

De outra forma, quando o solo é saturado, estas tensões são eliminadas, o que pode alterar completamente a estrutura do solo.

Em resumo, as pontes de argilas, agindo conjuntamente com as forças capilares e mais agentes cimentantes, caso presentes, formam uma espécie de cola que mantém o solo estável.

o colapso, propriamente dito, ocorre quando as tensões cisalhantes entre os grãos excede à resistência ao cisalhamento das pontes de argila num determinado teor de umidade. Nesta situação, os grãos rolam ou transladam entre si e assumem um novo estado de equilíbrio sob as novas pressões com redução da porosidade. Assim, com um maior número de contatos entre os grãos, aumenta-se a resistência ao cisalhamento do solo com redução das tensões cisalhantes transmitida entre os grãos.

\subsection{2 - Avaliação da colapsividade do solo de Bauru}

LOBO (1991) e AGNELLI (1992) estudaram o potencial de colapsividade do solo, em determinados locais de Bauru, com base em duas formas de análise, assim classificadas:

a) Critérios baseados em Índices Físicos e Limites de Atterberg: consistem em formulações empiricas ou semiempíricas, que avaliam a potencialidade de colapso do solo através de ensaios de simples execução em laboratório. Estes critérios não possibilitam quantificar os recalques que eventualmente venham a ocorrer.

b) Critérios baseados em Ensaios Oedométricos: possibilitam uma avaliação quantitativa da colapsividade do solo. Dado à analogia que se pode fazer entre as deformações que ocorem durante o ensaio, com as que podem 
ocorrer no campo, estes critérios são largamente empregados.

De acordo com os autores acima citados, e segundo os vários critérios por eles empregados, os solos de Bauru, nos diversos locais ensaiados, são do tipo colapsível.

\section{3 - CAPACIDADE DE CARGA E RECALQUES}

LOBO (1991) e AGNELLI (1992), desenvolveram estudos, em determinados locais de Bauru, sobre a capacidade de carga e recalques para fundações diretas ou com uso de estacas de pequeno porte.

A Tabela 5.1 apresenta os valores calculados das pressões de ruptura e admissíveis para fundações diretas, obtidas mediante as provas de carga e também com o método semi-empírico de Terzaghi;

TABELA 5.1 - PRESSÕES DE RUPTURA E ADMISSÍVEIS ( $\mathrm{kPa}$ )

\begin{tabular}{|c|c|c|c|c|c|c|c|c|c|}
\hline \multirow[t]{3}{*}{ PROF. } & \multirow{2}{*}{\multicolumn{3}{|c|}{$\begin{array}{l}\text { RESULTADOS DAS } \\
\text { PROVAS DE CARGA } \\
\text { (placa, D }=0,80 \mathrm{~m} \text { ) }\end{array}$}} & \multicolumn{6}{|c|}{$\begin{array}{l}\text { RESULTADOS COM BASE NA FÓRMULA } \\
\text { DE TERZAGHI }\end{array}$} \\
\hline & & & & \multirow{2}{*}{\multicolumn{2}{|c|}{$\begin{array}{c}\text { sapata quadrada } \\
(B=0,70 \mathrm{~m})\end{array}$}} & \multirow{2}{*}{\multicolumn{2}{|c|}{$\begin{array}{l}\text { sapata contínua } \\
(B=0,70 \mathrm{~m})\end{array}$}} & \multirow{2}{*}{\multicolumn{2}{|c|}{$\begin{array}{l}\text { sapata circular } \\
(D=0,80 \mathrm{~m})\end{array}$}} \\
\hline & & & & & & & & & \\
\hline (m) & $\sigma 25 \mathrm{~N}$ & $\sigma \mathrm{rN}$ & $\sigma$ ad & $\mathrm{qu}$ & $\sigma$ ad & qu & $\sigma$ ad & $\mathrm{qu}$ & $\sigma \mathrm{ad}$ \\
\hline 1,00 & $\begin{array}{l}99 \\
\end{array}$ & 132 & 66 & 217 & 72 & 205 & 68 & 213 & 71 \\
\hline 2,00 & 124 & 164 & 82 & 331 & 110 & 319 & 106 & 327 & 109 \\
\hline
\end{tabular}

(Fonte: AGNELLI, 1992)

onde:

D = diâmetro da placa; diâmetro da sapata circular.

$\mathrm{B}=$ lado da sapata quadrada; menor dimensão da sapata contínua.

$\sigma 25 \mathrm{~N}=$ pressão correspondente à deformação de $25 \mathrm{~mm}$, quando o solo é submetido ao carregamento no estado natural.

$\sigma r N=$ pressão de ruptura média ( calculada com base nos valores obtidos através dos métodos de Van der Veen, Mazurkiewicz e Chin).

бad $=$ pressão admissível. 
qu = pressão de ruptura determinada com base na fórmula de Terzaghi.

Para o cálculo da pressão admissível, adotou-se um fator de segurança igual a dois (2) para os resultados obtidos através das provas de carga e um fator de segurança igual a três (3) para os resultados obtidos pela fórmula semi-empírica de Terzaghi.

A Tabela 5.2 apresenta os valores de carga última ou de ruptura para estacas escavadas e apiloadas. Os resultados são decorrentes de provas de cargas em estacas e do método semi-empírico de previsão de carga última de Decourt e Quaresma. Calculou-se também o coeficiente de correção $\left(\mathrm{C}_{\mathrm{DQ}}\right)$, que consiste na razão das cargas últimas, avaliada pelos dois métodos.

TABELA 5.2 - CARGA ÚLTIMA PREVISTA POR DECOURT-QUARESMA, E COEFICIENTES DE CORREÇÃO (kPa)

\begin{tabular}{|c|c|c|c|c|c|c|c|c|c|c|c|}
\hline \multirow{2}{*}{$\begin{array}{c}\mathrm{L} \\
(\mathrm{m})\end{array}$} & \multirow{2}{*}{$\begin{array}{c}\mathrm{D} \\
(\mathrm{m})\end{array}$} & \multicolumn{5}{|c|}{ ESCAVADAS } & \multicolumn{5}{|c|}{ APILOADAS } \\
\hline & & $\begin{array}{c}\mathrm{Pu} \\
\text { (VDV) }\end{array}$ & Plu & $\mathrm{Ppu}$ & $\mathrm{Pu}$ & $\mathrm{C}_{\mathrm{DQ}}$ & $\begin{array}{c}\mathrm{Pu} \\
(\mathrm{VDV})\end{array}$ & Plu & $\mathrm{Ppu}$ & $\mathrm{Pu}$ & $\mathrm{C}_{\mathrm{DQ}}$ \\
\hline 2 & 0,25 & & & & & & 192 & 32 & 65 & 97 & 1,97 \\
\hline 4 & 0,25 & 172 & 52 & 42 & 94 & 1,83 & 289 & 74 & 80 & 154 & 1,88 \\
\hline 6 & 0,25 & 175 & 82 & 52 & 134 & 1,31 & 585 & 118 & 99 & 217 & 2,70 \\
\hline 8 & 0,25 & 151 & 101 & 58 & 159 & 0,95 & 332 & 144 & 112 & 256 & 1.30 \\
\hline 12 & 0,30 & 322 & 182 & 110 & 292 & 1,10 & 592 & 256 & 210 & 466 & 1,27 \\
\hline 12 & 0,35 & 398 & 231 & 127 & 358 & 1,11 & 855 & 330 & 243 & 573 & 1,49 \\
\hline & & & & $\overline{\mathrm{C}} \mathrm{DQ}$ & $=$ & 1,26 & & & $\overline{\mathrm{C}} \mathrm{DQ}$ & $=$ & 1,77 \\
\hline
\end{tabular}

( Fonte: LOBO, 1991)

Alguns métodos de previsão de carga última utilizam valores do ensaio de penetração contínua (qc), que muitas vezes não existem ou não foi possível a sua realização. Nestas situações faz-se uso das correlações entre os valores de resistência do ensaio de penetração contínua (qc) com os valores de $\mathrm{N}$ do ensaio de penetração padronizada.

ALBIERO (1990), utilizando-se da técnica de regressão linear múltipla, obteve as seguintes expressões, para o solo de Bauru: 
(qc) com os valores de $\mathrm{N}$ do ensaio de penetração padronizada.

ALBIERO

regressão linear múltipla, obteve as seguintes expressões, para o solo de Bauru:

$\mathrm{qC}=-841 \mathrm{kPa}+881 \mathrm{kPa} / \mathrm{golpe} \times \mathrm{N}-82 \mathrm{kPa} / \mathrm{m} \times \mathrm{Z} \quad \mathrm{r}=0,839$

$f_{C}=35,45 \mathrm{kPa}+0.019 \times 9 \mathrm{c} \quad r=0,416$

onde:

$$
\begin{aligned}
\mathrm{qc}= & \text { resistência à penetração contínua do cone } \\
& (\text { ensaio com o cone de penetração) } \\
\mathrm{N}= & \text { índice de resistência à penetração do } \\
& \text { amostrador padrão (SPT) } \\
\mathrm{Z}= & \text { profundidade } \\
\mathrm{fC}= & \text { resistência lateral obtida no ensaio de } \\
& \text { penetração contínua. }
\end{aligned}
$$

Com relação aos recalques, AGNELLI (1992) calculou valores de recalques para o solo local, nas profundidades de 1,00 e 2,00 metros, através de ensaios de provas de carga executados em terreno natural e também com base nos métodos empíricos. Os resultados obtidos para uma pressão de $100 \mathrm{kPa} x$ largura (B) da fundação igual a $0,80 \mathrm{~m}$, encontram-se na Tabela 5.3.

TABELA 5.3 - RECALQUES (mm) PARA UMA PRESSÃO DE $100 \mathrm{kPa}$

\begin{tabular}{||c|c|c|c|l|c||}
\hline $\begin{array}{l}\text { PROF. } \\
(\mathrm{m})\end{array}$ & $\begin{array}{l}\text { TERZAGHI } \\
\& \text { PECK } \\
(1948)\end{array}$ & $\begin{array}{l}\text { BAZARAA } \\
(1967)\end{array}$ & $\begin{array}{l}\text { MEYERHOF } \\
(1976)\end{array}$ & $\begin{array}{l}\text { VALOR } \\
\text { MÉDIO DOS } \\
\text { MÉTODOS } \\
\text { EMPÍRICOS }\end{array}$ & $\begin{array}{l}\text { PROVA DE } \\
\text { CARGA }\end{array}$ \\
\hline 1,00 & 9,5 & 20,3 & 41,1 & 23,6 & 25,5 \\
\hline 2,00 & 8,1 & 19,0 & 27,4 & 18,2 & 16,5 \\
\hline
\end{tabular}

(Fonte: AGNELLI, 1992). 


\section{6. - APRESENTAÇÃO E DISCUSSÃO DOS RESULTADOS}

O mapa da Figura 6.1 apresenta a localização das 175 obras, de onde foram extraidos os perfis médios das sondagens assim como, a localização das 5 seções sísmicas realizadas na área. o polígono interno do mapa representa - centro urbano da cidade de Bauru, onde se concentraram os estudos relacionados aos Índices de Resistência à Penetração.

\section{1 - ESTUDOS GEOFÍSICOS - SÍSMICA DE REFRAÇÃO}

Como já descrito, a técnica da refração sísmica é baseada na propagação de ondas no subsolo, o que permite caracterizar o perfil de alteração em termos de estratos sísmicos.

Os sismogramas, gerados por cada tiro dos ensaios, foram armazenados em registros do sismógrafo e transferidos em seguida para disquetes de microcomputadores, onde os resultados podem ser analisados. O Apêndice II apresenta os sismogramas dos 25 tiros efetuados para as 5 seções sísmicas.

Após terem sido coletados os tempos de chegada das ondas refratadas, para cada geofone, são elaborados os gráficos "tempo x distância", que possibilitam o cálculo das espessuras dos estratos sísmicos. Estes gráficos representam parte dos produtos gerados pelo programa "SISREFRA", recentemente desenvolvido por MALAGUTTI FILHO \& LOPES (1994). Os gráficos para as 5 seções encontram-se no Apêndice III.

Os resultados da interpretação final das seções sísmicas, encontram-se nas figuras $6.2,6.3,6.4,6.5$ e 6.6. 


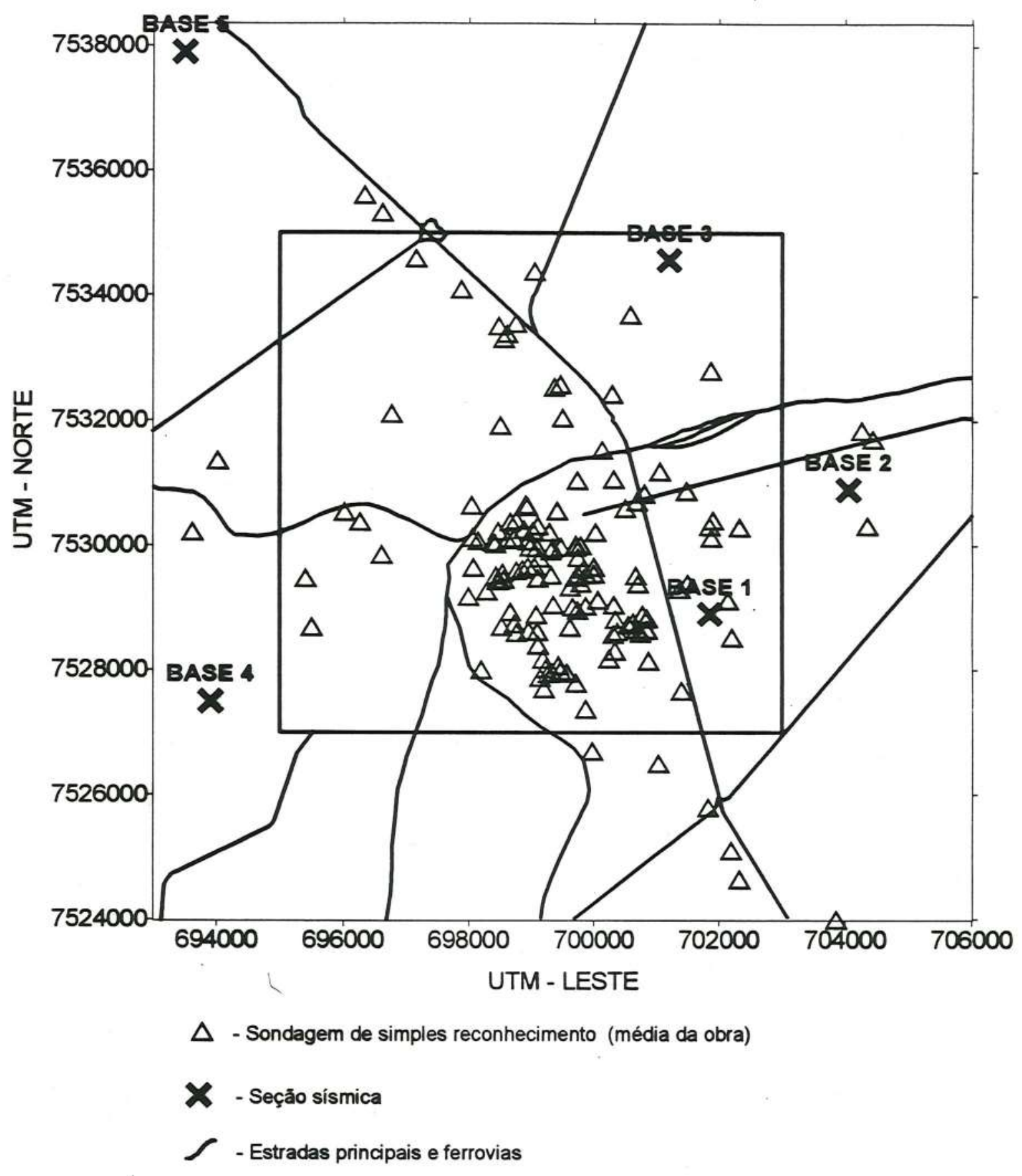

Figura 6.1 - Mapa de localização dos perfis médios das sondagens e das seções sísmicas. 
A seção da Figura 6.2 apresenta 4 estratos sísmicos, representando os dois primeiros estratos um solo mais desenvovido, constituído por uma areia fina argilosa, com baixa compacidade. O aumento de velocidade das ondas refratadas para o segundo estrato deve-se a um aumento significativo da umidade do solo, a partir da profundidade de dois metros, verificada em furos feitos a trado, no local. O terceiro estrato é atribuído a um solo pouco desenvolvido, cuja correlação com sondagens de simples reconhecimento, efetuadas nas proximidades, corresponde a uma areia fina, silto-argilosa, medianamente compacta, interpretada como solo de alteração da rocha. o quarto e último estrato, com velocidade de onda igual a $2,4 \mathrm{~km} / \mathrm{s}$, constitui-se na própria rocha sã, representado no local pelos arenitos da Eormação Marília.

A seção da Figura 6.3 apresenta 3 estratos sísmicos. Os dois primeiros estratos representam praticamente o mesmo solo, ou seja, um solo bem desenvolvido, constituído por uma areia fina argilosa, de muito fofa a fofa, com variação de velocidades de ondas refratadas, entre 0,33 e $0.47 \mathrm{~km} / \mathrm{s}$.

Embora a interpretação desta seção não apresente uma camada de transição solo-rocha, a mesma pode ocorrer, tendo em vista uma limitação da técnica da refração sísmica em detectar determinadas camadas; isto é, em função de uma determinada relação entre espessuras e velocidades, a energia refratada proveniente desta camada, chega à superfície alguns milessegundos após a chegada das ondas refratadas num meio superior, de maior velocidade (MALAGUTTI FILHO, 1992).

Assim, pode-se inferir, com base nos conhecimentos pedólogicos da região, a existência de uma camada relativamente delgada de solo de alteração (cerca de 1 a 2 metros), não detectada pelo ensaio sísmico. 0 último estrato sísmico, com velocidade de onda igual a 2,3 km/s, representa a rocha sã da Formação Marília.

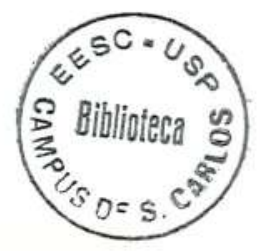




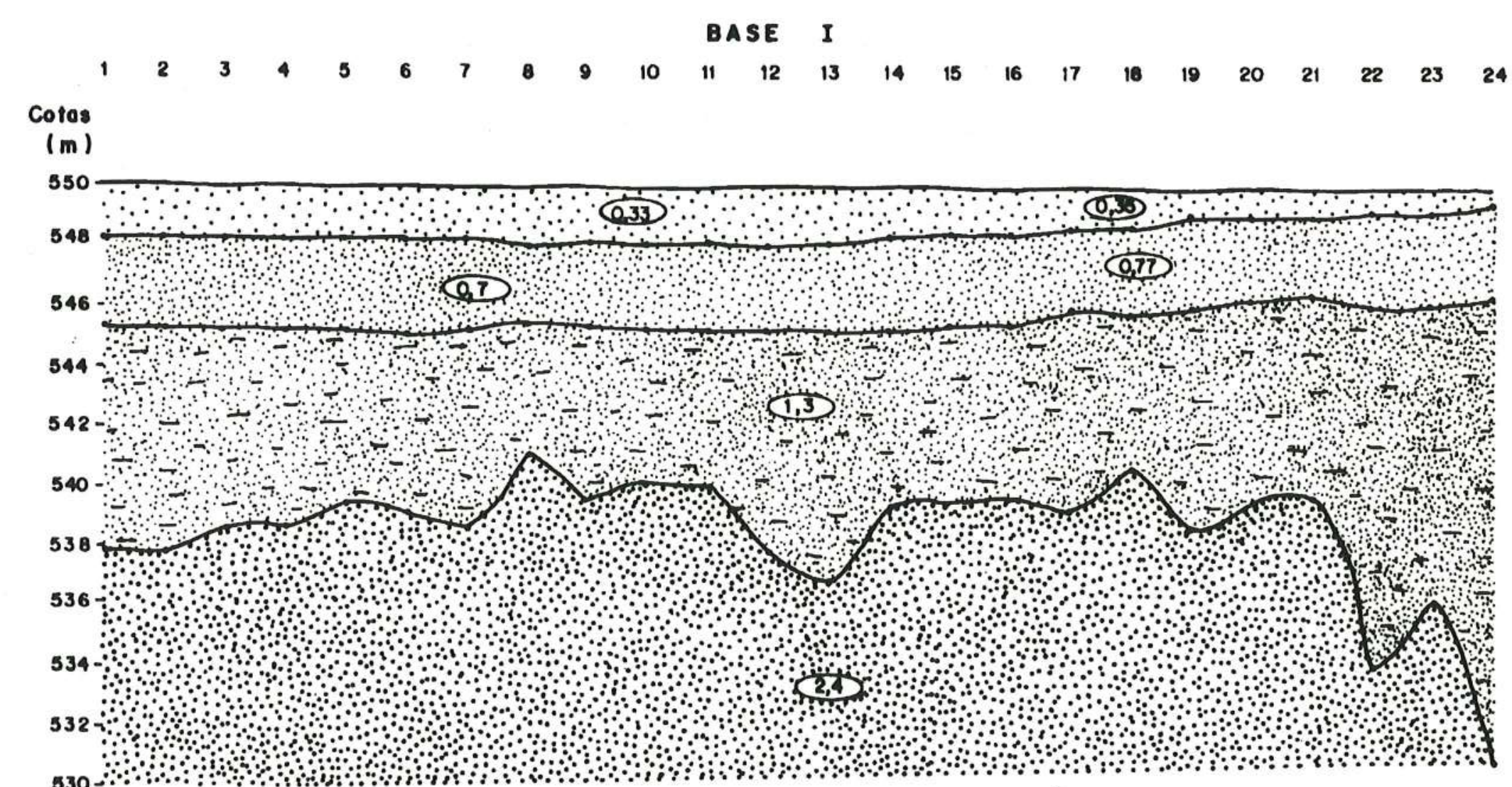

Figura 6.2- Seção sísmica da base 1 . 
BASE II
1
23
4
6
8
10
11
$13 \quad 14$
$15 \quad 16$
$17 \quad 18$
$19 \quad 20$
21
$22 \quad 23$

\section{Cotes}

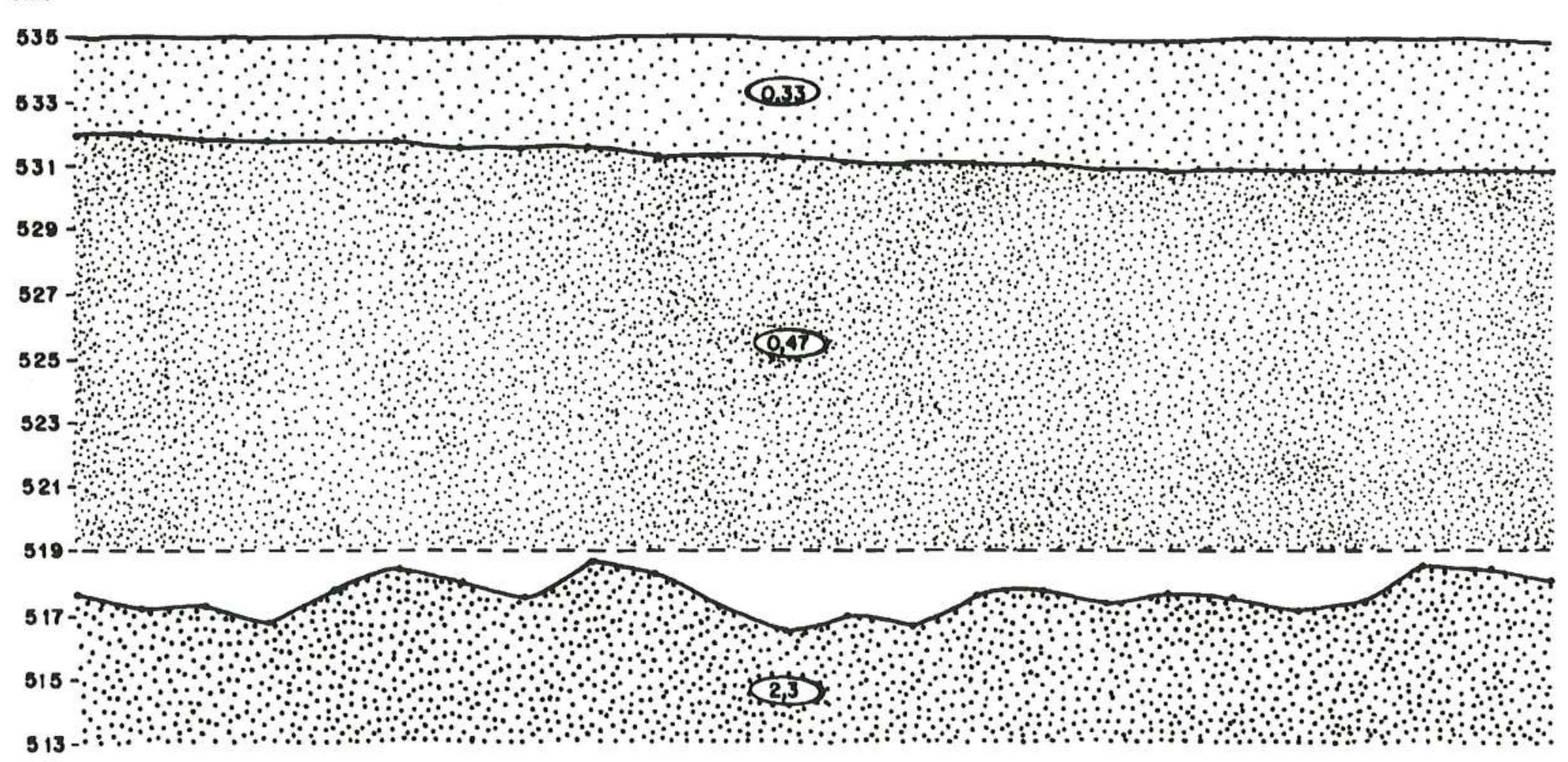

Figura 6.3 - Seção sísmica da base 2 . 
A seção da Figura 6.4 apresenta-se de forma similar à seção da Figura 6.3. Assim, neste local, também foram detectados 3 estratos sísmicos, sendo que os dois primeiros são solos arenosos, bem desenvolvidos e de baixa compacidade. A partir dos 5 metros de profundidade, ocorre um pequeno aumento de velocidade das ondas sísmicas, com provável aumento relativo da compacidade do solo.

Neste perfil, também é inferida uma "camada escondida", de pouca espessura, que representa a transição solo-rocha. O último estrato com velocidade de onda igual a $2,3 \mathrm{~km} / \mathrm{s}$, representa a rocha sã da Formação Marília.

Próximo ao local deste ensaio, encontram-se várias boçorocas em processo acelerado de erosão.

Nota-se que, nos locais onde o ensaio sísmico não detecta a presença da camada de transição solo-rocha, parece haver um maior desenvolvimento de vossorocas.

A seção da Figura 6.5 foi executada em uma área topograficamente alta e apresenta o perfil completo, admitido para área. A seção apresenta quatro estratos sísmicos, sendo o primeiro estrato mais superficial com espessura de 3 a 4 metros, um solo bem desenvolvido com baixa compacidade. O segundo estrato apresenta velocidade de $0.55 \mathrm{~km} / \mathrm{s}$, que denota um solo bem desenvolvido, de compacidade média com provável aumento do teor de argila. Este estrato é bastante espesso, atingindo espessuras de 15 metros. Sotoposto a este estrato, encontra-se o horizonte do solo de transição com a rocha, que apresenta espessura irregular, com valores situados entre 2 a 12 metros. Por último, encontra-se o substrato rochoso da Formação Marília, com uma superfície bem irregular e velocidade de propagação de onda igual a $2,4 \mathrm{~km} / \mathrm{s}$. 


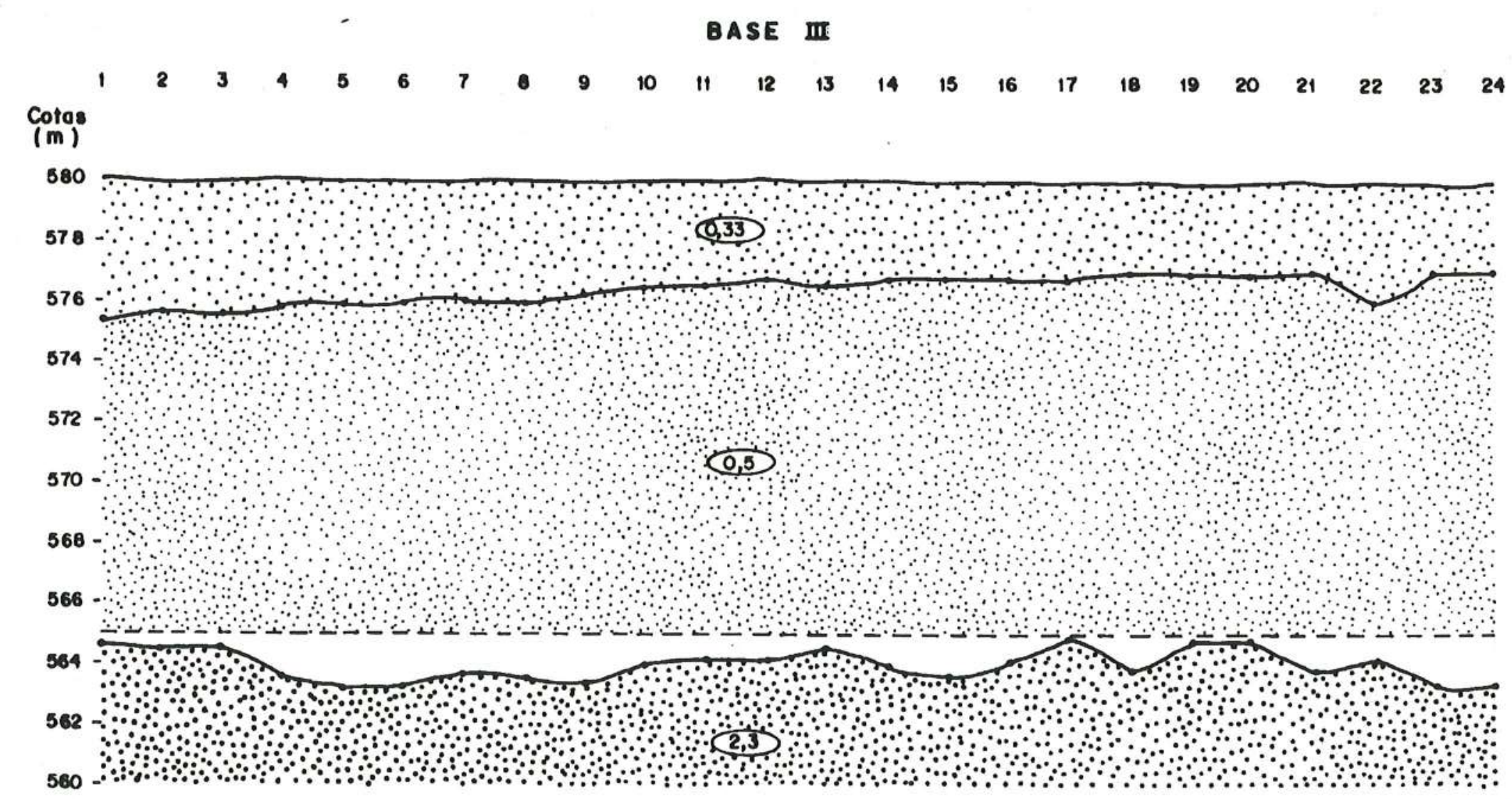

Figura 6.4 - Seção sísmica da base 3 . 
BASE W

\section{Cotes}

(mos

583

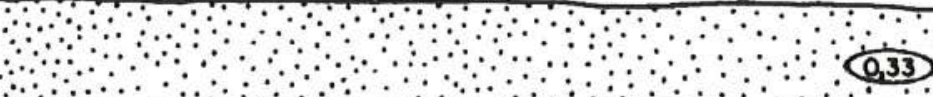

58

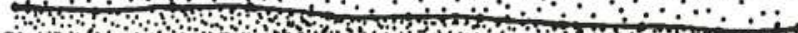

57

577

575

575

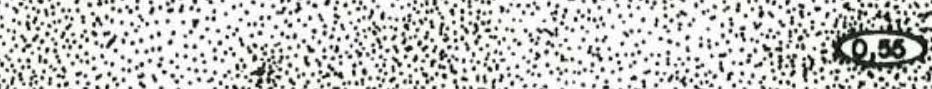

57

569

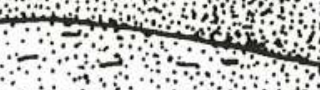

$567-10$

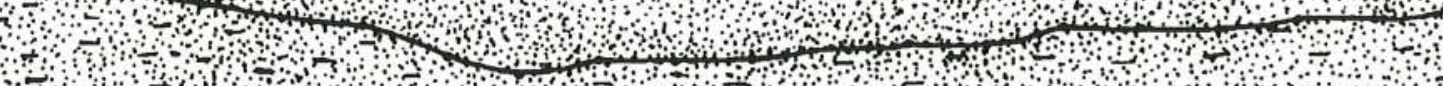

565 (1,

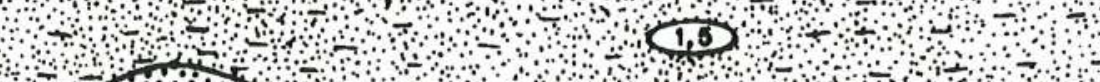
563 -

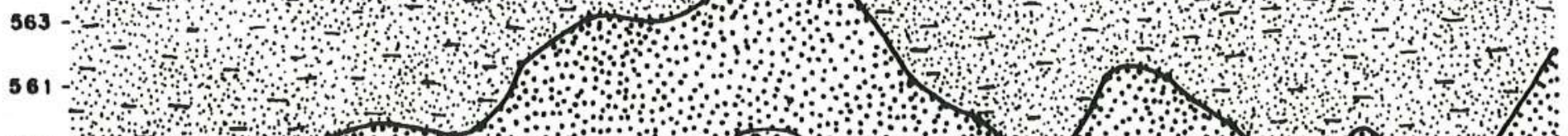
501 50 1

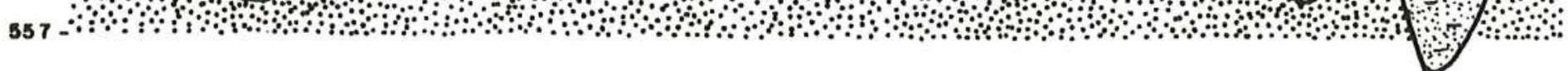

Figura 6.5 - Seção sísmica da base 4 . 
A seção da Figura 6.6 foi realizada no local mais afastado do centro urbano, próximo às futuras instalações do aterro sanitário da cidade de Bauru.

Esta seção apresenta três estratos sísmicos, que podem ser correlacionados a sondagens efetuadas próximo ao local do ensaio. Através dessa correlação, o estrato mais superficial, com velocidade de onda igual a 0.33 $\mathrm{km} / \mathrm{s}$, representa um solo bem desenvolvido, constituído de areia fina siltosa, muito fôfa a fôfa. O segundo estrato, com velocidade de $1,2 \mathrm{~km} / \mathrm{s}$, constitui-se em um solo de alteração de arenito, cuja composição é uma areia fina siltosa, algo argilosa. o último estrato, representa a rocha sã, constituído pelos arenitos da Formação Marília.

Estudos realizados pela CESP(1992), constataram nesta área, que a profundidade do topo rochoso aumenta signicativamente em direção ao talvegue local e diminui junto às encostas. O lençol freático acompanha a topografia local e não está condicionado ao topo rochoso. Ensaios de infiltração realizados ao longo do perfil de 8 sondagens de reconhecimento, apresentaram baixa absorção de água e consequentemente baixas permeabilidades, que se situaram na faixa de $10^{-4} \mathrm{~cm} / \mathrm{s}$ a $10^{-6} \mathrm{~cm} / \mathrm{s}$. 


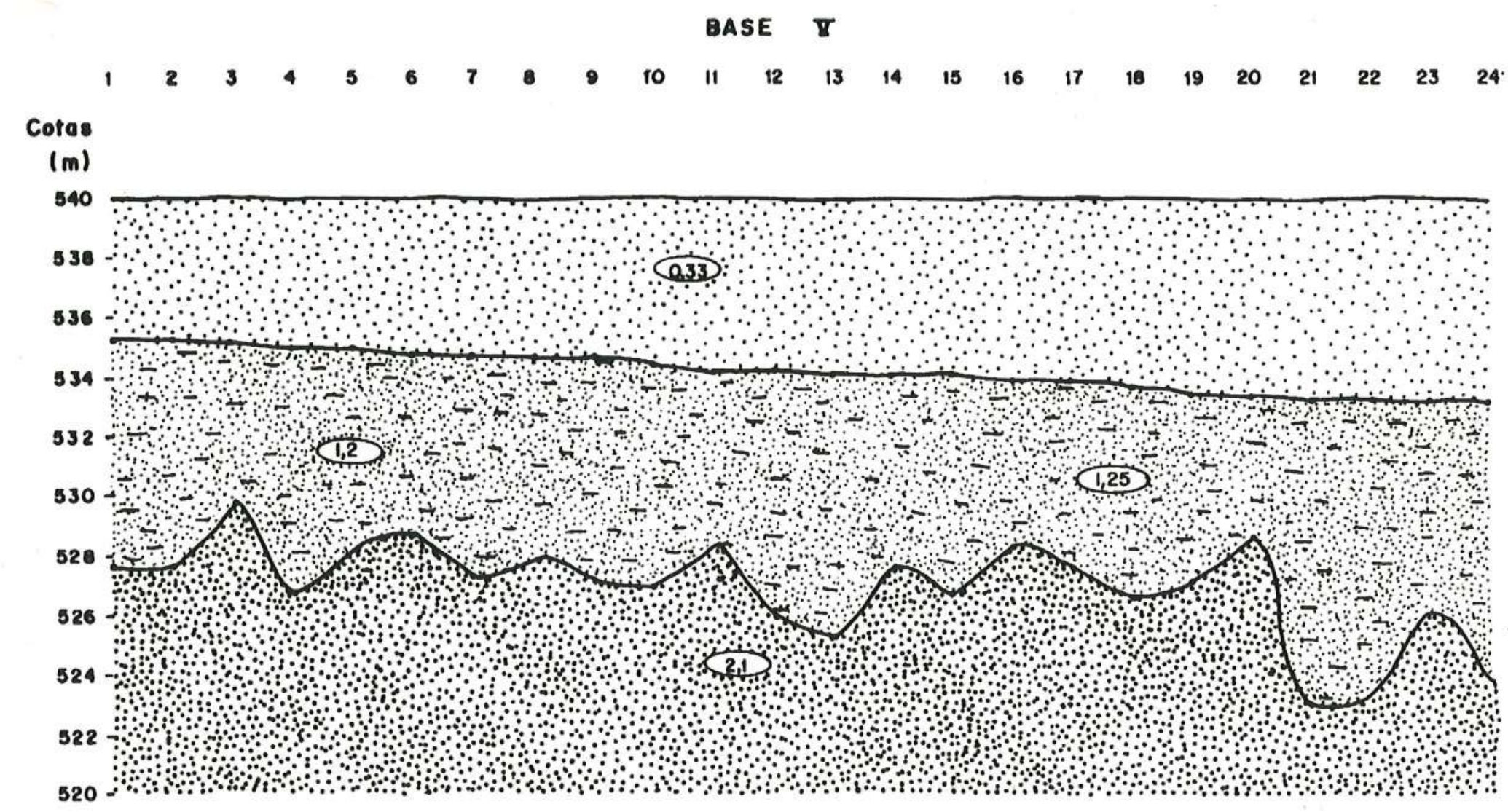

Figura 6.6 - Seção sísmica da base 5 . 


\section{2 - EstAtísticas BÁsicAs}

A Figura 6.7 mostra a distribuição da frequência relativa para todos os SPT's, com truncamento para valores situados acima de 60 golpes, pois em torno deste valor, as sondagens praticamente já se encerraram.

Nota-se uma assimetria na distribuição, com as maiores concentrações dos SPT's nas classes de 2 a 10. Dado à assimetria positiva da distribuição, os valores médios estão situados numa faixa de 9 (mediana) a 12,6 (média aritmética), e a dispersão indicada pelo coeficiente de variação aritmético, é relativamente alta com o valor de $92 \%$.

Com o intuito de estudar a relação do SPT com a profundidade, foi elaborada a análise de correlação linear entre estas duas variáveis. Assim, para cada nível de profundidade foi extraída a mediana desse nível e correlacionada com a respectiva profundidade. Dessa forma foi feito o gráfico de dispersão do SPT com a profundidade, cujo coeficiente de correlação linear encontrado foi de 0.993, próximo a um ajuste linear ideal, conforme mostra a Figura 6.8 .

Entretanto, observando atentamente a curva dos pontos experimentais, notam-se alterações ao longo desta curva da sua taxa de crescimento. Associando-se estas mudanças, com perfil de alteração, pode-se segmentar o gráfico em três partes que representariam as principais camadas do subsolo, em termos de compacidade média.

A primeira camada, constituída dos índices mais baixos, atingiria a profundidade de 5 metros; a segunda camada, pela taxa de crescimento, apresentaria 13 metros e a terceira camada seria de 12 metros de espessura.

Por fim, foi feita uma experimentação com ajustes de vários polinômios e adotou-se o polinômio de grau 6 , tendo por base a estratificação do solo, avaliada nos estudos pedológicos e geofísicos e o bom ajuste visual da curva para com os pontos, dentro do intervalo de 
profundidade ensaiado. A expressão do polinômio é dada pela seguinte função:

$$
\begin{aligned}
S P T= & 1.6177+0.3027 p-2.4299 \times 10^{-3} p^{2}+0.0132 p^{3}-9.3455 \times 10^{-4} p^{4}+ \\
& 2.2768 \times 10^{-5} p^{5}-1.7460 \times 10^{-7} p^{6} \quad \mathrm{p}=\text { profundidade }
\end{aligned}
$$

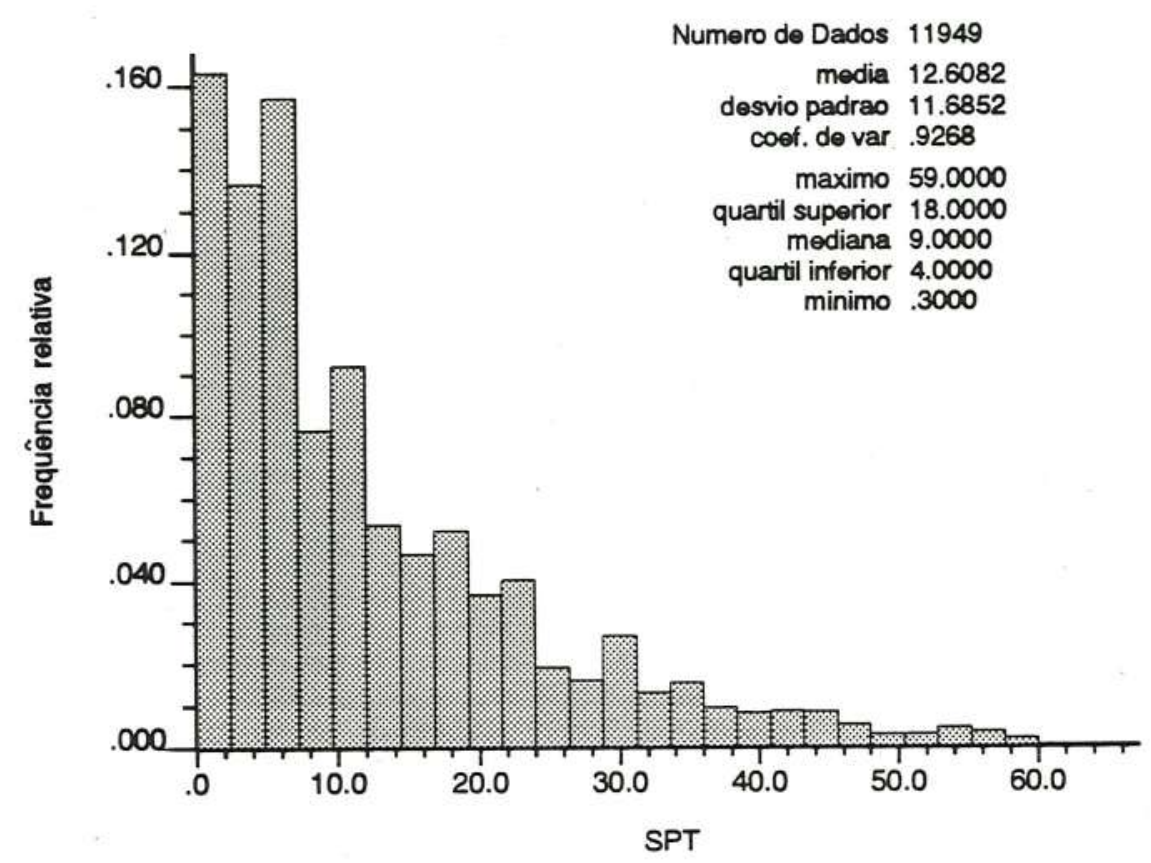

Figura 6.7 - Distribuição de freqüência relativa para todos os dados $($ SPT $<60)$.

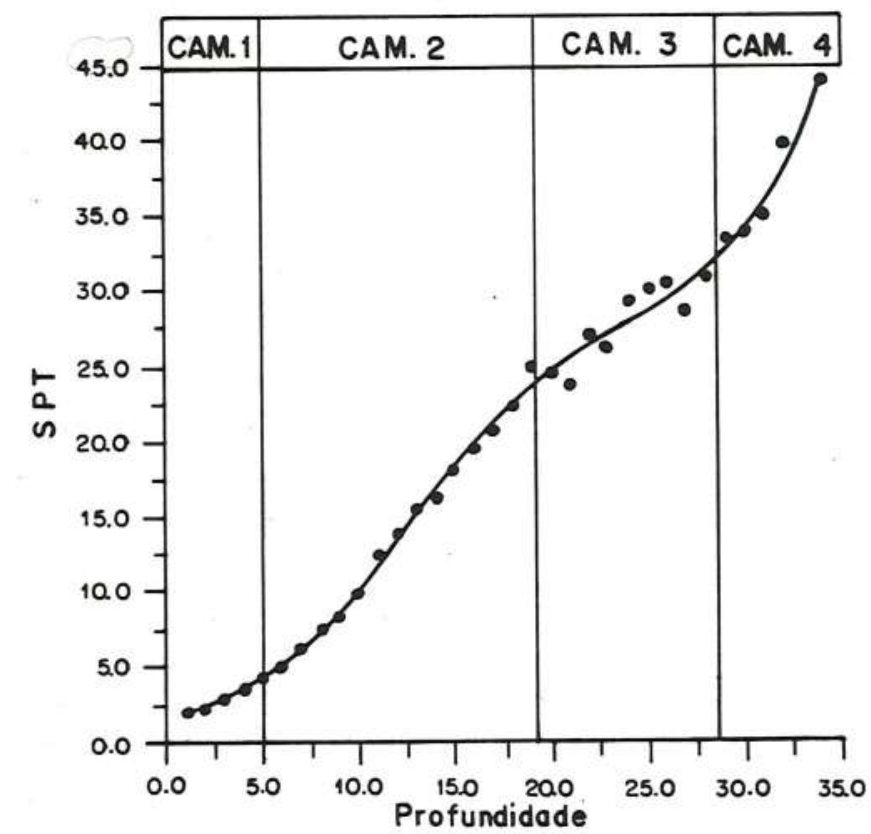

Figura 6.8 - Gráfico de correlação SPT x profundidade. 
A distribuição de freqüência dos ensaios para o estrato mais superficial está demonstrada na Figura 6.9.

Nota-se, por este histograma, a elevada assimetria da distribuição, com as maiores concentrações nas duas classes inferiores. Este fato era esperado, visto que a análise foi feita na camada mais superficial e fofa do solo. Os valores de tendência central encontram-se no intervalo de 2,8 (mediana) e 3,49 (média) e a dispersão relativa, avaliada pelo coeficiente de variação, situa-se em $70 \%$, que representa um valor relativamente alto.

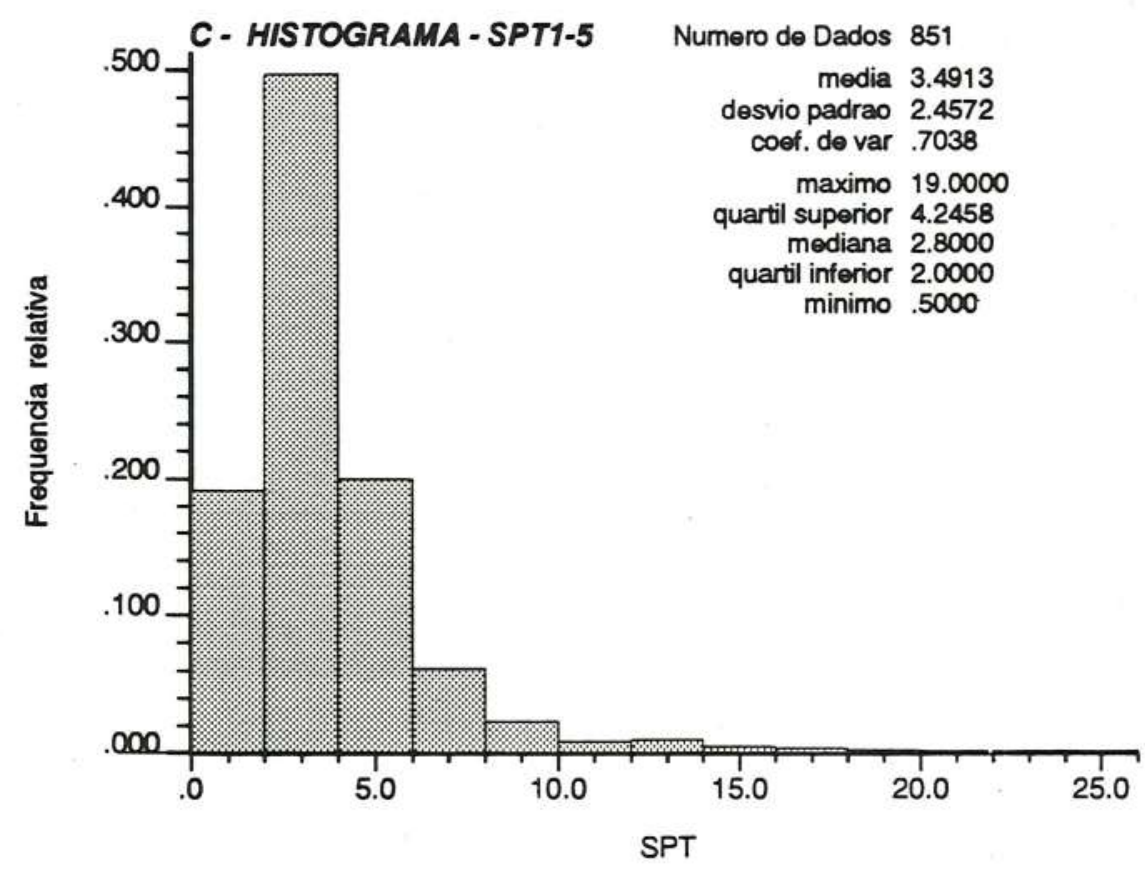

Figura 6.9 - Distribuição de freqüência relativa do estrato superficial (espessura $5 \mathrm{~m}$ ).

Os histogramas dos valores de SPT, para cada nível ou profundidade, estão representados nas figuras $6.10 \mathrm{e}$ 6.11 .

Nota-se uma configuração assimétrica para as distribuições de freqüência dos vários níveis. Esta assimetria não ocorre de maneira uniforme, ou seja, com uma decrescência dos valores altos para os baixos de forma regular, mas devido a poucos valores anômalos ("outliers") que surgem nos níveis de profundidades pesquisados; ocorrem algumas classes isoladas, que 
mascaram uma assimetria regular ou do tipo lognormal. Estes valores anômalos podem ocorrer, devido, ou a resistências elevadas do solo, localizadas em poucos pontos dispersos na área, ou à possíveis erros de execução do ensaio de penetração padrão.

a)

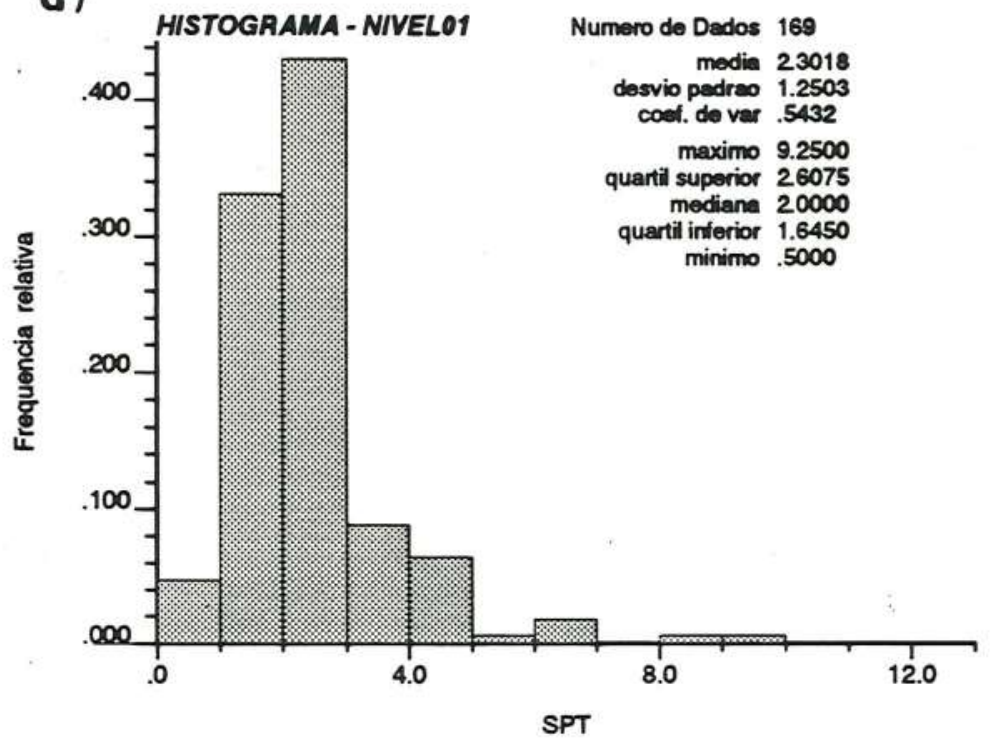

b)

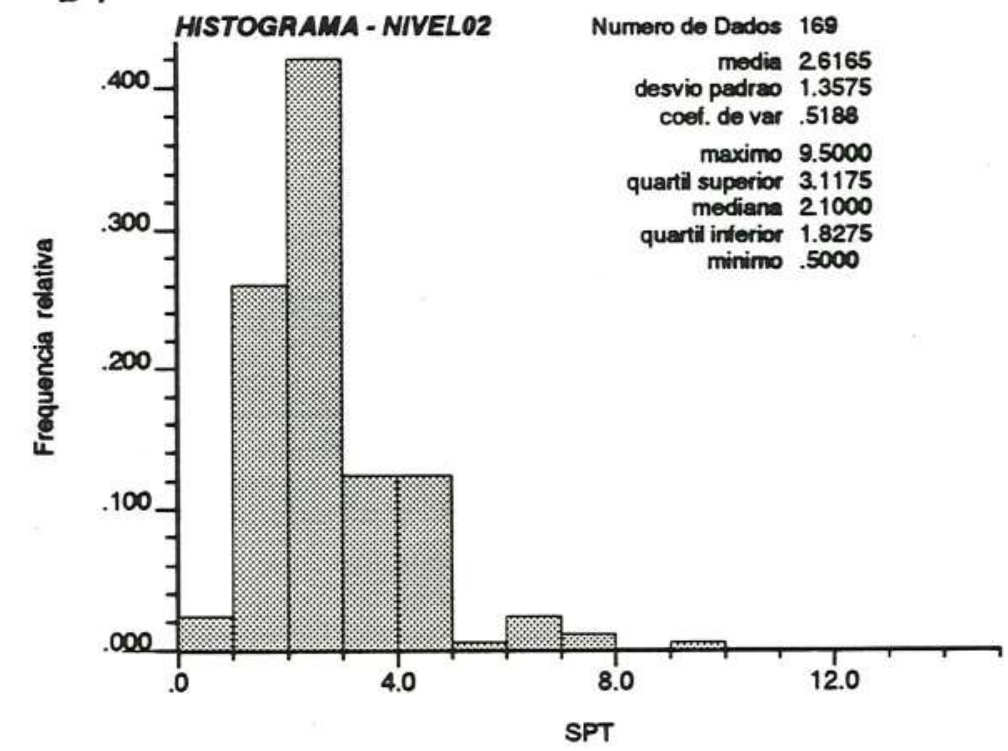

Figura 6.10 - Histogramas dos SPT's dos níveis; a) 1 e b) 2 . 
a)
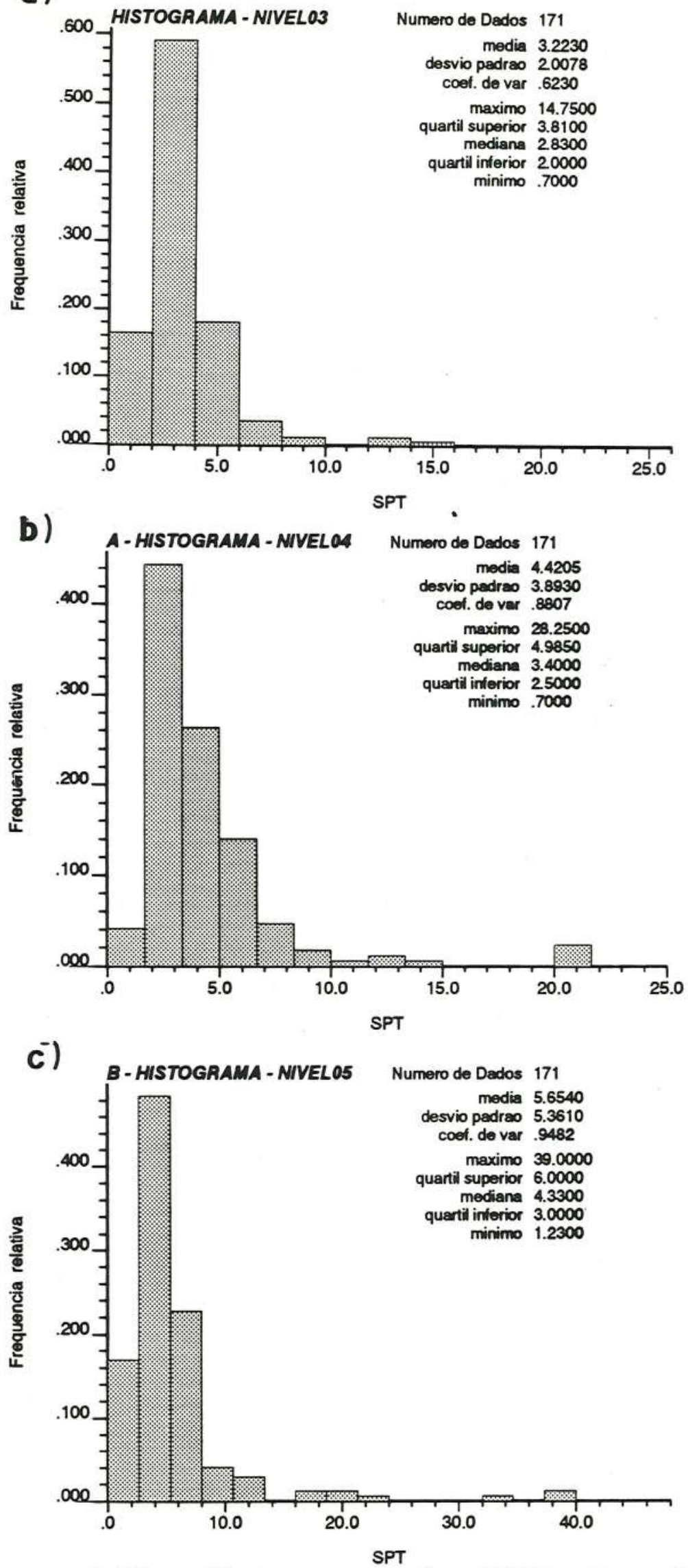

Figura 6.11 - Histogramas dos SPT's dos níveis; a) 3 , b) 4 e c) 5 . 
As tabelas 6.1 e 6.2 apresentam os resultados das estatísticas básicas para cada nível, bem como para a camada mais superficial, reconhecida na análise do perfil de alteração da área de estudo. As estatísticas da Tabela 6.1 representam a avaliação de uma distribuição normal para os dados, entretanto, como os testes de normalidade, com base na assimetria e curtose, revelaram uma não-normalidade dos conjuntos de dados, são apresentadas, na Tabela 6.2, as estatísticas básicas alternativas, para distribuições assimétricas.

TABELA 6.1 - ESTATÍSTICAS BÁSICAS DO SPT DOS DIVERSOS NIVEIS E DA CAMADA SUPERFICIAL

\begin{tabular}{|c|c|c|c|c|c|}
\hline NIVEIS & MÉDIA & DESVIO & COEFICIENTE & ASSIMETRIA & CURTOSE \\
\hline & ARITMÉTICA & PADRÃO & DE VARIAÇÃO & & \\
\hline 01 & 2.301 & 1.250 & 0.543 & 3.604 & 18.751 \\
02 & 2.616 & 1.357 & 0.516 & 4.119 & 22.850 \\
03 & 3.223 & 2.007 & 0.518 & 5.568 & 40.445 \\
04 & 4.420 & 3.893 & 0.880 & 4.033 & 21.065 \\
05 & 5.654 & 5.361 & 0.948 & 4.015 & 21.148 \\
CAMADA & 3.491 & 2.457 & 0.703 & 4.942 & 33.720 \\
\hline
\end{tabular}

TABELA 6.2 - ESTATÍSTICAS BÁSICAS ALTERNATIVAS DO SPT PARA DISTRIBUIÇÕES ASSIMÉTRICAS

\begin{tabular}{|l|c|c|c|}
\hline NIVEIS & MÉDIA & DESVIO & MEDIANA \\
\hline & GEOMÉTRICA & GEOMÉTRICO & \\
\hline 01 & 2.143 & 1.700 & 2.000 \\
03 & 2.445 & 1.742 & 2.125 \\
04 & 2.895 & 1.745 & 2.833 \\
05 & 3.736 & 1.872 & 3.500 \\
CAMADA & 4.590 & 1.863 & 4.400 \\
\hline
\end{tabular}




\section{3- ANÁLISE DOS DADOS PELA GEOESTATÍSTICA}

Após toda a caracterização geológico-geotécnica da área e do reconhecimento das camadas no perfil de alteração, os estudos voltaram-se para $\circ$ mapeamento geoestatístico das principais variáveis do banco de dados, como o SPT distribuído em profundidade e por camada, topo do impenetrável e topo do lençol freático.

$$
\text { Para atingir devidamente estes objetivos, }
$$

empregaram-se três técnicas da geoestatística, descritas no capítulo da metodologia, que são:

- krigagem ordinária (geoestatística paramétrica)

- cokrigagem (geoestatística paramétrica)

- krigagem indicativa (geoestatística não paramétrica)

O processamento e as análises geoestatísticas foram baseados em DEUTSCH \& JOURNEL (1992), ENGLUND \& SPARKS (1988) e GRUNDY \& MIESCH (1988)

\subsection{1 - Estimativas através da krigagem ordinária}

o intuito destas estimativas constituiu-se na aplicação da geoestatística paramétrica mais convencional, para a análise de variabilidade espacial, através dos variogramas, das variáveis objetivadaś deste trabalho.

Após esta fase, foram elaborados os mapas geoestatísticos do SPT para as profundidades de 1 a 5 metros, denominados de níveis $1,2,3,4$ e 5, compreendendo a camada mais superficial. Foi empregada também a estimativa por bloco desta camada, através da krigagem ordinária tridimensional.

Associados aos mapas geoestatísticos, encontram-se os mapas dos desvios-padrão das estimativas, que refletem a confiabilidade das estimativas principalmente, com relação à distribuição espacial das amostras na área. 
Os variogramas foram elaborados para duas direções principais, que são a norte-sul e leste-oeste. Estas direções são praticamente coincidentes com as direções de maior e menor continuidade da variável em estudo observada em mapas preliminares. Juntamente a estas direções, foi elaborado o variograma para uma direção global, que em processos isotrópicos, serve como um guia para o modelo matemático a ser ajustado aos variogramas.

Tendo em vista que a malha de sondagens apresenta distribuição irregular, empregaram-se programas de computação que utilizam ângulos de tolerância na pesquisa dos pares de pontos no espaço. Neste caso as direções norte-sul e leste-oeste foram variografadas com ângulo de tolerância igual a 300 .

As figuras 6.12 e 6.13 apresentam os variogramas experimentais bidimensionais para os niveis 1, 2, 3, 4, 5 e os variogramas tridimensionais para a camada superficial, com os respectivos modelos ajustados.

Nota-se nos variogramas, em todos os níveis, um comportamento isotrópico até uma distância de 1200 a 1300 metros, onde, a partir desta distância, a variabilidade na direção norte-sul aumenta significativamente.

Este aspecto pode ser explicado com base na configuração do relevo da área, onde a maior drenagem, representada pelo rio Bauru, encontra-se alinhada praticamente na direção leste-oeste. Como o relevo está diretamente associado aos tipos de solos que ocorrem na região, é de se esperar uma maior continuidade espacial das propriedades geotécnicas dos solos na direção leste oeste.

Com relação à isotropia dos variogramas, verificadas até à distância de 1200 a 1300 metros, deve-se à uma provável equivalência das dimensões entre os interflúvios das drenagens secundárias na direção leste-oeste com os morrotes alinhados na direção norte-sul. 


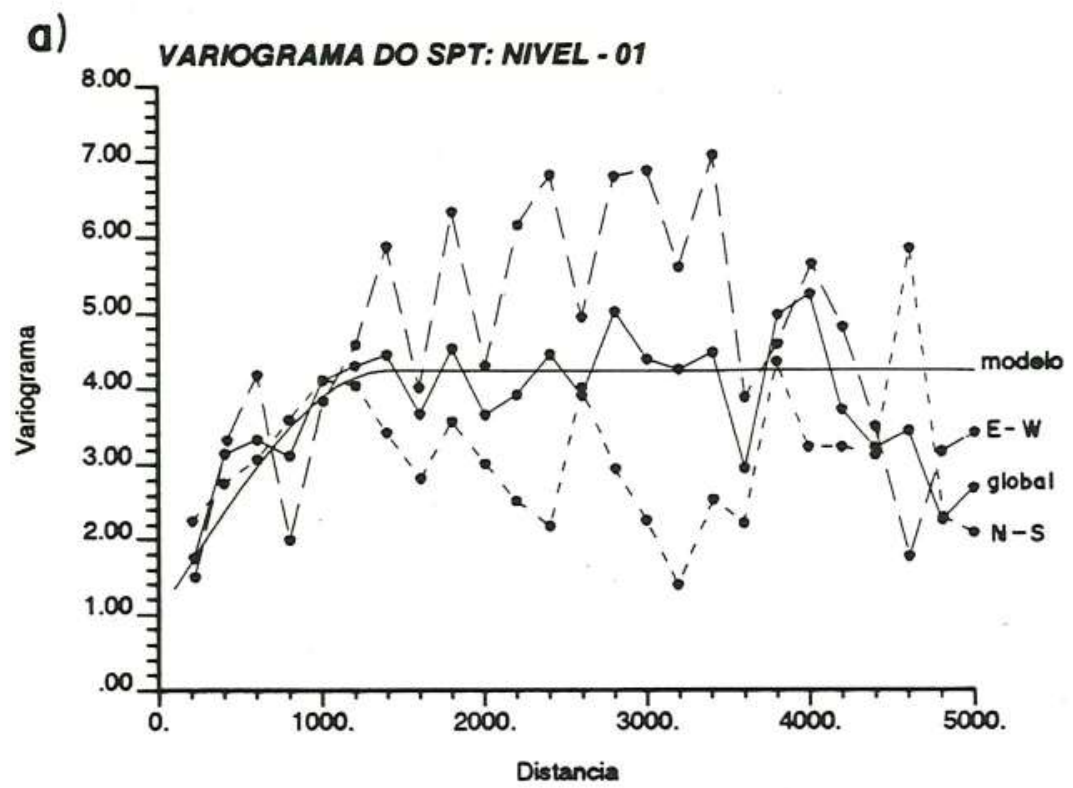

b) VARIOGRAMA DO SPT: NIVEL - 02

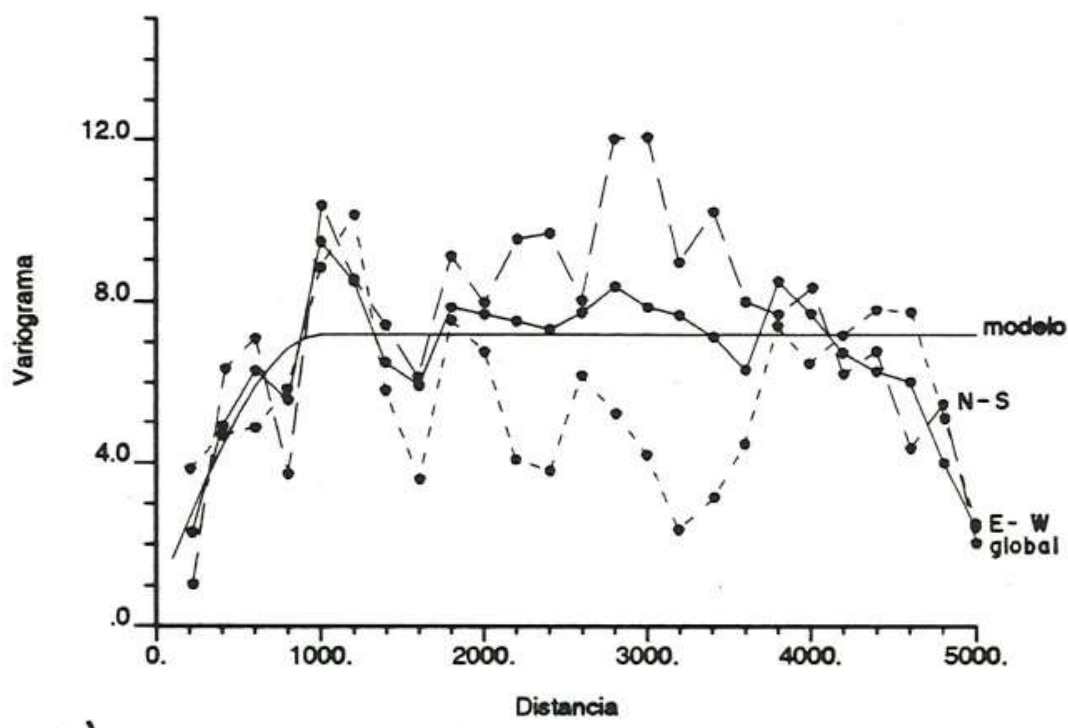

c)

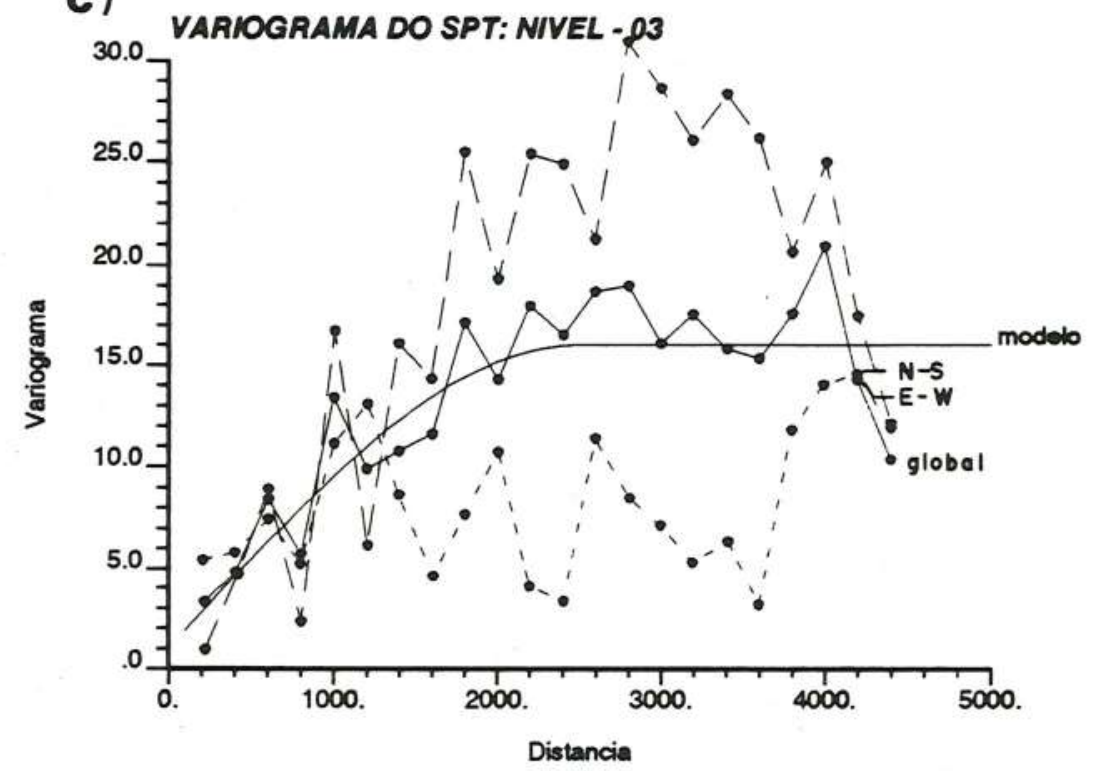

Figura 6.12 - Variogramas para os níveis (profundidade);
a) $1 \mathrm{~m}$
b) $2 \mathrm{~m}$
c) $3 \mathrm{~m}$. 


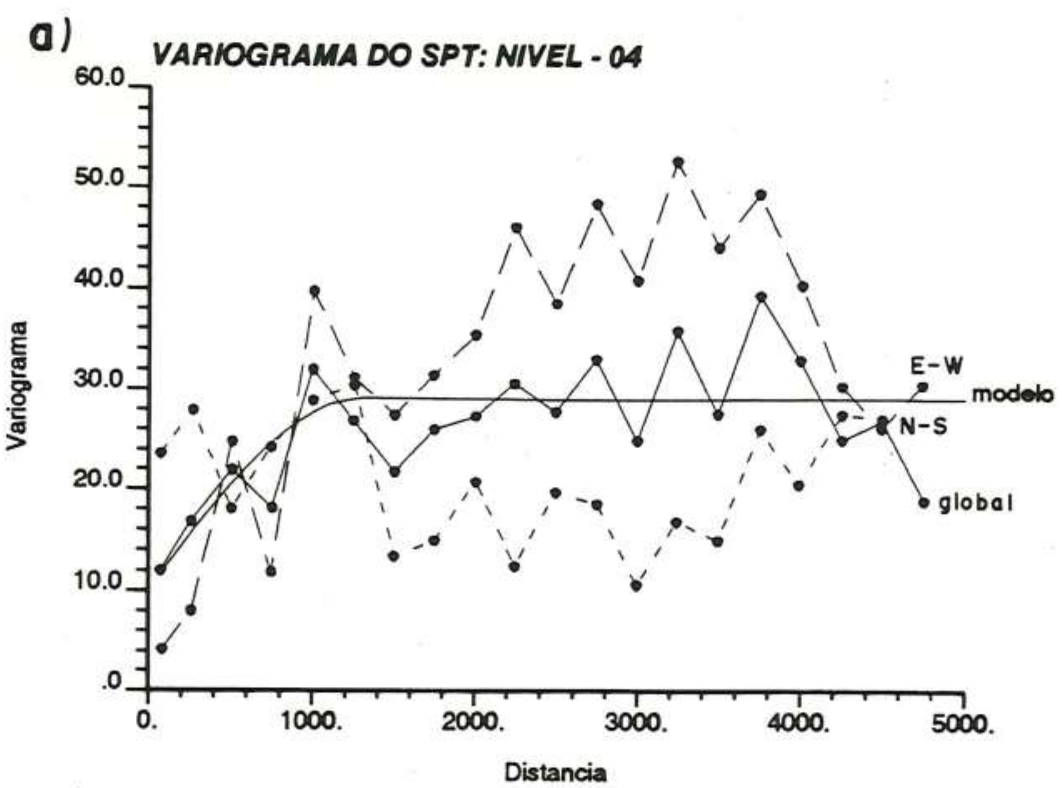

b)
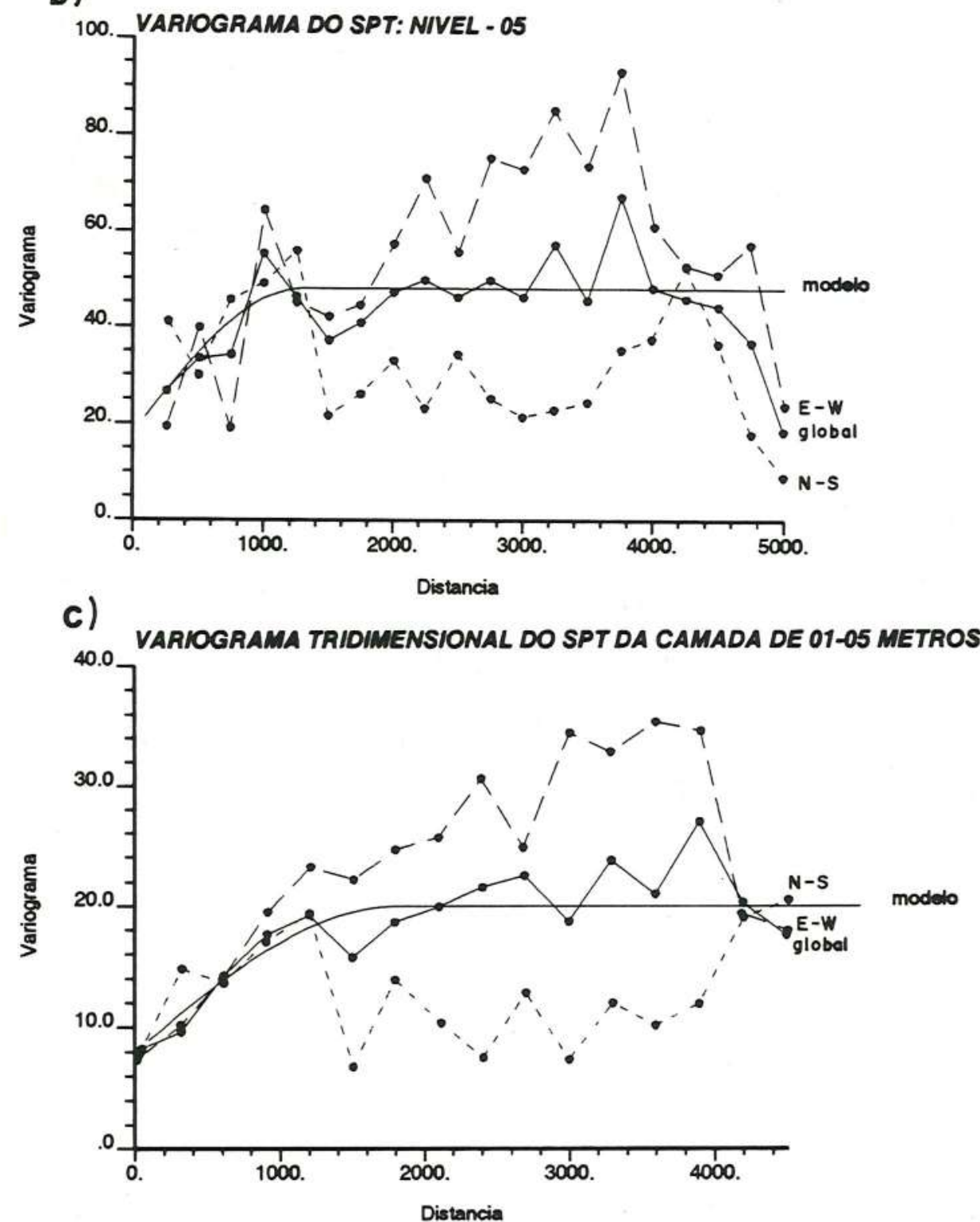

Figura 6.13'- Variogramas para os níveis; a) $4 \mathrm{~m}$ b) $5 \mathrm{~m} e$ c) camada superficial. 
Esta configuração morfológica faz com que, a comparação dos pares de amostras dos variogramas esteja condicionada em ambientes morfopedológicos de variabilidade similares.

o modelo que melhor se ajustou para os diversos níveis, foi o modelo esférico simples, com uma única estrutura. Destacam-se os variogramas direcionais do nível 03, que apresentaram elevada anisotropia a partir da distância de 1200 metros.

A camada superficial, de um modo geral, apresentou também um modelo esférico simples que, a rigor, representou a média de todos os modelos dos vários níveis. A Tabela 6.3 apresenta os parâmetros básicos dos modelos ajustados para os diversos níveis e para a camada mais superficial (1-5 metros).

TABELA 6.3 - PARÂMETROS DOS MODELOS ESFÉRICOS AJUSTADOS

\begin{tabular}{|c|c|c|c||}
\hline \hline Níveis & $\begin{array}{c}\text { Amplitude } \\
\text { variográfica } \\
(\mathrm{a})\end{array}$ & $\begin{array}{c}\text { Efeito de } \\
\text { pepita } \\
\text { (Co) (E) }\end{array}$ & $\begin{array}{c}\text { Patamar } \\
\text { (C1) }\end{array}$ \\
\hline 1 & 1400 & 1,0 & 3,25 \\
\hline 2 & 1000 & 0,7 & 6,50 \\
\hline 3 & 2500 & 1,0 & 15,0 \\
\hline 4 & 1300 & 10,0 & 19,0 \\
\hline 5 & 1300 & 18,0 & 30,0 \\
\hline Camada $1-5$ & 1800 & 8,0 & 12,0 \\
\hline
\end{tabular}

Como era esperado, a componente aleatória (E) é muito significativa, exceto para os níveis浆2 e 3 . A componente aleatória que reflete a casualidade dos resultados do SPT e está associada aos efeitos de pepita dos variogramas, é interpretada neste trabalho como uma componente totalmente gerada pelos problemas operacionais, inerentes à falta de uma melhor padronização do ensaio, que inserem um fator aleatório nos resultados. A Tabela 6.4 resume a importância da componente aleatória para os diversos níveis e para a camada em análise. 
TABELA 6.4 - AVALIAÇÃO DA COMPONENTE ALEATÓRIA DOS VARIOGRAMAS .

\begin{tabular}{|c|c|c|c|c||}
\hline Níveis & Co & C1 & $\mathrm{E}(\%)=\frac{\mathrm{C}_{0}}{\mathrm{C}_{1}} \times 100$ & $\begin{array}{c}\text { Avaliação } \\
\text { de E }\end{array}$ \\
\hline 1 & 1,0 & 3,25 & 30,7 & significativa \\
\hline 2 & 0,7 & 6,5 & 10,7 & baixa \\
\hline 3 & 1,0 & 15,0 & 6,6 & baixa \\
\hline 4 & 10,0 & 19,0 & 52,6 & $\begin{array}{c}\text { muito } \\
\text { significativa }\end{array}$ \\
\hline 5 & 18,0 & 30,0 & 60,0 & $\begin{array}{c}\text { muito } \\
\text { significativa }\end{array}$ \\
\hline camada 1-5 & 8,0 & 12,0 & 66,6 & $\begin{array}{c}\text { mito } \\
\text { significativa }\end{array}$ \\
\hline
\end{tabular}

o aumento da componente aleatória reflete uma ausência da correlação espacial. Este fato conduz às estimativas geoestatísticas mais próximas da média aritmética da estatística clássica, bem como em um aumento da variância das estimativas e, por conseguinte, da confiabilidade da própria estimativa.

\subsubsection{2- Krigagem ordinária}

Com base nos modelos variográficos estabelecidos, a próxima etapa constituiu-se no emprego da técnica da krigagem ordinária para efetuar as estimativas; por ponto, para os níveis e por blocos, para a camada em análise.

As estimativas geoestatísticas do SPT foram realizadas dentro do perímetro urbano em uma área quadrada de $8.000 \times 8.000 \mathrm{~m}$. A malha de pontos estimados possui uma distância entre os nós de $80 \mathrm{~m}$, próximo a um quarteirão do arruamento urbano. Desta forma, foi estimada uma malha de $100 \mathrm{x} 100$ pontos, totalizando 10.000 pontos estimados. No caso da camada, a estimativa foi feita por bloco, de dimensões $80 \times 80 \times 5 \mathrm{~m}$, totalizando também 10.000 blocos estimados.

Para cada ponto ou bloco estimado, foi também avaliada a variância da estimativa $\left(\sigma_{k}^{2}\right)$, representada 
em mapas de desvios-padrão da krigagem $\left(\sigma_{k}\right)$. Estes valores reproduzem a confiabilidade das estimativas, relacionadas principalmente a dois aspectos principais que são, a distribuição dos pontos de sondagem na área e a componente aleatória dos modelos variográficos.

Os mapas dos valores estimados e os de desvios padrão associados às estimativas para os diversos níveis, estão representados nas figuras 6.14 a 6.18 , os mapas para a camada encontram-se na Figura 6.19.

observa-se nos mapas do diferentes níveis, a concentração dos valores mais altos dos SPT's médios estimados, na porção centro-noroeste da área de estudo e também em núcleos menores nos locais centro-leste e centro-sul.

Comparando estes mapas com demais mapas do meio f́́sico como o geológico, pedológico e geotécnico, não se encontra uma relação direta ou expressiva de controle por qualquer unidade diferenciada ou mapeada. A rigor, os valores mais elevados do SPT encontram-se nos contatos das unidades geotécnicas II e III, definidas em uma drenagem secundária com direção noroeste, conforme pode ser visto no mapa geotécnico da Figura 5.1.

o mapa da camada, representado na Figura 6.19, reflete praticamente uma média dos valores estimados pela krigagem dos diferentes níveis. Tendo em vista que, à medida que se aumenta o volume das estimativas, diminuemse as variâncias das mesmas, os desvios-padrão da krigagem por blocos na camada são por conseguinte menores, considerando-se obviamente a escala dos variogramas.

De forma geral, todos os mapas elaborados pela krigagem ordinária apresentam menores desvios-padrão das estimativas nas porções com maior densidade de sondagens, onde as estimativas são mais precisas e há um aumento dos valores de desvios-padrão da krigagem para as bordas, onde a malha de amostragem é mais rarefeita. 

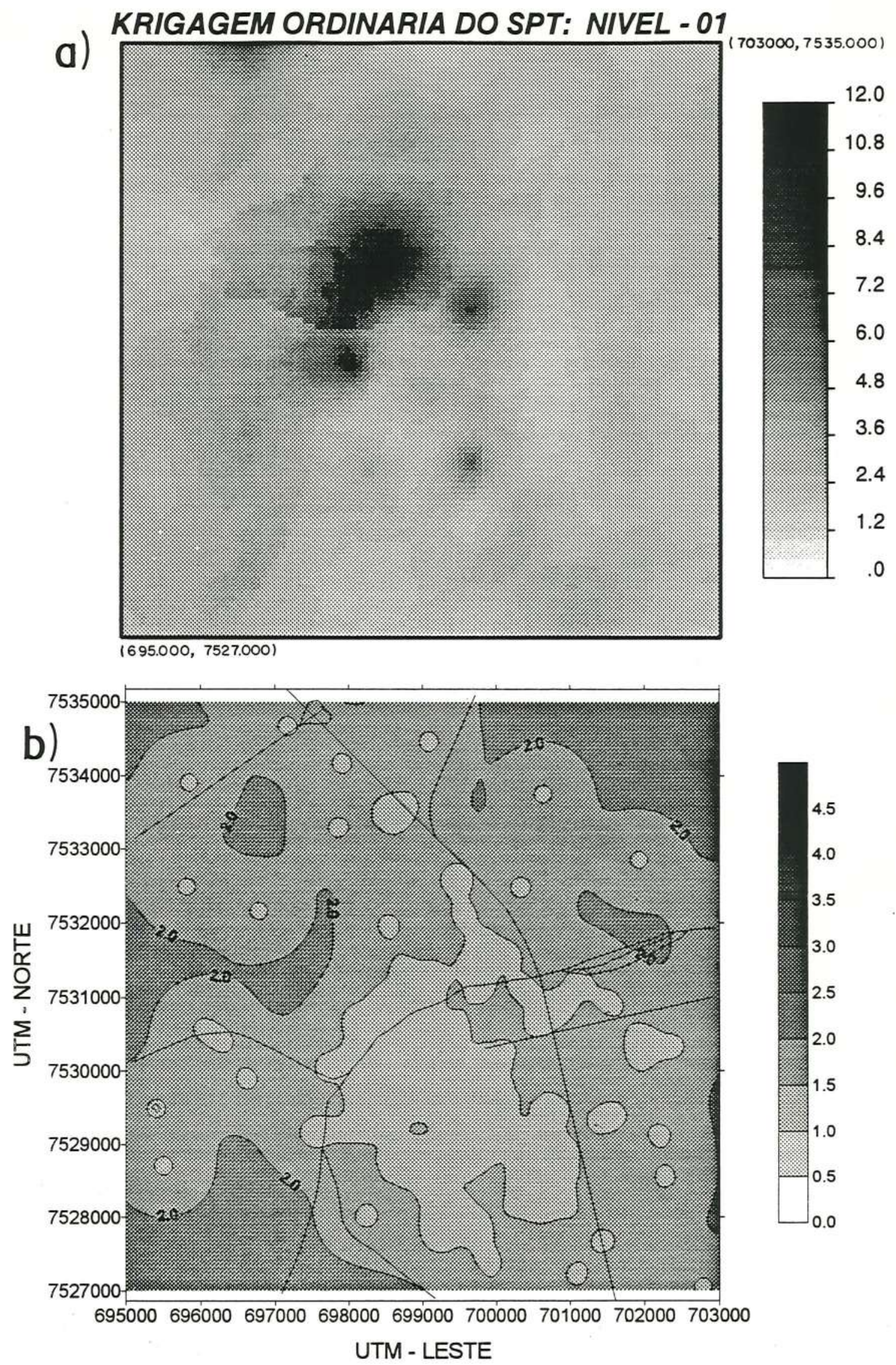

Figura 6.14 - Mapas do nível 1, estimados pela krigagem ordinária: a) SPT estimado ; b) desviospadrão das estimativas. 

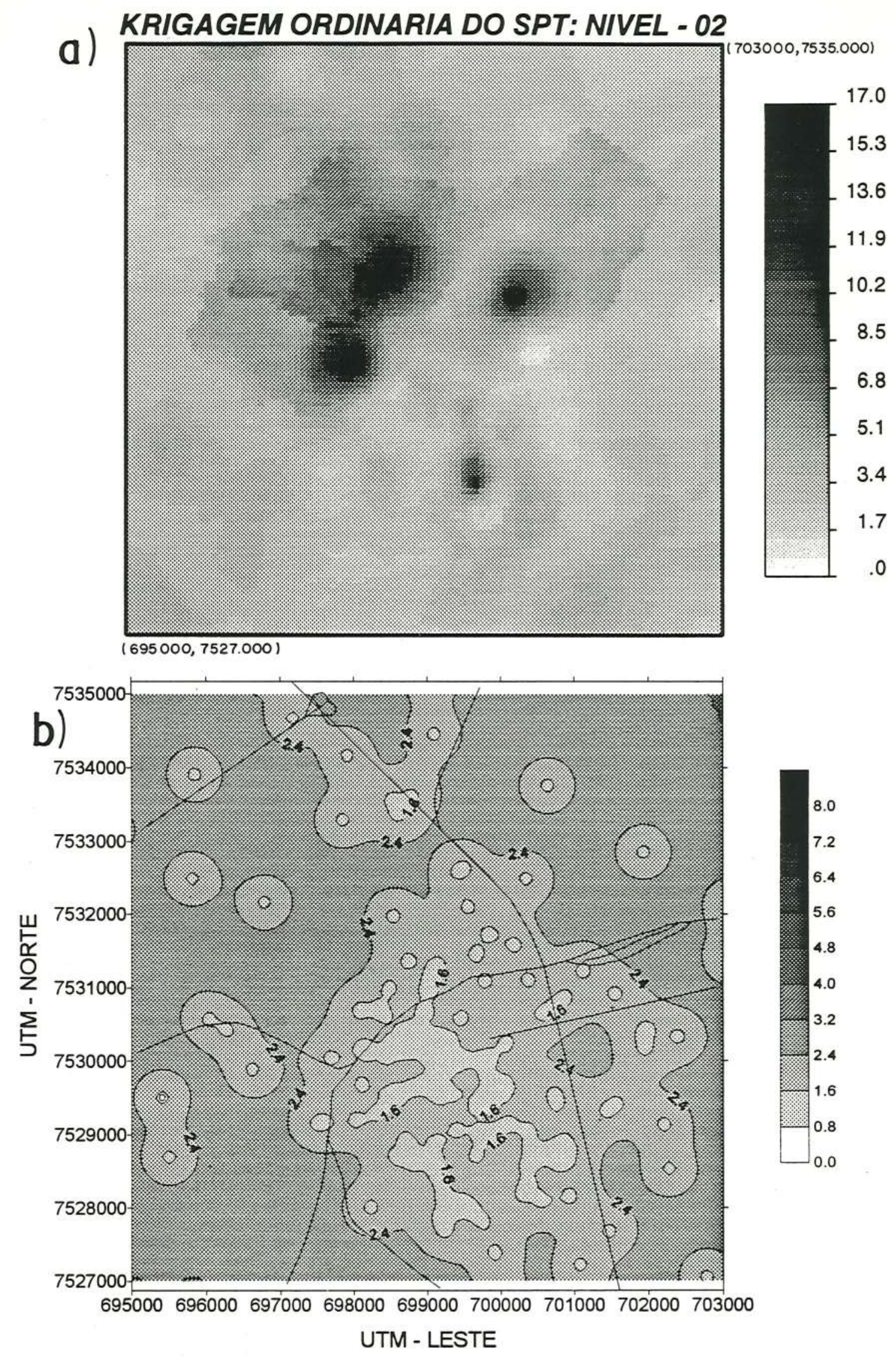

Figura 6.15 - Mapas do nível 2, estimados pela krigagem ordinária: a)SPT estimado ; b) desviospadrão das estimativas. 
a)
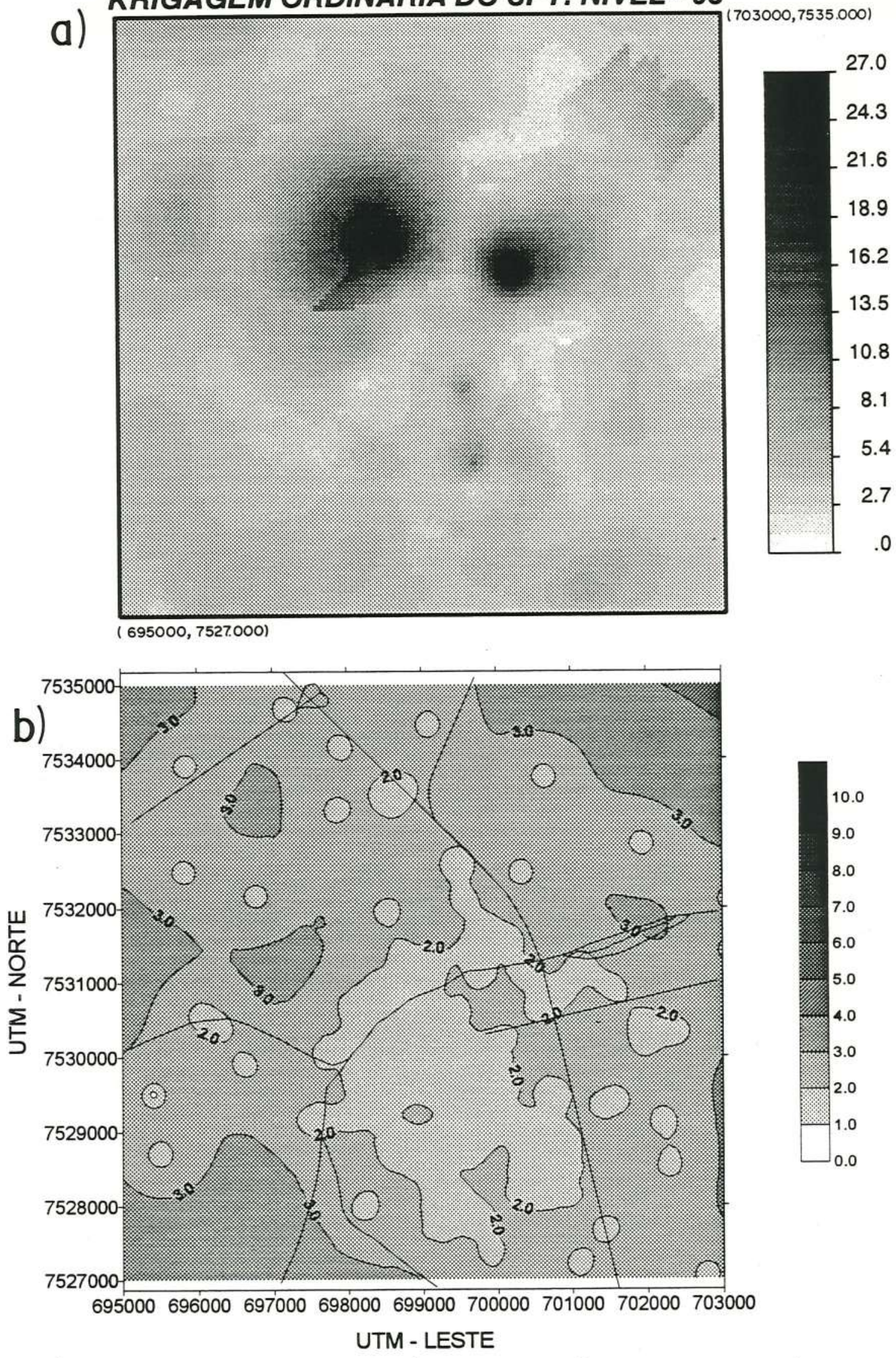

Figura 6.16 - Mapas do nível 3, estimados pela krigagem ordinária: a) SPT estimado ; b) desviospadrão das estimativas. 

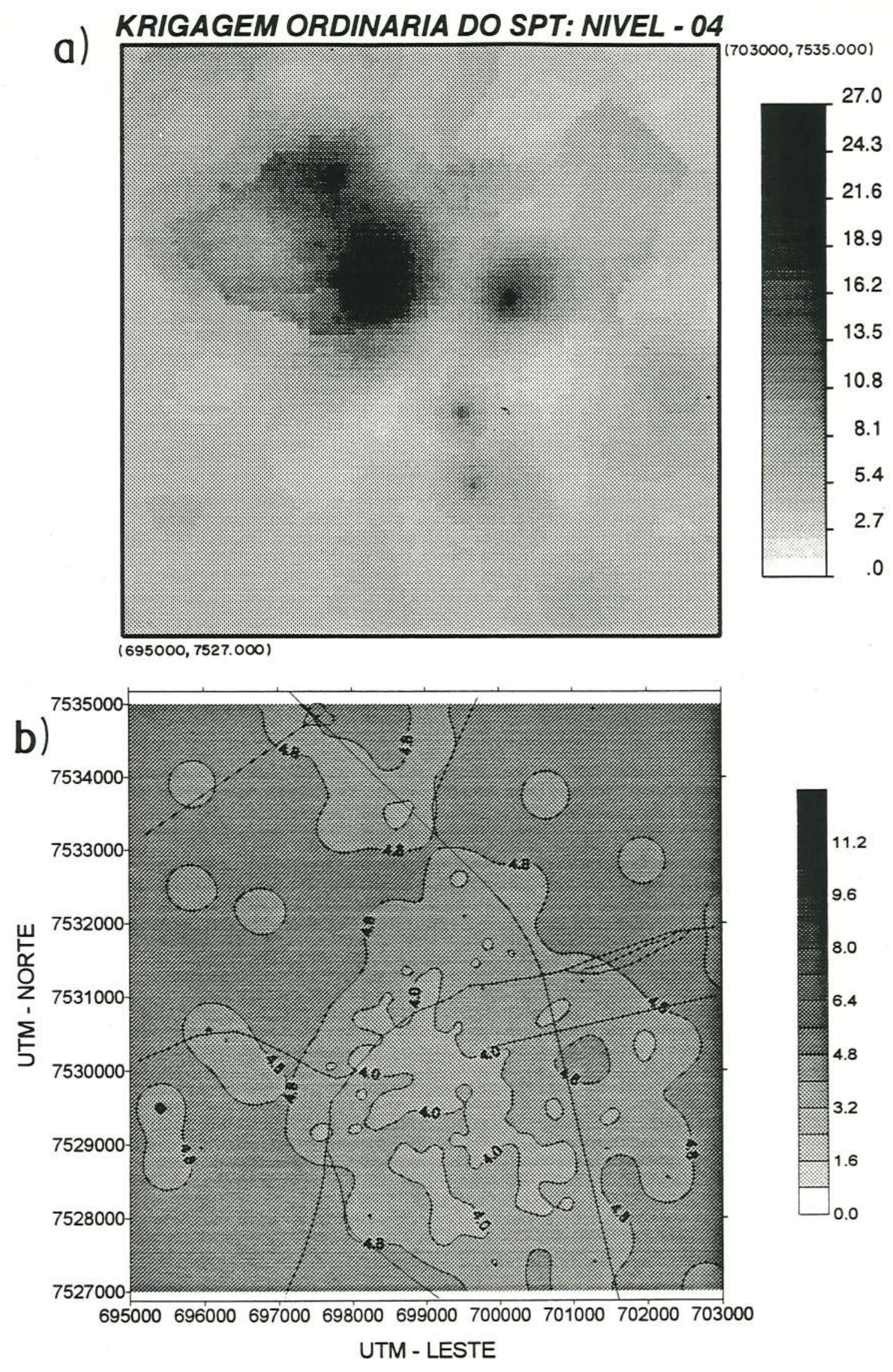

Figura 6.17 - Mapas do nível 4, estimados pela krigagem ordinária: a) SPT estimado ; b) desviospadrão das estimativas. 


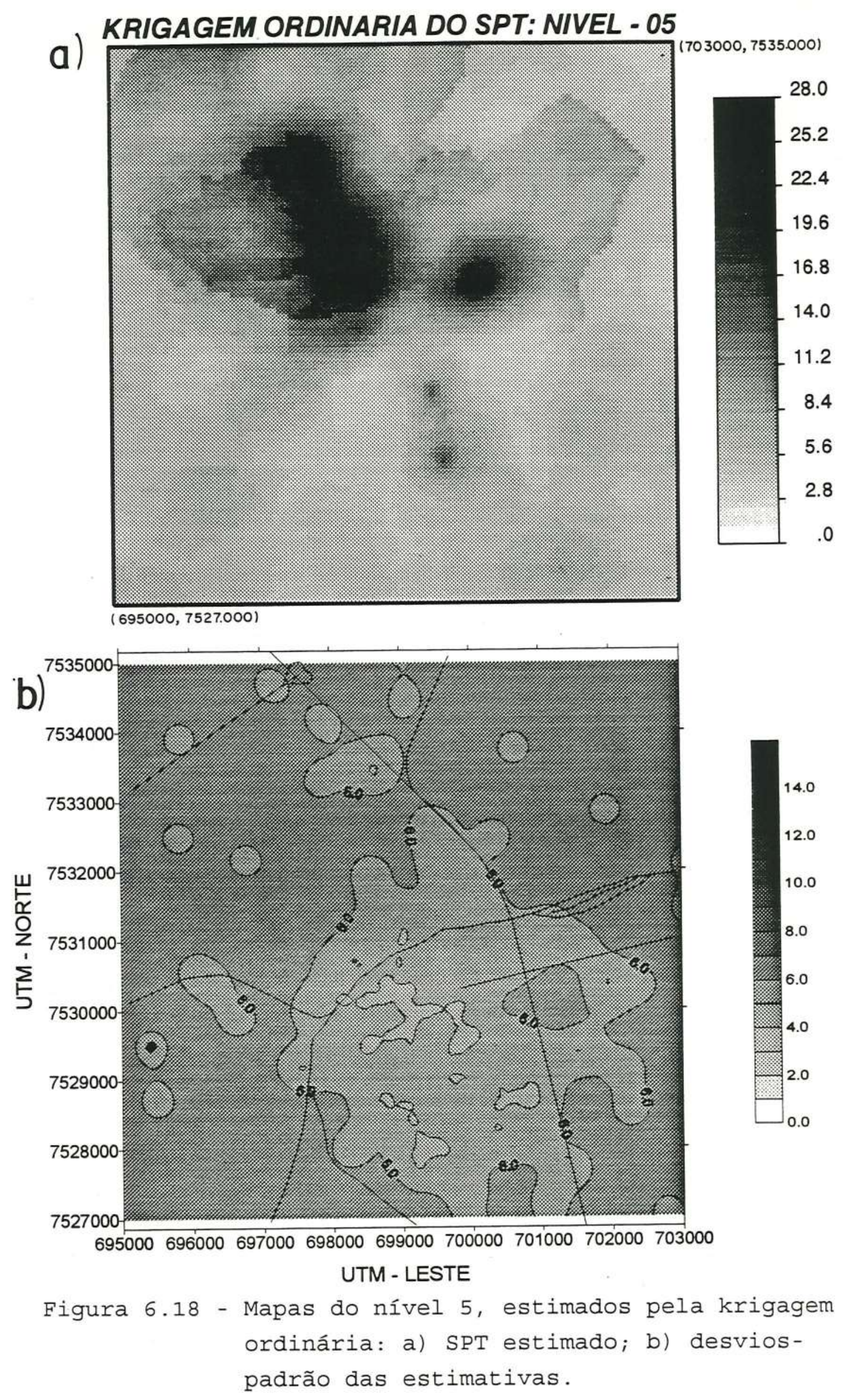




\section{KRIGAGEM ORDINARIA DA CAMADA $(80 \times 80 \times 5 \mathrm{~m})$}

a)
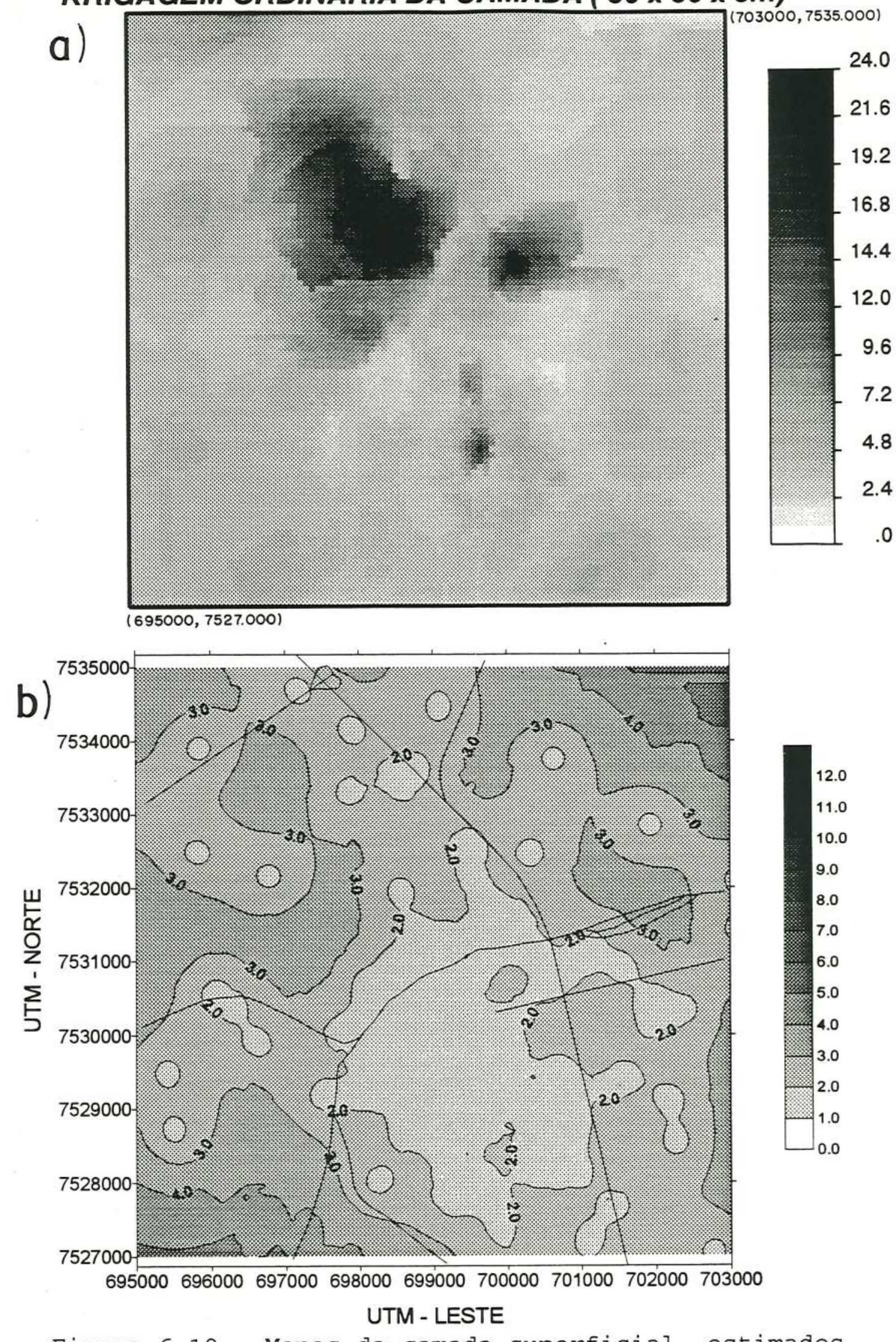

Figura 6.19 - Mapas da camada superficial, estimados pela krigagem ordinária: a) SPT estimado; b) desvios-padrão das estimativas. 


\subsection{2- Estimativas pela Cokrigagem}

A cokrigagem foi utilizada neste trabalho para estimar basicamente duas variáveis que são: 0 topo do lençol freático e o topo do impenetrável.

Estas variáveis são linearmente correlacionadas com uma outra variável de fácil aquisição, que é a cota topográfica, como está demonstrado na Figura 6.20.
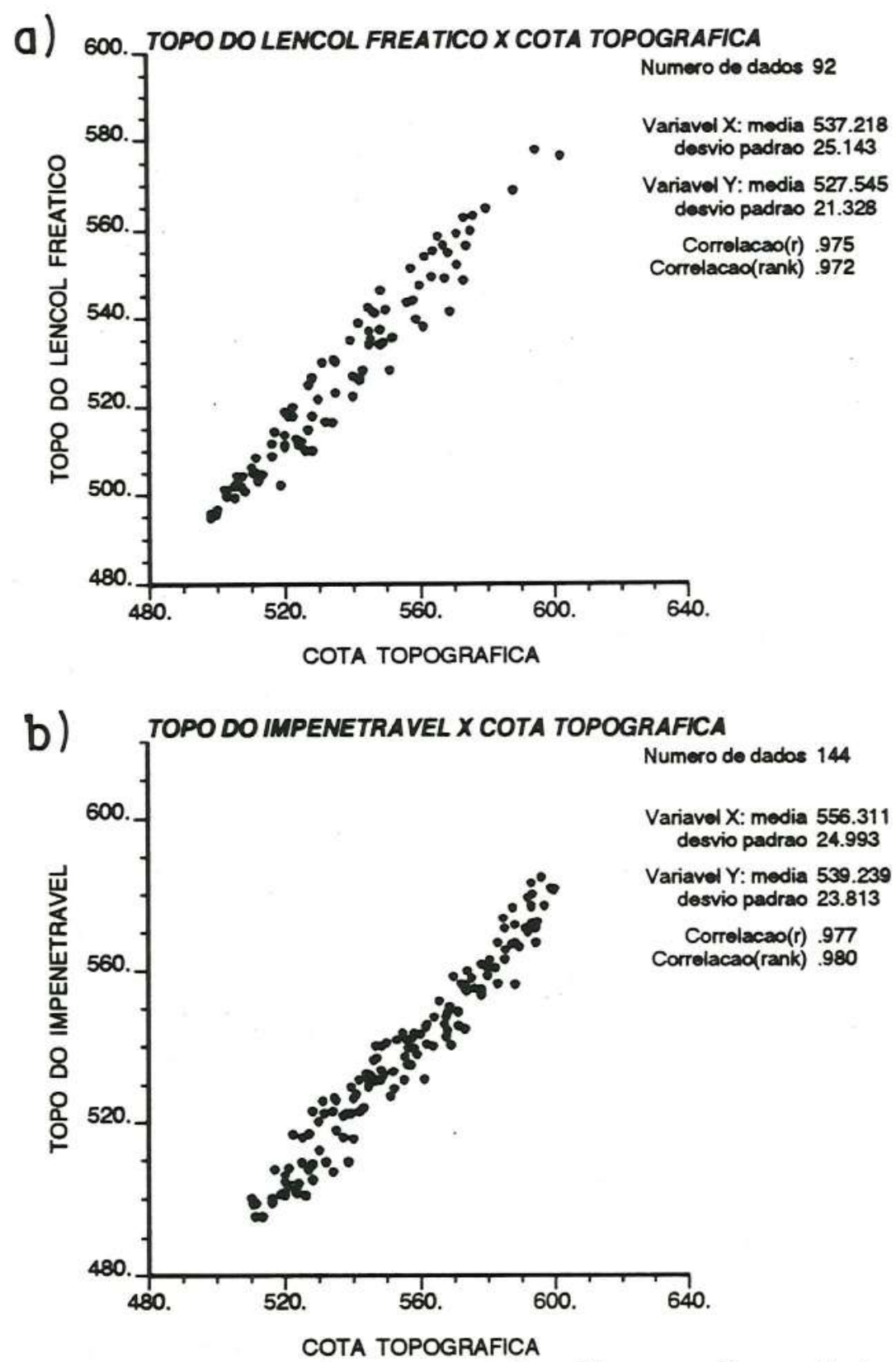

Figura 6.20 - Diagramas de dispersão: a) topo do lençol freático x cota topográfica; b) topo do impenetrável $x$ cota topográfica 
Dado a estas expressivas correlações lineares, optou-se pelo uso da cokrigagem que permite a estimativa de uma variável primária subamostrada, por uma variável secundária superamostrada.

Neste caso, dado às evidentes correlações, fez-se uso da cokrigagem para estimar as variáveis primárias, como o topo do lençol freático e do impenetrável, obtidas somente nos furos de sondagens, com a variável secundária, a cota topográfica, facilmente obtida dos mapas topográficos.

Além destas estimativas terem-sido feitas na área mais amostrada, representada pelo setor mais urbanizado (polígono interno), houve também uma extrapolação das estimativas para a periferia da cidade (polígono externo) que é subamostrada nas variáveis primárias, mas que pode ser densamente amostrada na variável secundária (cota topográfica), conforme indica a Figura 6.21.

\subsubsection{1- Análise variográfica}

o primeiro passo para efetivar estimativas pela cokrigagem foi a elaboraração dos variogramas individuais para as variáveis envolvidas na análise. Assim foram confeccionados os variogramas para a cota topográfica, topo do lençol freático e topo do impenetrável das sondagens, representados na Figura 6.22.

Os variogramas experimentais foram realizados nas duas principais direções $\mathrm{N}-\mathrm{S}$ e E-W, com ângulos de tolerância de $30^{\circ}$, juntamente com a direção global isotrópica.

Os variogramas experimentais da cota topográfica (Figura 6.22a) apresentaram um comportamento praticamente isotrópico, com uma variabilidade ligeiramente menor na direção E-W. A componente aleatória é muito baixa, denotando uma boa correlação espacial. Ao observar atentamente a ascensão dos variogramas, nota-se a presença de dois patamares que refletem a presença de duas estruturas variográficas conjugadas. 


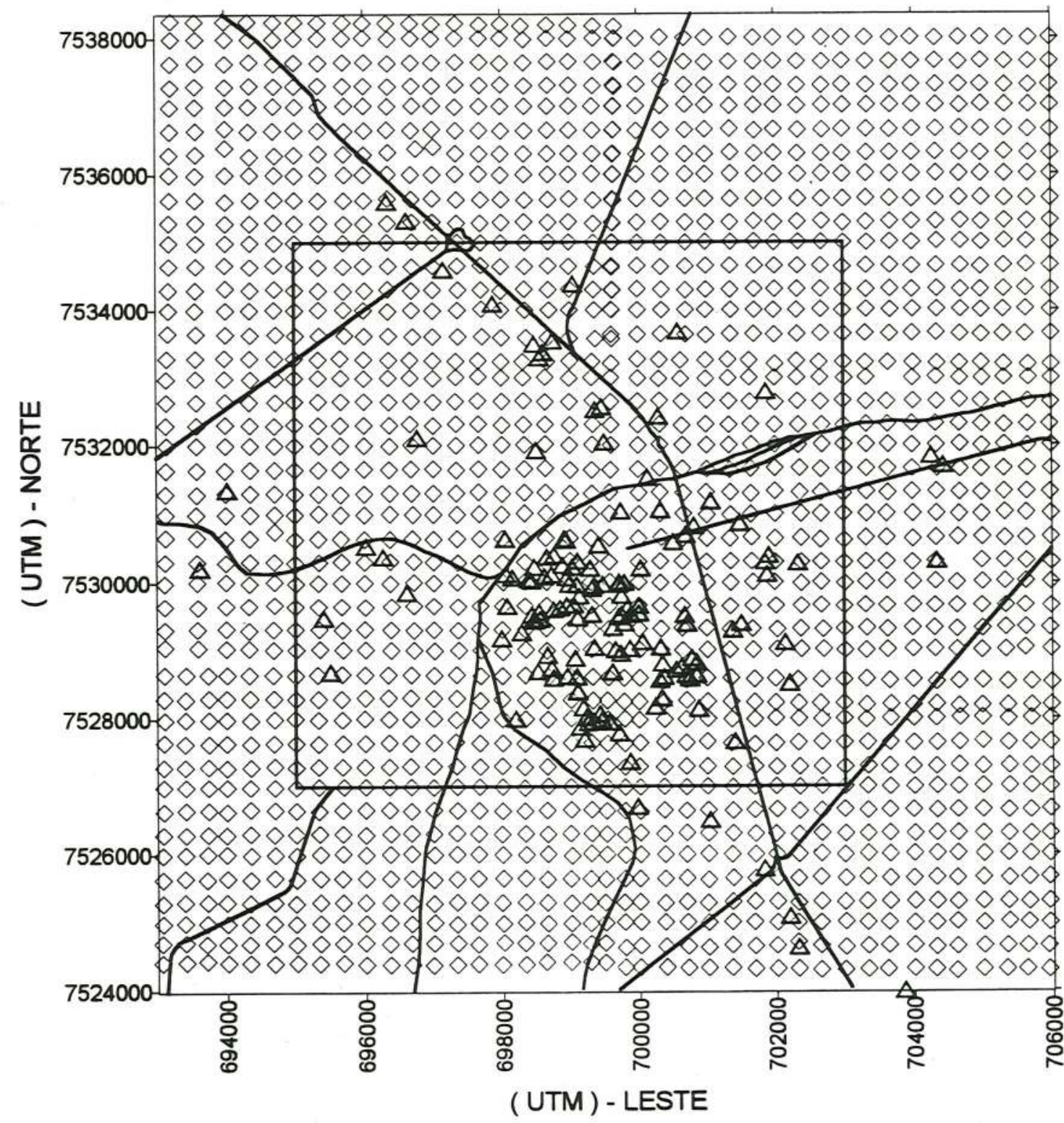

\footnotetext{
$\Delta \quad$ - Sondagens de simples reconhecimento ( média das obras )

$\diamond \quad$ - Cota topográfica

- Estradas principais e ferrovias
}

Figura 6.21 - Mapa das malhas primária e secundária. 

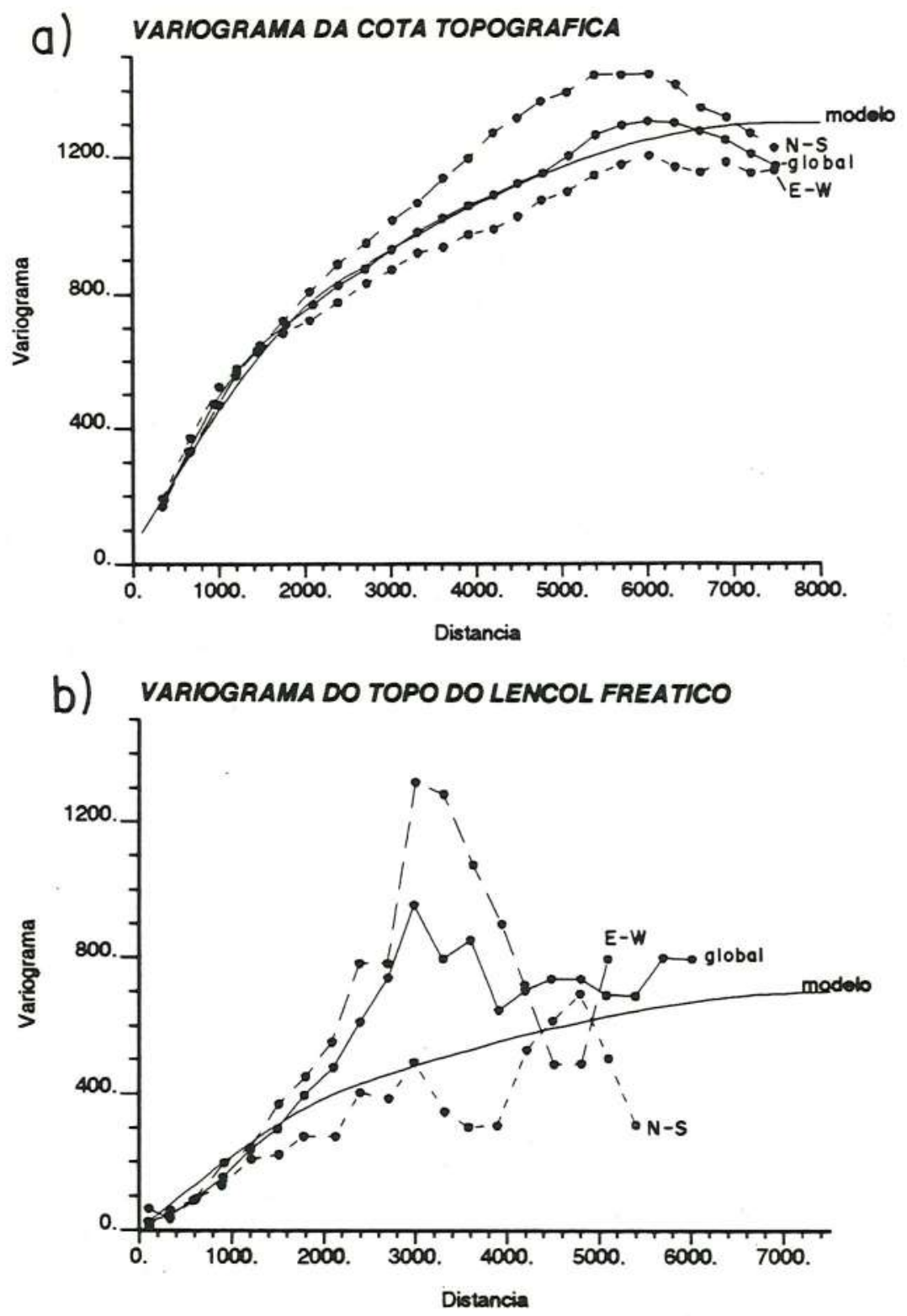

C) VARIOGRAMA DO TOPO DO IMPENETRAVEL

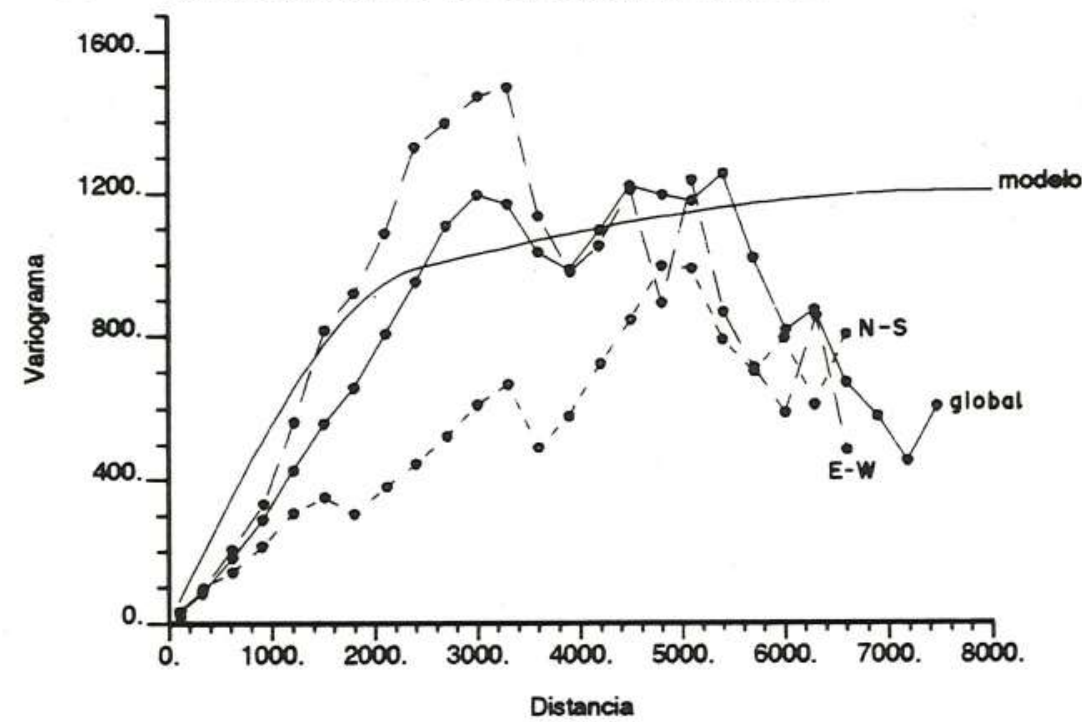

Figura 6.22 - Variogramas: a) cota topográfica b) topo do lençol freático c) topo do impenetrável 
que resultaram no seguinte modelo variográfico isotrópico:

$$
\gamma(h)=50+400 \operatorname{Esf}_{2400}(h)+850 \operatorname{Esf}_{7600}(h)
$$

Este modelo serviu de base para modelar os demais variogramas, visto que este modelo está fundamentado em uma densa malha pontos regular (Figura 6.21), que the confere significativa representatividade na variabilidade do processo geológico. Como o topo do lençol freático e do impenetrável mantêm estrita relação com a topografia, conforme mostraram os gráficos de correlações, é de se esperar estruturas de variabilidade semelhantes.

Desta forma, apesar das configurações dos variogramas dos topos do lençol freático e do impenetrável não se apresentarem devidamente na forma de estruturas de variabilidade conjugadas, seguiu-se 0 modelo usado para as cotas topográficas, visto que as malhas das variáveis de topollençol freático e impenetrável) são muito inferiores com relação à quantidade e regularidade da malha topográfica, o que também pode ocasionar um mascaramento das reais estruturas de variabilidade. Assim, com base no modelo topográfico, foram adotados os seguintes modelos para as variáveis de topo, representados nas figuras $6.22 \mathrm{~b}$ e $6.22 \mathrm{c}:$

- topo do lençol freático:

$$
\gamma(h)=200 \operatorname{Esf}_{2400}(h)+500 \operatorname{Esf}_{7600}(h)
$$

- topo do impenetrável:

$$
\gamma(h)=4+500 \operatorname{Esf}_{2400}(h)+400 \operatorname{Esf}_{7600}(h)
$$

o seguinte passo foi o de confeccionar os variogramas cruzados que, de forma similar aos variogramas anteriores, foram modelados conforme o modelo 
variogramas anteriores, foram-modeladós conforme o modelo básico da topografia cujas funções, que se encontram na Figura 6.23, são as seguintes:

- cota topográfica $\mathrm{x}$ topo do lençol freático:

$\gamma(h)=1^{\circ}+200 E s f_{2400}(h)+600 E s f_{7600}(h)$

- cota topográfica $\mathrm{x}$ topo do impenetrável:

$\gamma(h)=100+400 \operatorname{Esf}_{2400}(h)+400 E s f_{7600}(h)$
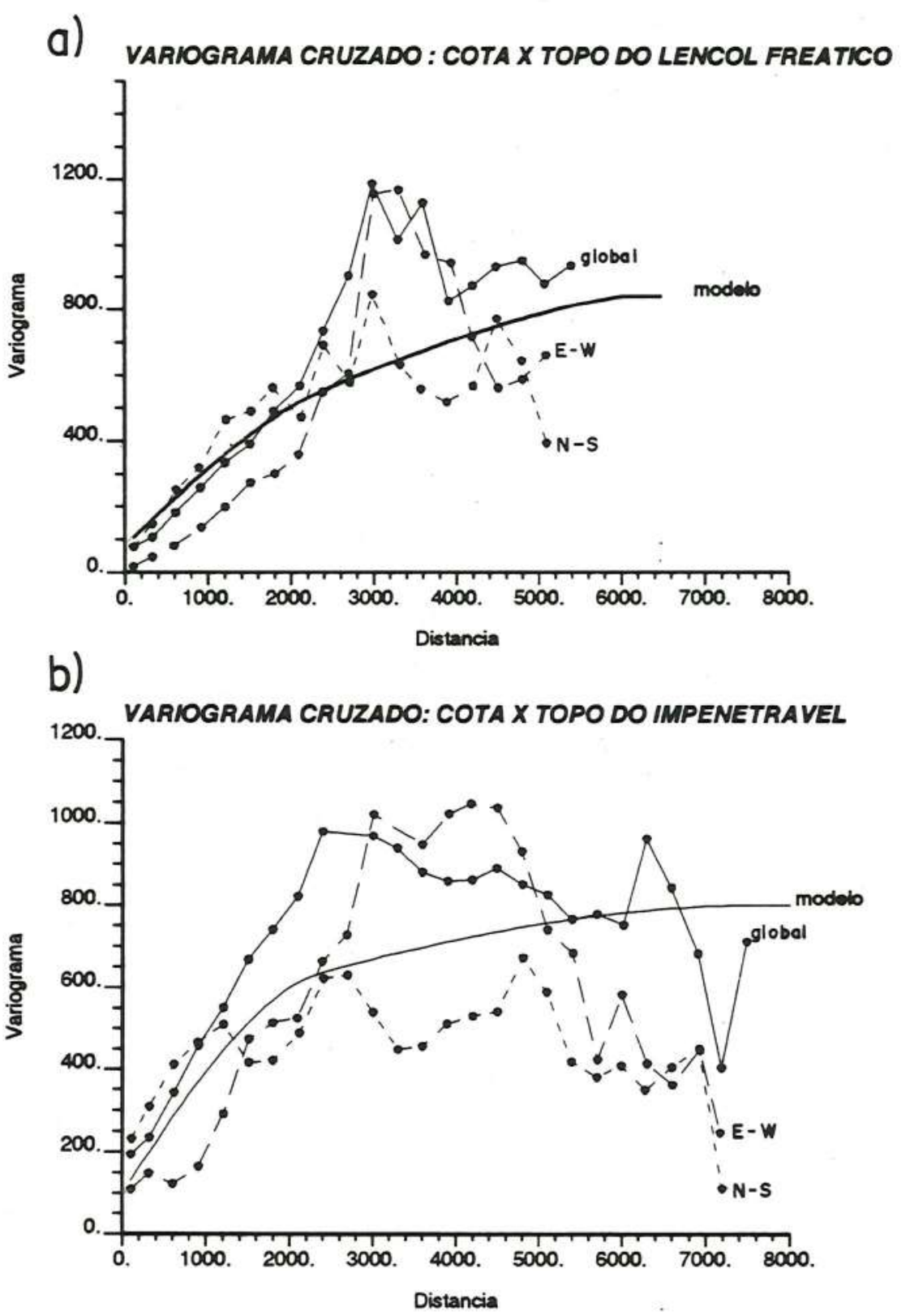

Figura 6.23 - Variogramas cruzados das cotas topográficas com; a) topo do lençol freático b) topo do impenetrável. 


\subsubsection{2- Aplicação da cokrigagem}

As estimativas foram feitas para o polígono mais amplo do mapa da Figura 6.21. Assim foi feita uma extrapolação das variáveis, topo do lençol freático e topo do impenetrável para os arredores do perímetro urbano.

A malha resultante das estimativas apresenta uma cela básica de 130 x 143,5 metros, sendo uma matriz de $100 \times 100$ nós, totalizando assim 10.000 pontos estimados.

A rigor, não haveria interesse em se fazer o mapa do relevo, por estimativa geoestatística. Entretanto, tendo em vista que, em mapeamentos geotécnicos existe um interesse maior para as profundidades do lençol freático e do impenetrável, foi gerado por krigagem ordinária o mapa topográfico no mesmo formato de malha que os mapas do topo do lençol freático e do impenetrável, para possíveis deduções das profundidades.

A Figura 6.24a mostra a imagem do relevo da área estudada, enquanto a Figura 6.24 b mostra $\circ$ mapa de isovalores dos desvios-padrão das estimativas das cotas do relevo. Nota-se que os desvios padrão apresentam uma grande homogeneidade em área, com valores situados entre 11 e 12m, refletindo a densa e regular malha de amostragem.

A imagem da Figura 6.25a mostra o topo do lençol freático, cujo padrão espacial reflete a imagem do relevo. Observa-se que, nos locais que são configuradas as drenagens do relevo, o topo do lençol freático apresenta equivalência de altitudes, denotando proximidade ou afloramento do lençol freático nestes locais.

o mapa de isovalores dos desvios-padrão das estimativas (Figura 6.25b) apresenta maior variação dos valores em relação às estimativas das cotas topográficas, visto que neste caso ocorre a integração das duas malhas de amostragem. 
Desta forma, nos setores com maior densidade de amostragem, os desvios padrão são relativamente mais baixos e homogêneos, aumentando bruscamente para a periferia, onde a malha corresponde somente à variável secundária que são as cotas topográficas.

A Figura 6.26a representa a imagem do topo do impenetrável ao amostrador padrão. De forma coerente, com - mapa estimado para o relevo, o topo do impenetrável acompanha as cotas topográficas, refletindo a correlação linear positiva entre as duas variáveis.

Com relação ao mapa de isovalores dos desvios-padrão das estimativas, mostrado na Figura $6.26 \mathrm{~b}$, o mesmo apresenta configuração similar ao do topo do lençol freático, com valores relativamente baixos e mais uniformes nos locais mais amostrados, e valores mais altos e progressivos à medida em que se afasta do centro mais amostrado. Entretanto, neste caso, a amplitude de variação dos desvios padrão da cokrigagem é maior, como reflexo de uma maior componente aleatória encontrada no variograma cruzado entre a cota topográfica e o topo do impenetrável, demonstrado na Figura 6.23b.

6.3.2.3 - Estimativas das profundidades do lençol freático e do topo do impenetrável

Tendo em vista que na construção de obras civis, o maior interesse se concentra nas profundidades do lençol freático e do topo do impenetrável, elaborou-se, então, os referidos mapas com base nas estimativas feitas pela krigagem para as cotas topográficas e pela cokrigagem para as cotas do lençol freático e do impenetrável, cujos mapas estão representados na Figura 6.27 .

Os mapas de profundidades constituem-se em resíduos de duas estimativas e apresentam portanto, a propagação de dois intervalos de confiança para o valor final. Este aspecto aumenta a incerteza com relação às profundidades avaliadas, principalmente para a periferia da cidade, onde a amostragem da variável primária inexiste. 

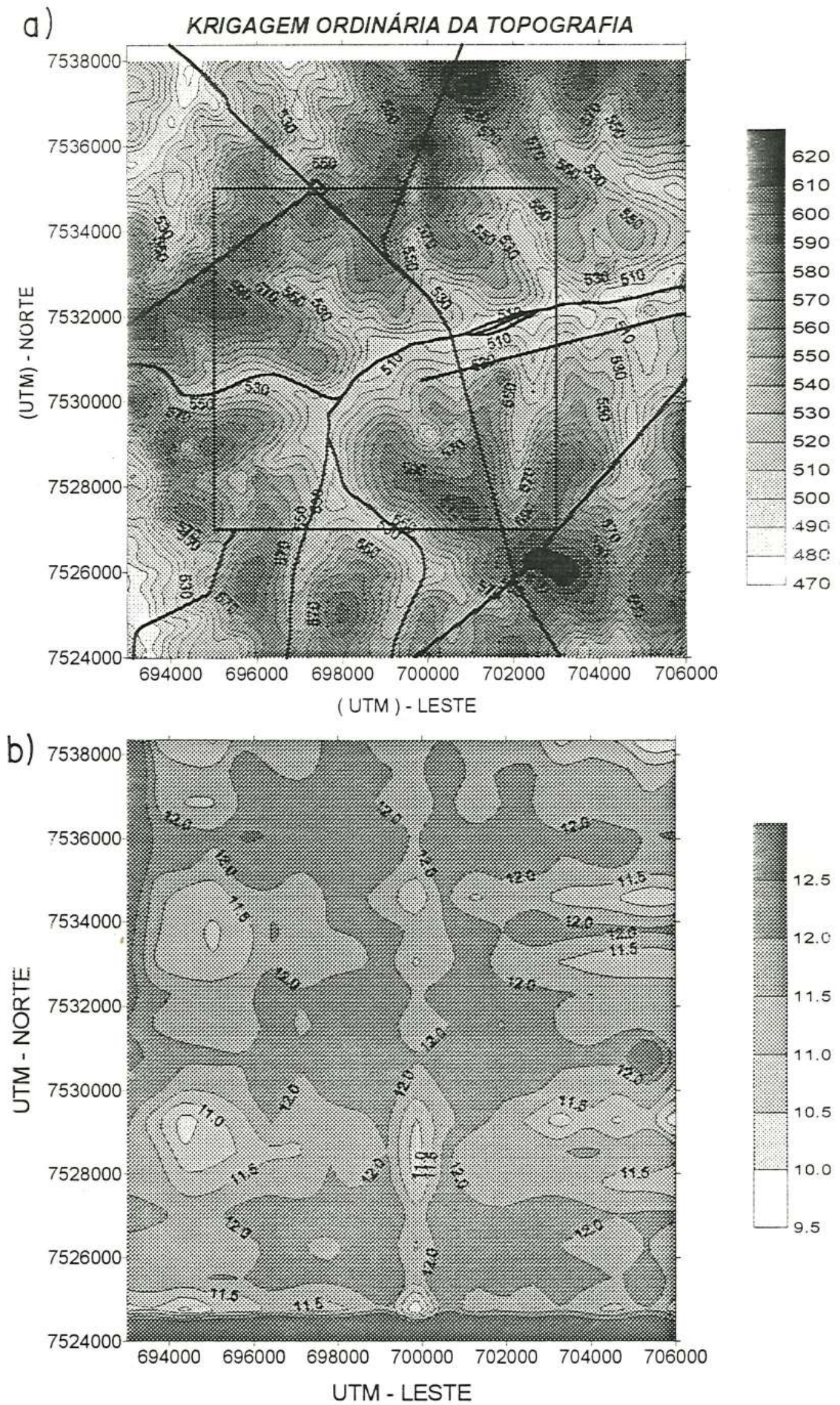

Figura 6.24 - Mapas estimados pela krigagem ordinária do relevo: a) cotas topográficas b) desviospadrão das estimativas 

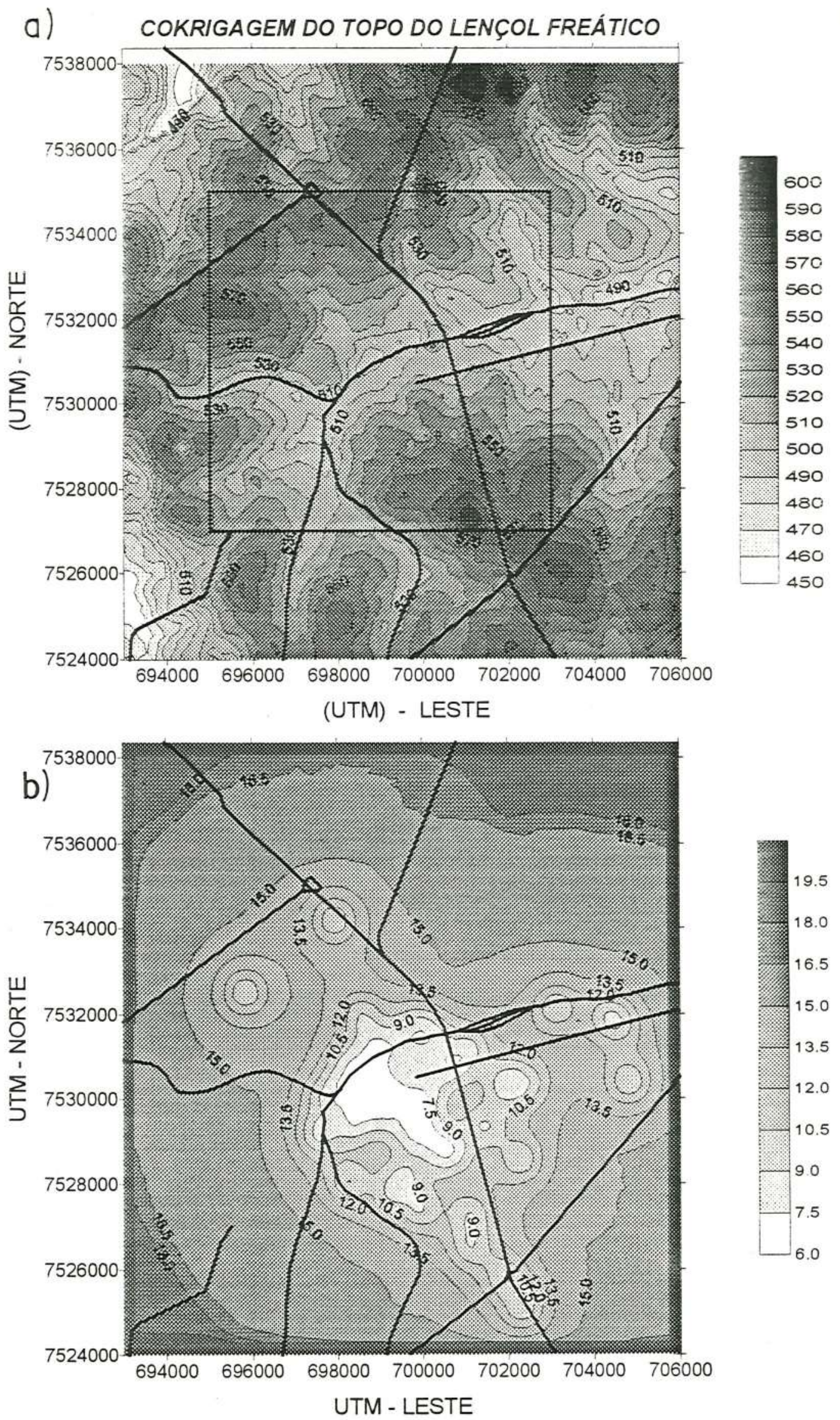

Figura 6.25 - Mapas estimados pela cokrigagem para:
a) topo do lençol freático
b) desvios - padrão das estimativas 

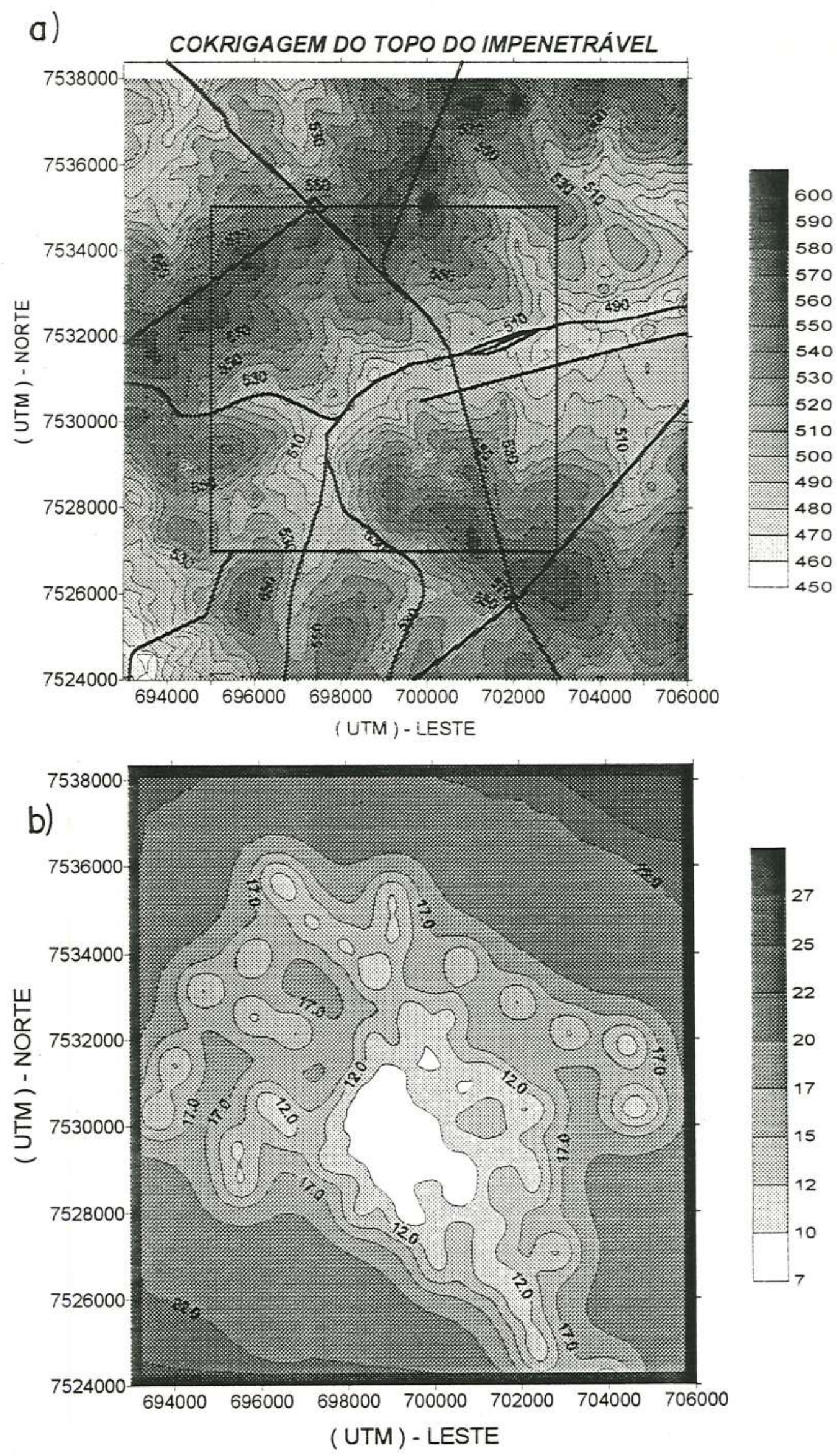

Figura 6.26 - Mapas estimados pela cokrigagem para:

a) topo do impenetrável

b) desvios-padrão das estimativas 

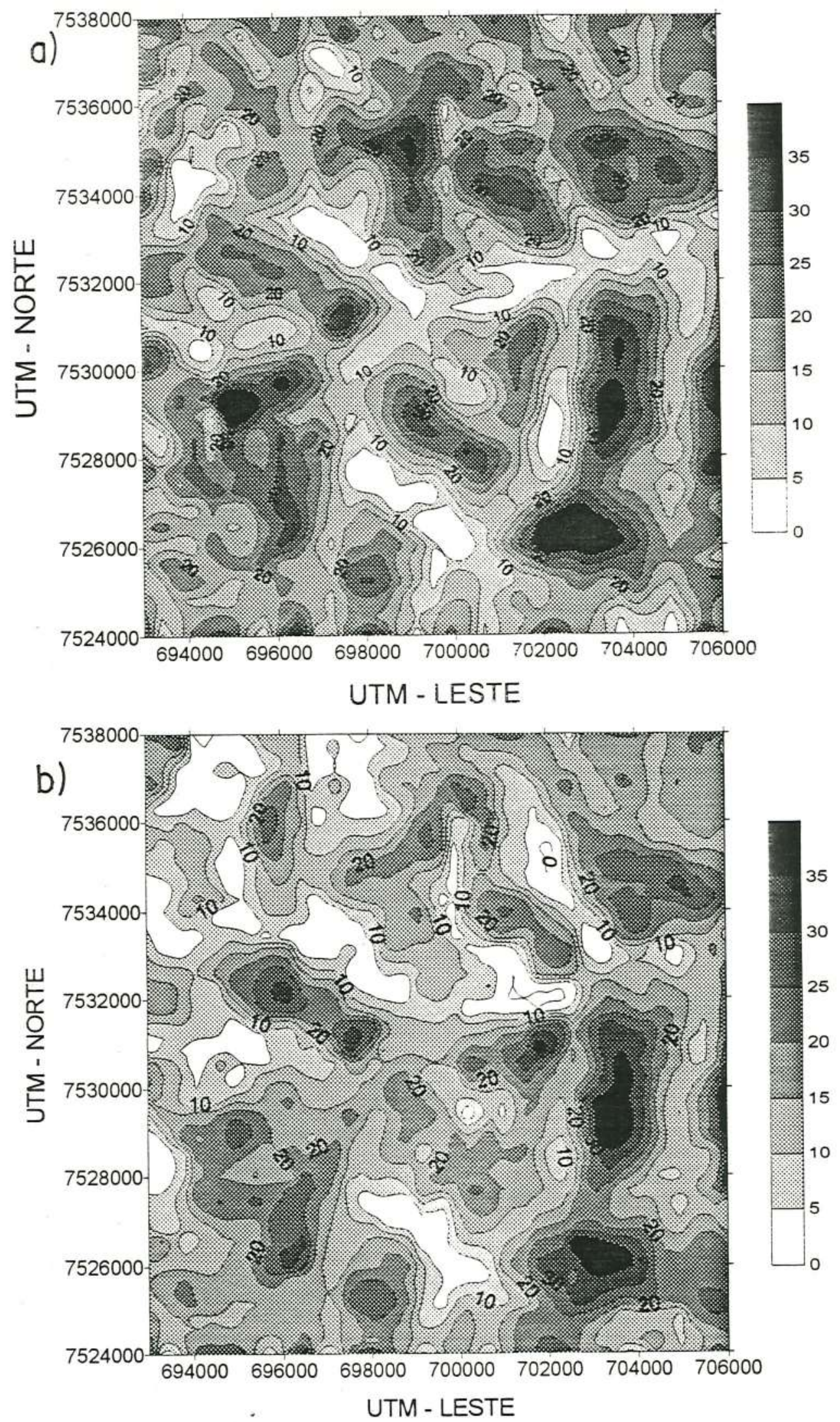

Figura 6.27 - Mapas estimados (deduzidos) das profundidades: a) lençol freático b) topo do impenetrável 
Comparando-se a configuração destes mapas com os mapas topográfico e geotécnico, nota-se alta concordância entre os mesmos, principalmente entre os mapas topográfico e de profundidade do lençol freático. Neste caso, as principais drenagens estão associadas às baixas profundidades ou aos afloramentos do lençol freático. Com relação à profundidade do impenetrável, que representa praticamente a espessura do material inconsolidado (material de alteração), o mesmo apresenta os maiores valores nos locais mais elevados, representados pelos altos das colinas da região, onde o perfil de alteração é mais profundo.

\subsection{3 - Estimativas pela krigagem indicativa}

Nesta etapa dos trabalhos geoestatísticos, o objetivo foi obter para cada ponto ou bloco, a estimativa das distribuições de probabilidade acumulada.

A partir destas estimativas, pode-se elaborar mapas com diversos enfoques, por exemplo:

- mapas referentes a um determinado percentil, inclusive a mediana.

- mapas probabilísticos da variável em estudo situar-se acima ou abaixo de um determinado nível de corte (cutoff).

- mapas probabilísticos de classificação da variável em um determinado intervalo.

Neste trabalho, com o intuito de avaliar os locais de maior compacidade, adotou-se determinar para cada nível, a probabilidade do SPT estar situado acima do terceiro quartil da distribuição de probabilidade inferida. Entretanto, a elaboração mapas probabilísticos para outros níveis de corte é perfeitamente possível, tendo em vista que a distribuição de probabilidades já se encontra estimada.

No caso do estudo da camada, adotou-se o critério de mapear a probabilidade do SPT estar situado nos intervalos clássicos, definidos em TERZAGHI \& PECK 
(1957), que classificam os solos arenosos com relação à sua compacidade, ou seja: 0 a 4 fofo; 5 a 10 pouco compacto; 11 a 30 medianamente compacto; 31 a 50 compacto; maior 50 muito compacto.

As malhas dos pontos estimados para os níveis e dos blocos para a camada seguiram a mesma configuração adotada na krigagem padrão (ordinária), ou seja, foram estimados 10.000 pontos ou blocos, dispostos numa matriz 100 x 100, cujo intervalo entre os nós da malha quadrada é de 80 metros, enquanto os blocos da camada apresentaram dimensões de $80 \times 80 \times 5 \mathrm{~m}$.

\subsubsection{1- Análise Variográfica Indicativa e Estimativas}

Com base nas distribuições de freqüência dos diversos níveis estudados, bem como na distribuição de freqüência da camada (figuras 6.9, 6.10 e 6.11), estabeleceram-se os valores de corte dos SPT's para cada nível e para a camada.

De acordo com KIM (1988), o número de valores de corte entre 5 e 10 e com proporções similares de observações entre os intervalos, representa condições adequadas para inferir a distribuição de probabilidade acumulada.

Um problema que surgiu na elaboração dos variogramas indicativos foi com a distribuição irregular da malha de sondagens. Segundo ISAAKS \& SRIVASTAVA(1989), 0 agrupamento de pontos afeta consideravelmente os variogramas indicativos. Este aspecto foi notado nos variogramas preliminares elaborados neste trabalho.

Para superar este problema, foi elaborada uma malha regular disposta numa matriz de 25 x 25, cujos nós foram estimados pelo método do Inverso do Quadrado da Distância (IQD).

Para evitar que estas estimativas preliminares distorcessem os valores originais, adotou-se o menor raio de influência possível para o IQD, cujo valor, após uma série de testes, foi de 500 metros. 
A seguir são apresentadas as análises para cada nível, fechando-se todas as análises com a camada superficial individualizada.

- Nível 01 - profundidade igual a 1 metro.

Com base no histograma do nível 01, foram definidos cinco valores de corte, para inferir as distribuições de probabilidade dos pontos estabelecidos na malha básica.

Os variogramas experimentais foram elaborados para os diversos valores de corte nas direções N-S, E-W e a direção SW-NE. Todos os variogramas foram ajustados ao modelo variográfico esférico e com uma única estrutura, cujos parâmetros encontram-se na Tabela 6.5 e demonstrados nas figuras 6.28 e 6.29 .

TABELA 6.5- PARÂMETROS VARIOGRÁFICOS DOS MODELOS INDICATIVOS - NÍVEL 01

\begin{tabular}{|c|c|c|c||}
\hline $\begin{array}{c}\text { Valores de } \\
\text { Corte }\end{array}$ & Co & C1 & a (m) \\
\hline 1,75 & 0,00 & 0,17 & 1100 \\
\hline 2,00 & 0,04 & 0,17 & 1200 \\
\hline 2,63 & 0,00 & 0,20 & 1400 \\
\hline 3,00 & 0,02 & 0,14 & 1400 \\
\hline 3,63 & 0,02 & 0,11 & 1150 \\
\hline
\end{tabular}

As componentes aleatórias são relativamente baixas, exceto para os valores de corte mais altos, e a configuração dos variogramas direcionais se apresenta de forma isotrópica.

$\mathrm{Na}$ variografia indicativa, o modelo da mediana é o mais representativo para o conjunto de dados de um determinado nível, visto que a mediana constitue o valor de corte, que separa equitativamente os dados. Neste caso, para o nível 01, o modelo da mediana é dado pela função:

$$
\gamma(h)=0.04+0.17 \operatorname{Esf}_{1200}(h)
$$

o mapa da Figura 6.30 representa a probabilidade do SPT ser maior que o quartil superior 
$(2,65)$ do nível 01. Estas estimativas foram feitas para os 10.000 pontos da malha padrão adotada neste trabalho.

As maiores probabilidades ocorrem na direção NW-SE, com concentrações também no setor SW da cidade. Este mapa apresenta maiores alternativas de locais com determinada compacidade, quando comparado com o mapa da krigagem padrão da Figura 6.14. Como no mapa da krigagem ordinária, as concentrações das probabilidades mais altas não apresentam relação direta com as unidades individualizadas nos mapas do meio físico.

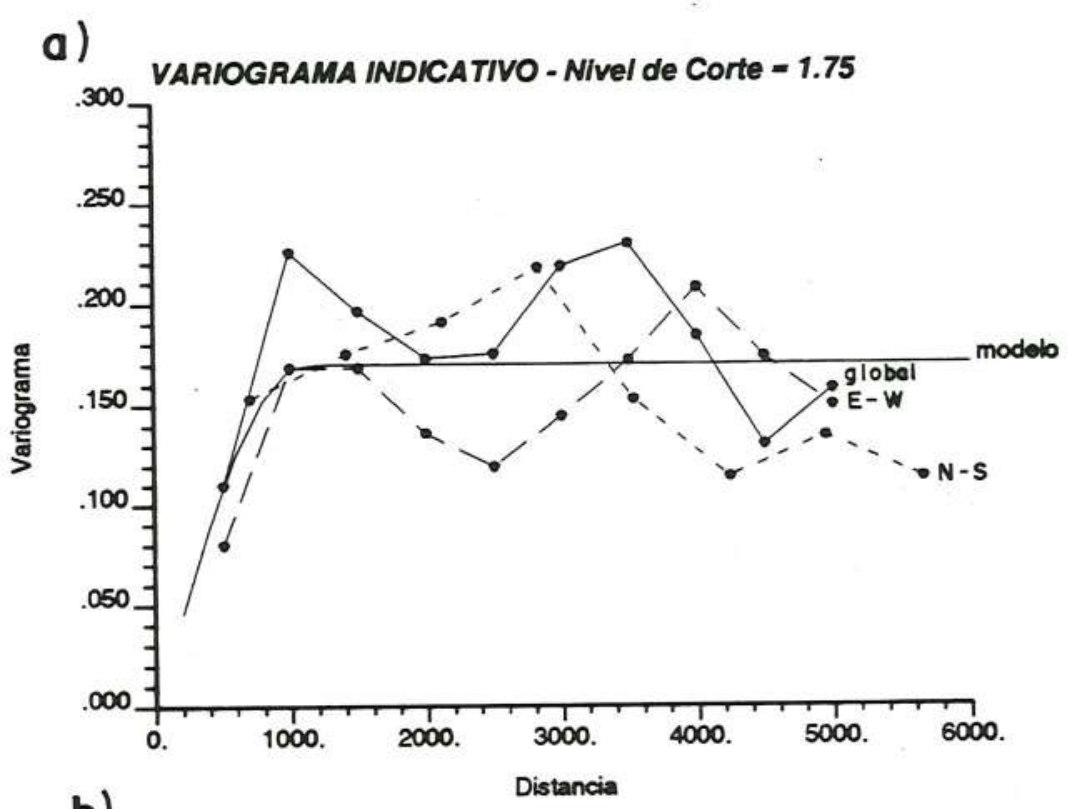

b)

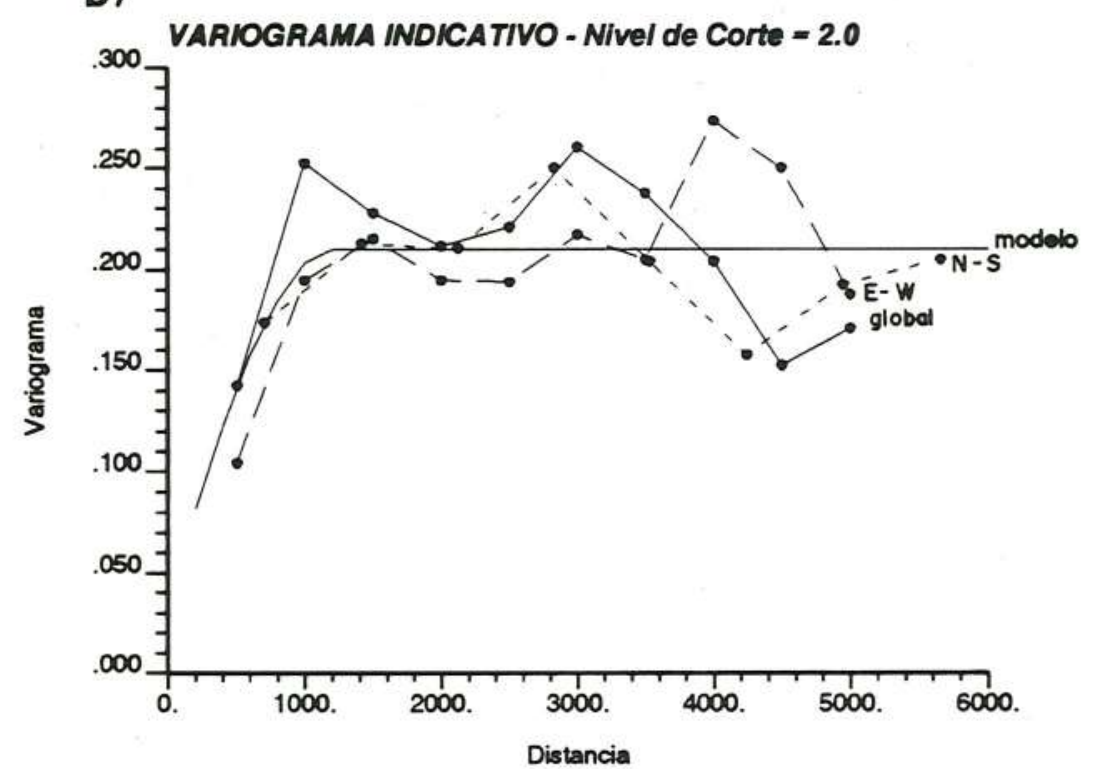

Figura 6.28 - Variogramas indicativos para o nivel 01, com niveis de corte: a) 1.75 ; b) 2.0 . 

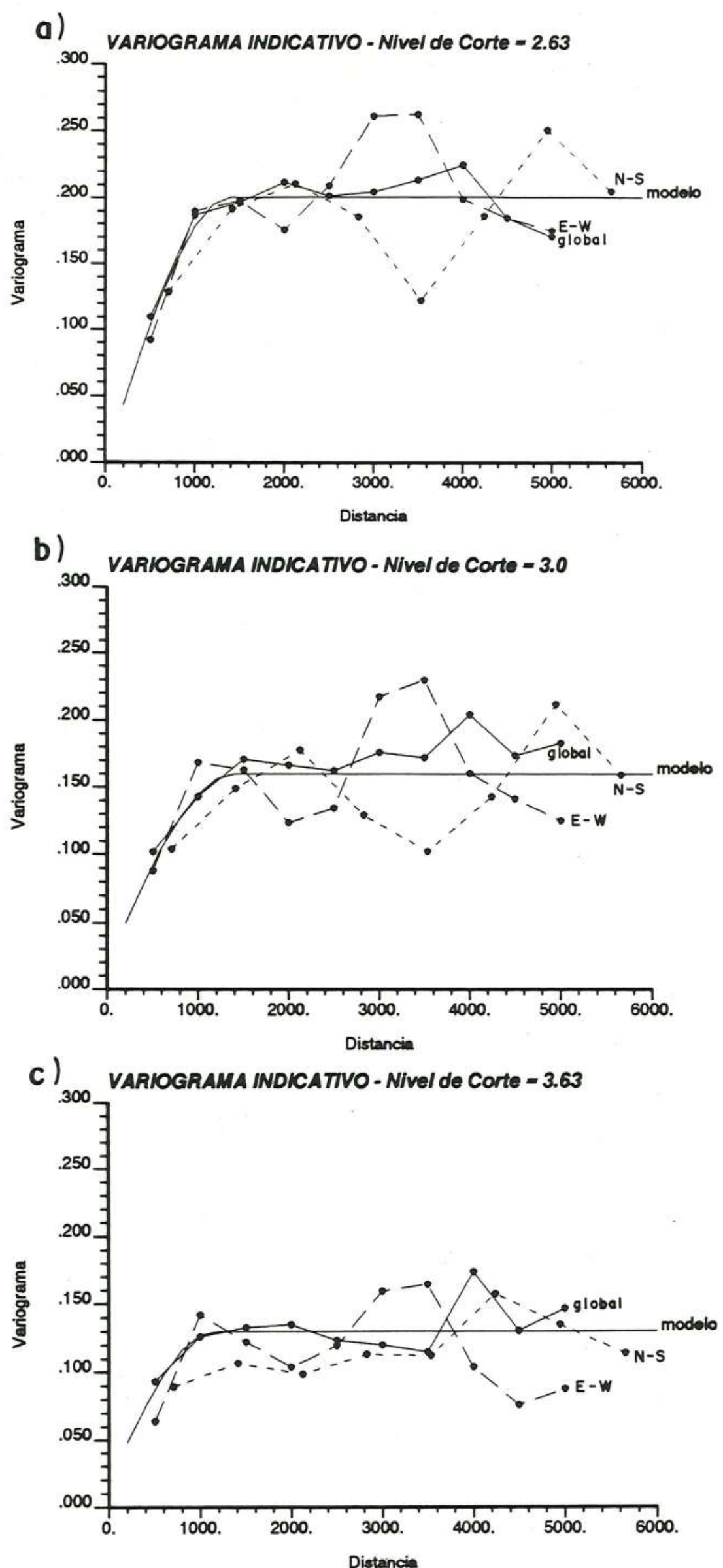

Figura 6.29 - Variogramas indicativos para o nível 01, com niveis de corte: a) 2.63 b) 3.0 c) 3.63 


\section{PROBABILIDADE DO SPT $>2.65$}

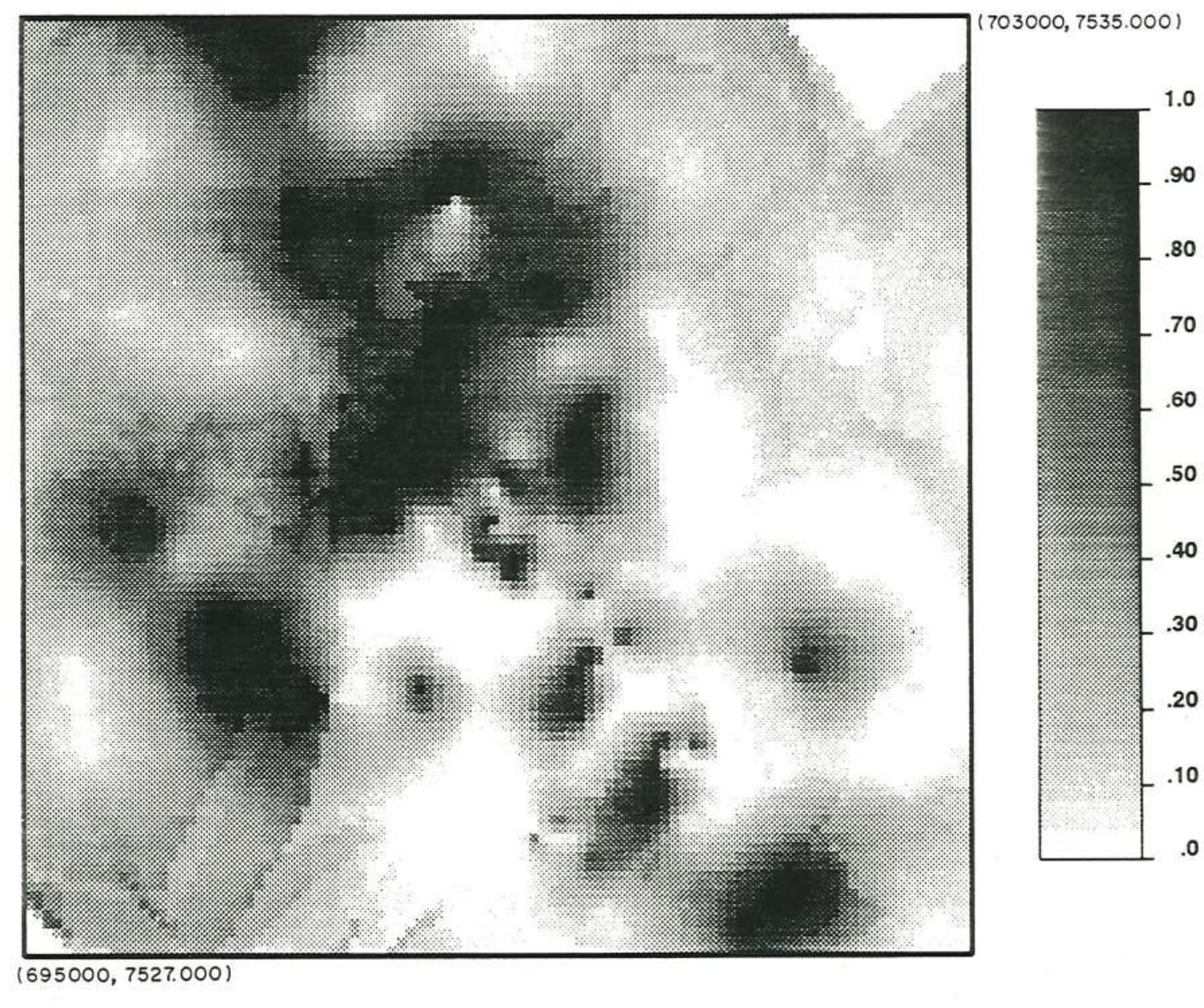

Figura 6.30 - Mapa probabilístico do nível 01; probabilidade do $\mathrm{SPT}>2.65$. 
Nível 02 - profundidade igual a 2 metros

Foram elaborados os diversos variogramas experimentais, para os cinco valores de corte extraídos do histograma do nível 02 , cujos gráficos estão demonstrados nas figuras 6.31 e 6.32 .

Os variogramas experimentais apresentam boa isotropia e efeito de pepita normalmente nulo ou muito baixo. É esperada uma diminuição do patamar para os variogramas com índices de corte mais elevados, como se observa no variograma da Figura 6.32c. Este fato deve-se ao mecanismo de transformação não linear das variáveis originais, ou seja, quanto mais próximo das extremidades dos valores máximo e mínimo do conjunto de dados, os valores indicativos tendem para um determinado lado ( 0 ou 1), o que torna a variabilidade menor e, por conseguinte - patamar dos variogramas.

Os modelos ajustados foram do tipo esférico com uma única estrutura. A Tabela 6.6 mostra os parâmetros deste modelo para os diversos valores de corte.

TABELA 6.6 - PARÂMETROS DOS MODELOS VARIOGRÁFICOS INDICATIVOS - NÍVEL 02

\begin{tabular}{||c|c|c|c||}
\hline $\begin{array}{c}\text { Valores de } \\
\text { corte }\end{array}$ & C0 & C1 & A (m) \\
\hline 1,86 & 0,00 & 0,17 & 1200 \\
\hline 2,32 & 0,00 & 0,23 & 1200 \\
\hline 3,00 & 0,02 & 0,20 & 1400 \\
\hline 3,70 & 0,00 & 0,16 & 1400 \\
\hline 4,30 & 0,02 & 0,07 & 1300 \\
\hline
\end{tabular}

Destaca-se o modelo variográfico indicativo da mediana, que é o mais representativo do nível, dado pela função:

$$
\gamma(h)=0.23 E s f_{1200}(h)
$$

O mapa da Figura 6.33 representa a probabilidade do SPT ser maior que o quartil superior do nível 02 . O mapa 
apresenta uma configuração de concentrações elevadas do SPT, similar ao mapa do nível 01, notando-se uma tendência de maior aglutinação dos valores altos. A rigor, estas concentrações encontram-se nas unidades geotécnicas II e III, apresentadas no mapa geotécnico da Figura 5.1.
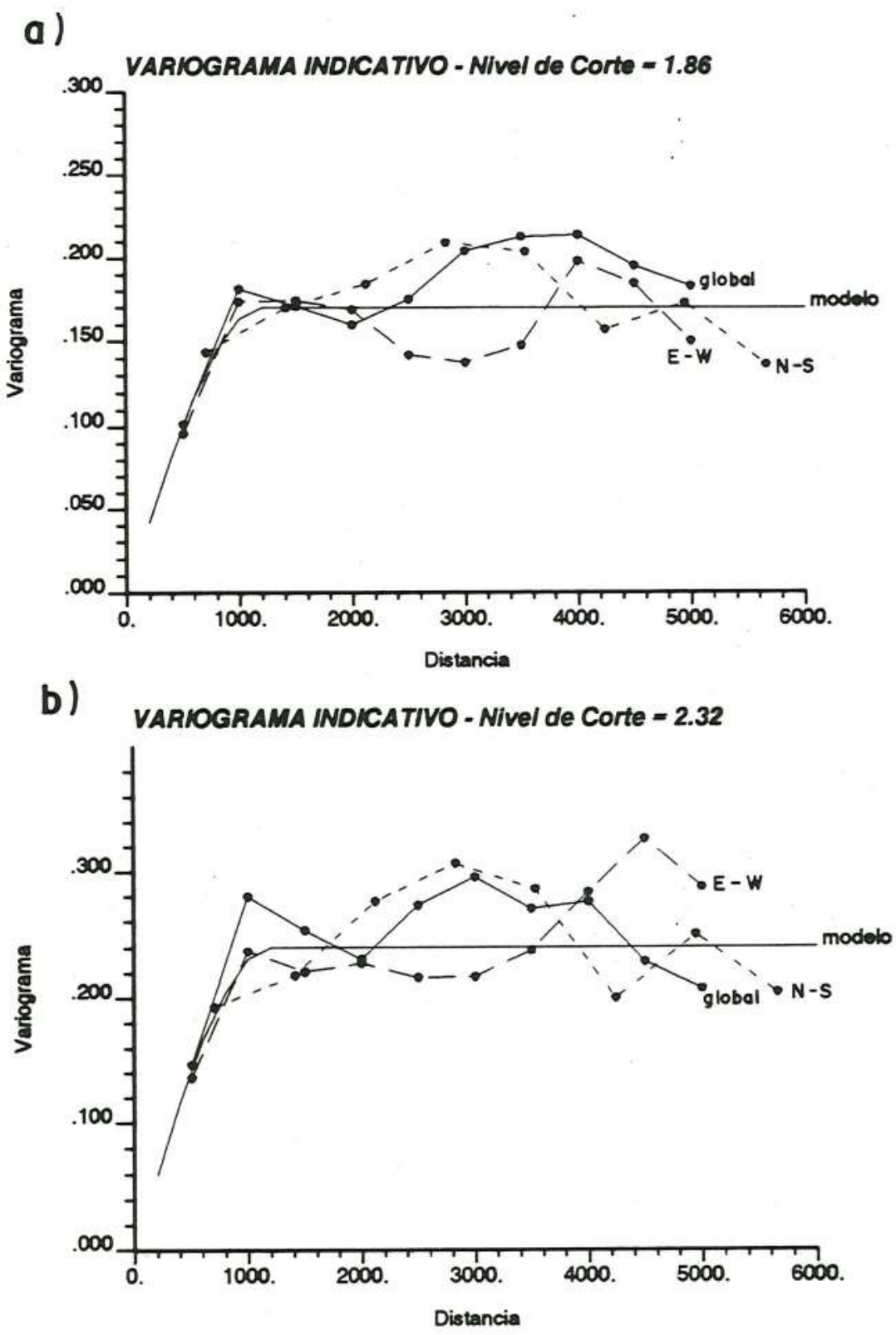

Figura 6.31 - Variogramas indicativos do nível 02, com níveis de corte: a) 1.86 , b) 2.32 


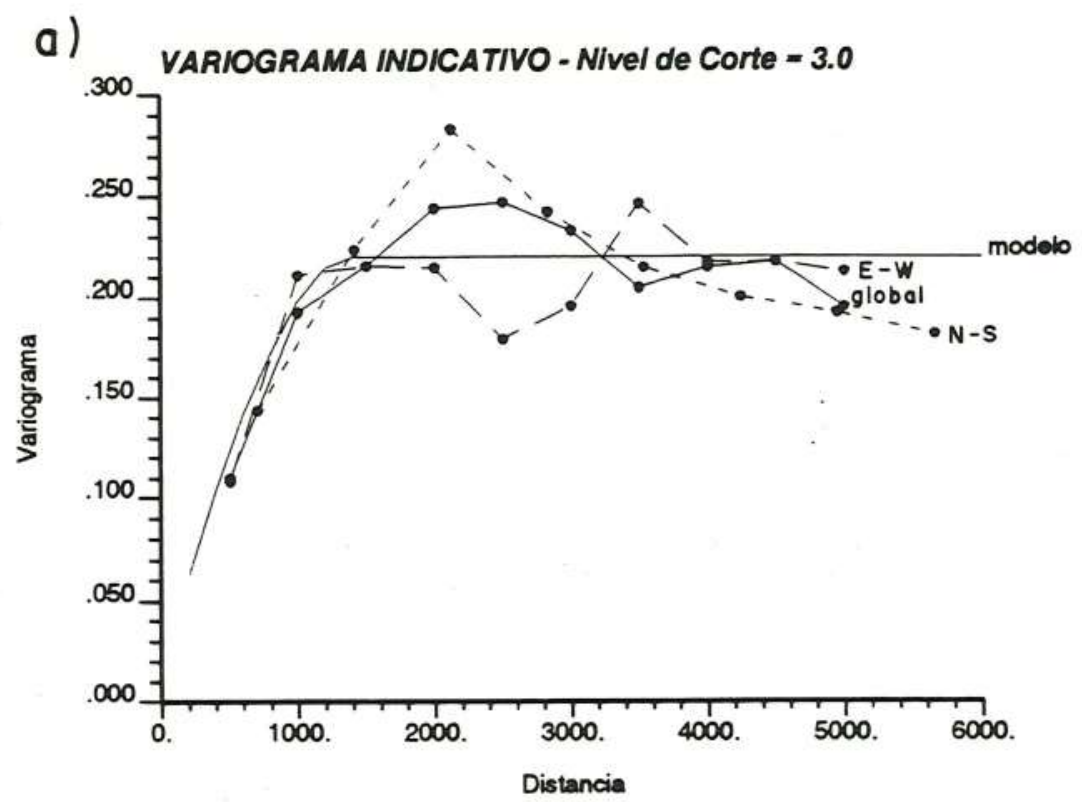

b) .300 VARIOGRAMA INDICATIVO - NIvel de Corte $=3.7$

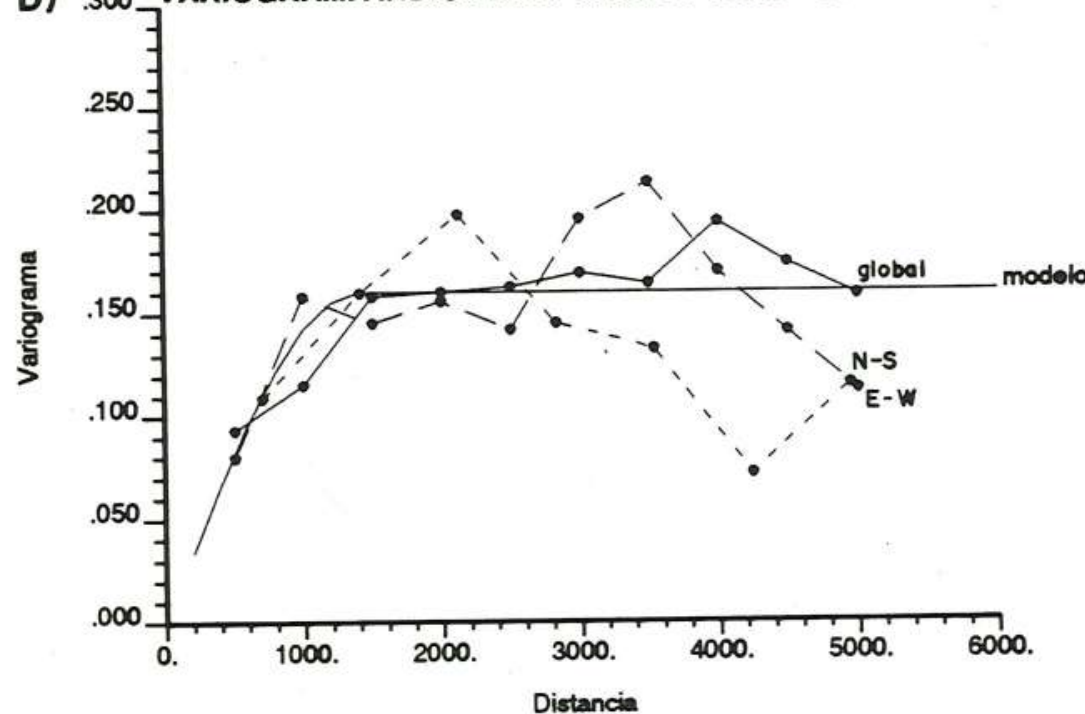

C) VARIOGRAMA INDICATIVO - Nivel de Corte $=4.3$

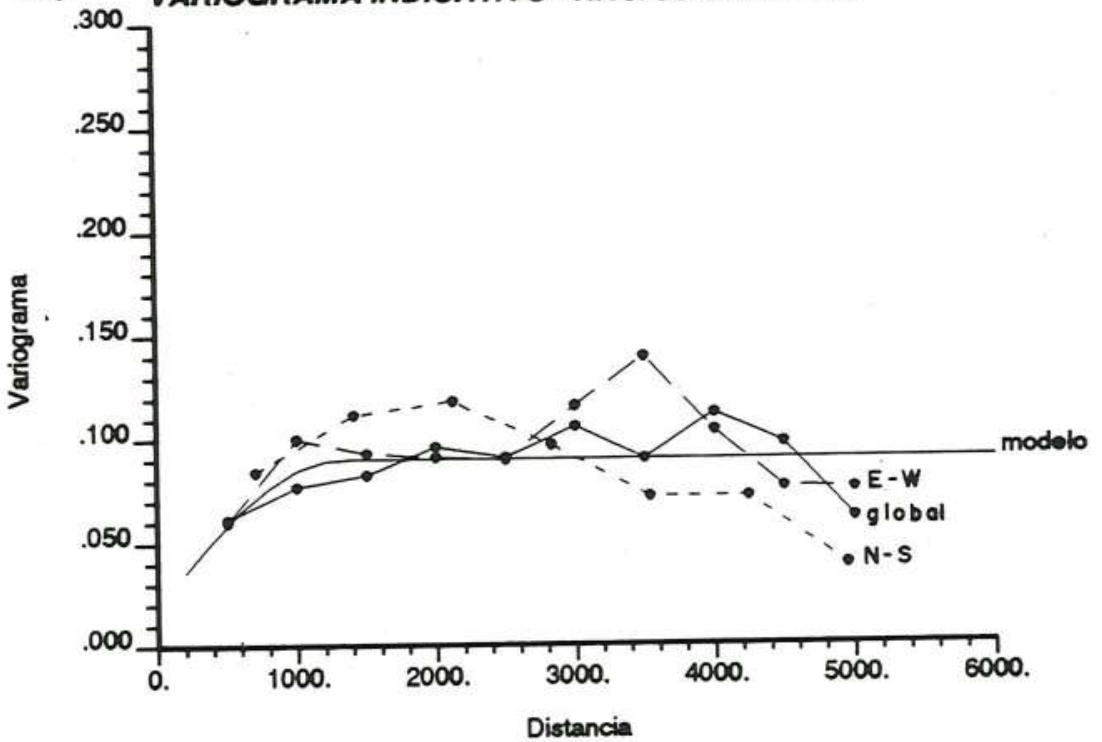

Figura 6.32 - Variogramas indicativos do nível 02 , com níveis de corte: a) 3.0 b) 3.7 c) 4.3 
PROBABILIDADE DO SPT $>3.2$

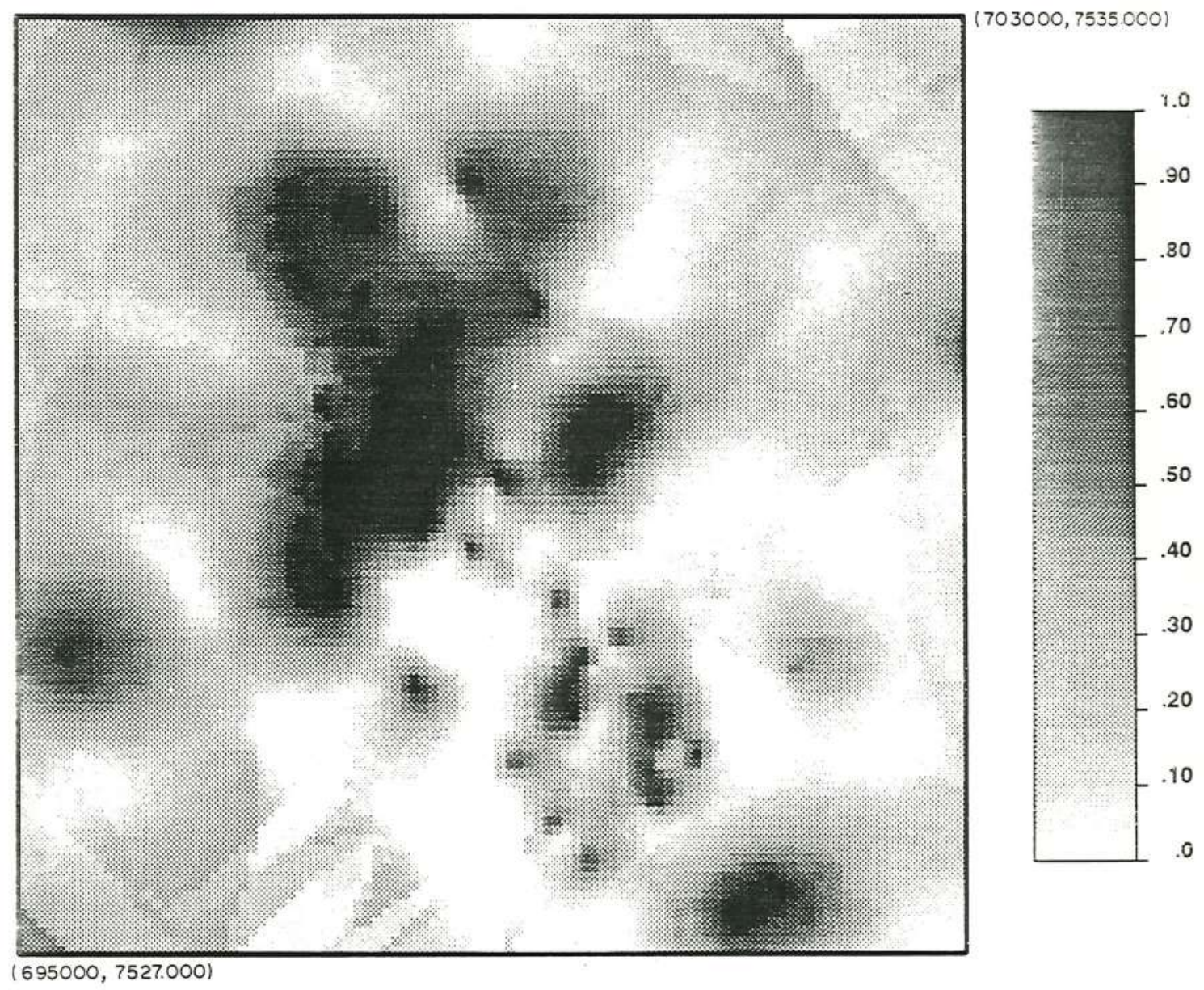

Figura 6.33 - Mapa probabilístico do nível 02; Probabilidade do $\mathrm{SPT}>3.2$ 
Nível 03 - profundidade de 3 metros

os variogramas experimentais deste nível com os respectivos modelos ajustados, encontram-se nas figuras 6.34 e 6.35 .

Analisando-se o conjunto dos variogramas para os 5 valores de corte, nota-se um aumento do caráter isotrópico para os índices de corte mais elevados. Particularmente, os variogramas direcionais do índice de corte igual a 2.0 (Figura 6.34a), apresentam considerável anisotropia a partir da distância de 1100 metros, sendo que a direção $\mathrm{N}-\mathrm{S}$ apresenta uma notável queda de variabilidade.

As maiores componentes aleatórias (Co/c $x$ 100) encontram-se nos variogramas dos índices de corte igual a 2,8 e 3,6 (Figuras $6.34 \mathrm{~b}$ e 6.34c), cujos valores são de $33 \%$ e $38 \%$, respectivamente.

Os modelos variográficos ajustados foram do tipo esférico, com uma única estrutura. A Tabela 6.6 mostra os parâmetros básicos dos modelos ajustados.

TABELA 6.6 - PARÂMETROS DOS MODELOS VARIOGRÁFICOS INDICATIVOS - NÍVEL 03

\begin{tabular}{||c|c|c|c||}
\hline $\begin{array}{l}\text { Valores de } \\
\text { corte }\end{array}$ & C0 & C1 & A (m) \\
\hline 2,0 & 0,00 & 0,13 & 1400 \\
\hline 2,8 & 0,06 & 0,18 & 1400 \\
\hline 3,6 & 0,08 & 0,21 & 1400 \\
\hline 4,4 & 0,01 & 0,14 & 1400 \\
\hline 5,2 & 0,00 & 0,11 & 1400 \\
\hline
\end{tabular}

O modelo esférico da mediana para este nível é dado pela função:

$$
\gamma(h)=0.06+0.18 \operatorname{Esf}_{1400}(h)
$$

o mapa da Figura 6.36 apresenta a imagem das probabilidades serem maiores que 4,0. Este mapa possui as principais concentrações alinhadas na direção SE-NW, 
encontradas nos mapas anteriores, apresentando novos núcleos de probabilidades altas, situados ao sul e a oeste-noroeste da área. Estes novos núcleos situam-se na unidade geotécnica II, formada basicamente pela cobertura latossólica.
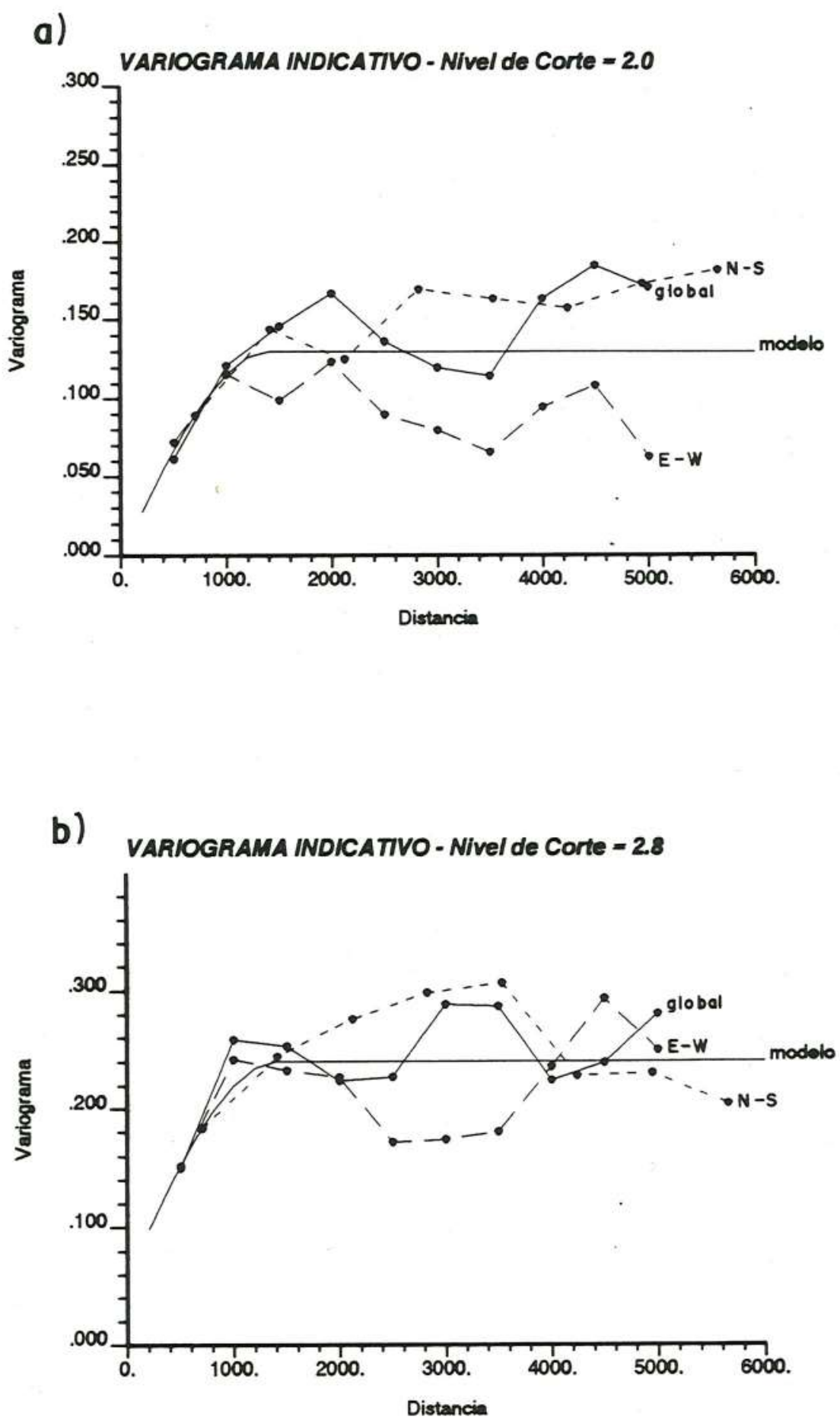

Figura 6.34 - Variogramas indicativos do nível 03, com níveis de corte a) 2.0 b) 2.8 

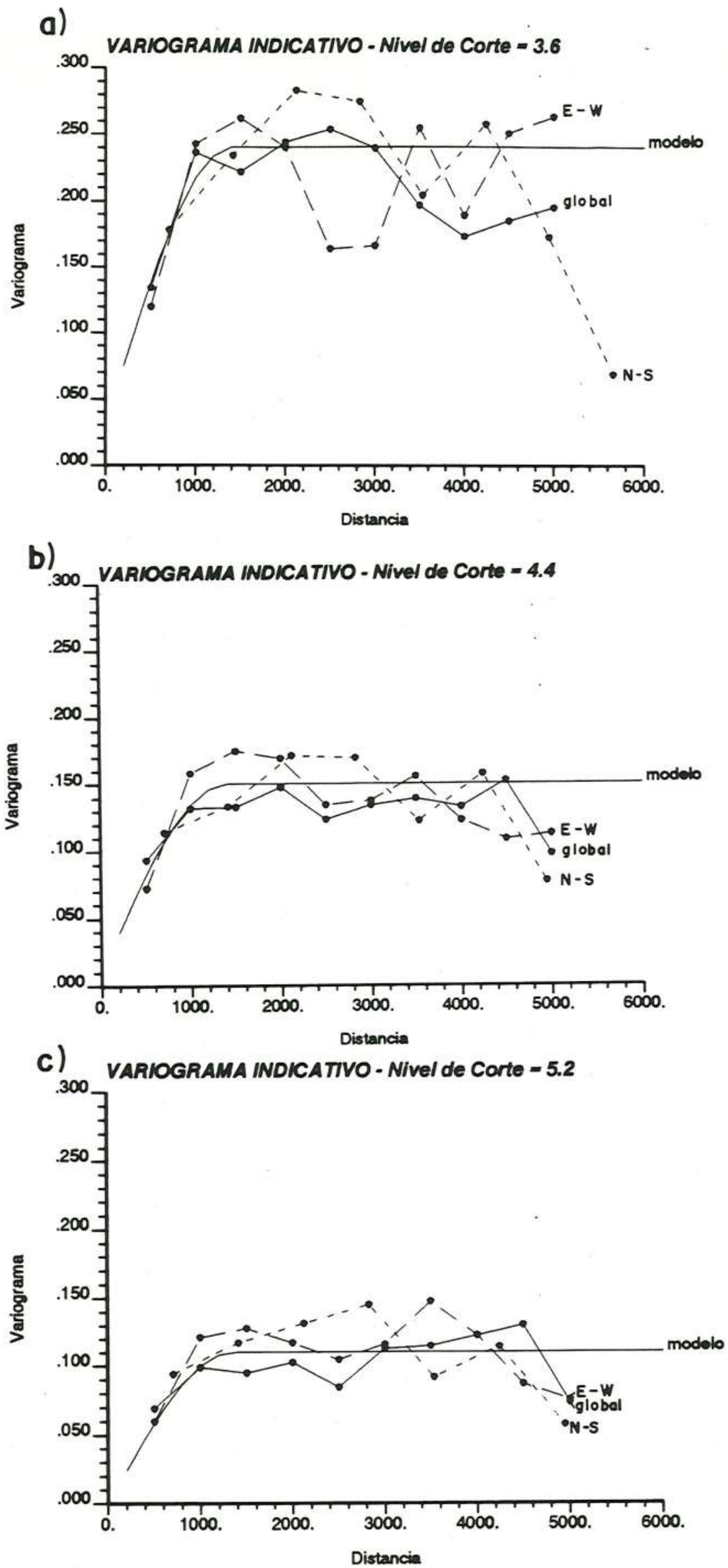

Figura 6.35 - Variogramas indicativos do nível 03, com níveis de corte a) 3.6 b) 4.4 c) 5.2 


\section{PROBABILIDADE DO SPT $>4.0$}

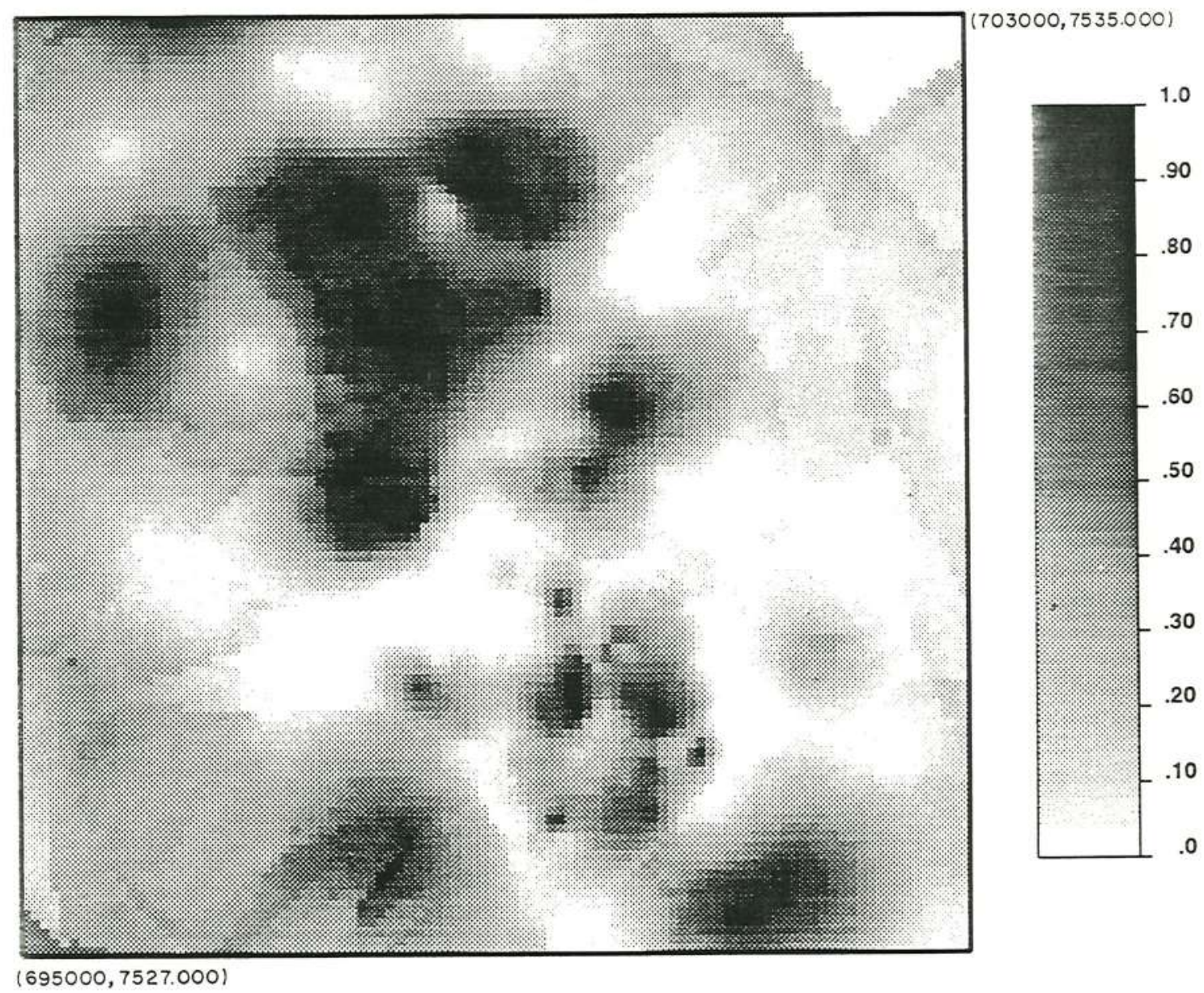

Figura 6.36 - Mapa probabilístico do nível 03. Probabilidade do $\mathrm{SPT}>4.0$ 
Nível 04 - profundidade de 4 metros

As figuras 6.37 e 6.38 mostram os variogramas experimentais, elaborados para as direções N-S, E-W e SWNE, para os cinco valores de corte, extraídos com base nos quartis da distribuição de freqüência do nível 04 (Figura 6.11).

De forma geral, os variogramas apresentam um mesmo padrão isotrópico, com exceção em parte, para os variogramas do valor inferior de corte $(2,7)$, onde a direção N-S volta a apresentar menor variabilidade que as demais direções. As componentes aleatórias dos diversos variogramas são notadamente baixas, o que representa uma boa estruturação das variáveis indicativas para este nível.

Os modelos variográficos ajustados foram do tipo esférico com uma única estrutura. Os parâmetros básicos destes modelos encontram-se na Tabela 6.8 .

TABELA 6.8 - PARÂMETROS DOS MODELOS VARIOGRÁFICOS INDICATIVOS - NÍVEL 04

\begin{tabular}{|c|c|c|c||}
\hline $\begin{array}{c}\text { Valores de } \\
\text { corte }\end{array}$ & C0 & C1 & A (m) \\
\hline 2,7 & 0,01 & 0,17 & 1350 \\
\hline 3,7 & 0,01 & 0,24 & 1200 \\
\hline 4,7 & 0,06 & 0,16 & 1800 \\
\hline 5,5 & 0,01 & 0,15 & 1400 \\
\hline 6,5 & 0,01 & 0,11 & 1500 \\
\hline
\end{tabular}

o modelo do variograma do valor de corte da mediana apresenta a seguinte função:

$$
\gamma(h)=0.01+0.24 E s f_{1200}(h)
$$

Nota-se que 0 patamar $\left(\mathrm{Co}+\mathrm{C}_{1}\right)$ corresponde à variância, a priori, das variáveis indicativas, igual a 0,25 , definido pela expressão:

$\operatorname{Var}(I)=m(1-m)$, onde $m$ é a média aritmética $(\cong 0,5)$ 
o mapa da Figura 6.39 representa as probabilidades que, distribuídas espacialmente, podem ser maiores que 0 quartil superior deste nível.

Este mapa apresenta muita similaridade com o mapa do nível anterior, com exceção de uma alta concentração situada a leste da área, onde a probabilidade do SPT de ser maior que 5,0, atinge valores da ordem de $80 \%$.
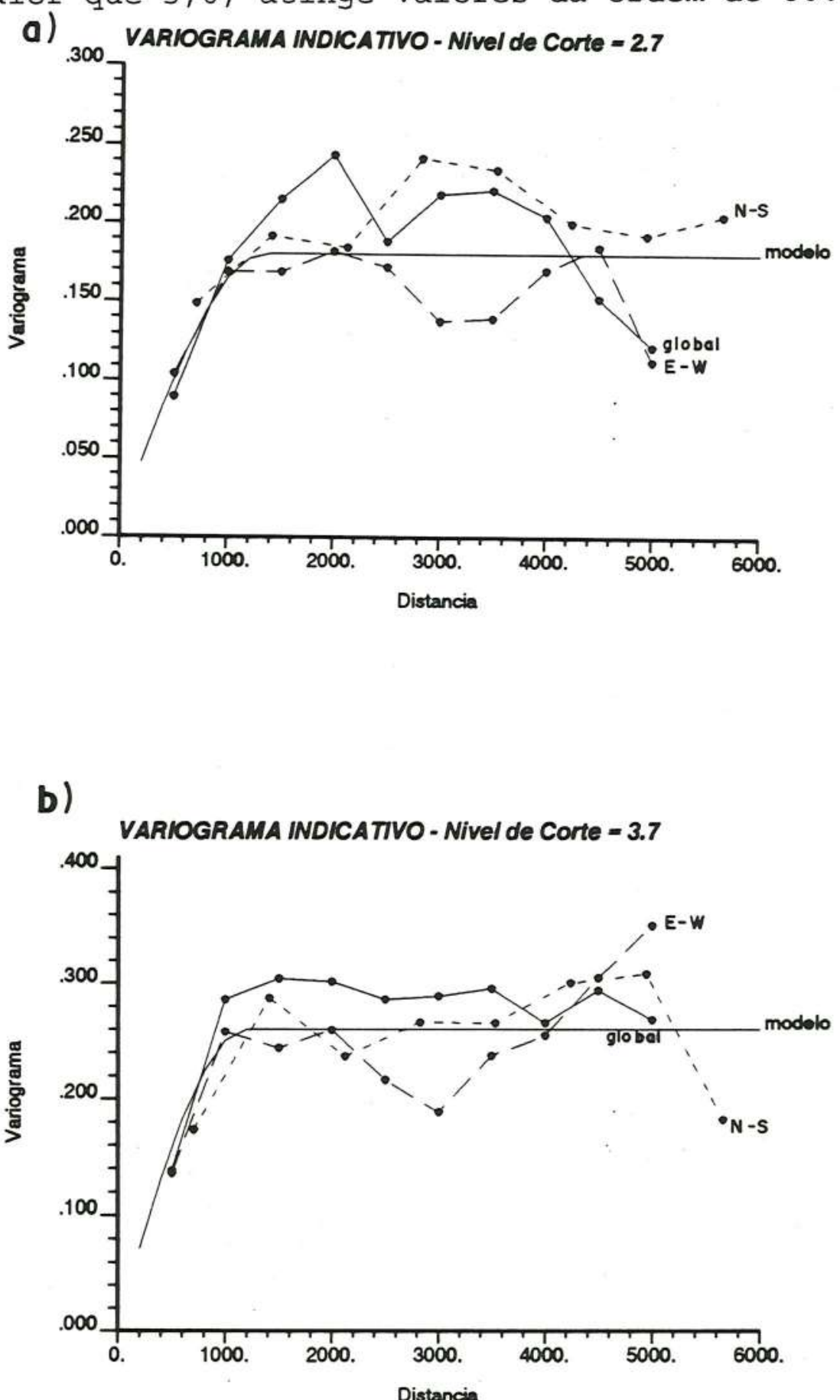

Figura 6.37 - Variogramas indicativos do nível 04 , com níveis de corte a) 2.7 b) 3.7 

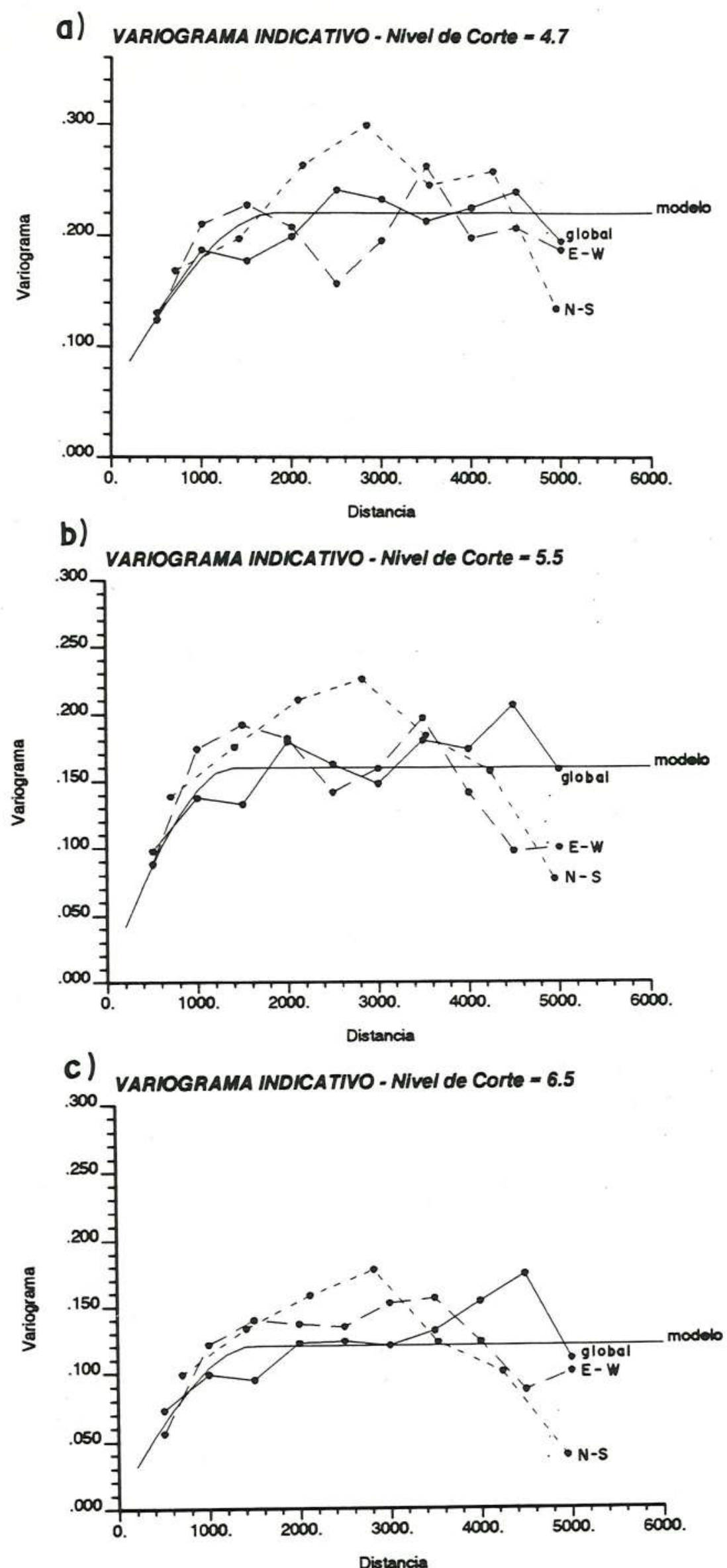

Figura 6.38 - Variogramas indicativos do nível 04, com níveis de corte: a) 4.7 b) 5.5 c) 6.5 


\section{PROBABILIDADE DO SPT $>5.0$}

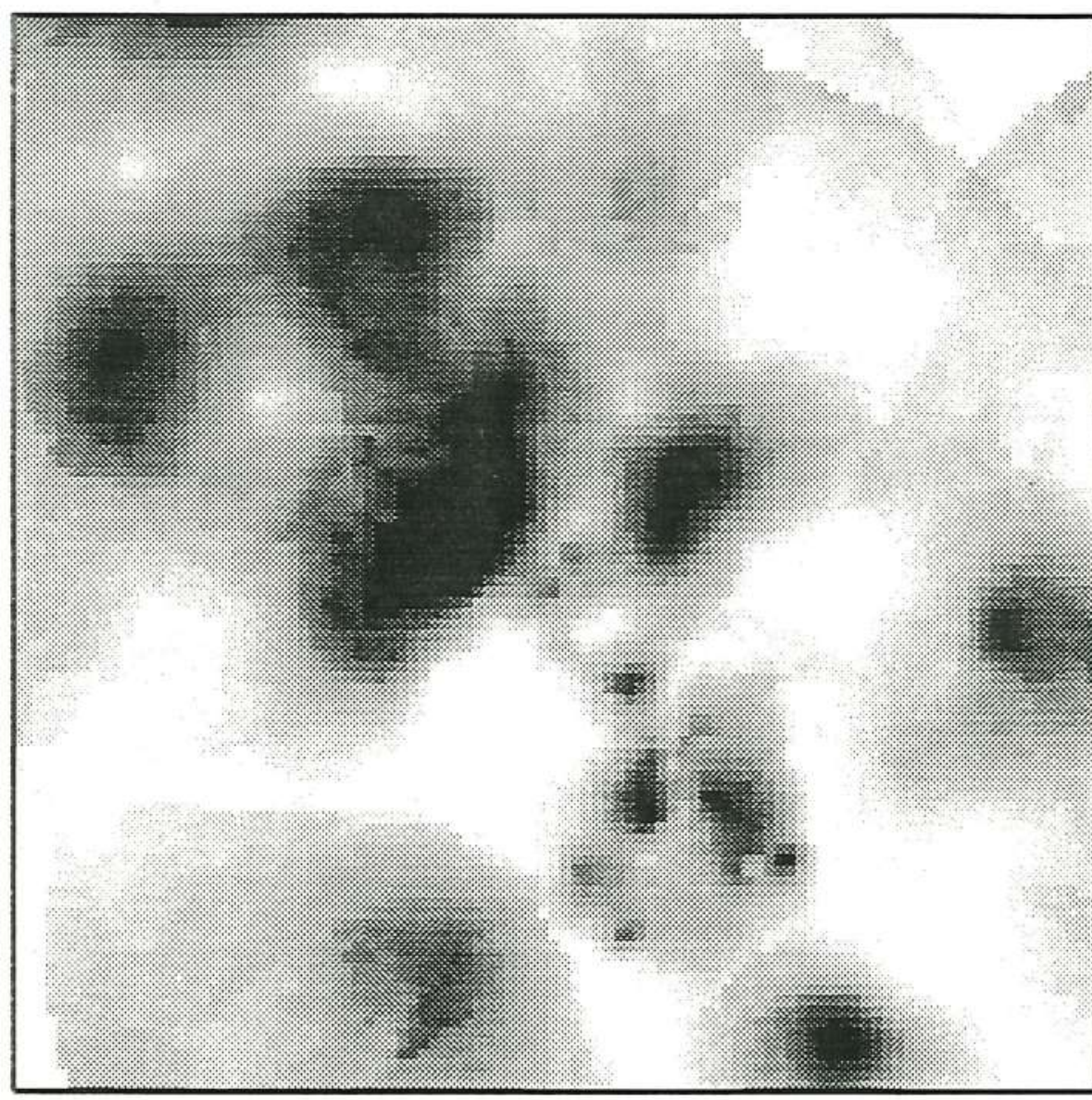

$(703000,7535.000)$

$(695000,7527.000)$

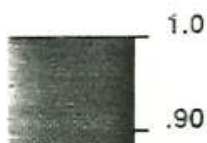

Figura 6.39 - Mapa probabilístico do nível 04; probabilidade do $\mathrm{SPT}>5.0$ 
Nível 05 - profundidade igual a 5 metros

Os variogramas experimentais com os devidos modelos variográficos ajustados estão demonstrados nas figuras 6.40 e 6.41. Os indices de corte foram baseados no histograma deste nível, referenciados nos quartis, visto que os mesmos dividem o conjunto de dados em proporções iguais

Os variogramas, como nos outros níveis, apresentam boa isotropia para todos os valores de corte. As componentes aleatórias são muito baixas, refletindo um grau expressivo das variáveis indicativas para tal nível. Este aspecto é reflexo do trabalho de regularização das malhas de dados, efetuadas para todos os níveis.

o modelo mais simples e adequado para os variogramas experimentais, dos diversos valores de corte, foi o modelo tipo esférico com uma única estrutura. A Tabela 6.9 apresenta os parâmetros básicos dos modelos esféricos ajustados e demonstrados nas figuras 6.40 e 6.41 .

TABELA 6.9 - PARÂMETROS DOS MODELOS VARIOGRÁFICOS INDICATIVOS - NÍVEL 05

\begin{tabular}{||c|c|c|c||}
\hline \hline $\begin{array}{c}\text { Valores de } \\
\text { corte }\end{array}$ & C0 & C1 & a (m) \\
\hline 3,4 & 0,00 & 0,180 & 1250 \\
\hline 4,6 & 0,00 & 0,250 & 1250 \\
\hline 5,5 & 0,00 & 0,225 & 1250 \\
\hline 6,5 & 0,00 & 0,200 & 1600 \\
\hline 7,5 & 0,01 & 0,155 & 1420 \\
\hline
\end{tabular}

o modelo mais representativo do nível constitui-se naquele ajustado para o valor de corte correspondente à mediana, representado na Figura 6.40b, cuja expressão é a seguinte:

$$
\gamma(h)=0.25 E s f_{1250}(h)
$$


O mapa de probabilidades do SPT ser maior que o quartil superior $(6,0)$ está representado pela imagem da Figura 6.42. Este mapa representa a base da camada estudada e nota-se um maior número de concentrações de probabilidades elevadas, como reflexo do aumento da profundidade e, por conseguinte, da pressão geoestática, da densidade relativa e da compacidade.
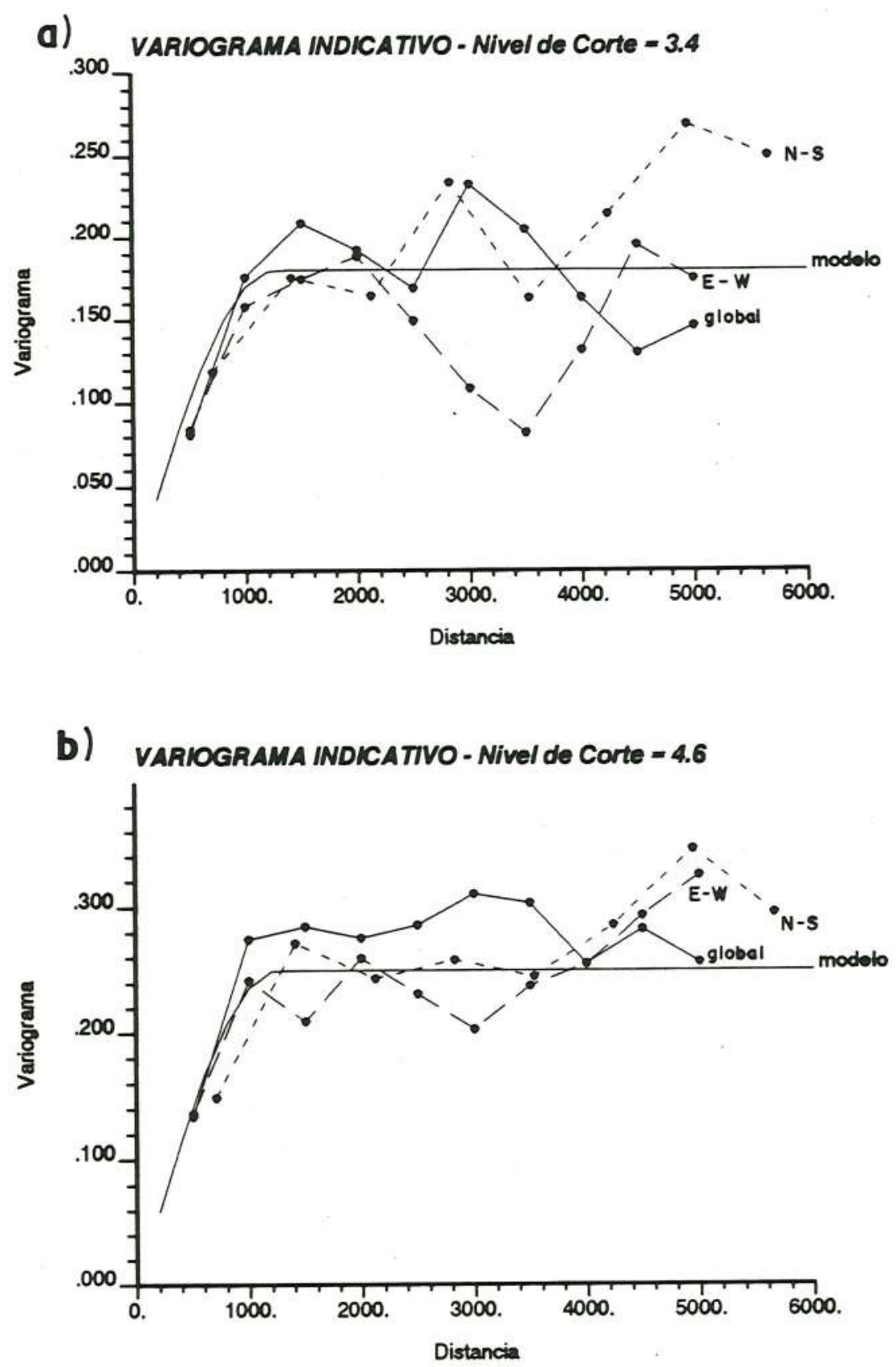

Figura 6.40 - Variogramas indicativos do nível 05, com níveis de corte: a) 3.4 b) 4.6 

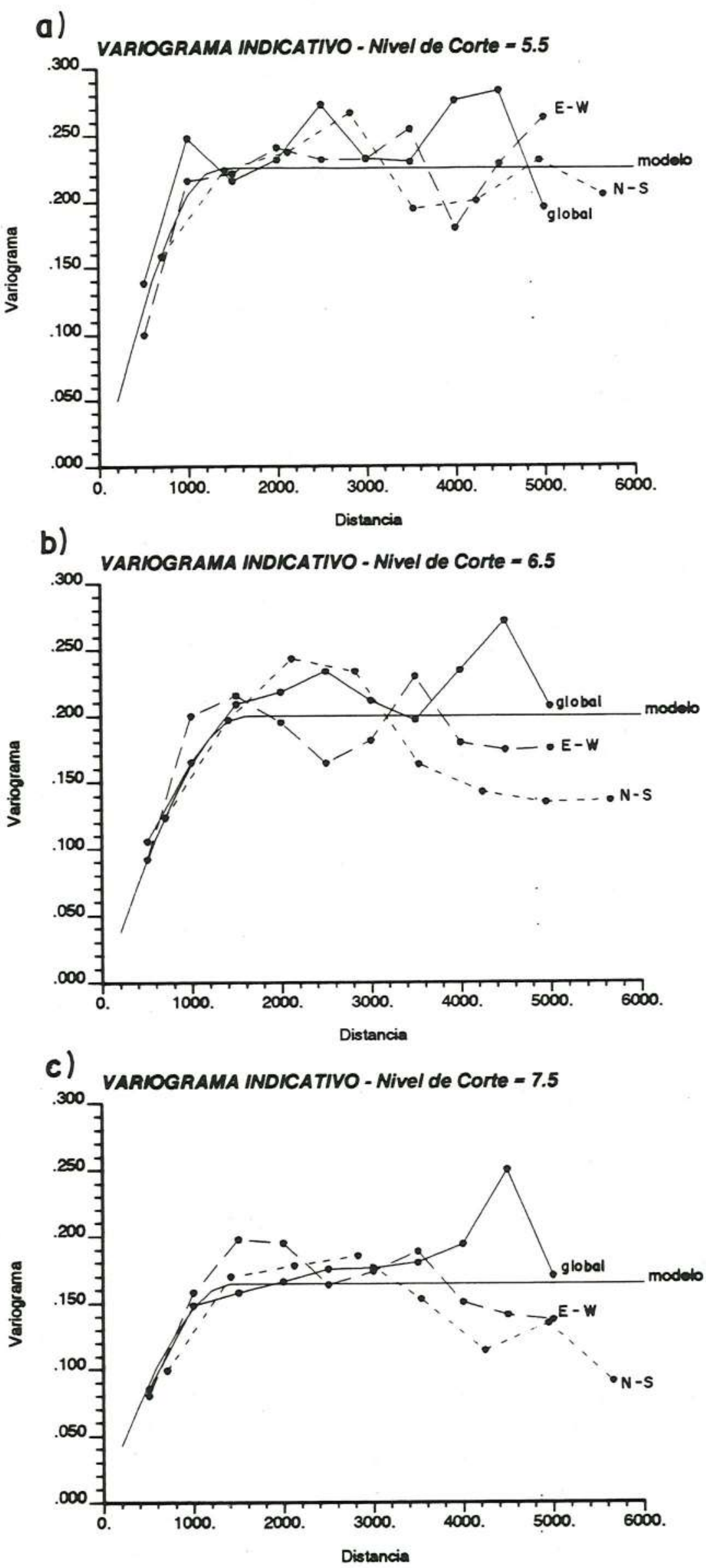

Figura 6.41 - Variogramas indicativos do nível 05, com níveis de corte: a) 5.5 b) 6.5 c) 7.5 
PROBABILIDADE DO SPT $>6.0$

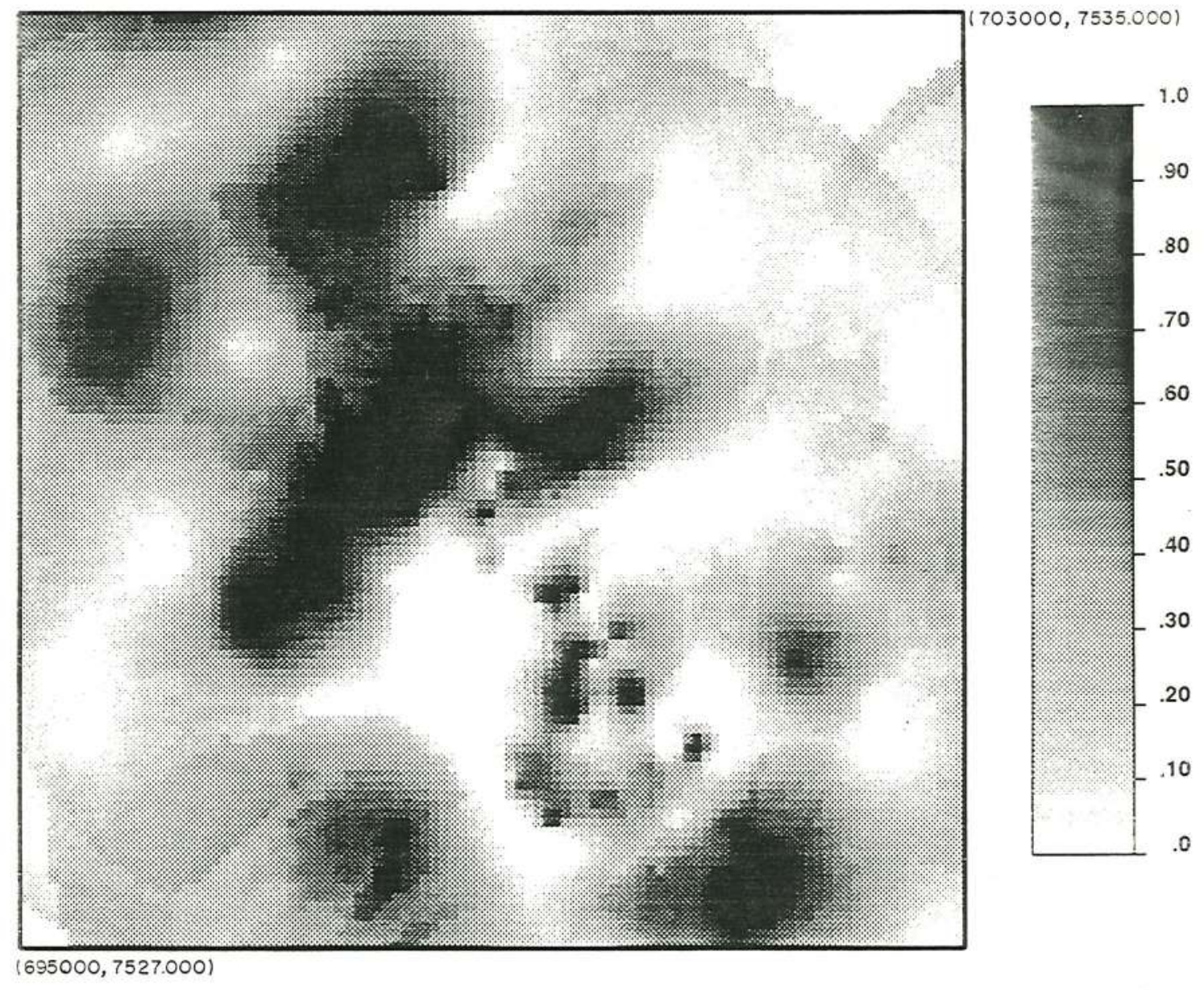

Figura 6.42 - Mapa probabilístico do nível 05; probabilidade do $\mathrm{SPT}>6.0$ 
Camada Superficial - espessura de 5 metros

Foram elaborados os variogramas experimentais tridimensionais para as principais direções, N-S e E-W. Dado ao maior número de dados ( $\mathrm{N}=851)$, aumentou-se 0 número de valores de corte para 6,0 , com base na distribuição de freqüência da Figura 6.9 , referenciados nos quartis e nos limites inferior e superior da distribuição. Este aumento dos índices de corte permite uma melhor discretização, o que auxilia na inferência das distribuições de probabilidade, efetuadas para cada bloco.

As figuras 6.43 e 6.44 mostram os variogramas experimentais efetuados para as duas direções principais em todos os índices de corte, com os respectivos modelos variográficos ajustados.

Como ocorreu em todos os níveis analisados, os variogramas apresentam boa isotropia, principalmente para os valores de corte mais elevados. As componentes aleatórias mantiveram-se baixas em todos os variogramas analisados, em função do baixo efeito de pepita, definidos nos modelos variográficos. Embora este ajuste deva-se a poucos pontos experimentais, os mesmos têm expressiva representatividade nos variogramas, pois o número de pares que os geraram supera a 600, sendo estatisticamente bem significativo.

os modelos ajustados para os variogramas experimentais foram do tipo esférico com uma única estrutura. A Tabela 6.10 mostra os parâmetros básicos dos modelos ajustados, cujas curvas encontram-se nos próprios variogramas das figuras 6.43 e 6.44 .

o modelo variográfico referente à mediana da camada é dado pela expressão:

$$
\gamma(h)=0.015+0.175 \operatorname{Esf}_{1200}(h)
$$


TABELA 6.10 - PARÂMETROS BÁSICOS DOS MODELOS VARIOGRÁFICOS INDICATIVOS - CAMADA

\begin{tabular}{||c|c|c|c||}
\hline $\begin{array}{l}\text { Valores } \\
\text { de } \\
\text { corte }\end{array}$ & C0 & C1 & a (m) \\
\hline 2,0 & 0,010 & 0,120 & 1200 \\
\hline 2,8 & 0,015 & 0,175 & 1200 \\
\hline 3,6 & 0,010 & 0,180 & 1300 \\
\hline 4,2 & 0,000 & 0,160 & 1200 \\
\hline 5,0 & 0,010 & 0,130 & 1200 \\
\hline 6,0 & 0,000 & 0,120 & 1300 \\
\hline
\end{tabular}

Neste caso, em que foi analisada a camada mais superficial, utilizou-se a krigagem indicativa para classificar $\circ \mathrm{SPT}$ segundo os intervalos de compacidade pré-estabelecidos.

Desta forma, as imagens demonstradas nas figuras $6.45,6.46$ e 6.47, refletem a classificação de 10.000 blocos com dimensões de 80 x 80 x 5 metros, com relação à sua compacidade, que permite efetuar, com a devida cautela, uma interpretação semi-empírica das tensões admissíveis do solo, com base na Tabela 2.7 .

O mapa da Figura 6.45, representa a probabilidade do solo da camada superficial analisada, ser uma areia fofa. A distribuição espacial deste solo é ampla na área, surgindo em diversos locais da cidade, principalmente na porção nordeste, onde a porcentagem de ocorrência é de 80 a $100 \%$.

O mapa da Figura 6.46 expressa a probabilidade dos blocos de solo serem classificados como uma areia pouco compacta. Neste caso, as freqüências de ocorrência são menores, concentrando-se em núcleos de várias dimensões, dispersos pela área de estudo.

O mapa da Figura 6.47 expressa a probabilidade do SPT estar situado no intervalo de 10.0 e 30.0 , denotando as possibilidades do solo ser uma areia medianamente compacta. Nota-se, pela distribuição dos valores no mapa, uma concentração maior na porção centro-noroeste, concordante com os valores mais altos no mapa dos SPT'S médios, estimados pela krigagem ordinária. 

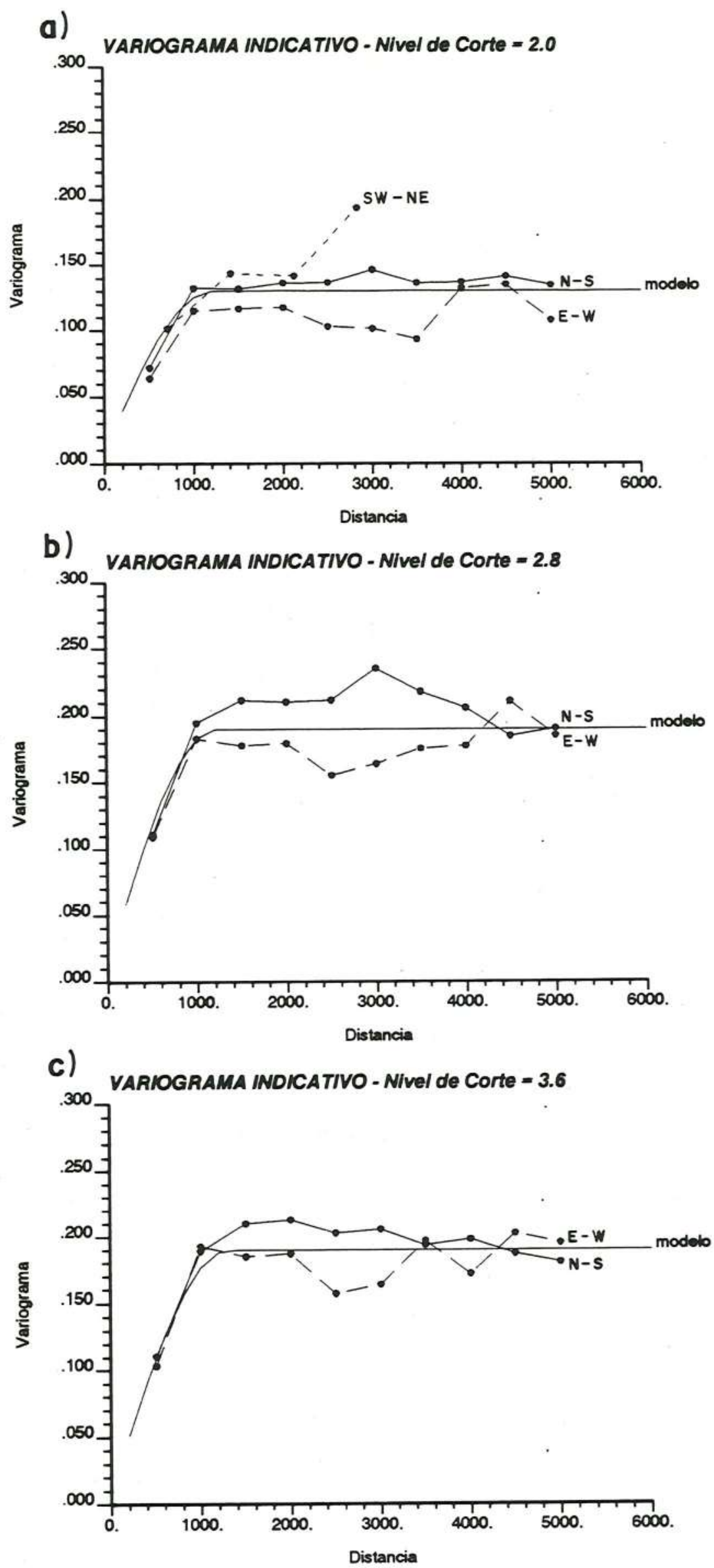

Figura 6.43-Variogramas indicativos da camada superficial com níveis de corte: a) 2.0 b) 2.8 c) 3.6 

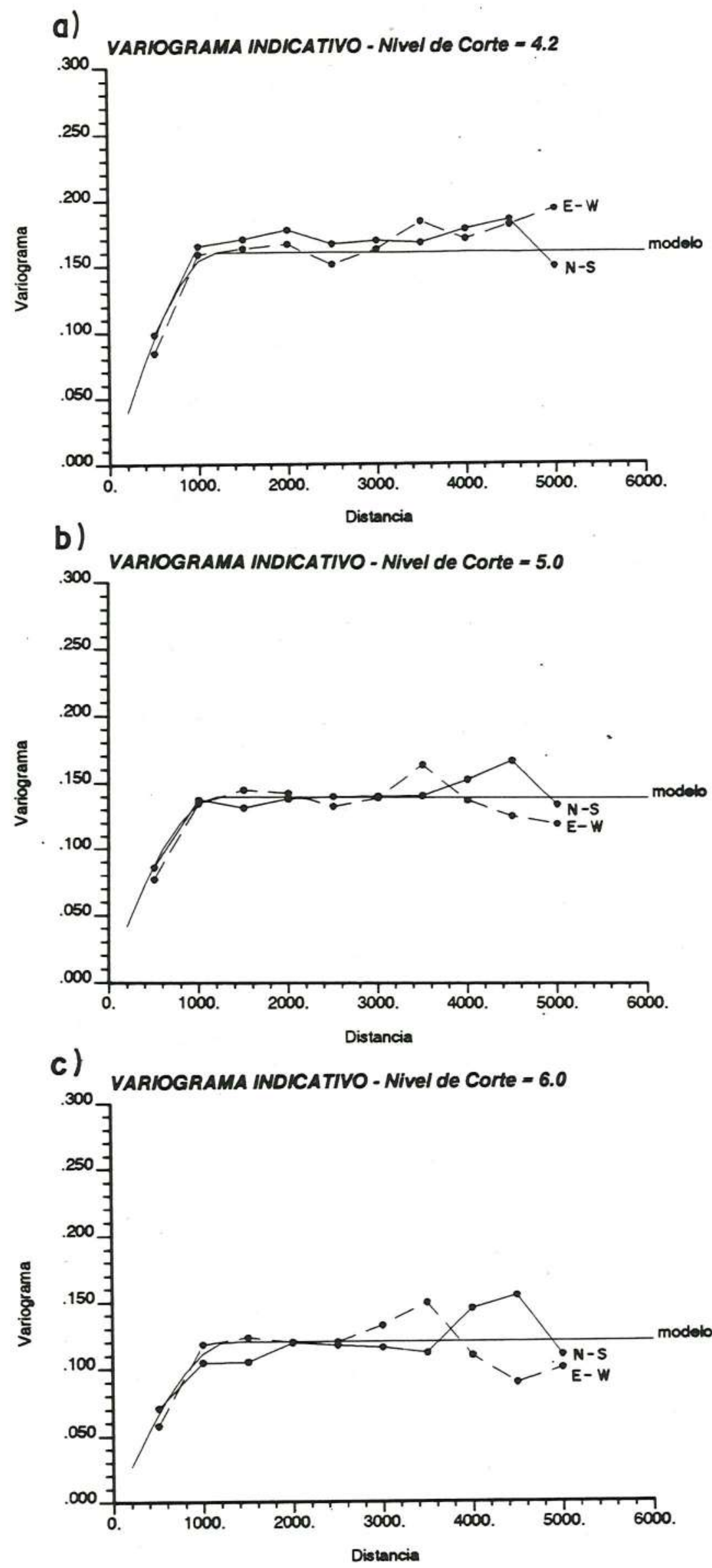

Figura 6.44-Variogramas indicativos da camada superficial com níveis de corte: a) 4.2 b) 5.0 c) 6.0 


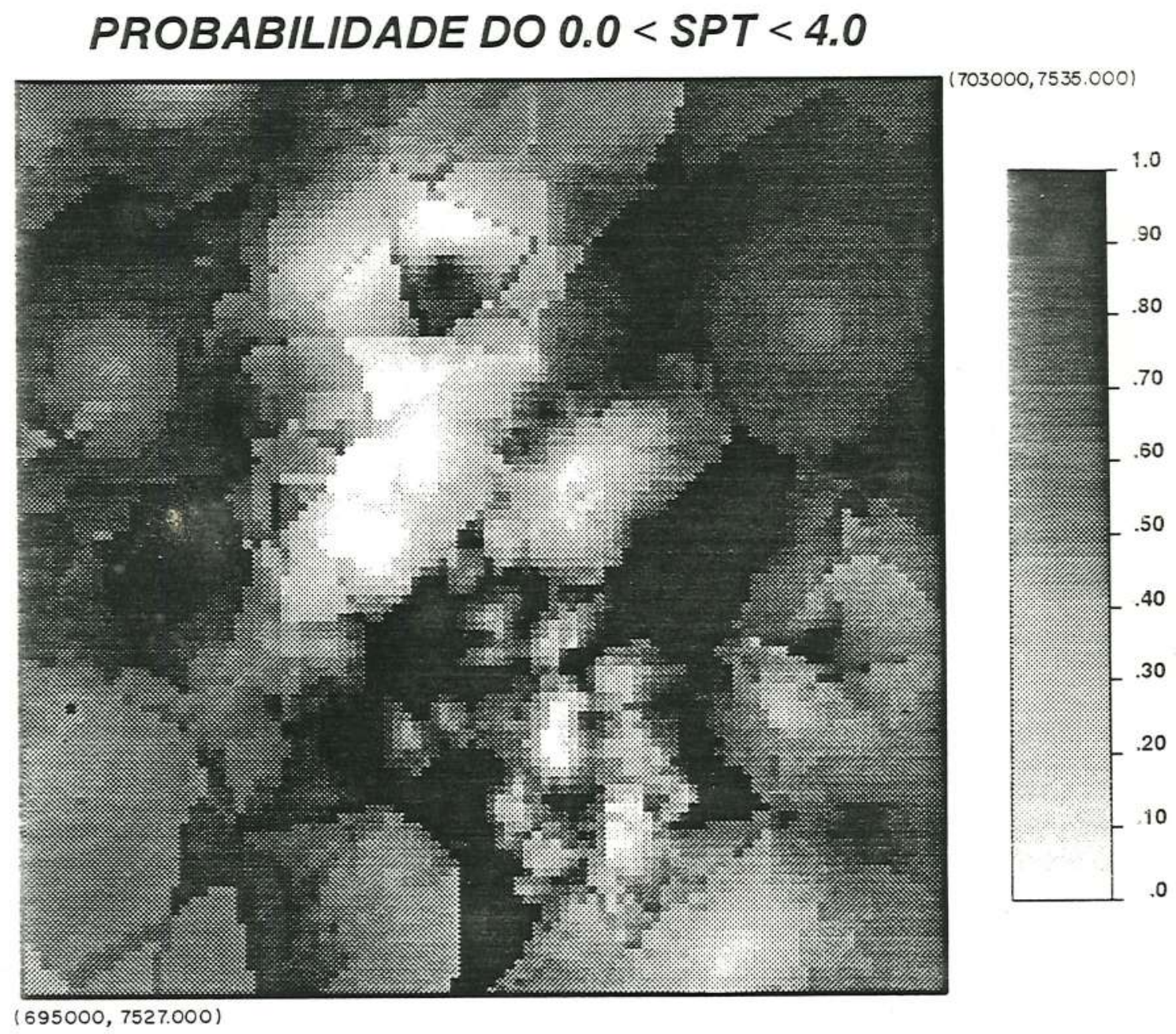

Figura 6.45 - Mapa probabilístico da camada superficial. Probabilidade do SPT estar situado no intervalo de 0.0 e 4.0 . 


\section{PROBABILIDADE DO $4.0<S P T<10.0$}

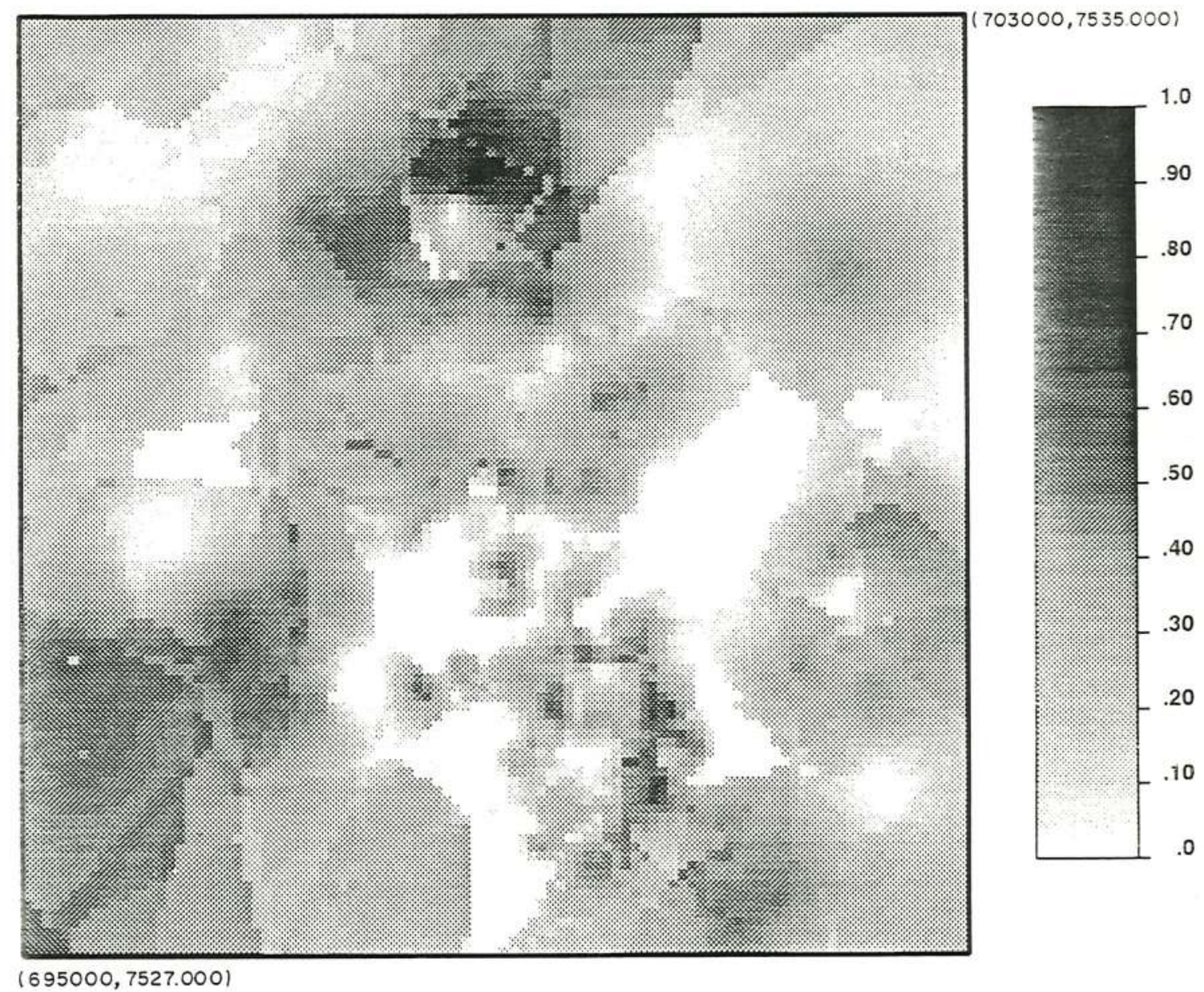

Figura 6.46 - Mapa probabilístico da camada superficial. Probabilidade do SPT estar situado no intervalo de 4.0 e 10.0 . 


\section{PROBABILIDADE DO $10.0<S P T<30.0$}

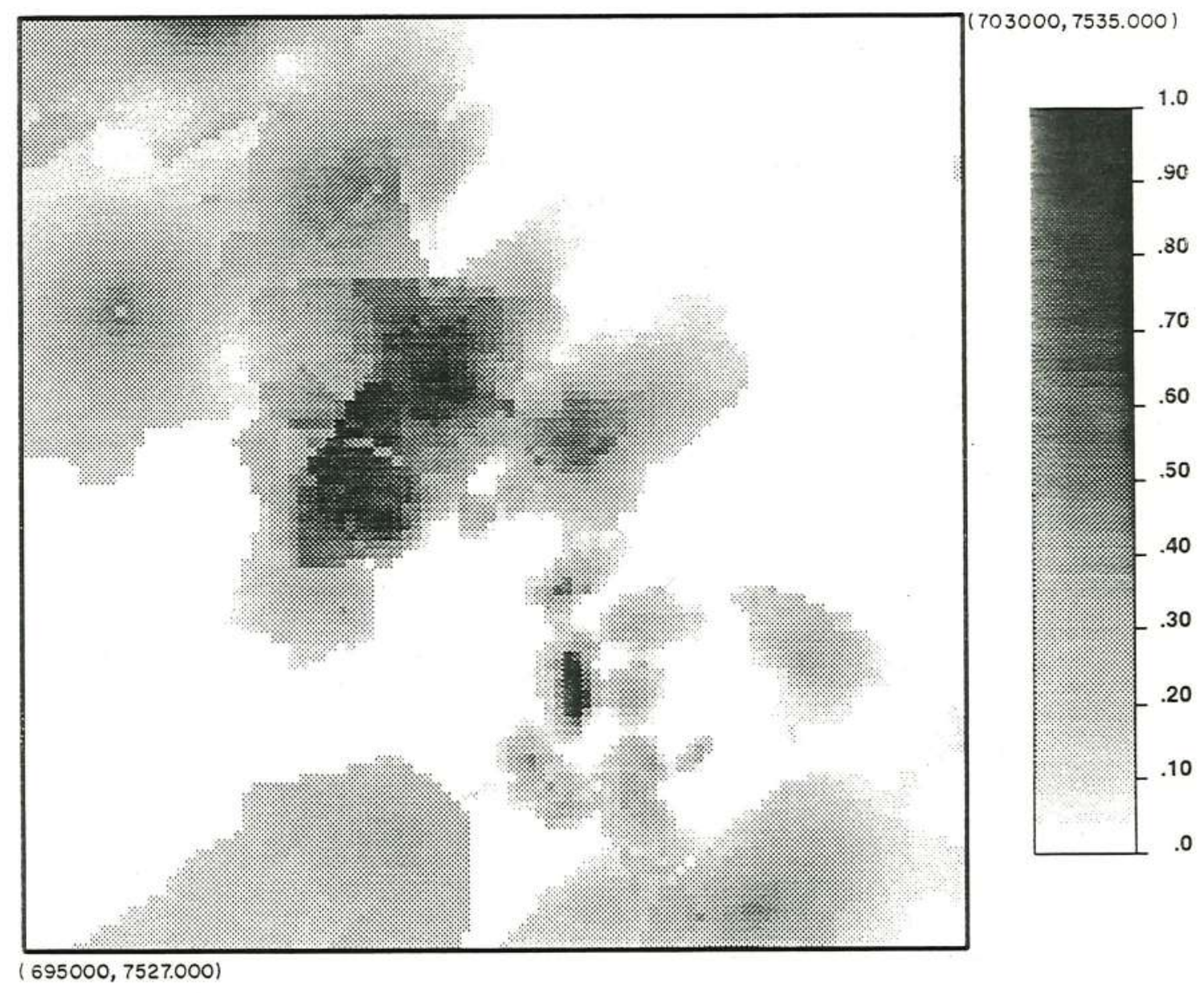

Figura 6.47 - Mapa probabilístico da camada superficial. Probabilidade do SPT estar situado no intervalo de 10.0 a 30.0 . 


\section{7. - CONSIDERAÇÕES FINAIS}

Para analisar geoestatisticamente um grande número de sondagens, foi necessária a elaboração de um banco de dados abrangente e flexível que possibilitasse a geração dos mais variados subprodutos, para serem devidamente processados nos "softwares" especializados.

o perfil de alteração, definido com base na velocidade de ondas sísmicas, apresentou normalmente quatro estratos sísmicos, salientando-se nos locais em que foram detectados três estratos, com a ausência da camada relativa ao solo de alteração de rocha, a presença de vossorocas bem desenvolvidas.

A análise da distribuição de freqüência para todos os dados $(N<60)$, revelou uma distribuição bem assimétrica, com um coeficiente de variação relativamente alto. Estes aspectos estão relacionados com os objetivos das sondagens, ou seja, a perfuração segue normalmente, nos intervalos com índices de resistência à penetração, baixos ou médios; entretanto, quando são atingidos índices mais elevados, a tendência é de se interromper a perfuração, resultando, desta forma, uma amostragem mais frequente dos SPT's mais baixos.

Uma análise, sem esta tendência, pode ser encontrada para o intervalo correspondente à camada superfical de 5 metros de espessura. Neste caso, a distribuição de freqüência é mais simétrica, embora alguns valores elevados, que aumentam significativamente - coeficiente de variação, possam ser considerados 
"outliers" decorrentes de erros de ensaios ou anomalias de resistência do solo.

Como parte das expectativas iniciais, os SPT's são linearmente correlacionados com a profundidade ( $r$ = $0,98)$, ainda que a função ajustada de grau 6 , tenha refletido, de forma mais adequada, as flutuações dos dados ao longo do perfil e também a "estratificação" do solo reconhecida na região. A análise integrada de perfis pedológicos, seções sísmicas e as sondagens resumidas no diagrama de dispersão da profundidade versus SPT mediano, permitiu estabelecer o perfil médio de alteração da região urbana de Bauru, conforme a seguinte configuração:

- estrato 1: 5 metros: camada superficial, solo arenoso pouco argiloso, poroso.

- estrato 2: 13 metros: solo areno-argiloso, estrutura microagregada, poroso.

- estrato 3: 2 a 12 metros: solo de alteração de rocha.

A análise variográfica que caracteriza a variabilidade espacial constatou uma elevada componente aleatória nos valores de SPT, sendo isso um reflexo dos problemas relacionados à execução dos ensaios, bem como à falta de melhor padronização dos mesmos.

O mapa resultante da krigagem ordinária fornece o SPT médio para blocos de 80 × 80 x 5 metros, pertencentes a uma camada de solo homogênea, previamente determinada. Também foram elaborados os mapas para os cinco níveis de profundidade dos ensaios, o que possibilitou uma análise integral dos SPT's para a camada superficial, delimitada para a região de Bauru. Apesar do elevado grau de quantificação, estes mapas têm por finalidade serem um guia de orientação aos engenheiros, sem substituirem os ensaios in situ, cujos resultados deverão ser empregados nos projetos das obras de engenharia. 
Considerados que os desvios-padrão da krigagem são independentes dos dados que estão sendo estimados, eles não devem ser usados como critério para avaliar as estimativas. Entretanto, os desvios-padrão da krigagem refletem a configuração da malha de amostragem e podem ser empregados como parâmetros para otimização ou implantação de malhas de sondagens ou amostragens. A propósito da variância da krigagem, YAMAMOTO(1991) sugere uma variância de interpolação para a krigagem, que consideraria tanto a disposição espacial dos dados, assim como sua dispersão.

o emprego de variáveis secundárias auxiliares, densamente amostrada para estimar uma primária (principal) subamostrada, deve, sempre que possível, ser praticado em mapeamento geotécnico, para outras váriaveis, mais difíceis de serem avaliadas. A cokrigagem apresenta todos os recursos que a krigagem ordinária para estimativas e pode portanto, ser utilizada eficazmente para interpolar e extrapolar variáveis correlacionáveis. Os mapas de profundidades do lençol freático e do impenetrável, deduzidos pela cokrigagem neste trabalho, devem ser usados como mapas indicativos, pois seus valores são resíduos que encerram duas incertezas associadas às duas estimativas.

Os valores de SPT apresentam distribuições assimétricas do tipo lognormal e coeficientes de variação relativamente altos. Nestas condições, métodos geoestatísticos tradicionais ou lineares, como krigagem ordinária, devem ser usados com muito critério para que não se incorra em superestimativas.

A geoestatística não-paramétrica representou uma ferramenta muito útil para classificação no espaço dos SPT's, tendo em vista os erros intrínsecos à execução dos ensaios de penetração, os altos coeficientes de variação dos dados na área e as suas distribuições assimétricas. 
As características da variável SPT são adequadas para o emprego da geoestatística não linear, como a krigagem indicativa. Esta técnica permite elaborar mapas indicativos sem influência significativa de valores discrepantes. Além disso, dados resultantes de procedimentos semi-empíricos podem ser incorporados ao conjunto de dados, pois os mesmos apresentam um papel indicativo, como se propõe a fazer a krigagem indicativa.

Os mapas resultantes da krigagem indicativa do SPT são muito úteis ao planejamento urbano, visto que apresentam de forma probabilística, áreas que podem atender a uma determinada ocupação do solo, principalmente com relação aos projetos de fundações. Por outro lado, esta metodologia pode ser usada como forma de classificação espacial do meio físico, como foi feito neste trabalho, com o grau de compacidade do solo.

A tendência atual em geoestatística é empregar a krigagem para construir modelos probabilísticos que estejam associados com valores e com a configuração dos dados, ao que se denomina de "simulação condicional" ou "imageamento estocástico". Esta técnica possibilita obterem-se inúmeros resultados de uma propriedade que esteja sendo analisada para, em seguida, construir-se o modelo de probabilidade e obter-se, desta forma, uma medida das incertezas em locais não amostrados.

Como sugestão, a simulação condicional poderia empregar os modelos de distribuição de freqüência e de variabilidade dos valores de SPT, obtidos na região de Bauru, para gerar imagens estocásticas, não somente na cidade de Bauru, mas também para outras cidades assentadas sobre as formações geológicas e perfis de alteração similares. Assim, estas imagens teriam perfeita representatividade, pois estariam condicionadas aos dados 
da nova localidade em estudo, o que ampliaria o emprego desta pesquisa ora finalizada. 


\section{8. - REFERÊNCIAS BIBLIOGRÁFICAS}

AgNelil, N. - Estudo da colapsidade do solo de Bauru através de provas de carga diretas. São Carlos : 1992.172p.Dissertação (Mestrado em Geotecnia)-Escola de Engenharia, Universidade de São Paulo.

ALBIERO, J.H. - 0 emprego de fórmulas empíricas na previsão de carga última de estacas. São Carlos : 1990. 253p. (Livre Docência) - Escola de Engenharia, Universidade de São Paulo.

ALMEIDA, F.F.M. de. Os fundamentos geológicos do relevo paulista. Boletim do Instituto Geográfico Geológico. (São Paulo). v. 41, p. 169-263, 1964.

ALPAN, I. - Estimating the settlements of foudations on sand. Civil Engineering and Public works Revisions, 1964. Vol. 59, p. 1415-1418.

ANDERSON, F.J. - Collapsing soils and their basic parameters in an area in the Tucson, Arizona vilinity. Arizona : 1968. 104p. Master (Science)- University of Arizona.

ASSOCIAÇÃO BRASILEIRA DE GEOLOGIA DE ENGENHARIA (ABGE). Diretrizes para execução de sondagens (2a tentativa) Boletim 03. São Paulo: 1977.

ASSOCIAÇÃO BRASILEIRA DE NORMAS TÉCNICAS (ABNT). EXecução de sondagens de simples reconhecimento- NBR 6484, 1980. 
ASSOCIAÇÃO BRASILEIRA DE GEOLOGIA DE ENGENHARIA (ABGE). Diretrizes para execução de sondagens, São Paulo: 1990.

ASSOCIAÇÃO BRASILEIRA DE GEOLOGIA DE ENGENHARIA (ABGE). Diretrizes para execução de sondagens, São Paulo: 1990.

BORTOLUCCI, A.A.. Caracterização Geológico-Geotécnica da região urbana de São Carlos - SP, a partir de sondagens de simples reconhecimento. São Carlos: 1983. Dissertação (Mestrado em Geotecnia) - Escola de Engenharia, Universidade de São Paulo.

BUENO, B.S. \& VILLAR, O.M. Mecânica dos Solos. São Carlos, Escola de Engenharia de são Carlos da Universidade de São Paulo, 1984. 131p.

BURLAND, J.B.; BROMS, B.B.; MELLO, V.F.B. - Behaviour of foundation and structures, state of the Art Review.In: INTERNATIONAL CONFERENCE ON SOIL MECHANICS AND FOUNDATION ENGINEERING, 9. Tokio, 1977.Anais...Tokio: 1977. v. 3, p.495-546.

CAVAGUTI, N. Geologia, estruturas e características hidrogeológicas mezosóicas da região de Bauru-SP. Bauru: 1981. 169p. Tese (Doutorado em Ciências) Faculdade de Filosofia Ciências e Letras.

CENTRO NACIONAL DE ENSINO E PESQUISAS AGRONÔMICAS, COMISSÃO DE SOLOS (CNEPA-CS). Levantamento de reconhecimento dos solos do Estado de São Paulo, contribuição à Carta de Solos do Brasil. Rio de Janeiro: 1960. 634p. (Boletim do Serviço Nacional de Pesquisas Agronômicas, 12).

COMPANHIA ELÉTRICA DE SÃO PAULO - CESP. Bauru - Aterro sanitário - Sondagens à percussão para estudo geológico/geotécnico. São Paulo: 1992. Laboratório Central de Engenharia Civil. ( Relatório LEC-G-16/92). 
CLARK, I. Pratical geostatistics. London: Applied Science Publishers, 1979. 129p.

CHAPMAN, R.P. Limitations of Correlation and regression analysis in geochemical exploration. Inst. Min. Metall. Trans. Sect B, v.85,p 279-283, 1975.

DAVIS, J.C. Statistics and data analysis in geology. New York: John Wiley, 1986. 646p.

DENVER, H. - Modulus of elasticity for sand determined by sprand CPT. In: EUROPEAN SYMPOSIUM ON PENETRATION RESTING, 2, 1982, Amsterdam. Proceedings... Rotterdam: A.A. Balkema, 1982. v.1, p. 441-46.

DECOURT, L. - Production of the bearing capacity of piles based exclusively on $\mathrm{N}$ values of the SPT. In: EUROPEAN SYMPOSIUM ON PENETRATION TESTING, 2, 1982, Amsterdam. Proceedings... Rotterdam: A. A. Balkema, 1982. v. 1, p. 29-34.

DECOURT,L.; QUARESMA, A.R. - Capacidade de carga de estacas a partir de valores de SPT. In: CONGRESSO BRASILEIRO DE MECÂNICA DOS SOLOS E ENGENHARIA DE FUNDAÇÕES, 6, Rio de Janeiro, 1978. Anais..., São Paulo: ABMS, 1978. v. 1, p. 45-53.

DEUTSCH, C.V.; JOURNEL, A.G. - GSLIB: Geostatistical software library and user's guide. New York: Oxford University Press, 1992. 340p.

ENGLUND, E. \& SPARKS A. - GEO-EAS: Geostatistical environmental assessment software - user's guide. Nevada: United States Environmental Protection Agency, 1988 .

FARAH, F.; YWASA; SALOMÃO, F.X.T. - Carta geotécnica da área urbana e periurbana de Bauru: considerado o meio 
físico para o desenvolvimento urbano. In: CONGRESSO BRASILEIRO DE GEOLOGIA DE ENGENHARIA, 7, POçOS de Caldas, 1993. Anais..., São Paulo: ABGE, 1993. vol. 2, p. 73-82.

FLECTCHER, G.F.A. Standart penetration East its uses and abuses. Journal of the Soil Mechanics and Foundations Division, ASCE, 1965. v.91,n.4,p. 67-75, 1965.

FERREIRA, C.V. - Caracterização geotectônica do solo de uma área da cidade de Bauru (SP). São Carlos : 1991. 141p. Dissertação ( Mestrado em Geotecnia)- Escola de Engenharia, Universidade de São Paulo.

GARCIA, P.A.G. Geoestatística operacional. Brasilia: Ministério de Minas e Energia, Departamento Nacional da Produção Mineral, 1988. 145p.

GIULIANI, F.; NICOLL, F.S.G. - New analyptical correlations between SPT, overburden pressure and relative density. In: EUROPEAN SYMPOSIUM ON PENETRATION TESTING 2, 1982, Amsterdam. Proceedings... Rotterdam: A.A. Balkema, 1982. V. 1, p. 29-34.

GRUNDY, W.D.; MIESCH, A.T. - Brief descriptions of STATPAC and related statistical programs for the IBM Personal Computer.Colorado: United States Department of the Interior Geological Survey, 1988.

HOUGHT, B.K. - Basic soils Engineering. New York: Ronald Press Company, 1957. 513p.

HOWARTH, R.J. Statistics and data analysis in geochemical prospection. Amsterdam: Elsevier, 1983. 437p.

HUIJBBREGTS, C.J. Regionalized variables and quantitative analysis of spatial data. In: DAVIS, J.C. \& MC CULLAGH, 
M. J. (ed.) Display and analysis of spatial data. New York: John Wiley, 1975. p.38 - 53.

INSTITUTO DE PESQUISAS TECNOLÓGICAS - IPT Prevenção da erosão urbana e conservação de recursos hídricos: projeto piloto de Bauru e rio Batalha (1a. Fase). São Paulo: Instituto de Pesquisas Tecnológicas, 1991, 76p. (Relatório Interno, 29.789).

INSTITUTO GEOGRÁFICO E CARTOGRÁFICO - IGC Mapa topográfico do Estado de São Paulo, São Paulo, 1983, escala: 1:10.000.

ISAAKS, E.H.; SRIVASTAVA, R.M. Applied geostatistics. New York: Oxford University Press, 1989. 561p.

JOURNEL, A.G.; HUIJBREGTS, J.C.H. Mining geostatistics. London: Academic Press, 1978. 600p.

JOURNEL, A.G. Non-parametric estimation of spatial distribution. Mathematical Geology, New York, 1983, v.15,n.2,p.445- 468 .

JOURNEL, A. Fundamentals of geostatistics in five lessons, short course in Geology. Washington: American Geophysical Union, 1989. Vol. 8.

KIM, Y.C. Advanced geostatistics for highly skewed data. Arizona : Department of Mining and Geological Engineering - The University of Arizona, 1988.

KIM, Y.C. Introductory geostatistics and mine planning. Arizona: Department of Mining and Geological Engineering, 1990.

KOCK, G.S.; LINK, R.F. Statistical analysis of geological data. New York: McGraw-Hill, 1965. 475p. 
KRUIZINGA, J. SPT-CPT correlations. In: EUROPEAN SYMPOSIUM ON PENETRATION TESTING, 2, 1982, Amsterdam. Procedings... Rotterdam: A.A. Balkema, 1982. v.1, p. 91-94.

LANDIM, P.M.B. Análise estatística de dados geológicos. Rio Claro: Laboratório de Geomatemática - Publicação Didática n.o 4,1993.116p.

LANDIM, P.M.B.; SOARES, P.C. Estratigrafia da Formação Caiuá. In: CONGRESSO BRASILEIRO DE GEOLOGIA, 29, Ouro Preto, 1976. Anais...ouro Preto: SBG. v.2, p.195-206.

LEE, I.K.; WHITE W.; INGLES,O.G. Geotechnical engineering. Boston: Pitman, 1983. 508p.

LIMA, M.J.C.P.A. Prospeç̧ão geotécnica do subsolo. Rio de Janeiro: Livros Técnicos e Científicos, 1979. 104p.

LOBO, A.S. - Colapsidade do Solo de Bauru e sua Influência em Estacas de Pequeno Porte. São Carlos: 1991. 211p. Tese ( Doutorado em Geotecnia) - Escola de Engenharia, Universidade de São Paulo.

MALAgUTtI FILHo, W. Utilização de Técnicas Geofísicas na Caracterização de Solos e Rochas com Aplicações na Geologia de Planejamento Urbano. Rio Claro: 1991. Tese ( Doutorado em Geologia Ambiental) - UNESP.

MALAGUTTI FILHO, W. \& LOPES, K.J. Programa para interpretação de dados de sísmica de refração a partir de tiros recíprocos. In: Simpósio de Quantificação em Geociências, 5, Rio Claro, 1994. Resumos...Rio Claro: IGCE/UNESP. p. 61-63.

MATHERON, G. Traité de Géostatistique appliquée. Memóires du Bureau de Recherches Géologiques et Miniéres, 1962. tome I, 333p. tome II, 172p. 
MATHERON, G. La théorie des variables regionalisées, et ses applications. Les Cahiers du Centre de Morphologie Mathématique de Eontainebleau. École Nationale Supérieure des Minas de Paris, 1970. Fascicule 5. 212p.

MELLO, V.F.B. - Considerações sobre os Ensaios de Penetração e sua Aplicação a Problemas de Fundações Rasas. São Paulo, 1967. Tese( Doutorado) - Faculdade de Arquitetura, Universidade de São Paulo.

MELLO, V.F.B. The standart penetration test - state of the art. In: PANAMERICAN CONFERENCE ON SOIL MECHANICS AND FOUNDATION ENGINEERING, 4, San Juan, Puerto Rico. 1971. Proceedings..., New York, ASCE, 1971. V.1, p. 186.

MEYER, P.L. Probabilidade - Aplicações à Estatística. Rio de Janeiro: Livros Técnicos e Científicos, 1981. 391p.

MEYERHOF, G.G. Penetration tests on bearing capacity of cohesionless soils. Journal of Mechanics and Foundations Divisions, ASCE, v.82(sm-1), $866 \mathrm{p}$.

MEYERHOF, G.G. - Shallow Foundations. Journal of the American Society of Civil Engineersv. v.92, sm 2, p.2131,1965 .

OLEA, R.A. Systematic sampling of spatiall function. Kansas: Kansas Geological Survey, 1984. 57p. (Series on Spatial Analysis, 7).

PARRY, R.H.G. - Estimating bearing capacity in sand from SPT values. Journal of the Soils Mechanics and Foundation Division, ASCE. v. 103, GT9, p.1014-1019, 1977. 
PEARSON, E.S. \& HARTLEY, H.O. Biometric tables for statisticians. New York: Cambridge University Press, 1966, 264p.

KRIGE, D.G. Log-normal de Wijsian for ore evaluation Johannesburg: South African Institute of Mining and Metal, 1978. (Geostatistics).

PECK,R.B.; HANSON, W.E.; THORNBURN, T.H. - Foundation Engineering. New York: John Willey, 1974. 511P.

PONÇANO, W.L.; CARNEIRO, C.R.; BISTRICHI, C.A.; ALMEIDA, F.F.M. de; PRANDINI, F.L. Mapa geomorfológico do Estado de São Paulo: escala 1:1000.000. São Paulo: Instituto de Pesquisas Tecnológicas, 1981. V. 1-2 (Monografias, 5) .

PRESTON, D.A. Fortran IV programs for sample normality tests. Computer Contribution. Lawrence: University of Kansas, 1970. SV(41), 27p.

RENDU, J.M. An introduction to geostatistical methods of mineral evaluation. Johannesburg: Institute of Mining and Metallurgy, 1978. 83p.

SAITO, A. - Characteristics of penetration resistance of a reclaimed sandy deposit and their change throught vibratory compaction. Soils and foundations, 1977. v. 17, n.4. p. 31-43, 1977.

SALOMÃO, F.X.T. Processos erosivos lineares em Bauru(SP): Regionalização cartográfica aplicada ao controle preventivo urbano e rural. São Paulo, 1994. 200p. Tese (Doutorado em Geografia Física)- Faculdade de Filosofia, Letras e Ciências Humanas, Universidade de São Paulo. 
SCHULTZE, E.; SHERIF, G. - Prediction of settlements from evaluated settlement observations for sand.In:III INTERNATIONAL CONFERENCE ON SOIL MECHANICS AND FOUDATION ENGINEERING, 3, Moscou. Proceedings...Moscou: ABMS, 19--.V. 1, p. 225-230.

SIMONS, E.N.; MENZIES, B.K. - Introdução à Engenharia de Fundações. Rio de Janeiro: Interciência, 1977. 199p.

SJOGREEN, B. Shallow Refraction Seismic. London: Chapman and Hall, 1984, 268p.

SOARES, P.C. O Mesozóico Gondwânico no Estado de São Paulo. Tese (Doutorado em Geologia) Faculdade de Filosofia, Ciências e Letras - Rio Claro: 1973. 152p.

SOARES, P.C.; LANDIM, P.M.B.; FULFARO, V.J.; SOBREIRO NETO, A.F. Ensaios de Caracterização estratigráfica do Cretáceo no Estado de São Paulo: Grupo Bauru. Revista Brasileira de Geociências, São Paulo, v. 10,n.3, p.177185,1980 .

SILVA, R.B. da; COUTO, E.A. do. Geologia do bloco 45, balizado pelas cidades de Bauru, Marilia, Ourinhos e Águas de Santa Bárbara. São Paulo : PAULIPETRO, 1980. (Relatório Interno PAULIPETRO BP-011/80).

SILVA, F.P.; CAVAGUTI, N. Nova caracterização estratigráfica e tectônica do mesozóico na cidade de Bauru-SP. In: SIMPÓSIO SOBRE AS BACIAS CRETÁCECAS BRASILEIRAS, 2, Rio Claro, 1992. Resumos... Rio Claro: UNESP, 1992 .

SRIVASTAVA, R.M. A non-ergodic framework for variograms and covariance functions. Stanford: 1987. 113p. Dissertation (Master's in Geostatistics) - Stanford University. 
StAmATOPOULOS, A.C.; KOTZIAS, P.C. - The use of the penetration test in classifying rocks. In: Congresso da International Society for Rock Mechanics, 3, Denver, v.1, p. 85-89.

STURARO, J.R.; CAVAGUTI, N.; RIEDEL, P.S.; BOSIO, N.J. ; CAMARGo, A.A.X. de. Elaboração de banco de dados e Análise estatística básica de dados de sondagens de simples reconhecimento. Revista Geociências. v.12, n.2, 1993.

TEIXEIRA, A.H. Um aperfeiçoamento das sondagens de simples reconhecimento. In: Solos do Interior de São Paulo - ABMS/Departamento de Geotecnia - EESC, São Carlos, 1993. Proceedings...são Carlos:1993.

TERZAGHI \& PECK (1948), Soil Mechanics in Engineering Practice. New York, John Wiley, 1948.

TERZAGHI \& PECK. Soil Mechanics in Engineering Practice. 2nd edition, New York, John Wiley, 1967. 729p.

VARGAS, M. - Introdução à Mecânica dos Solos. São Paulo: McGraw-Hill do Brasil, 1978. 509p.

VERRUIJT, A.; BERINGEN, F.L.; DE LEEUW, E.H. Penetration Testing. In: European Symposium on Penetration Testing/ESOPT II,2., Amsterdam, 1982. Proceedings... Amsterdam:1982. V.1.

VIOTT, A.; ROPERS, M.; CASTRO, C.G.J.; AISSAMI, O.H. ; XAVIER, J.A.P. e STURARO, J.R. Relatório do poço estratigráfico e exploratório 2-CB-1-SP-Cuiabá Paulista São Paulo, PAULIPETRo, 1981 (Relatório Interno).

YAMAMOTO, J.K. Comparação de métodos computacionais para avaliação de reservas: um estudo de caso na jazida de cobre de Chapada, Go. São Paulo: 1991. 175p. Tese 
(Doutorado em Recursos Minerais e Hidrogeologia)Instituto de Geociências, Universidade de São Paulo.

ZUQUETTE, L.V. Análise crítica da cartografia geotécnica e proposta metodológica para as condições brasileiras. São Carlos: 1987. 673p. Tese (Doutorado em Geotecnia) Escola de Engenharia, Universidade de São Paulo. 
APÊNDICE I 
SS SONDAF - SONDAGENS E FUNDACOES LTOA.

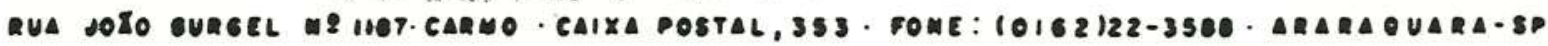

CLIENTE: SAT - ENGENHARIA E COMÉRCIO S/A

OBRA: EDIFICIOS

LOCAL: BAURU (SP)

\begin{tabular}{|c|c|c|c|c|}
\hline EM $60^{\circ}$ RE & DESEMWISTA & ESCALA & RELATOROROOO & OATA \\
\hline Dand. & $7 \sqrt{4}$ & $1: 1.000$ & $4944 / 91$ & $22 / 01 / 91$ \\
\hline & & LOC & & \\
\hline
\end{tabular}
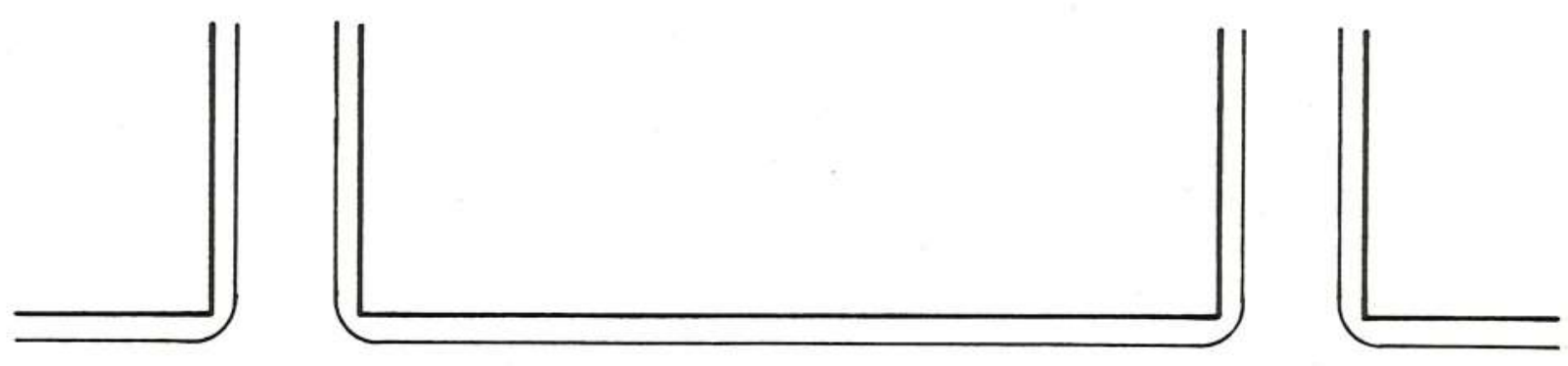

RUA ALFREDO R. DE SOUZA
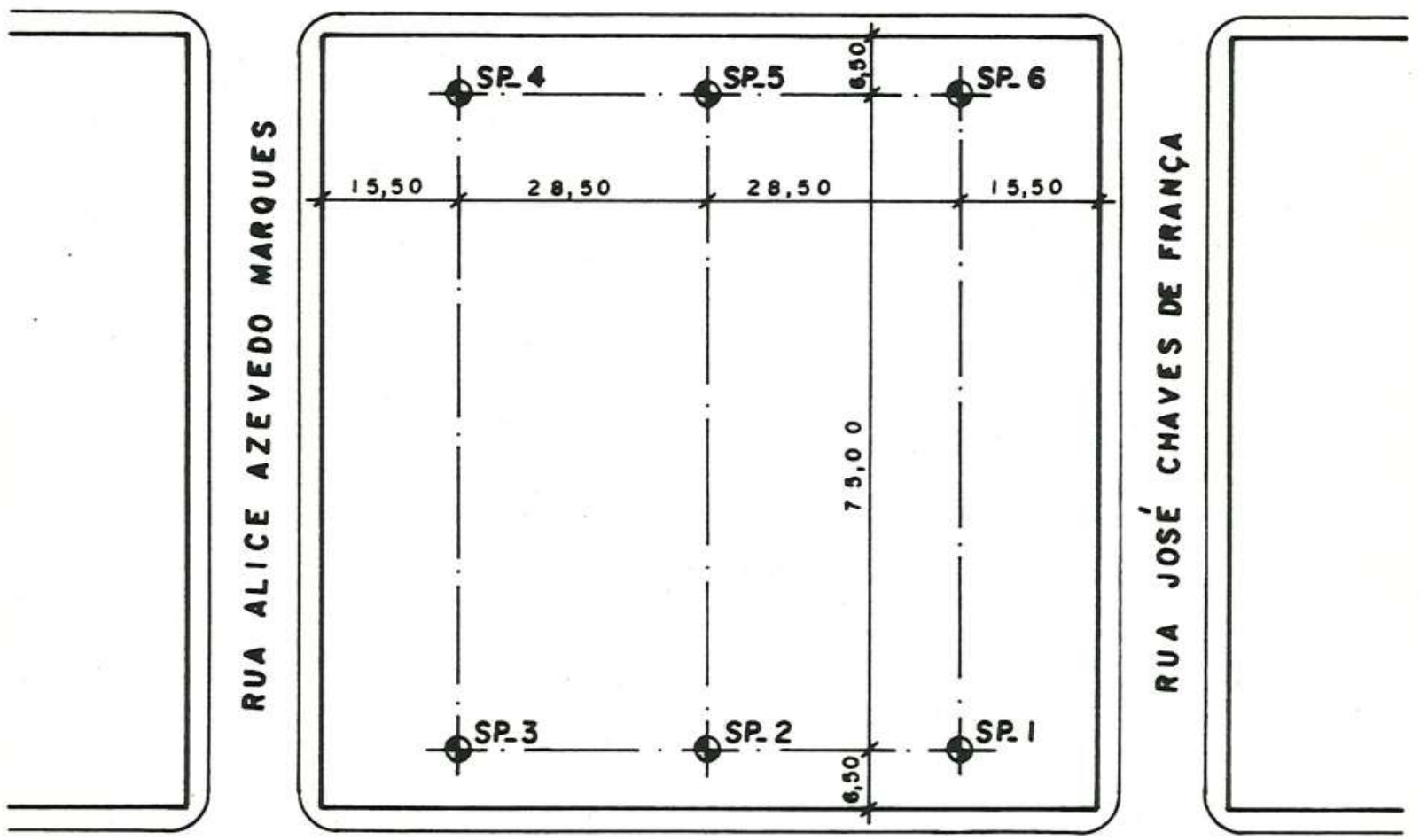

RUA MARIO GONZAGA

JUNOUEIRA

$R N=100,000$ ( SOLEIRA
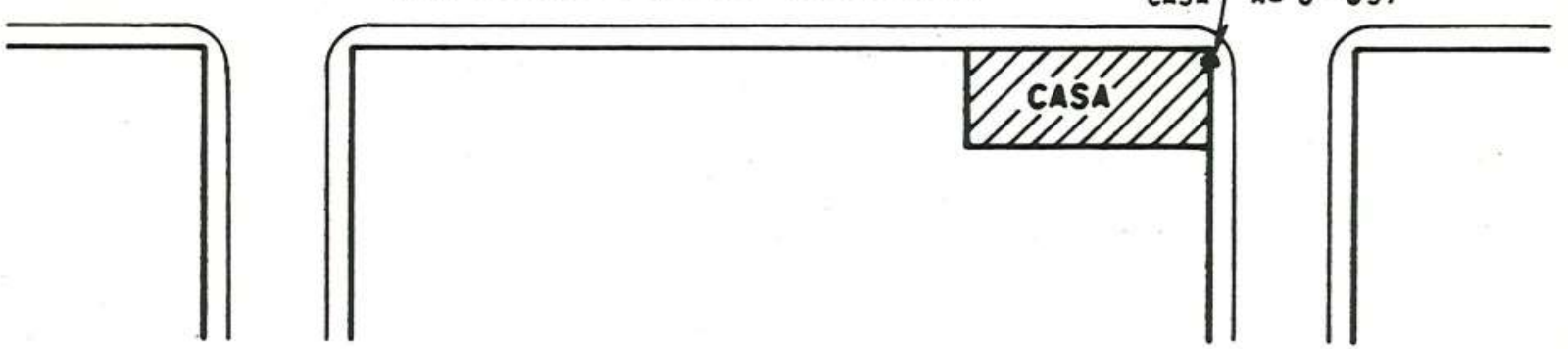
SONDAF - SOA $\triangle A=\because I=$ FUNOACOES LTDA. RUA JOĀO GURGEL N21187. CARMO-CAIXA POSTAL. JS3. FONE: $10162122-35$ E. ARARAQUARA-SP

CLIENTE: SAT - ENGENHARIA E COMÉRCIO S/A S.P.

OBRA: EDIFICIOS

LOCAL: BAURU (SP)

\begin{tabular}{|l||l||c||c||c|}
\hline ENG2 RESP. & OESERTISTA & ESCALA & RELATORIO & OATA \\
\hline \hline DuUf. & $1: 150$ & $4944 / 91$ & $22 / 01 / 91$ \\
\hline & SONDAGENS DE RECONHECIMENTO
\end{tabular}

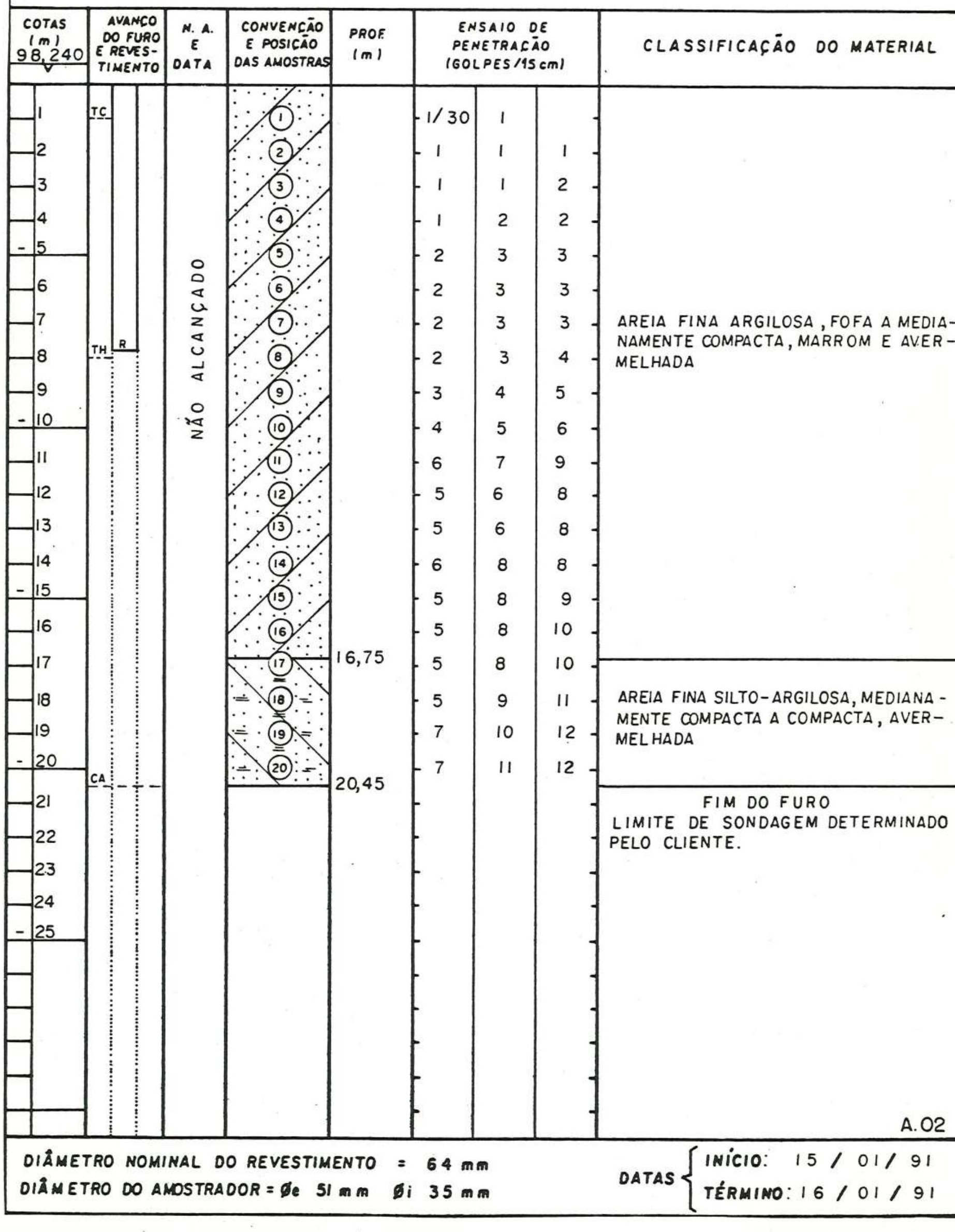


APÊNDICE II 

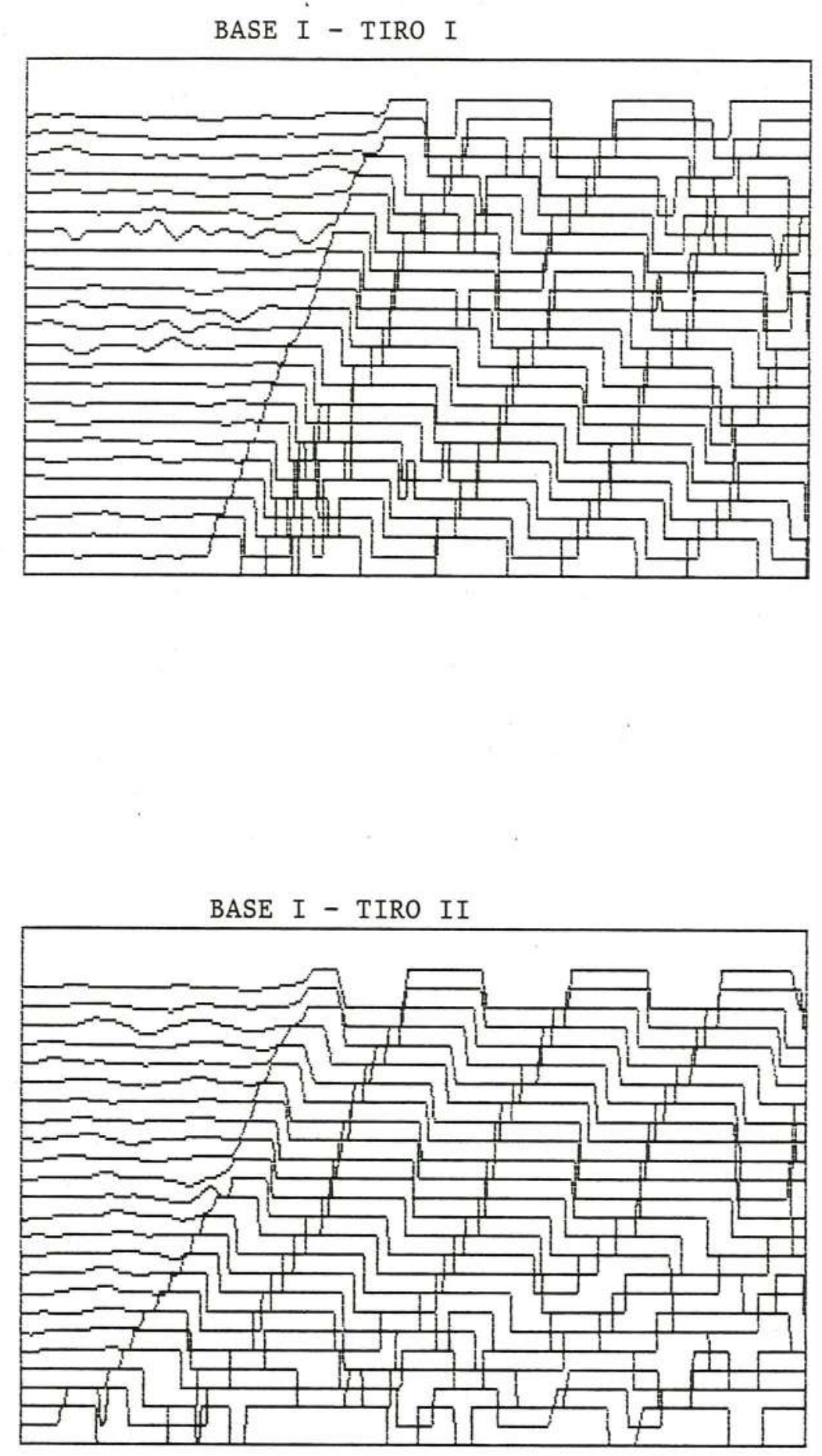
BASE I - TIRO III

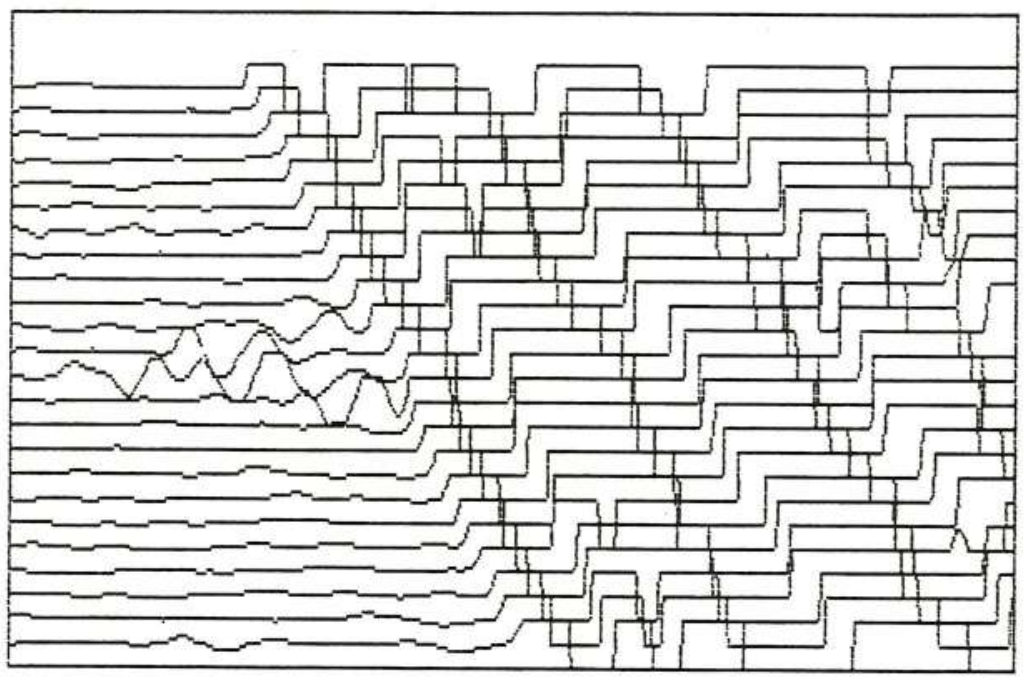

BASE I - TIRO IV

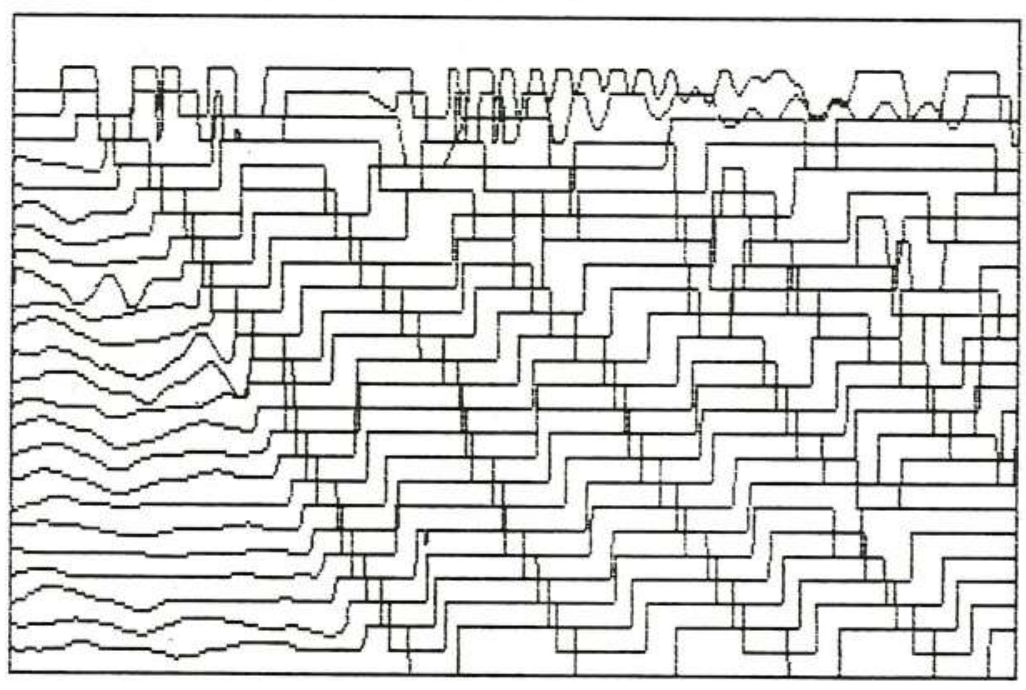


BASE I - TIRO V

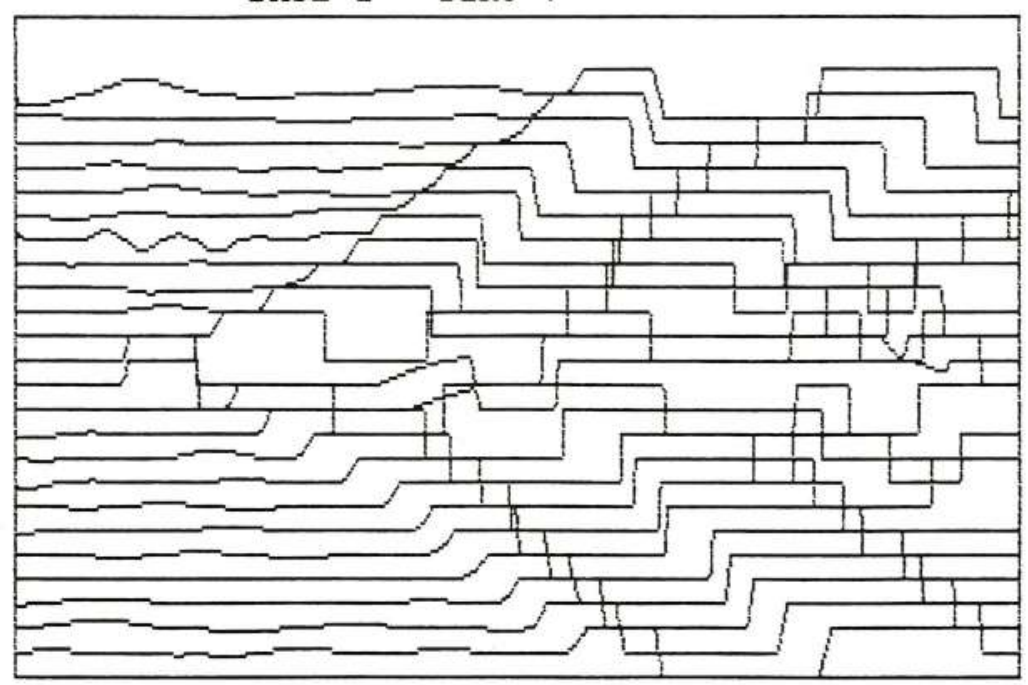

BASE II - TIRO I

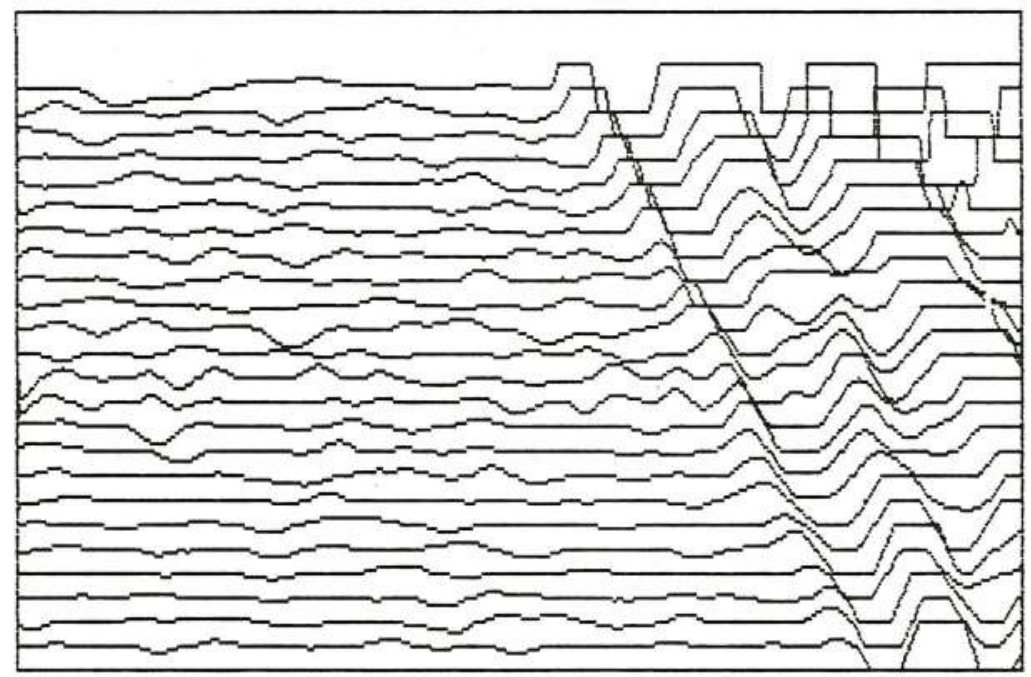




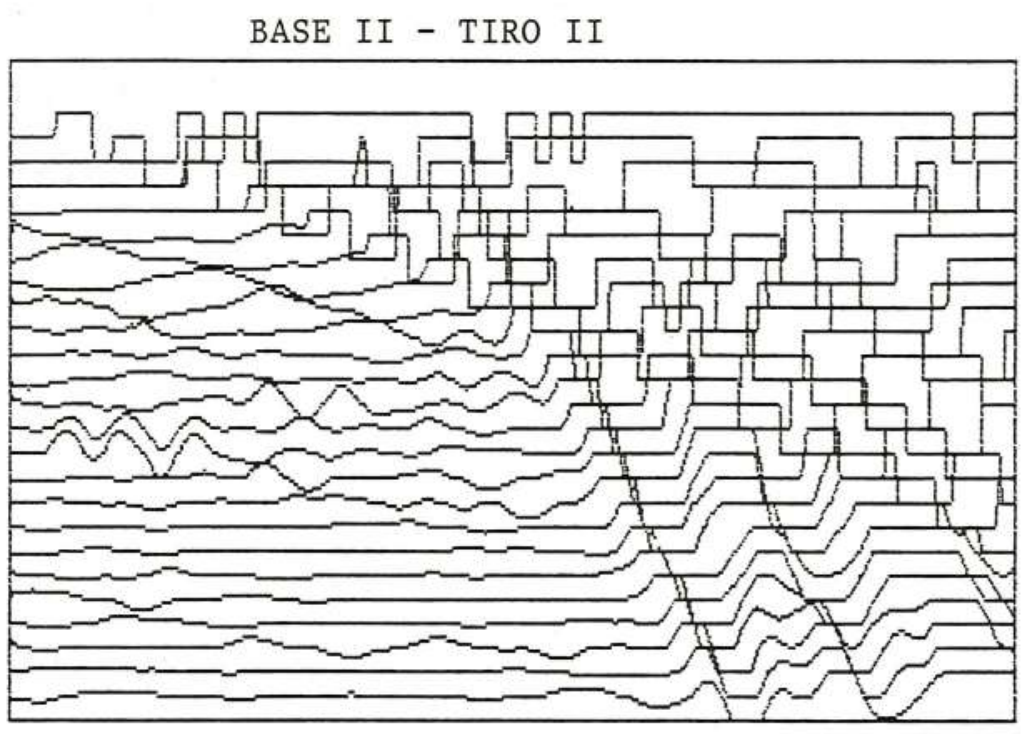

BASE II - TIRO III

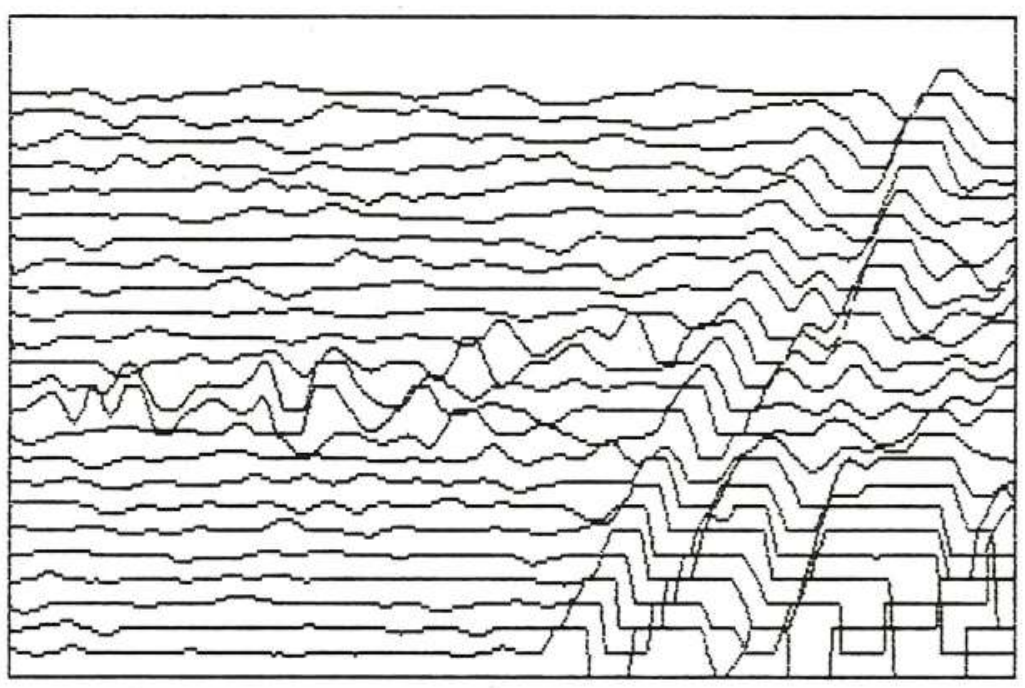




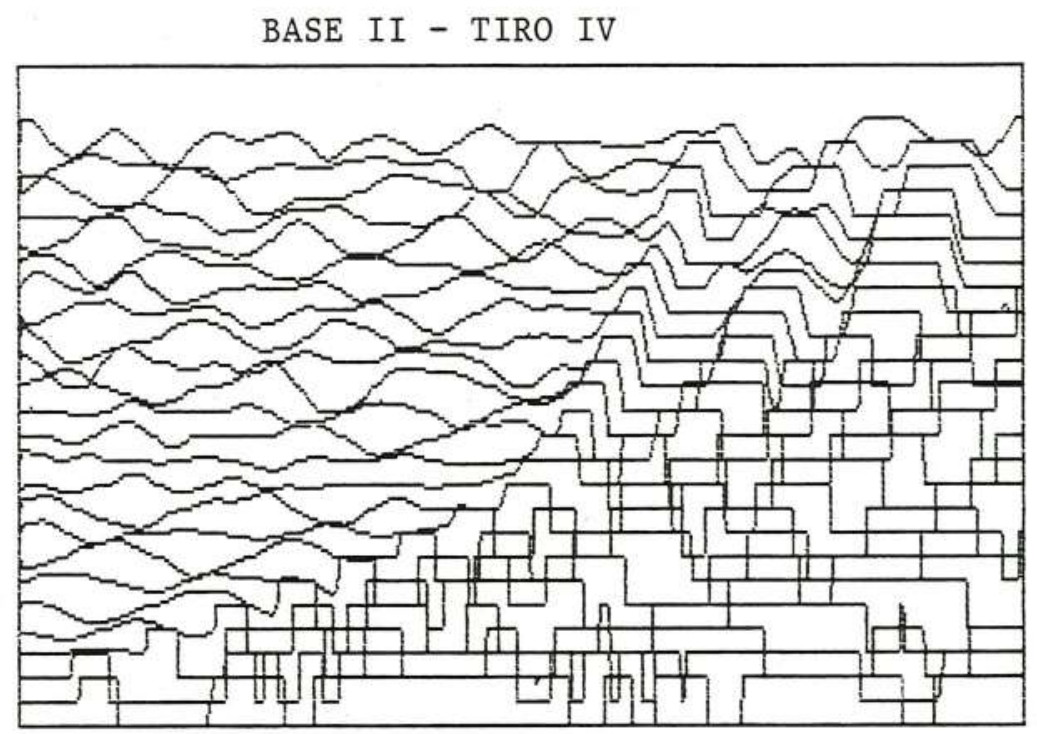

BASE II - TIRO V

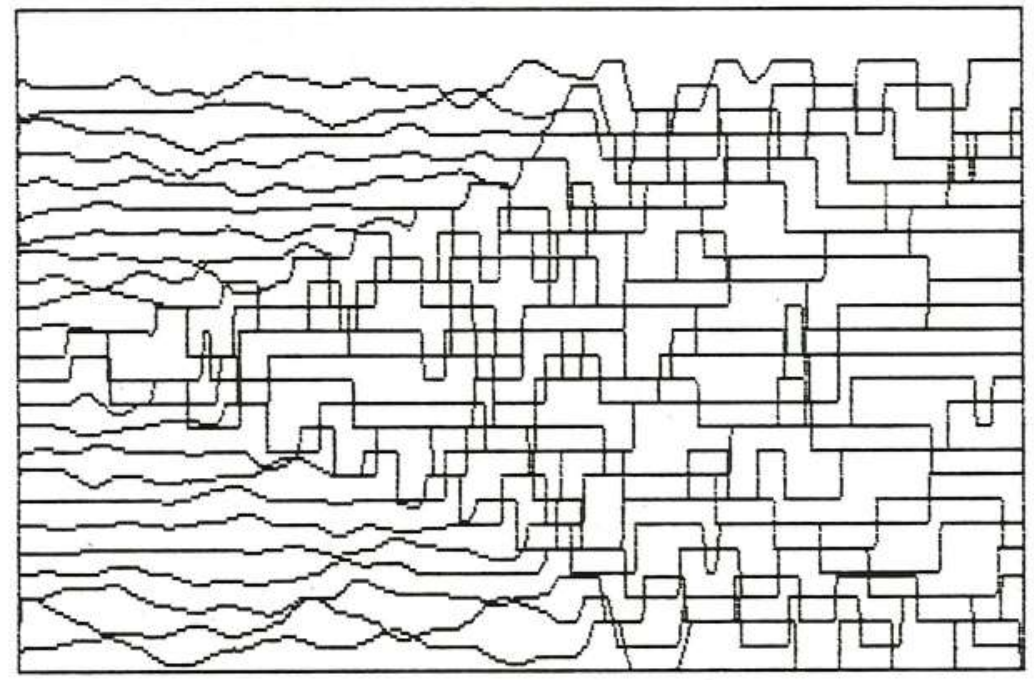


BASE III - TIRO I

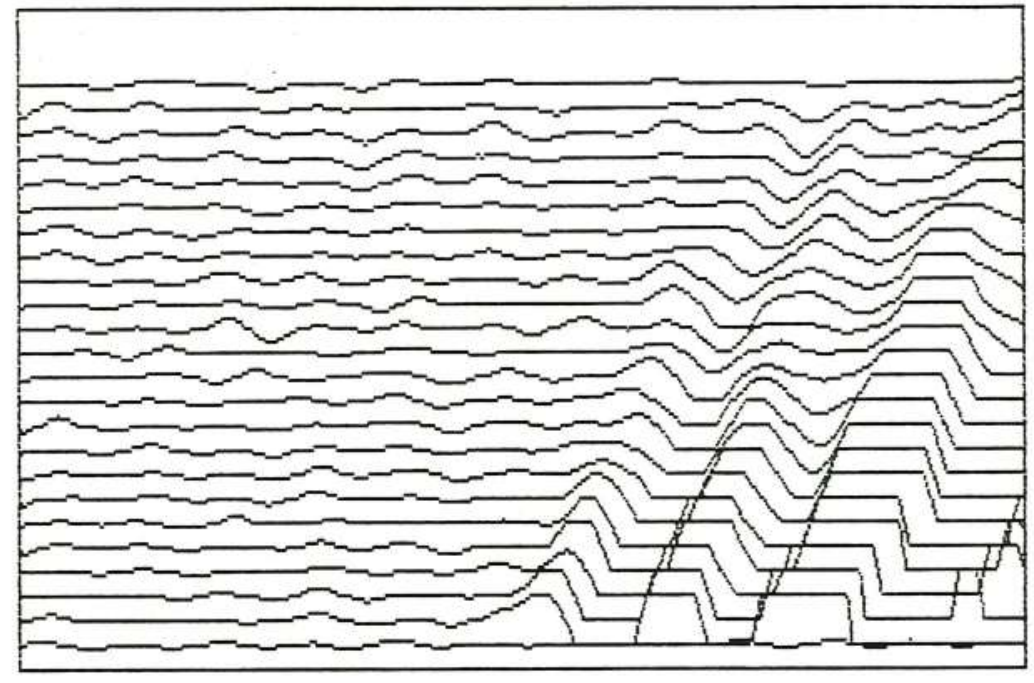

BASE III - TIRO II

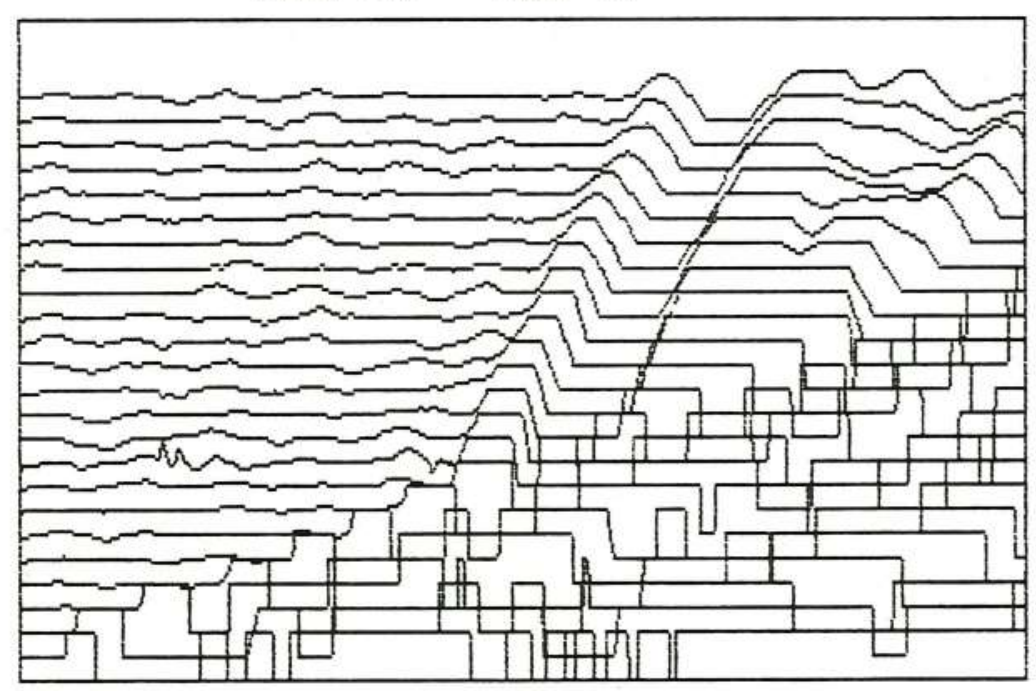


BASE III - TIRO III

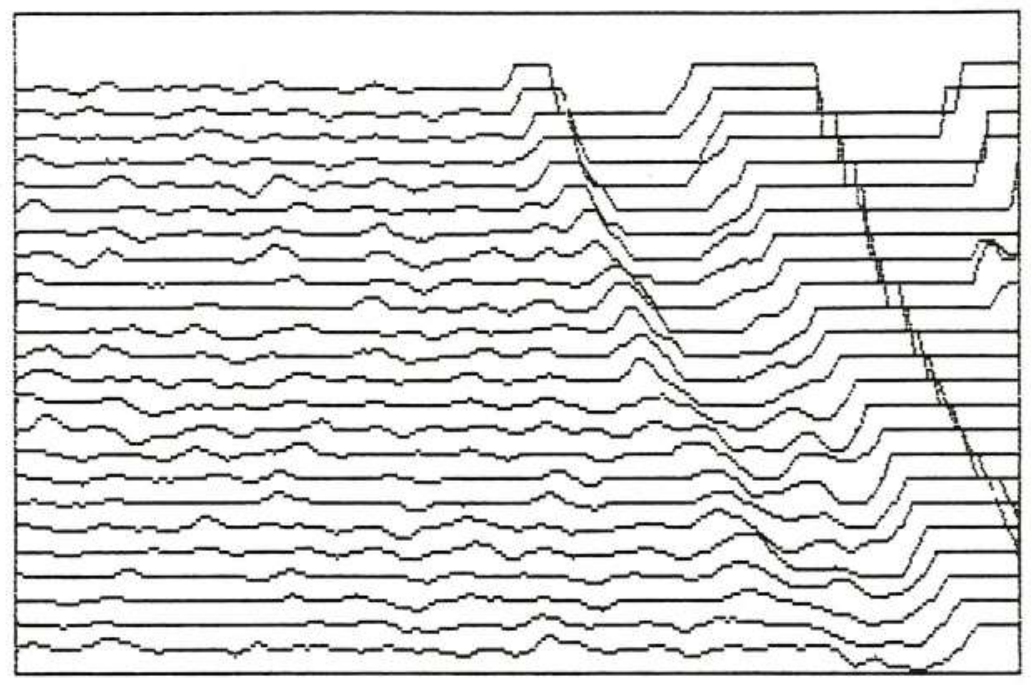

BASE III - TIRO IV

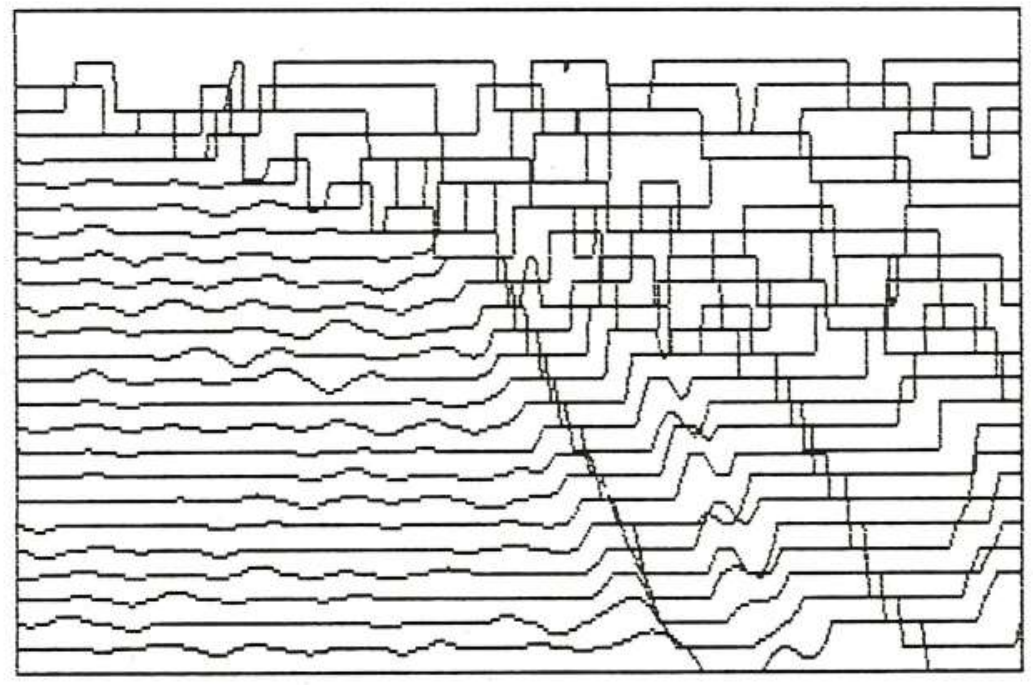


BASE III - TIRO V

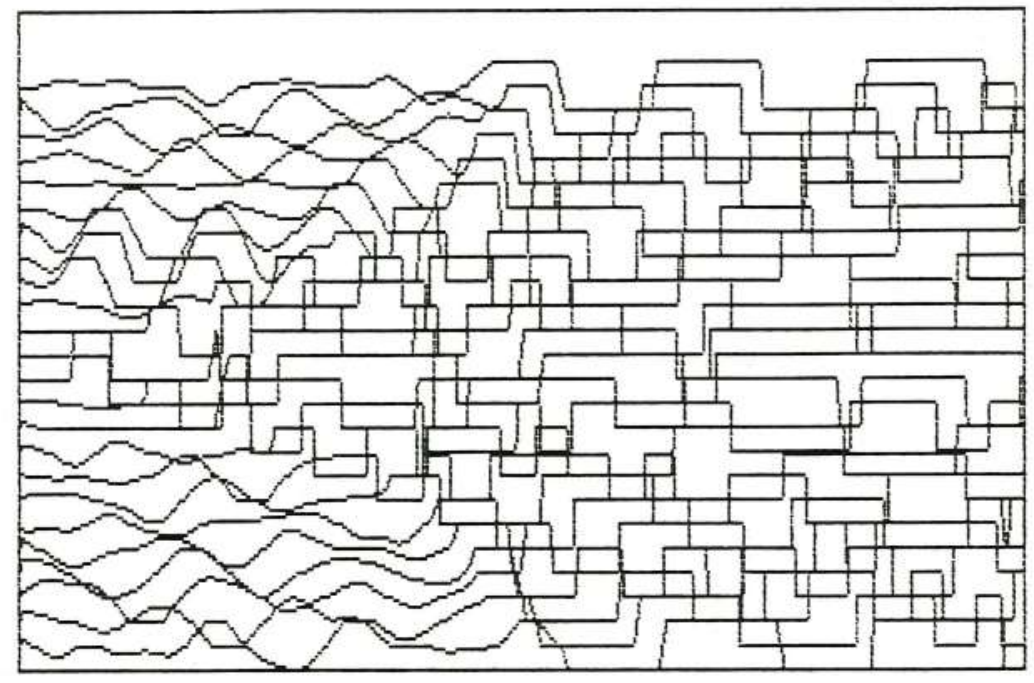

BASE IV - TIRO I

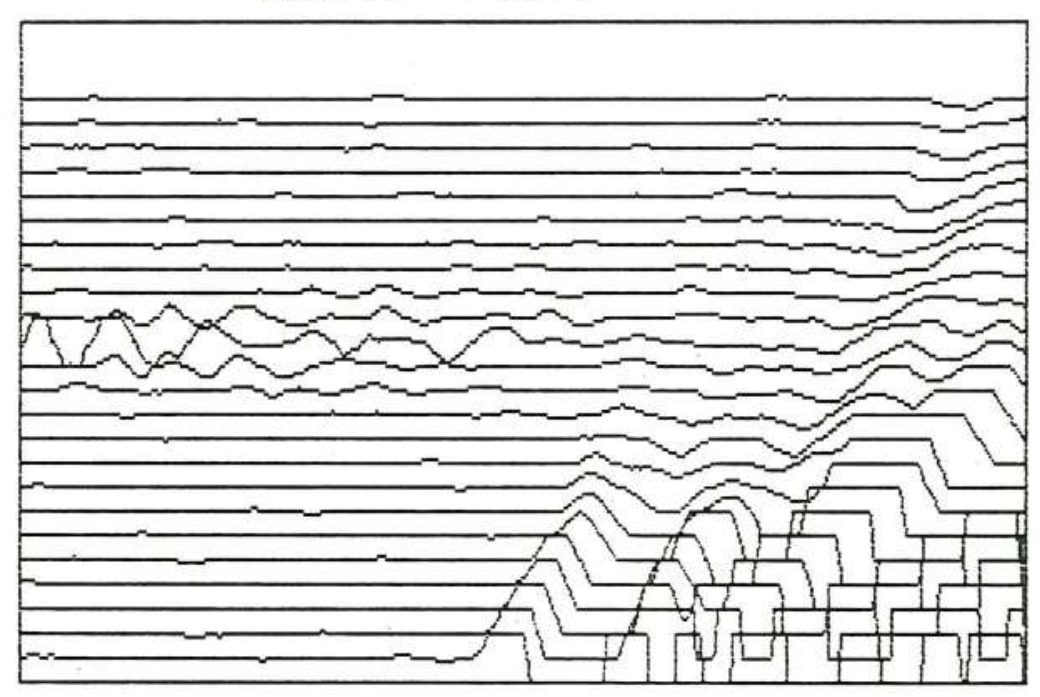


BASE IV - TIRO II

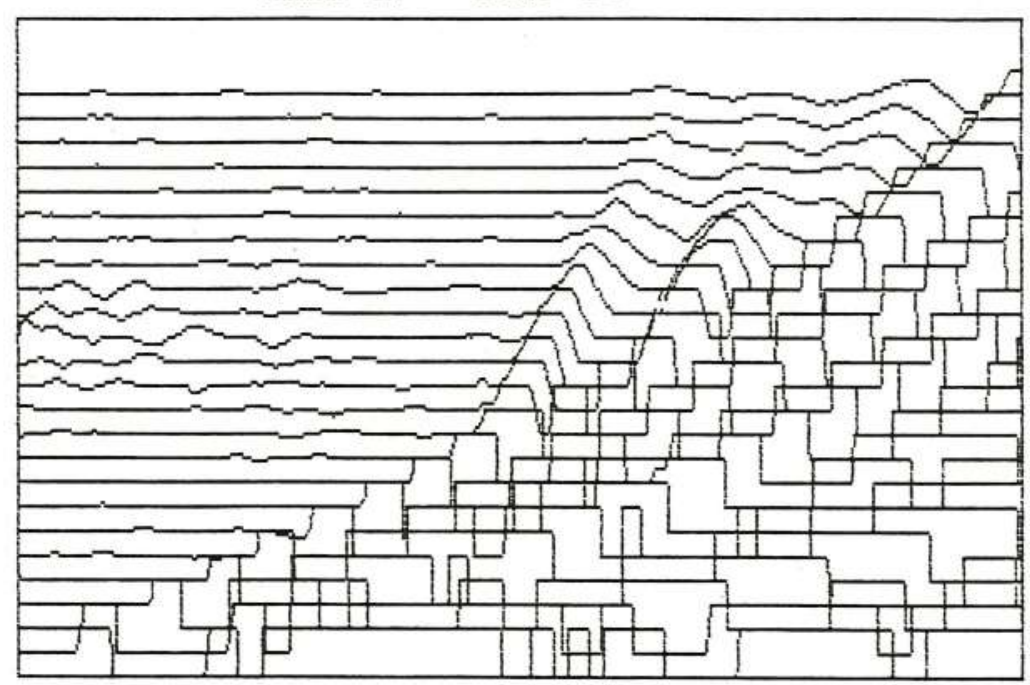

BASE IV - TIRO III

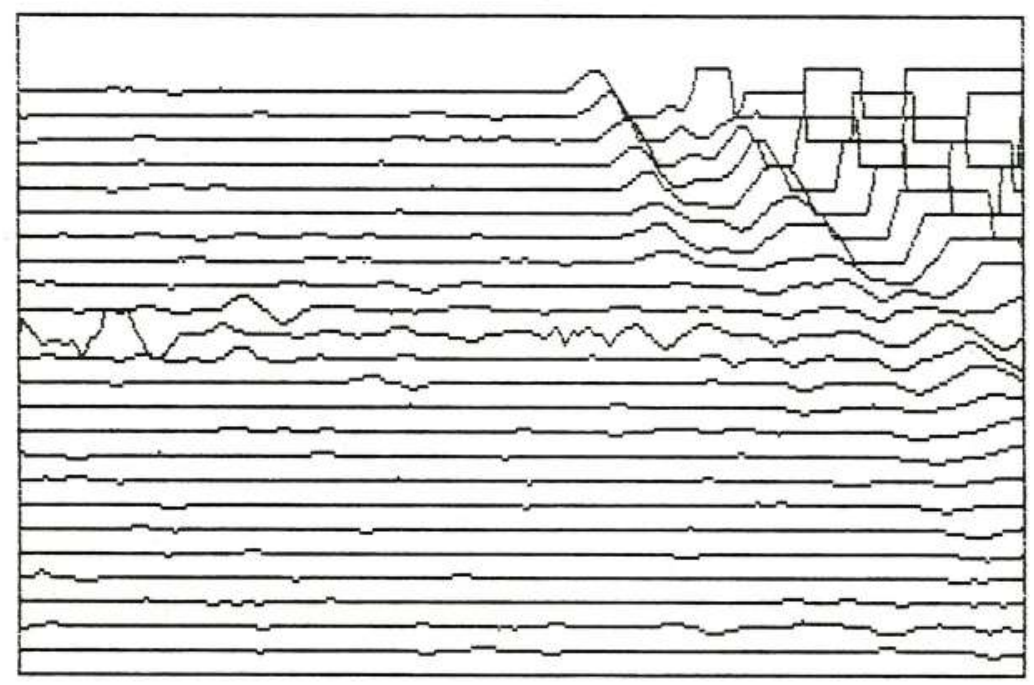




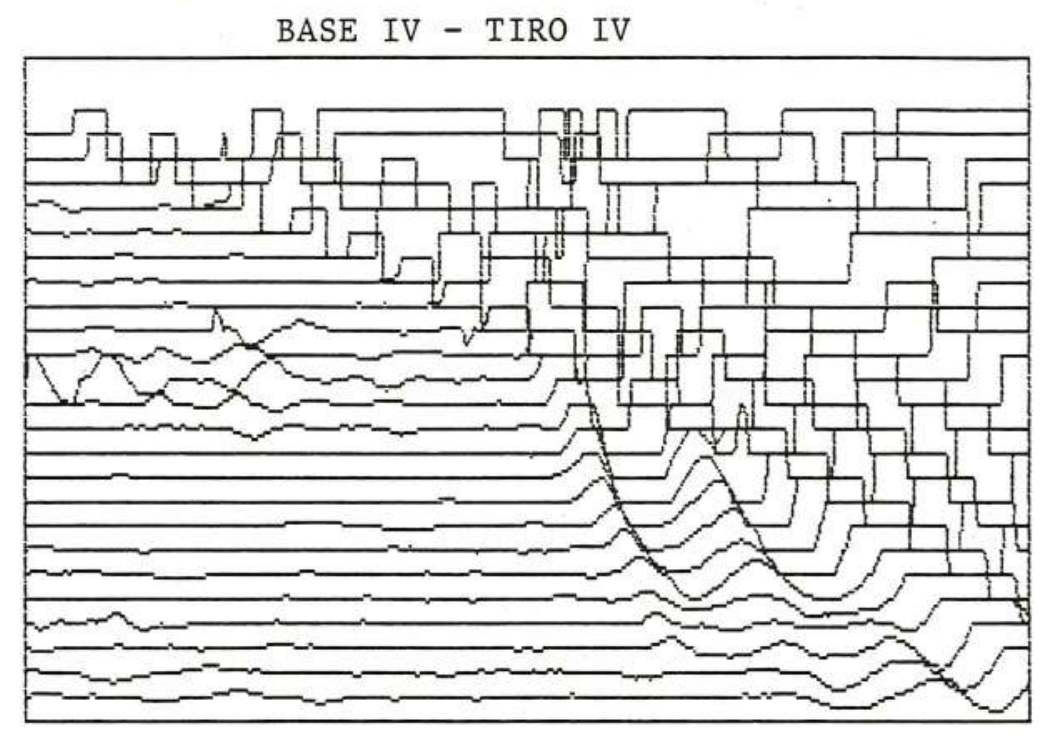

BASE IV - TIRO V

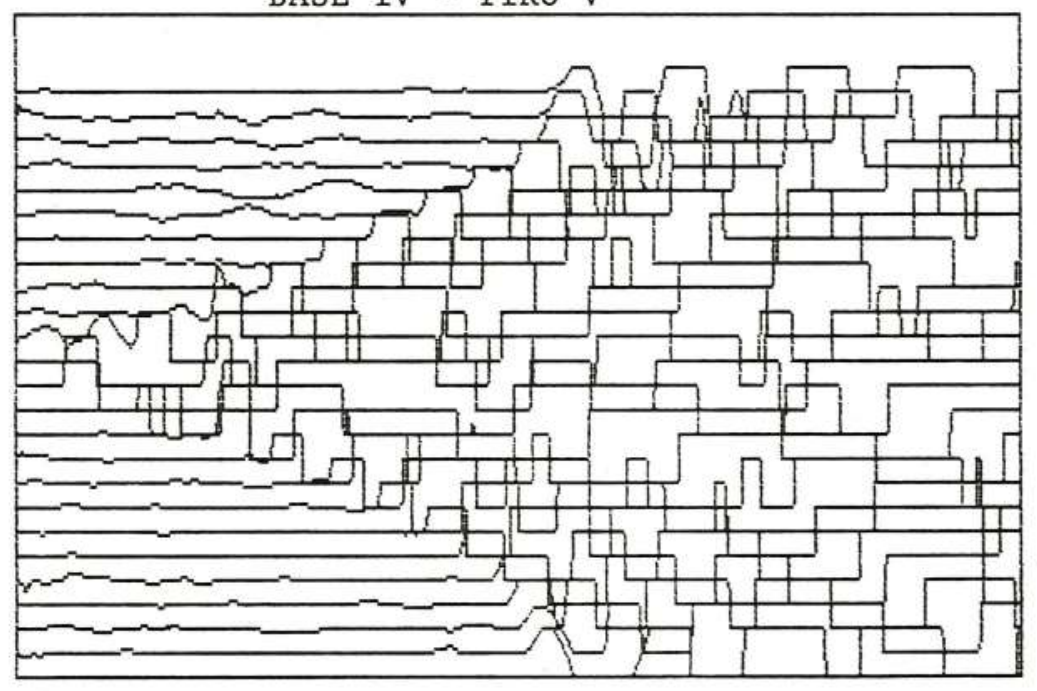


BASE V - TIRO I

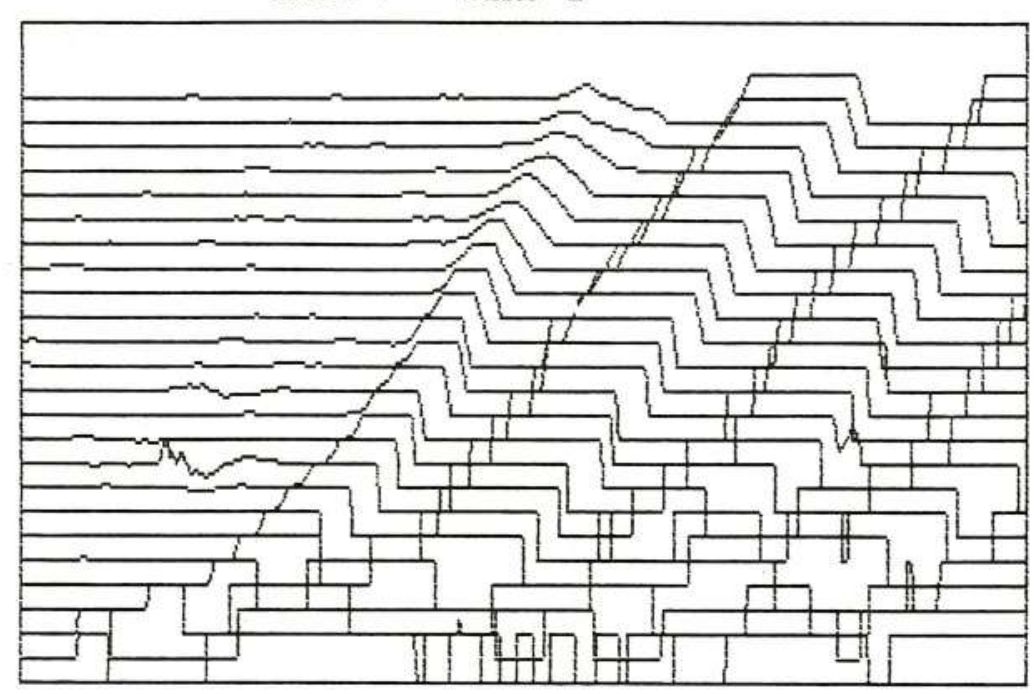

BASE V - TIRO II

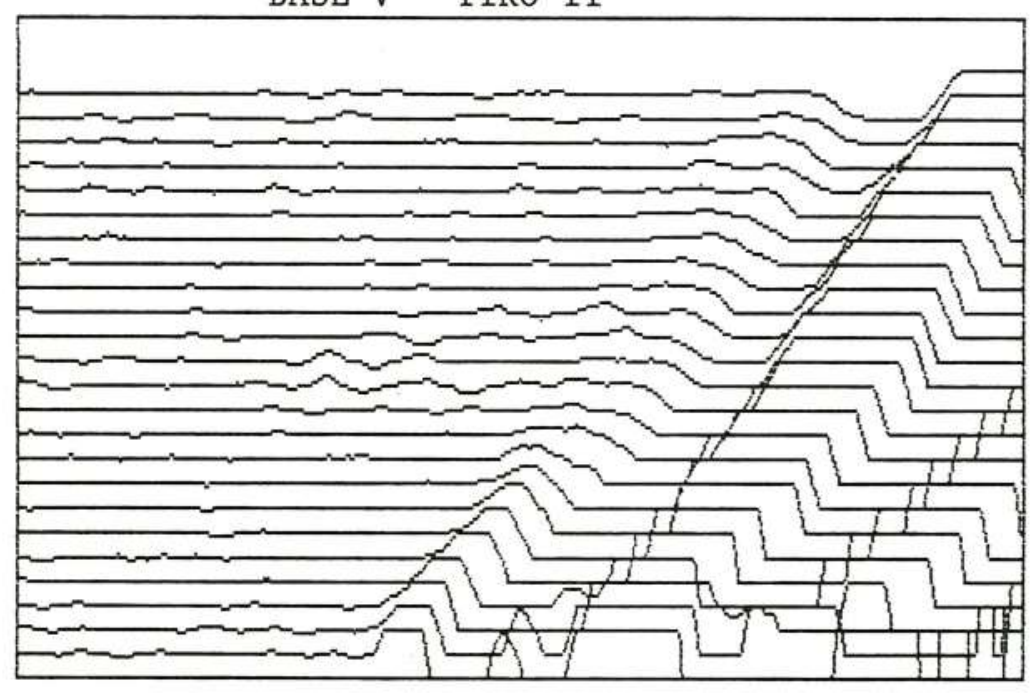


BASE V - TIRO III

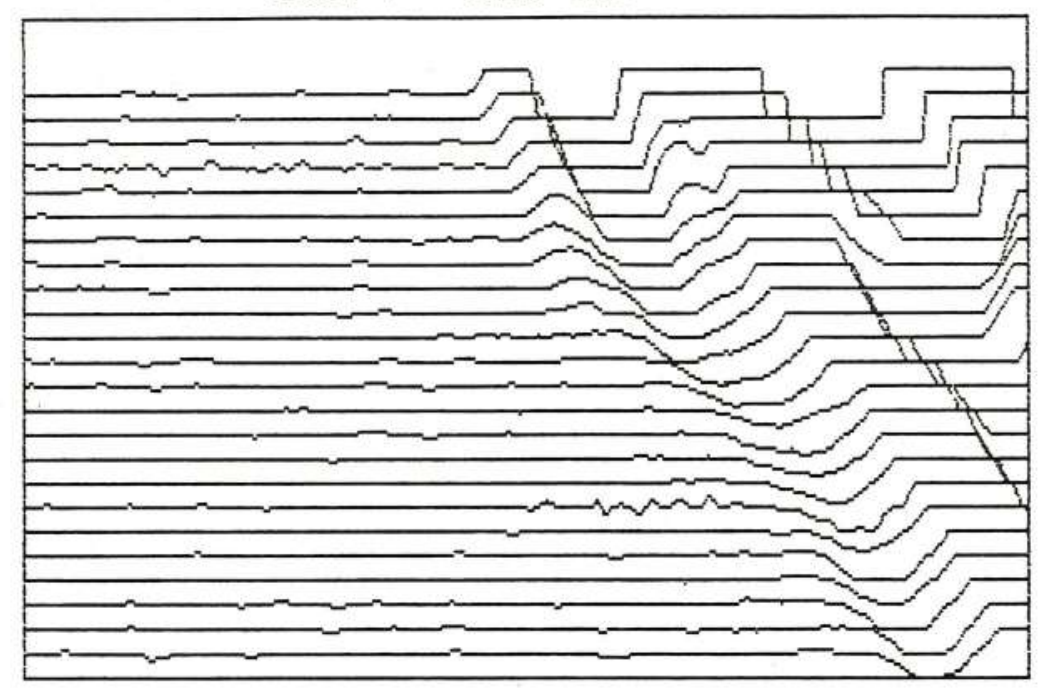

BASE V - TIRO IV

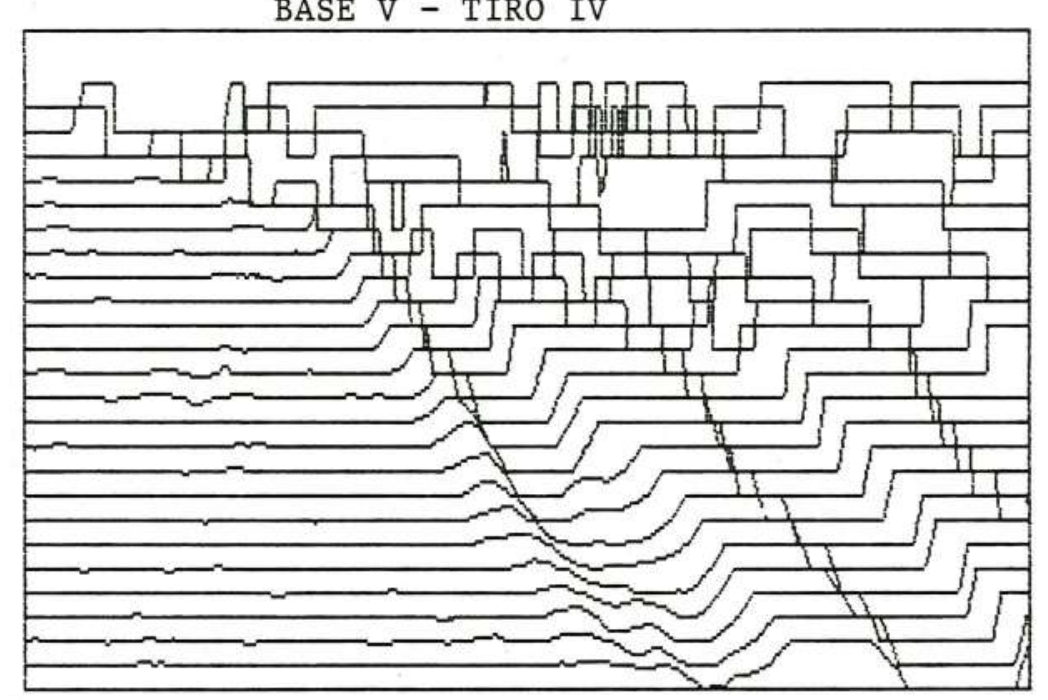


BASE $\mathrm{V}-$ TIRO $\mathrm{V}$

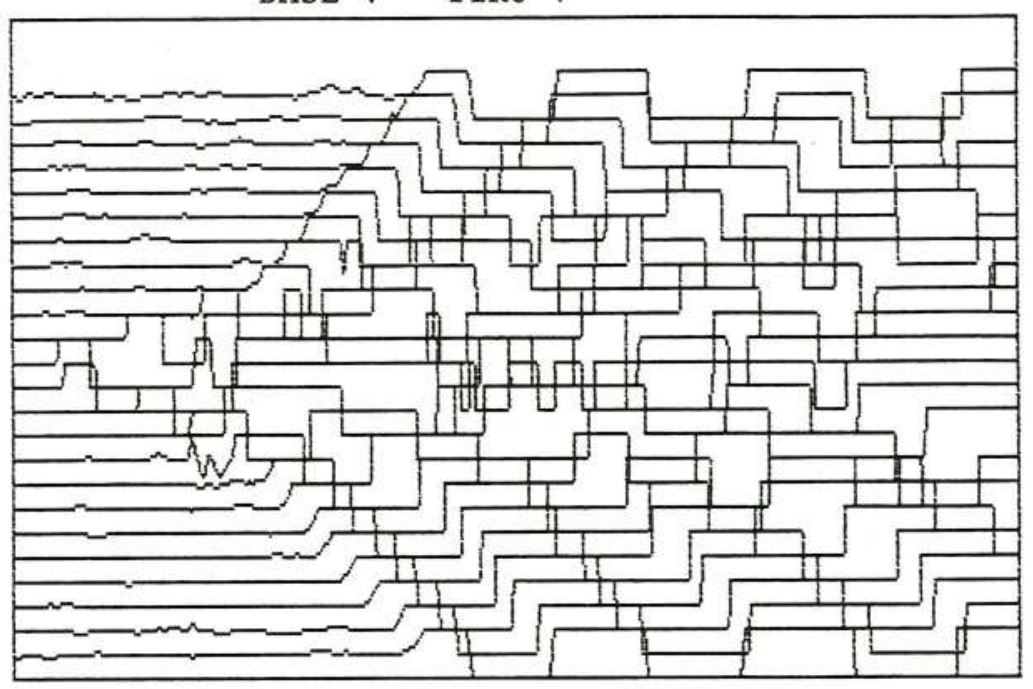


APÊNDICE III 
BASE I

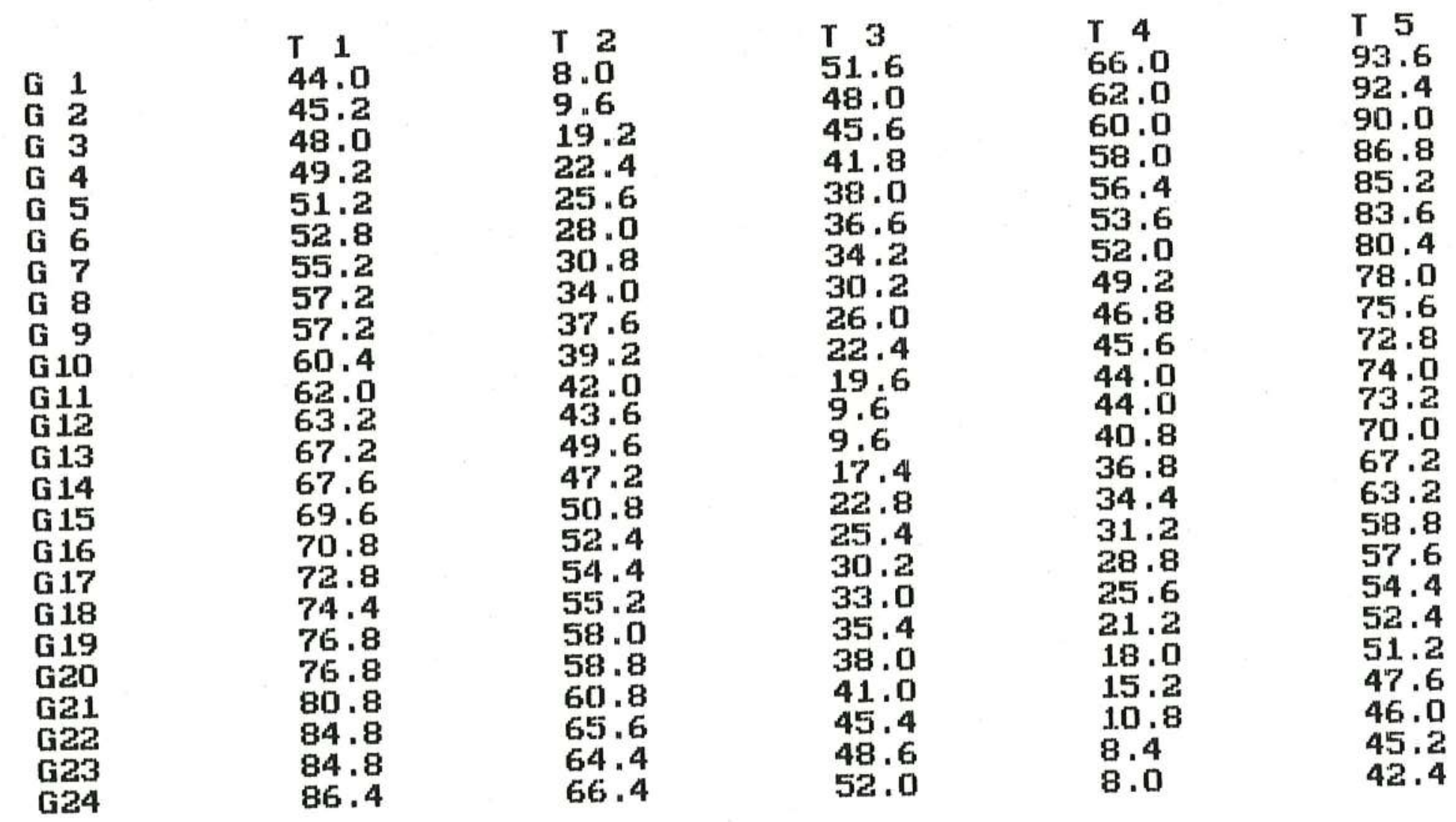

Tiros e respectivos Geofones 


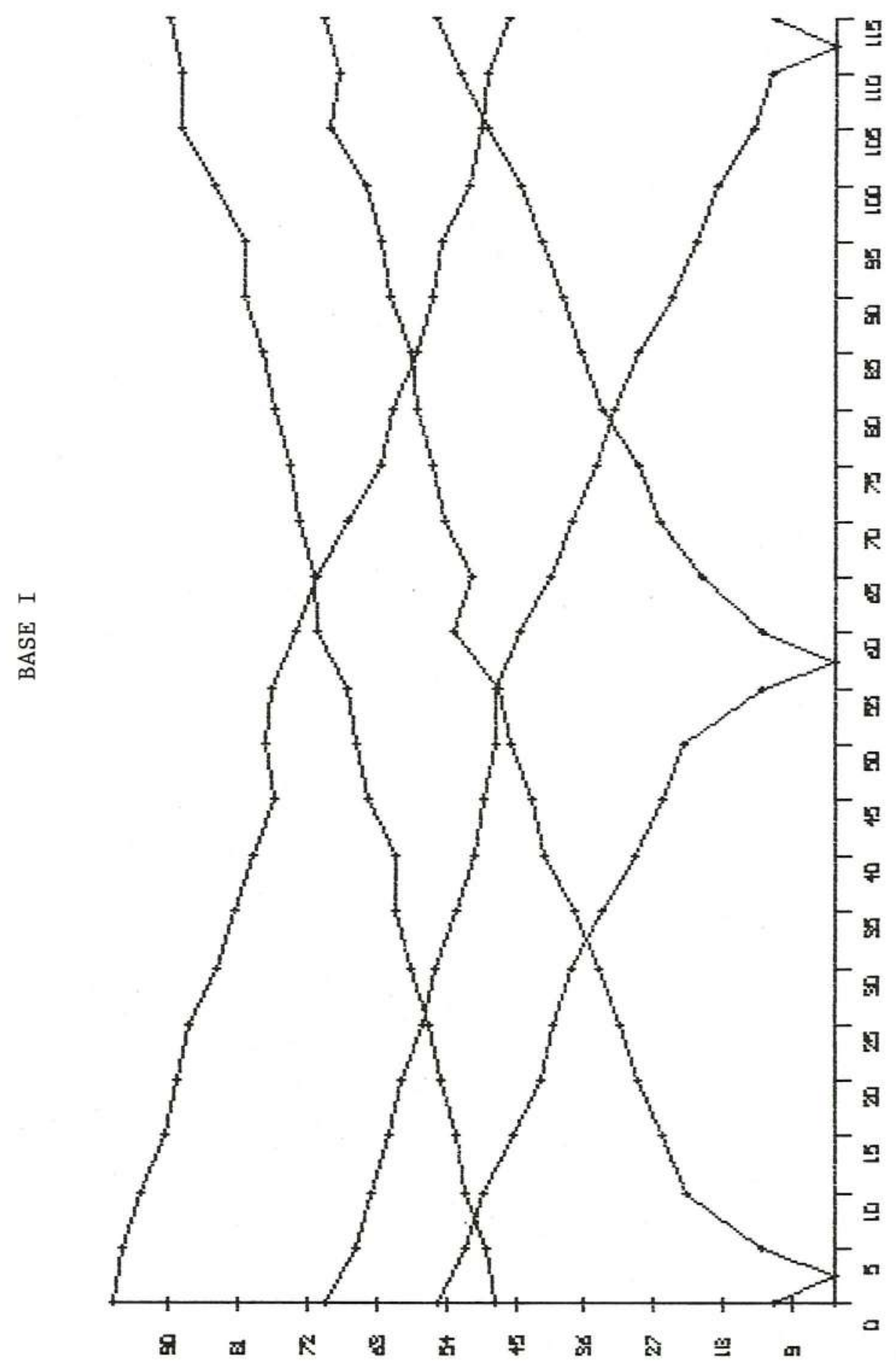

을 
BASE II

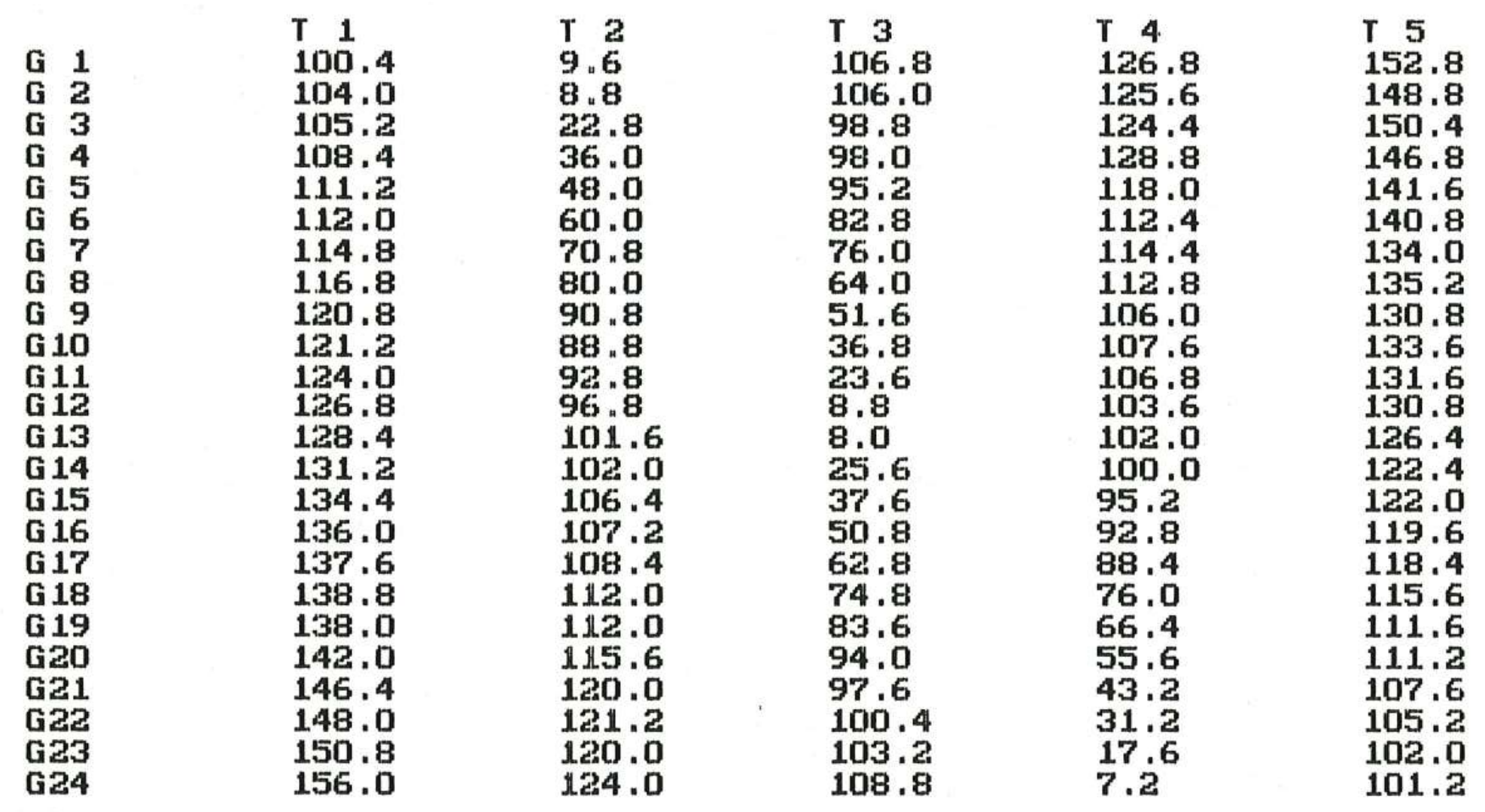

Tiros e respect ivos Geofones 


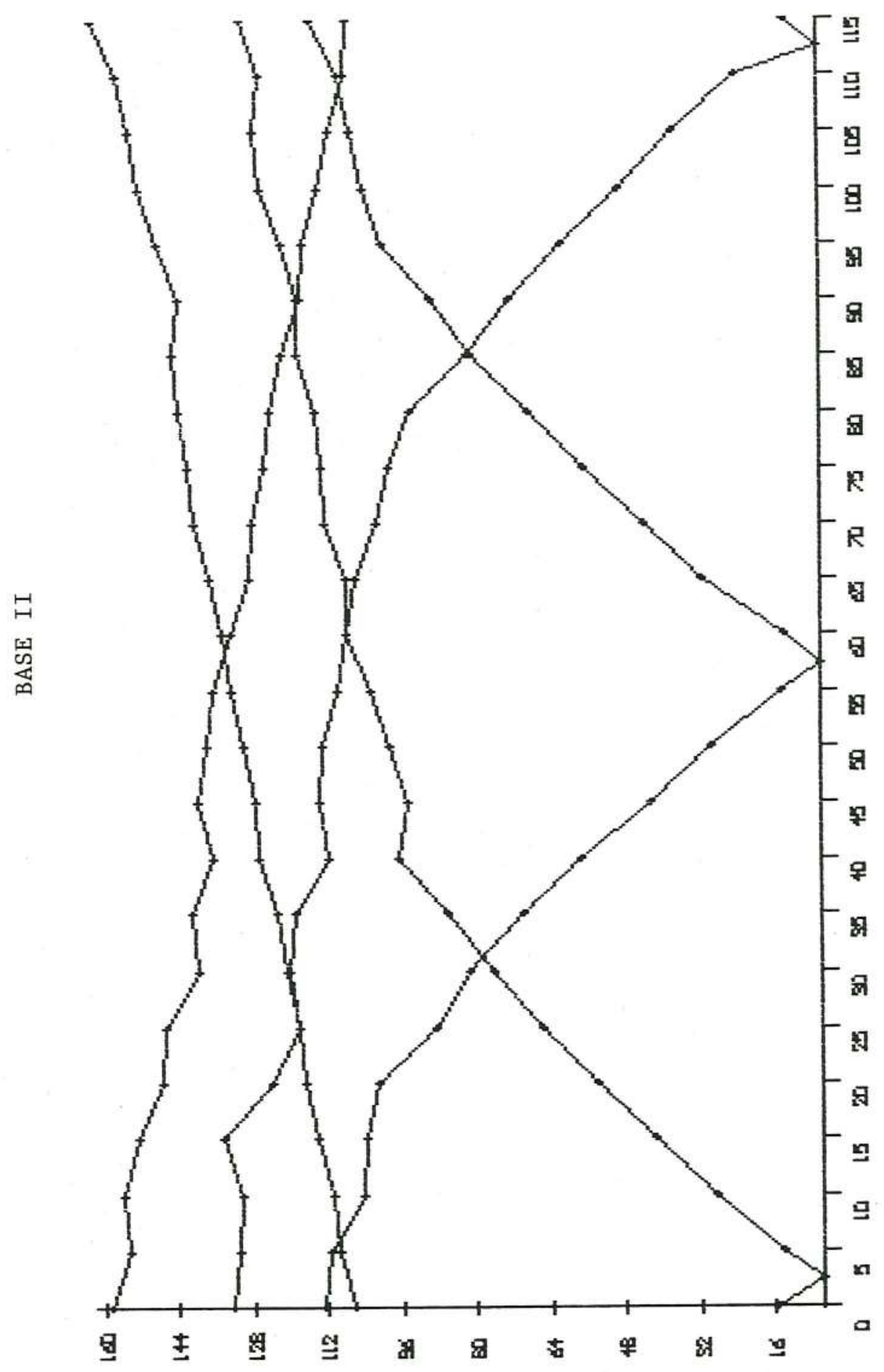

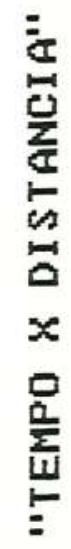

芑 
๒

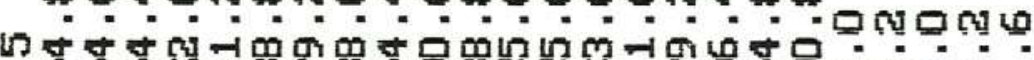

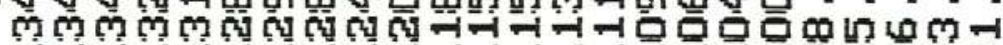
-

ชั

ช ช

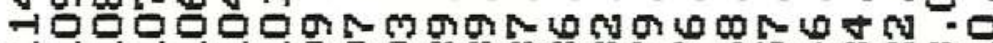

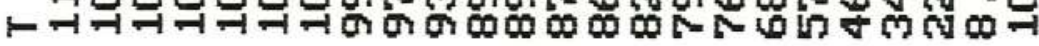

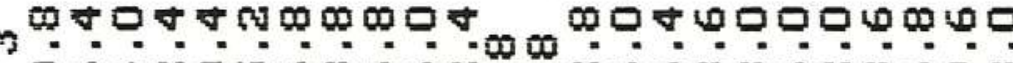
ㅁำ की

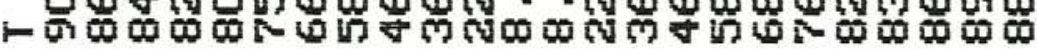

ง

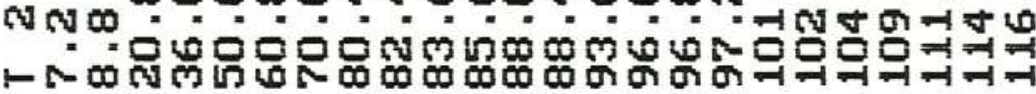

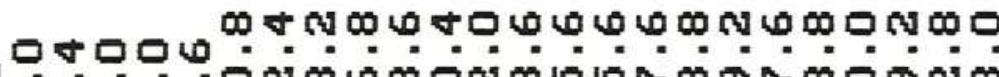

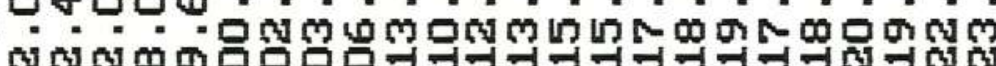

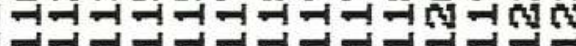

-

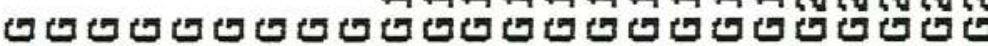


BASE III

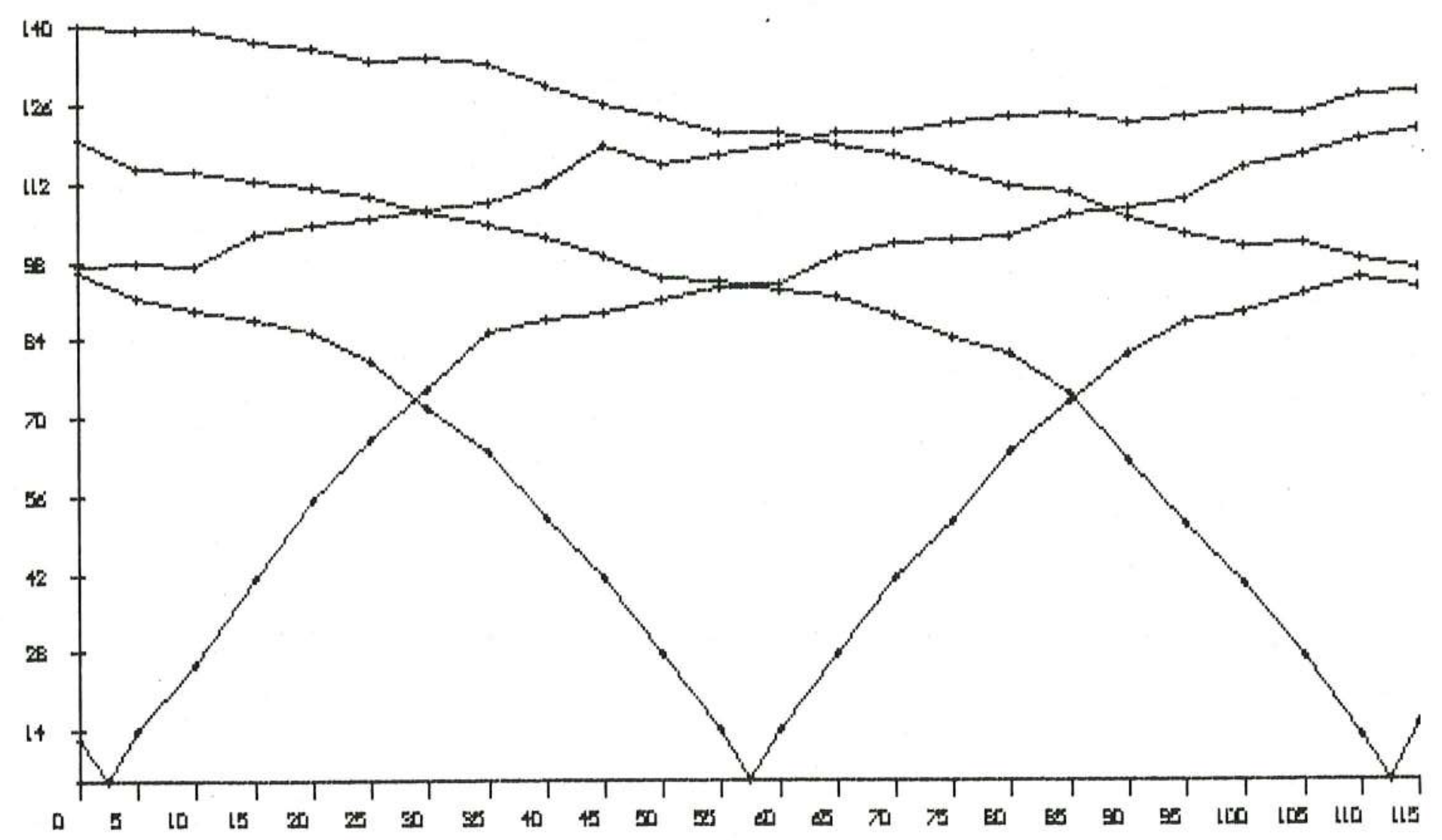


BASE IV

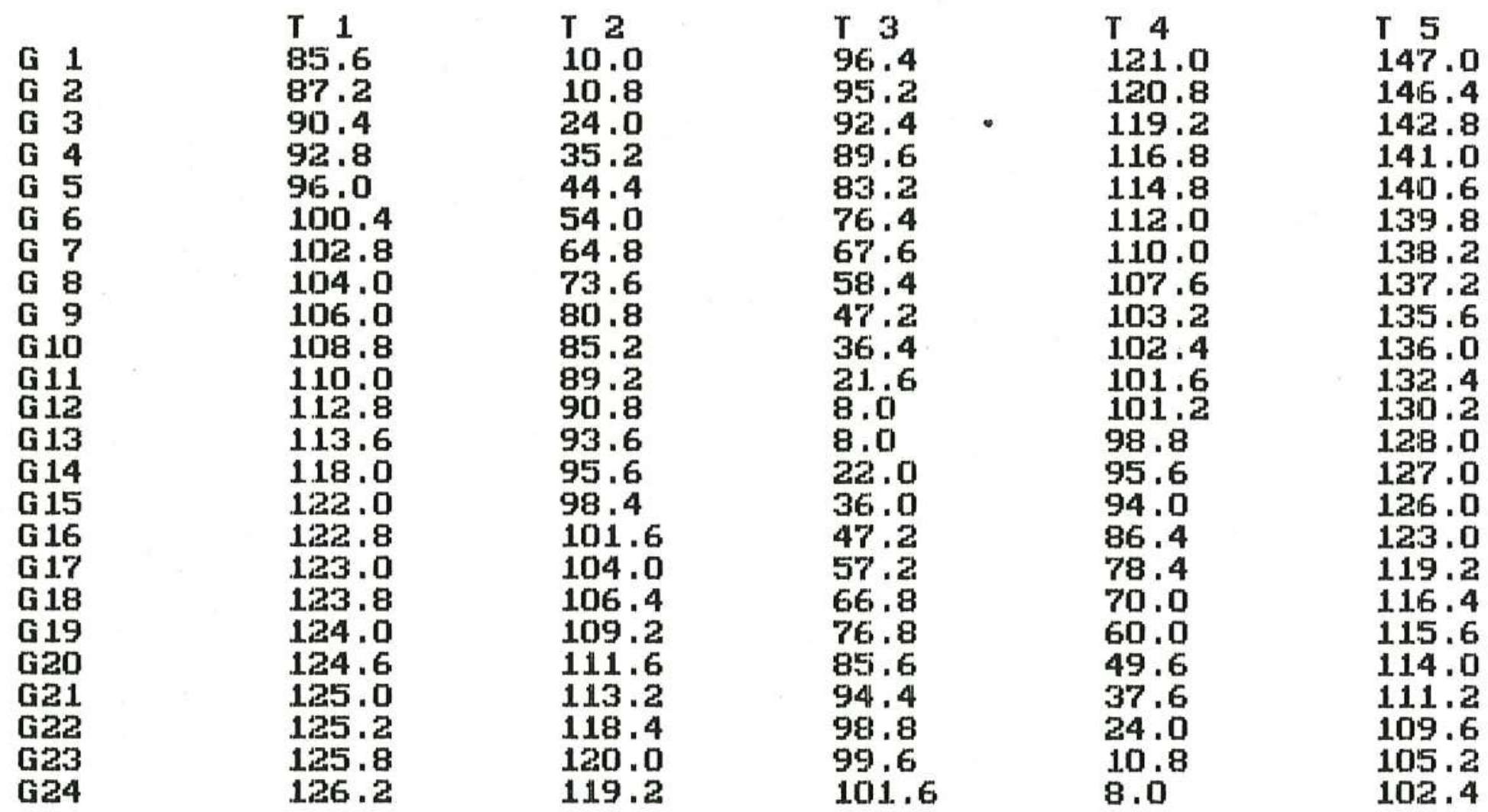

Tiros e respect ivos Geafones. 


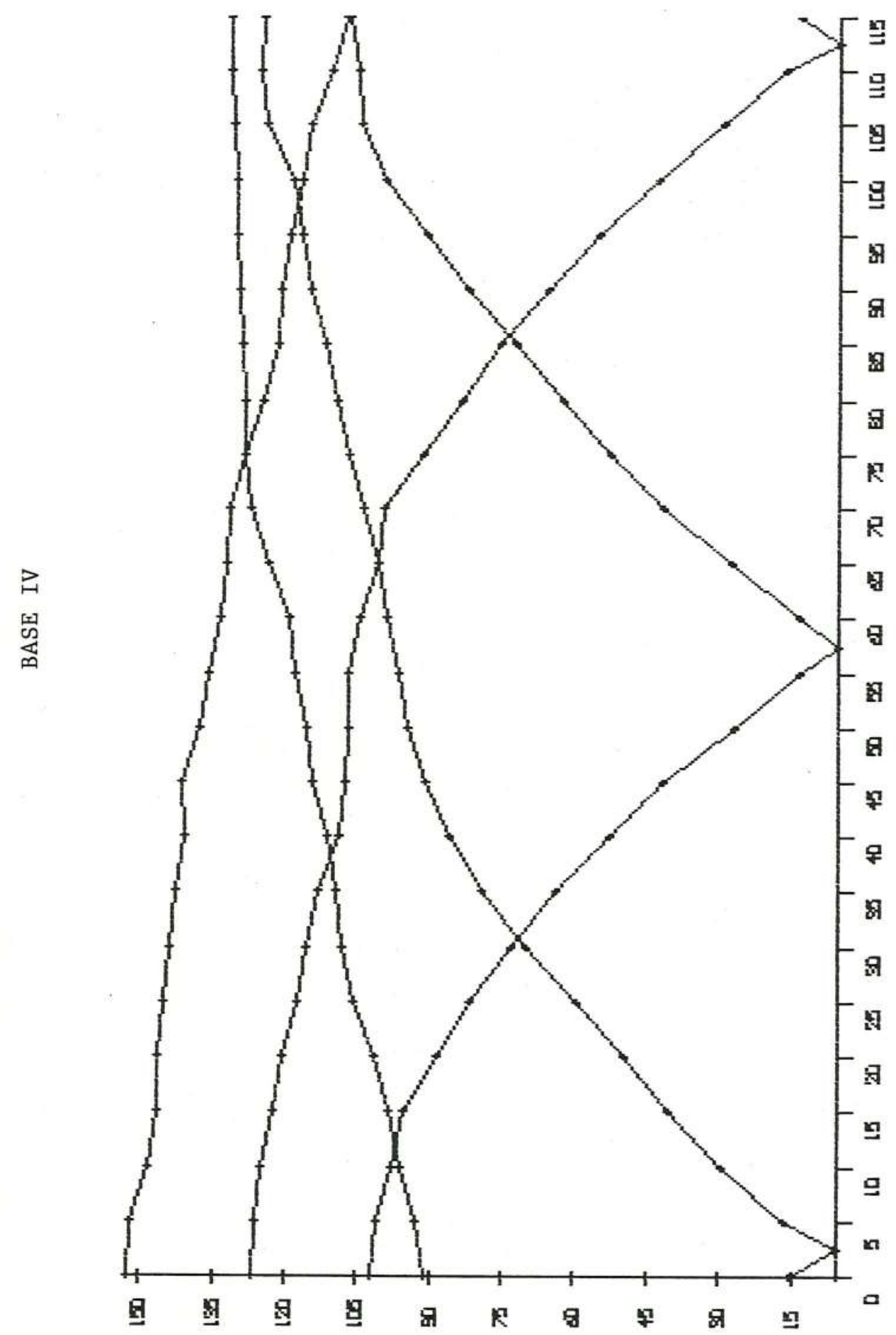

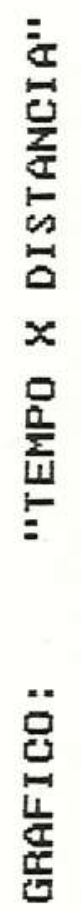


BASE V

\begin{tabular}{|c|c|c|c|c|c|}
\hline $\begin{array}{ll}G & 1 \\
G & 2 \\
G & 3 \\
G & 4 \\
G & 5 \\
G & 6 \\
G & 7 \\
G & 8 \\
G & 9 \\
G 10 \\
G 11 \\
G 12 \\
G 13 \\
G 14 \\
G 15 \\
G 16 \\
G 17 \\
G 18 \\
G 19 \\
G 20 \\
G 21 \\
G 22 \\
G 23 \\
G 24\end{array}$ & $\begin{array}{l}T 1 \\
65.6 \\
68.0 \\
68.0 \\
73.6 \\
77.2 \\
82.0 \\
86.0 \\
81.4 \\
90.8 \\
96.0 \\
97.2 \\
101.6 \\
106.8 \\
1.1 .2 \\
1.15 .2 \\
1.18 .6 \\
122.8 \\
128.8 \\
128.8 \\
1.27 .0 \\
126.0 \\
130.0 \\
132.2 \\
131.0\end{array}$ & $\begin{array}{l}\text { T } 2 \\
9.6 \\
9.6 \\
22.4 \\
34.4 \\
39.2 \\
43.6 \\
47.2 \\
52.0 \\
57.2 \\
61.2 \\
63.6 \\
67.2 \\
71.6 \\
72.8 \\
76.0 \\
77.6 \\
80.0 \\
84.0 \\
85.6 \\
89.2 \\
94.0 \\
97.2 \\
96.8 \\
102.4\end{array}$ & $\begin{array}{l}T .3 \\
74.4 \\
71.6 \\
66.0 \\
60.8 \\
56.8 \\
54.4 \\
50.0 \\
46.8 \\
40.0 \\
32.4 \\
22.0 \\
8.0 \\
8.0 \\
20.4 \\
34.0 \\
45.2 \\
50.8 \\
53.6 \\
56.4 \\
60.8 \\
65.6 \\
69.2 \\
73.2 \\
76.0\end{array}$ & $\begin{array}{l}T 4 \\
102.0 \\
98.8 \\
98.4 \\
97.2 \\
92.0 \\
85.6 \\
85.6 \\
84.0 \\
80.8 \\
77.6 \\
73.6 \\
74.4 \\
70.0 \\
66.4 \\
64.0 \\
61.2 \\
58.8 \\
56.0 \\
53.0 \\
46.4 \\
33.6 \\
23.2 \\
8.0 \\
9.6\end{array}$ & $\begin{array}{l}r 5 \\
135.2 \\
13.5 .0 \\
134.8 \\
130.8 \\
129.2 \\
130.0 \\
124.0 \\
116.0 \\
116.2 \\
115.6 \\
115.2 \\
11.7 .2 \\
111.6 \\
105.6 \\
102.0 \\
1.00 .0 \\
96.8 \\
96.0 \\
94.4 \\
92.0 \\
91.6 \\
88.18 \\
85.6 \\
84.0\end{array}$ \\
\hline
\end{tabular}

Tiros e respectivos Geafones 


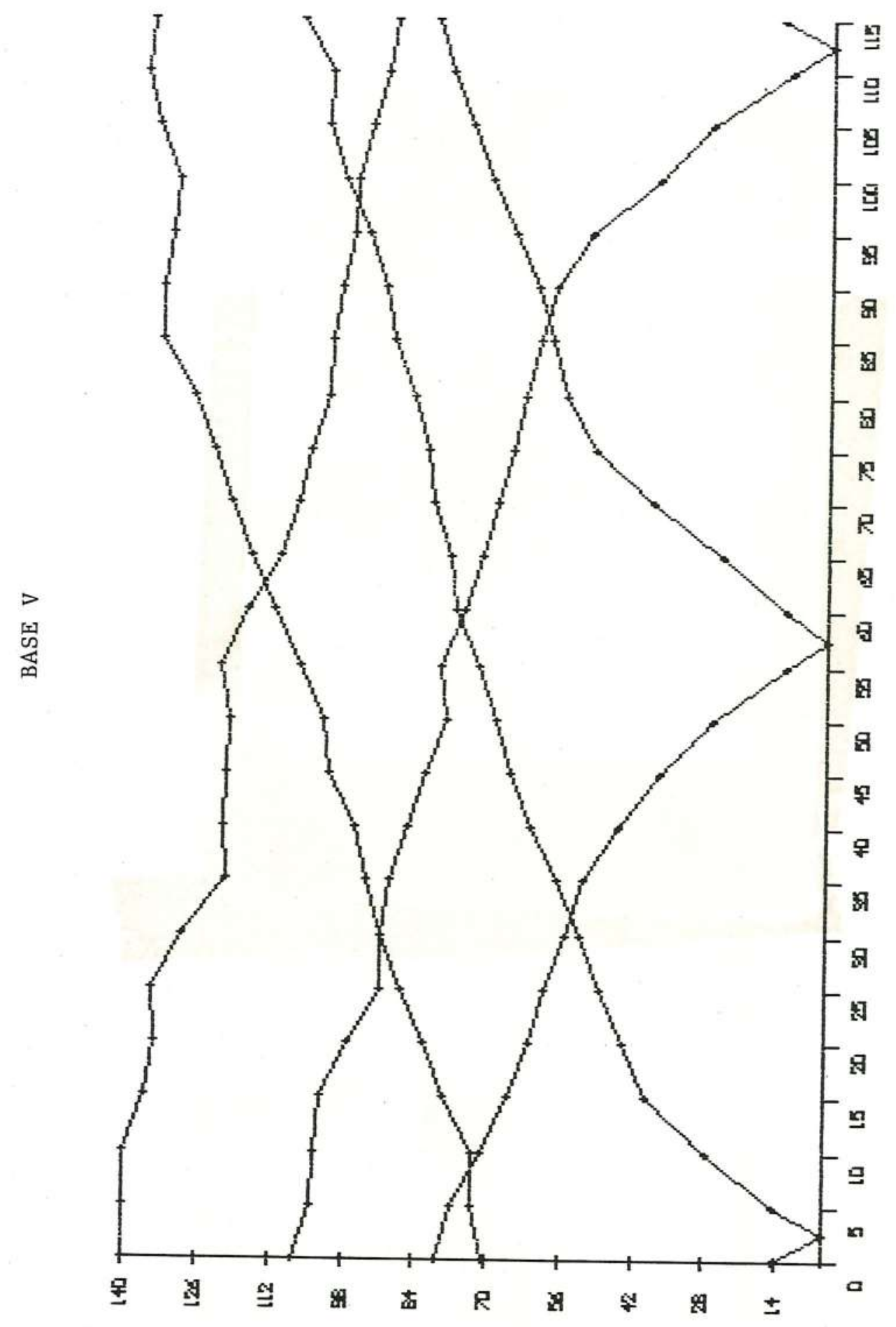

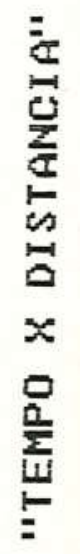

邑 